$$
\text { UNIVERSIDADE DE SÃO PAULO }
$$

ESCOLA DE ENFERMAGEM DE RIBEIRÃO PRETO

KARINA DAL SASSO MENDES

\title{
O processo ensino-aprendizagem para o candidato ao transplante de fígado
}




\section{O processo ensino-aprendizagem para o candidato ao transplante de fígado}

Tese apresentada à Escola de Enfermagem de Ribeirão Preto da Universidade de São Paulo para obtenção do título de Doutor em Ciências, Programa de Pós-Graduação Enfermagem Fundamental

Linha de pesquisa: Processo de cuidar do adulto com doenças agudas e crônicodegenerativas

Orientador: Profa Dra Cristina Maria Galvão

Ribeirão Preto 
Autorizo a reprodução e divulgação total ou parcial deste trabalho, por qualquer meio convencional ou eletrônico, para fins de estudo e pesquisa, desde que citada a fonte.

\author{
Catalogação da Publicação \\ Serviço de Documentação de Enfermagem \\ Escola de Enfermagem de Ribeirão Preto \\ da Universidade de São Paulo
}

Sasso-Mendes, Karina Dal

O processo ensino-aprendizagem para o candidato ao transplante de fígado, 2010.

225 p. : il. ; $30 \mathrm{~cm}$

Tese de Doutorado, apresentada à Escola de Enfermagem de Ribeirão Preto/USP. Área de concentração: Enfermagem Fundamental.

Orientador: Galvão, Cristina Maria.

1. Enfermagem. 2. Transplante de Fígado. 3. Ensino. 4. Aprendizagem. 5. Satisfação do Paciente. 
Nome: SASSO-MENDES, Karina Dal

Título: O processo ensino-aprendizagem para o candidato ao transplante de fígado

Tese apresentada à Escola de Enfermagem de Ribeirão Preto da Universidade de São Paulo para obtenção do título de Doutor em Ciências, Programa de Pós-Graduação Enfermagem Fundamental

Aprovado em: / 2010

Banca Examinadora

Prof. Dr.

Instituição: Assinatura:

Prof. Dr.

Instituição: Assinatura:

Prof. Dr.

Instituição: Assinatura:

Prof. Dr.

Instituição: Assinatura:

Prof. Dr.

Instituição: Assinatura: 



\section{DEDICATÓRIA}

\section{A minha Filha Gabriela,}

Filhinha, espero que perdoe a mamãe por todas as ausências e falta de temperamento nos momentos de dificuldades. Tudo o que fiz foi pensando no seu futuro e como tería orgutho de ser minha filha. Tenho muito orgulho de ser sua mãe. Você é um exemplo de luta pela vida para mim. Te amo muito! Obrigada por existir na minha vida! Obrigada por amar a mamãe!

\section{Ao meu Esposo Celso,}

Sou grata por ter você ao meu lado todos os momentos de minha vida. Obrígada pelo seu amor, compreensão e dedicação! Obrígada por me apoiar e por me ajudar a crescer. Te amo incondicionalmente!

"Doís corações unidos no Amor de Deus!"

\section{Aos meus Pais,}

Obrigada por terem me colocado neste mundo. Agradeço por toda educação que me deram. Sem vocês eu não sería a pessoa que sou hoje! Amo vocês!

\section{A toda minha Família,}

Agradeço pelo imenso apoío e compreensão! Perdoem-me por todas as minhas faltas e ausências. Amo vocês!

\section{Aos pacientes do Programa de Transplante de Fígado do HCFMRP,}

Nunca desistam de acreditar que viver é possivel!

\section{A Todos os Enfermeiros que Trabalham com Transplantes de Órgãos,}

Nunca desistam de seus sonhos e ideais para a melhoria da assistência de enfermagem! Desejo que este material seja útil nas empreitadas de ensino e aprendizagem para com seus pacientes! 



\section{AGRADECIMENTOS}

A Deus, pela força e perseverança concedidas ao longo deste estudo!

Profa Dra Cristina Maria Galvão,

Sua orientação, apoío, amizade e confiança, foram essenciais para a concretização deste sonho. Obrigada pela sua paciência e perseverança! Obrigada por me ajudar a crescer em nossa profíssão!

\section{Profa Dra Márcia Maria Fontão Zago,}

Suas sugestões e contríbuições para o percurso deste estudo foram fundamentais! Agradeço imensamente cada momento que pôde compartilhar comigo!

Profa Dra Maria Helena Larcher Caliri,

Agradeço as valiosas sugestões no exame de qualificação, as quaís foram essenciais para a realização deste estudo!

Profa Dra Maria Cristina Komatsu Braga Massarollo,

Agradeço pela disponíbilidade e atenção concedidas a este estudo!

Prof Dr Orlando de Castro e Silva Junior,

Obrigada por acreditar e apoiar a concretização deste sonho!

Às Enfermeiras e amigas da Unidade Especial de Transplante de Fígado Luciana, Fabiana e Kátia,

Agradeço pela amizade, confiança e por fazerem parte da realização desse sonho!

Profa Dra Janine Schirmer, Profa Dra Bartira de Aguiar Roza, e Enfermeira Renata Fabiana Leite,

Agradeço pelo carinho, amizade e apoío na realização deste estudo!

Às Enfermeiras da EERP Miyeko, Patrícia, Fernanda Titareli, Lívia, Aline, Clarissa, Cheila, Luiza, Luciana, Maria Verônica, Rosicler.

Às Professoras da EERP Renata Cristina, Namie, Ana Emília, Rosalina, Carla Regina, Maria Lúcia Zanetti, Helena, Rosana e Lídia.

A todos os docentes, funcionários e alunos da EERP-USP. 



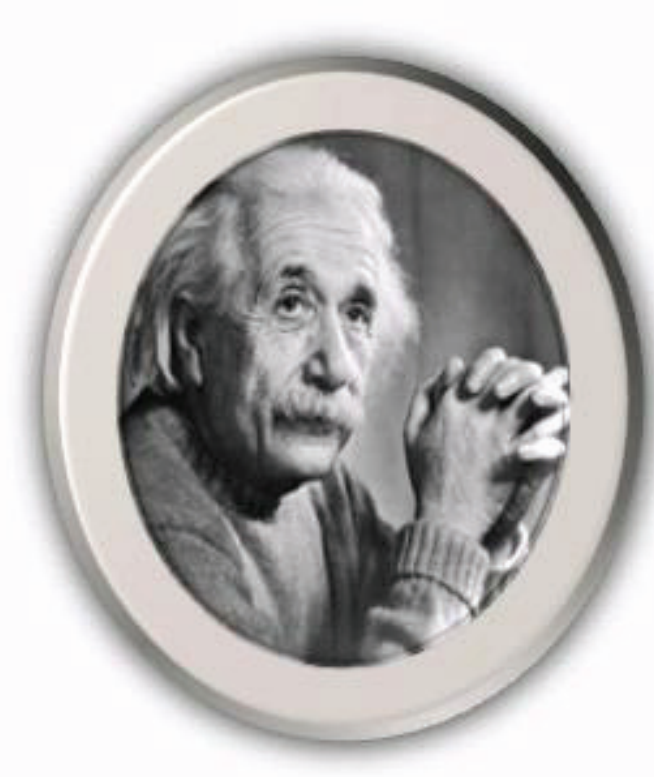

"Eu não me preocupo com as coisas que sei que não seí. Eu só me preocupo com as coísas que não sei que não sei. Porque as coisas que sei que não seí, é fácil - é só procurar que vou saber. Porém, as coisas que não sei que não sei, não tenho nem por onde começar!"

"A mente que se abre a uma nova idéia jamaís voltará ao seu tamanho original."

\section{Albert Finstein}





\section{RESUMO}

SASSO-MENDES, K. D. O processo ensino-aprendizagem para o candidato ao transplante de fígado. 2010. 225 f. Tese (Doutorado) - Escola de Enfermagem de Ribeirão Preto, Universidade de São Paulo, Ribeirão Preto, 2010.

O transplante de fígado é considerado o tratamento de eleição para o paciente com doença hepática progressiva, irreversível e terminal, o qual não encontra outro tipo de tratamento. O ensino é uma importante estratégia para o preparo dos candidatos ao transplante de fígado e constitui-se como papel relevante do enfermeiro. Para a condução da presente investigação adotou-se os pressupostos de Gagné e Ohler. O objetivo geral delimitado foi analisar o conhecimento de candidatos ao transplante de fígado, antes e depois da implementação de uma intervenção educativa. A investigação foi conduzida em duas fases. Na primeira fase realizou-se um estudo descritivo para identificar as características sócio-demográficas, clínicas e as necessidades de informação dos candidatos. Na segunda fase procedeu-se um estudo piloto, para analisar o conhecimento dos candidatos antes e depois da aplicação da intervenção educativa, e avaliar a satisfação destes com as informações recebidas. Frente a uma casuística de 55 candidatos na primeira fase, observou-se uma predominância do sexo masculino, com idade média de 50,25 anos, média de 8,49 anos de estudo, $70,91 \%$ dos sujeitos estavam afastados de atividades laborais e a renda predominante foi de dois a seis salários mínimos. A maioria dos candidatos era CHILD $B$, com MELD médio de 14,91 pontos, $72,72 \%$ estavam acima do peso e apresentavam uma evolução da doença crônica do fígado de 101,21 meses em média. A maioria da amostra apresentava cirrose causada por vírus e alcoolismo. O tempo médio de fila de espera foi de 1199,58 dias. Dentre as principais manifestações clínicas, destacou-se a presença de ascite $(58,18 \%)$, varizes esofágicas $(81,82 \%)$, encefalopatia hepática $(50,91 \%)$ e hemorragia digestiva prévia $(47,27 \%)$. As necessidades de informação relacionadas com o período pré-operatório foram as que obtiveram as pontuações médias maiores. As complicações após o transplante e os cuidados necessários após o transplante também foram necessidades de informação indicadas como relevantes pelos candidatos. Diante de uma amostra de 15 pacientes para a segunda fase do estudo, observou-se um ganho cognitivo significativo após a intervenção, com uma melhora de quase $20 \%$ no desempenho dos candidatos $(p<0,05)$. Em relação à satisfação dos candidatos, observou-se uma avaliação positiva da satisfação com as informações recebidas. As informações que geraram índices maiores de satisfação foram relacionadas ao período pós-operatório e os cuidados necessários por toda a vida. A relação entre o conhecimento após a intervenção e o grau de satisfação mostrou uma correlação significativa $(p<0,05)$. O estudo fornece evidências de que a provisão de informações de qualidade é capaz de aumentar o conhecimento e proporcionar satisfação para os candidatos ao transplante de fígado.

Palavras-Chave: Enfermagem. Transplante de Fígado. Ensino. Aprendizagem. Satisfação do Paciente. 



\begin{abstract}
SASSO-MENDES, K.D. The teaching-learning process for liver transplant candidates. 2010. 225 p. Doctoral Dissertation - University of São Paulo at Ribeirão Preto College of Nursing, 2010.

Liver transplant is considered the preferred treatment for patients with progressive, irreversible and terminal liver disease, who cannot find any other treatment type. Teaching is an important strategy to prepare liver transplant candidates and represents a relevant role for nurses. This research is based on Gagné and Ohler's premises. The general aim was to analyze liver transplant candidates' knowledge before and after an educative intervention. The research was conducted in two phases. First, a descriptive study was carried out to identify the candidates' sociodemographic and clinical characteristics and information needs. In the second phase, a pilot study was performed to analyze the candidates' knowledge before and after the educative intervention, as well as to assess their satisfaction with the information they received. The sample comprised 55 candidates: a majority were men; the average age was 50.25 years and average education 8.49 years; $70.91 \%$ of subjects were on leave from their job and the predominant income was between two and six minimum wages. Most candidates were CHILD B, the mean MELD score was 14.91 points, $72.72 \%$ were overweight and the average evolution of the chronic liver diseases was 101.21 months. Most patients in the sample presented cirrhosis caused by virus and alcoholism. The mean waiting time for a transplant was 1199.58 days. The main clinical manifestations included ascites (58.18\%), esophageal varices $(81.82 \%)$, hepatic encephalopathy $(50.91 \%)$ and previous digestive hemorrhage (47.27\%). Information needs related to the preoperative period obtained the highest mean scores. Candidates also indicated information needs related to post-transplant complications and necessary care. In a sample of 15 patients for the second phase, significant cognitive gain was observed after the intervention, with an almost $20 \%$ improvement in candidates' performance $(p<0,05)$. Candidates' satisfaction with the information they received was assessed positively. Higher satisfaction levels were found for information related to the postoperative period and care needed across the lifetime. Significant correlation was found $(p<0.05)$ between knowledge after the intervention and satisfaction level. This research evidences that providing quality information can increase liver transplant candidates' knowledge and give them satisfaction.
\end{abstract}

Key words: Nursing. Liver Transplantation. Teaching. Learning. Patient Satisfaction. 



\section{RESUMEN}

SASSO-MENDES, K.D. EI proceso enseñanza-aprendizaje para el candidato al trasplante de hígado. 2010. 225 h. Tesis (Doctorado) - Escuela de Enfermería de Ribeirão Preto, Universidad de São Paulo, Ribeirão Preto, 2010.

El trasplante de hígado es considerado el tratamiento elegido para el paciente con enfermedad hepática progresiva, irreversible y terminal, que no encuentra otro tipo de tratamiento. La enseñanza es una estrategia importante para la preparación de los candidatos al trasplante de hígado y constituye papel relevante del enfermero. Para conducir la presente investigación fueron adoptadas las premisas de Gagné y Ohler. La finalidad general delimitada fue analizar el conocimiento de candidatos al trasplante de hígado, antes y después de la implementación de una intervención educativa. La investigación fue conducida en dos fases. En la primera fase fue efectuado un estudio descriptivo para identificar las características sociodemográficas, clínicas y las necesidades de información de los candidatos. En la segunda fase fue llevado a cabo un estudio piloto para analizar el conocimiento de los candidatos antes y después de la aplicación de la intervención educativa y evaluar su satisfacción con las informaciones recibidas. Ante una casuística de 55 candidatos en la primera fase, fue observada una predominancia del sexo masculino, con edad promedia de 50,25 años, promedio de 8,49 años de estudio, el 70,91\% de los sujetos estaba de permiso de actividades laborales y la renta predominante varió entre dos y seis salarios mínimos. La mayoría de los candidatos era CHILD B, con MELD promedio de 14,91 puntos, el $72,72 \%$ estaba con exceso de peso y la evolución promedia de la enfermedad crónica del hígado fue de 101,21 meses. La mayoría de la muestra presentó cirrosis causada por virus y alcoholismo. El tiempo promedio de cola fue de 1199,58 días. Entre las principales manifestaciones clínicas, se destacó la presencia de ascitis $(58,18 \%)$, várices esofágicas $(81,82 \%)$, encefalopatía hepática $(50,91 \%)$ y hemorragia digestiva previa $(47,27 \%)$. Las necesidades de información relacionadas con el periodo preoperatorio fueron las que alcanzaron las mayores puntuaciones promedias. Las complicaciones tras el trasplante y los cuidados necesarios post-trasplante también fueron necesidades de información que los candidatos indicaron como relevantes. Ante una muestra de 15 pacientes para la segunda fase del estudio, se observó ganancia cognitiva significativa tras la intervención, con una mejora de casi el $20 \%$ en el desempeño de los candidatos $(p<0,05)$. Respecto a la satisfacción de los candidatos, se observó una evaluación positiva de la satisfacción con las informaciones recibidas. Las informaciones que generaron mayores índices de satisfacción fueron relacionadas al período postoperatorio y los cuidados necesarios por toda la vida. La relación entre el conocimiento después de la intervención y el grado de satisfacción mostró una correlación significativa $(p<0,05)$. El estudio evidencia que la provisión de informaciones de calidad es capaz de aumentar el conocimiento y proporcionar satisfacción para los candidatos al trasplante de hígado.

Palabras-Clave: Enfermería. Trasplante de Hígado. Enseñanza. Aprendizaje. Satisfacción del Paciente. 



\section{SUMÁRIO}

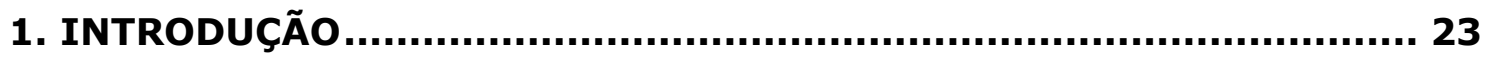

2. REFERENCIAL TEÓRICO-METODOLÓGICO ................................ 35

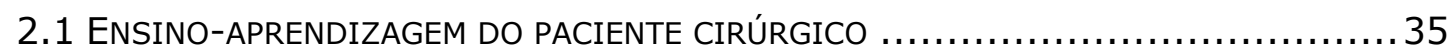

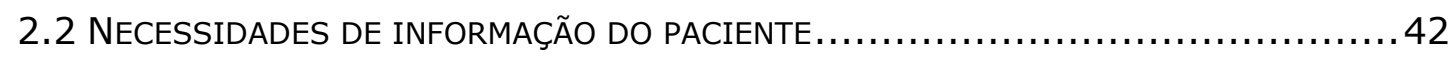

2.3 REFERENCIAL TEÓRICO: O DESENVOLVIMENTO DE APRENDIZAGENS DE ROBERT GAGNÉ 46

2.4 Referencial Metodológico: Modelo de ensino-APREndizagem Para

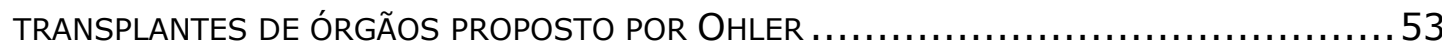

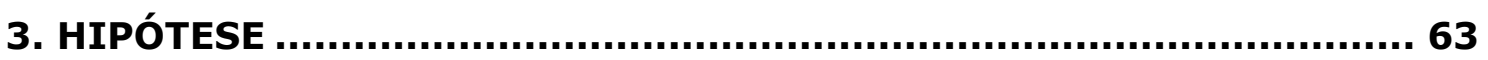

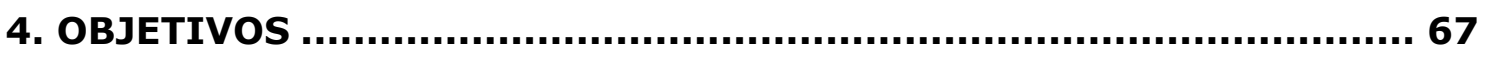

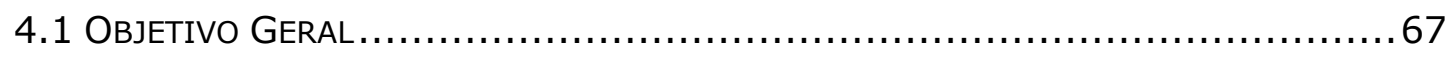

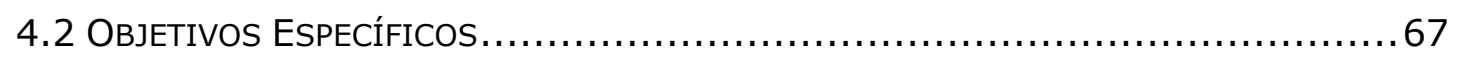

5. PROCEDIMENTO METODOLÓGICO ............................................ 71

5.1 DELINEAMENTO DE PESQUISA NÃO EXPERIMENTAL: ESTUdO DESCRITIVO............73

5.1 .1 Local do estudo .................................................... 73

5.1 .2 População .......................................................... 73

5.1 .3 Critérios de inclusão .............................................. 73

5.1 .4 Critérios de exclusão ............................................ 74

5.1 .5 Amostra ............................................................ 74

5.1.6 Elaboração e validação do instrumento de coleta de dados............74 74

5.1 .7 Coleta de dados.................................................. 77

5.1 .8 Análise de dados................................................ 77

5.2 DELINEAMENTO DE PESQUISA QUASE-EXPERIMENTAL: ESTUDO PILOTO GRUPO ÚNICO,

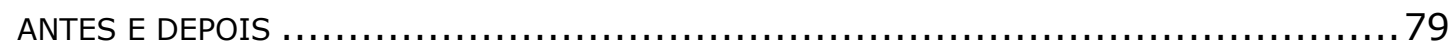

5.2.1 Local do Estudo ................................................. 79

5.2.2. Casuística ...................................................... 80

5.2 .2 .1 Amostra........................................................... 80

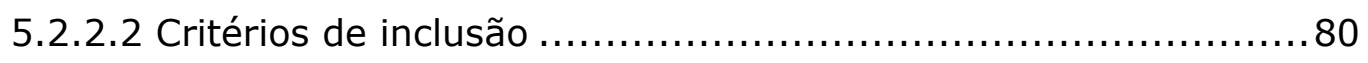

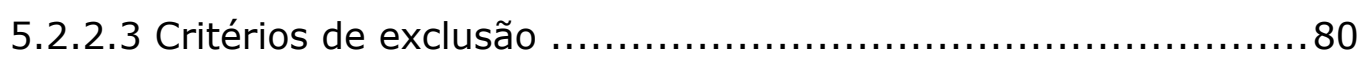

5.2 .3 Planejamento ................................................... 81

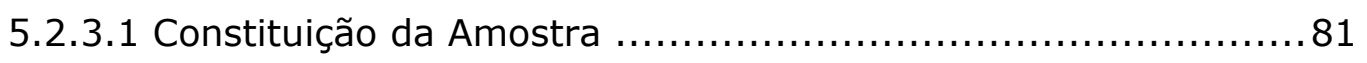

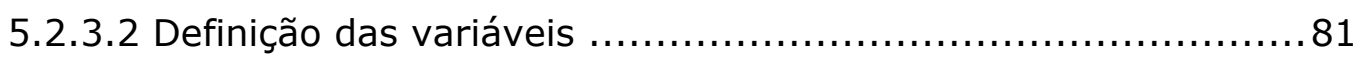

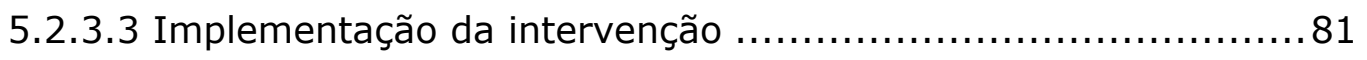


5.2.3.4 Avaliação do conhecimento sobre o processo de transplante de fígado e a satisfação do paciente em relação à intervenção educativa .. 84

5.2.3.5 Procedimento de coleta de dados................................ 85

5.2 .4 Análise Estatística .............................................. 85

5.2 .5 Aspectos Éticos............................................... 86

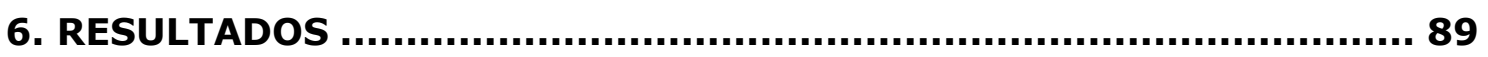

6.1 RESULTADOS DO DELINEAMENTO DE PESQUISA NÃO EXPERIMENTAL: ESTUDO

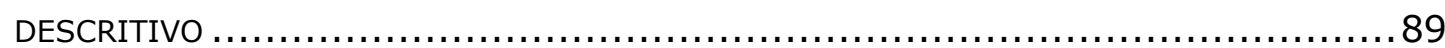

6.1.1 Caracterização da amostra do estudo................................. 89

6.1.2 Necessidades de informação dos candidatos em fila de espera..... 102 6.2 RESULTADOS DO DELINEAMENTO DE PESQUISA QUASE-EXPERIMENTAL: ESTUDO PILOTO

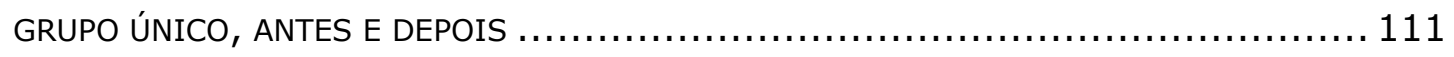

6.2.1 Conhecimento dos candidatos sobre o processo de transplante de fígado, antes e depois da implementação da intervenção educativa ...... 111

6.2.2 Satisfação dos candidatos após a implementação da intervenção educativa.

7. DISCUSSÃO.

7.1 DisCUSSÃO DO DELINEAMENTO DE PESQUISA NÃO EXPERIMENTAL: ESTUDO

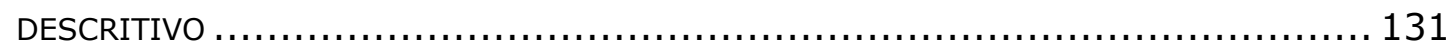

7.1.1 Caracterização da amostra do estudo................................ 131

7.1.2 Necessidades de informação dos candidatos em fila de espera.... 139 7.2 DisCUSSÃO DO DELINEAMENTO DE PESQUISA QUASE-EXPERIMENTAL: ESTUDO PILOTO GRUPO ÚNICO, ANTES E DEPOIS

7.2.1 Conhecimento dos candidatos sobre o processo de transplante de fígado, antes e depois da implementação da intervenção educativa ...... 151 7.2.2 Satisfação dos candidatos após a implementação da intervenção educativa...

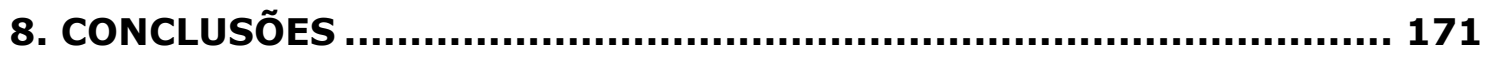

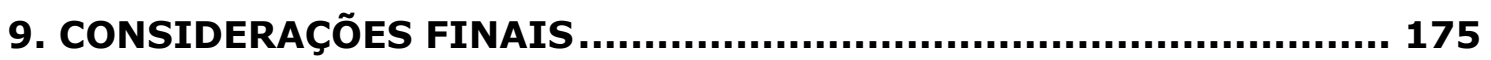

10. REFERÊNCIAS BIBLIOGRÁFICAS ...................................... 181

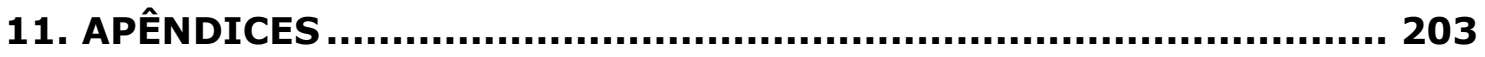

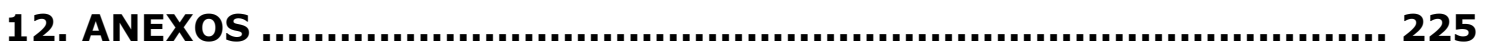




\section{IJntroduçãa}




\section{INTRODUÇÃO}

O enfermeiro é o elemento da equipe de saúde que permanece mais tempo ao lado do paciente, o que torna essencial seu papel como educador nas diversas necessidades de aprendizagem que as morbidades exigem (ZAGO, 1993). Para tanto, é relevante que o enfermeiro tenha fundamentação científica e proporcione a implementação de estratégias efetivas no sentido de promover mudanças de comportamento, atitudes e estilos de vida de pacientes.

Nesta perspectiva, o presente estudo tem o anseio de despertar nos enfermeiros com atuação nos diversos programas de transplante de fígado, um olhar científico no que se refere às ações de ensino e aprendizagem de pacientes que aguardam a cirurgia, ou seja, os candidatos ao transplante de fígado, com vistas à melhoria da assistência de enfermagem e, por conseguinte, a melhoria dos resultados dos transplantes.

O fígado é o maior órgão sólido do corpo e considerado um dos mais complexos. Está localizado no lado direito do abdômen, à direita do estômago, abaixo das costelas inferiores e pulmões e pesa em torno de 1,3 a 1,8 kg, aproximadamente $2 \%$ do peso corporal. O fígado realiza mais de 500 funções a cada dia para manter a homeostase. Juntamente com a vesícula biliar e o pâncreas, o fígado produz substâncias que auxiliam na digestão e no uso dos alimentos (FLYNN, 2003; GORDON, 2007). Algumas das suas principais funções são:

- produção de bile que permite o uso de proteínas, gorduras e carboidratos pelo organismo;

- uso e armazenamento de gorduras, açúcares, ferro e vitaminas;

- produção de fatores de coagulação como a protrombina;

- remoção e quebra de drogas, álcool, e outras substâncias potencialmente perigosas;

- produção de albumina que auxilia na manutenção dos fluidos corporais dentro dos vasos sangüíneos;

- monitora a presença de bactérias no sangue (GORDON, 2007). 
Devido à complexidade e inúmeras funções, o fígado é afetado por muitas desordens que podem produzir uma variedade de problemas fisiológicos e psicossociais para os pacientes que aguardam a cirurgia, ou seja, os candidatos ao transplante de fígado. O grau da doença do fígado pode variar de crítico, requerendo cuidados de enfermagem intensivos, ao crônico, requerendo cuidados domiciliares (THOMAS, 1999a; FLYNN, 2003).

As pessoas com doença crônica do fígado requerem intervenções de enfermagem a fim de auxiliá-los a adquirir mudanças necessárias em seu estilo de vida com o intuito de ajudar no controle do problema e na prevenção da progressão da doença. Muitos pacientes com doença crônica do fígado irão apresentar em algum momento exacerbações agudas, os quais necessitarão de cuidados no contexto hospitalar. O foco do cuidado de enfermagem para o paciente com doença crônica do fígado é promover habilidades para o automanejo da doença, as quais só serão possíveis com o uso de intervenções educativas pelo enfermeiro e equipe multidisciplinar (THOMAS, 1999b).

Aproximadamente $90 \%$ dos candidatos a um transplante de fígado apresentam cirrose hepática. A cirrose hepática é o termo utilizado para a doença crônica do fígado caracterizada por uma inflamação difusa e fibrose do tecido hepático, e conseqüentemente, alterações estruturais drásticas e perda significante da função do fígado. A principal mudança acarretada pela cirrose é a morte celular e a substituição de tecido normal, graças a sua peculiar capacidade de regeneração, por tecido cicatricial, resultando em nódulos no parênquima hepático circundado por tecido fibrótico e gordura. Tais alterações implicam em perda da função e distorção da estrutura do fígado, levando a obstrução da irrigação sanguínea intra-hepática (THOMAS, 1999b; FLYNN, 2003).

A cirrose pode resultar de uma doença hepática secundária a colestase intra ou extra-hepática, hepatite viral e outras hepatotoxinas (drogas e produtos químicos). O alcoolismo e a desnutrição são os fatores de risco mais importantes para o desenvolvimento de cirrose. As causas menos comuns são a insuficiência cardíaca congestiva direita, a hemocromatose, a doença de Wilson, a fibrose cística, entre outras. Em alguns pacientes a causa é idiopática. O resultado da cirrose, independente do seu fator causal, é a perda de função e obstrução do fluxo de sangue portal no fígado. As alterações fisiológicas são normalmente percebidas na fase tardia de progressão da doença, graças a grande capacidade de reserva do fígado. A função fisiológica do fígado se torna alterada quando ocorre a destruição de 
até três quartos do fígado, ou seja, quando apenas restam $25 \%$ de fígado saudável (THOMAS, 1999b).

Uma variedade de sinais e sintomas pode ser visto em pessoas com cirrose hepática. O paciente pode se sentir tanto saudável, quanto apresentar todos os sinais e sintomas que acompanham a doença. As manifestações clínicas variam desde histórico de náusea, vômito, anorexia, fadiga, indigestão, flatulência e constipação, perda de peso mascarada por retenção hídrica, desnutrição, dor abdominal, normalmente no quadrante superior direito, até sinais tardios, tais como ascite, icterícia, edema, anemia, encefalopatia e sangramentos, os quais ocorrem gradualmente (THOMAS, 1999b). Na fase cujo tratamento convencional já não surte o efeito desejado, lança-se mão do transplante de fígado como opção terapêutica.

O transplante de fígado é considerado um dos mais importantes avanços na medicina (ABBASOGLU, 2008). Historicamente, o primeiro transplante de fígado foi realizado em 1963, nos Estados Unidos da América (EUA), por Thomas Earl Starzl e sua equipe, na Universidade do Colorado (Denver). A mortalidade, naquela época, girava em torno de $70 \%$ dos casos, devido às freqüentes complicações e carência de terapêuticas imunossupressoras seguras e eficazes (GONZÁLEZ et al., 1998). Apenas no início da década de 1980 houve uma padronização das retiradas de múltiplos órgãos, o surgimento de novos imunossupressores e o desenvolvimento de uma solução de conservação de órgãos, o Belzer. Esse desenvolvimento científicotecnológico levou os resultados de transplantes de rim, coração, pulmão e fígado a atingirem uma sobrevida de $80 \%$ em dois anos. Como resultado destes avanços, desde 1983, o transplante de fígado é aceito como um tratamento universalmente válido para doenças hepáticas terminais, com a consagração de Thomas Earl Starzl, como o "pai" do referido transplante (MONTERO et al., 1998; D'ALBUQUERQUE et al., 2001).

No Brasil, as primeiras tentativas de transplante de fígado foram realizadas pelo Prof. Marcel César Machado em 1968, no Hospital das Clínicas da Faculdade de Medicina da Universidade de São Paulo (HC-FM-USP); entretanto, somente em 1985 foi realizado o primeiro transplante de fígado com sucesso no Brasil e na América Latina, pelo Prof. Silvano Raia do HC-FM-USP. A mesma equipe realizou pioneiramente no mundo o primeiro transplante de fígado intervivos em 1988 (THE TRANSPLANTATION SOCIETY OF LATIN AMERICA AND THE CARIBBEAN, 2007). 
No período de 1999 a 2009, no Brasil, foram realizados 9.348 transplantes de fígado, de um total de 15.329 transplantes realizados em toda a América Latina. Atualmente, o Brasil conta com 50 centros transplantadores ativos cadastrados no Sistema Nacional de Transplantes e possui uma fila de espera com mais de 4.800 pessoas portadoras de doença crônica do fígado (ASSOCIAÇÃO BRASILEIRA DE TRANSPLANTE DE ÓRGÃOS, 2009; THE TRANSPLANTATION SOCIETY OF LATIN AMERICA AND THE CARIBBEAN, 2009).

Dados recentes da Associação Brasileira de Transplante de Órgãos (ABTO) mostram que no ano de 2009 ocorreram 1.322 transplantes de fígado no Brasil. Em relação ao número de doações de órgãos no ano de 2009, no Brasil, foram notificados 6.490 potenciais doadores, sendo que destes apenas $1.658(25,55 \%)$ se tornaram doadores efetivos; e, em apenas 1.237 casos de morte encefálica ocorreu a retirada de múltiplos órgãos (ASSOCIAÇÃO BRASILEIRA DE TRANSPLANTE DE ÓRGÃOS, 2009; THE TRANSPLANTATION SOCIETY OF LATIN AMERICA AND THE CARIBBEAN, 2009). De acordo com a literatura nacional e internacional ressalta-se que a mortalidade em fila de espera para o transplante de fígado gira em torno de 20 a $30 \%$ dos casos, tornado-se crítico o número de transplantes de fígado realizados frente ao número de doadores disponíveis (MASSAROLLO et al., 2003; SANCHEZ-PEREZ et al., 2005; DEL PINO et al., 2006; FINK et al., 2007).

O transplante de fígado é considerado o tratamento de eleição para os pacientes com doença hepática progressiva, irreversível e terminal, o qual não encontra outro tipo de tratamento (FERRER; RAFFAN, 2003). É considerado o procedimento mais complexo da cirurgia moderna, uma vez que interfere com diversas funções do organismo (MIES, 1998). As taxas atuais de sobrevivência de pacientes são aproximadamente de $85 \%$ no primeiro ano e maior do que $70 \%$ em cinco anos de transplante (FLYNN, 2003; NEIL, 2007).

A doença hepática pode ocorrer repentinamente (aguda), como a falência hepática fulminante, na qual o surgimento da disfunção hepática e a encefalopatia ocorrem dentro de oito semanas após o surgimento dos sintomas. A doença aguda do fígado se inicia na maioria das vezes com sintomas vagos, tais como anorexia e mal estar e geralmente é descrita como uma síndrome viral até a ocorrência da icterícia. O exemplo mais comum de doença aguda do fígado é a toxicidade por acetominofeno, mas podem ocorrer outras causas como a criptogênica, hepatite $B$ induzida por drogas, hepatite A, doença de Wilson, esteato-hepatite durante a gestação, Budd-Chiari e envenenamento por cogumelos. A doença aguda geralmente 
ocorre em jovens, os quais são relativamente saudáveis até o surgimento da doença. Até a realização do transplante do fígado, a falência hepática aguda está associada com altos índices de mortalidade, uma vez que o transplante deve ocorrer entre $24 \mathrm{e}$ 48 horas para se evitar a morte (FLYNN, 2003).

A doença crônica do fígado causa falência hepática por meio de danos no fígado em um longo período. O dano é usualmente irreversível. A doença crônica causa cirrose na maioria dos casos, a qual se desenvolve quando as células normais do fígado são danificadas, morrem e são substituídas por tecido cicatricial. A cirrose surge de várias doenças no fígado, incluindo hepatite viral crônica, cirrose biliar primária e colangite esclerosante primária (FLYNN, 2003; FOX, 2007).

As complicações da doença hepática indicam quando o transplante é necessário. Tais complicações são divididas em duas categorias: a hipertensão portal e a redução do parênquima hepático. A presença de hipertensão portal pode levar a hemorragia gastrointestinal e a ascite refratária. As complicações decorrentes da redução do parênquima hepático incluem a coagulopatia, icterícia, metabolismo reduzido de drogas e encefalopatia (FLYNN, 2003).

As indicações mais comuns para o transplante de fígado na população adulta são a hepatite C crônica, doença hepática alcoólica, hepatite B crônica, cirrose biliar primária, colangite esclerosante e hepatite auto-imune (FLYNN, 2003).

O número de pacientes que necessitam de um transplante de fígado continua crescente a cada ano, mas devido ao desproporcional número de doadores de órgãos disponíveis e das diferenças entre os critérios de inclusão em lista de espera dos diferentes centros transplantadores, critérios mínimos para a cirurgia e contraindicações são aceitos. As contra-indicações absolutas a cirurgia incluem a falência multissistêmica de órgãos, a presença de tumores malignos extra-hepáticos, doença cardíaca ou pulmonar avançada, infecção extra-hepática severa ou incontrolada e o uso ativo de substâncias como drogas e álcool (FLYNN, 2003; BUFTON; EMMETT; BYERLY, 2008).

As pessoas com tumores primários de fígado que não são candidatas à ressecção cirúrgica e que não apresentem evidências de metástases fora do fígado ou envolvimento macrovascular podem ser consideradas para o transplante. 0 paciente pode apresentar um nódulo único de até $5 \mathrm{~cm}$ de tamanho, ou dois ou três nódulos menores do que $3 \mathrm{~cm}$ em um único lóbulo do fígado. Os indivíduos com 
nódulos maiores do que $5 \mathrm{~cm}$ ou com nódulos nos dois lóbulos do fígado com evidências de tumores extra-hepáticos não devem ser transplantados (FLYNN, 2003).

O processo de avaliação do paciente envolve a realização de vários exames laboratoriais e clínicos realizados pela equipe de transplante, a qual geralmente é composta por hepatologistas, cirurgiões, coordenador, assistente social, psiquiatra ou psicólogo, anestesiologista, patologista, farmacêutico, nutricionista e enfermeiros. Ainda durante a fase de avaliação é necessária a realização de exame ginecológico Papanicolau e mamografia para mulheres e antígeno prostático específico para homens. Dependendo da idade, diagnóstico, e da história do paciente, podem ser adicionados ou excluídos outros testes e avaliações, conforme indicação (FLYNN, 2003; BUFTON; EMMETT; BYERLY, 2008).

Uma vez que os testes são completados, o potencial candidato é formalmente apresentado à equipe para discussão de sua adequação para o transplante. Nesse momento, qualquer consideração especial que possa afetar a fase pós-transplante é trazida para a atenção da equipe, tais como, suporte familiar, situação financeira e história psiquiátrica. Desse modo, assim que o paciente preenche os critérios mínimos requeridos, a equipe decide quando incluir o paciente em lista de espera. $O$ coordenador de transplante geralmente informa ao paciente e a equipe médica quando o paciente é ativado na lista de espera (FLYNN, 2003).

O escore CHILD-Pugh (Quadro 1) completa os critérios mínimos para listagem dos potenciais candidatos a um transplante de fígado. O escore é obtido utilizando a classificação de CHILD-Turcotte Pugh, também chamada de escore de CHILD-Pugh, a fim de garantir que os pacientes com doença hepática realmente necessitam de um transplante, devido à severidade de sua doença. A classificação inclui a avaliação da presença e grau de encefalopatia, ascite, nível de bilirrubina, tempo de protrombina e a relação normalizada internacional (INR). A somatória da pontuação, de acordo com os sinais e sintomas apresentados pelo paciente, permite a classificação em CHILD A (5-6 pontos), CHILD B (7-9 pontos) e CHILD C (10-15 pontos) (BOTERO; LUCEY, 2003; FLYNN, 2003). 


\begin{tabular}{|l|c|c|c|}
\hline \multicolumn{1}{|c|}{ Pontos } & $\mathbf{1}$ & $\mathbf{2}$ & $\mathbf{3}$ \\
\hline $\begin{array}{l}\text { Encefalopatia } \\
\text { Ascite }\end{array}$ & Ausente & Moderada & Severa \\
\hline $\begin{array}{l}\text { Bilirrubina } \\
\text { Para CBP* ou CEP** }\end{array}$ & Ausente & Estágio $1-2$ & Estágio 3-4 \\
\hline \multicolumn{1}{|c|}{ Para outras doenças } & $1-4$ & $4-10$ & \\
\hline Albumina & $<2$ & $2-3$ & $>10$ \\
\hline Tempo de Protrombina & $>3,5$ & $2,8-3,5$ & $<2,8$ \\
\hline INR*** & $<4$ & 4,6 & $>6$ \\
\hline
\end{tabular}

*CBP = Cirrose Biliar Primária; $* *$ CEP = Colangite Esclerosante Primária; $* * *$ INR $=$ Razão Normalizada Internacional.

Quadro 1 - Classificação de CHILD-Turcotte Pugh segundo Flynn, 2003

O candidato ao transplante deve ter um escore de no mínimo 7 pontos para ser inserido na lista de espera, ou seja, ser classificado como CHILD Classe B. O sangramento de varizes esofágicas recorrente, encefalopatia, ascite e peritonite bacteriana espontânea são complicações que indicam uma conduta adequada para a inclusão do indivíduo em lista de pacientes em circunstâncias extenuantes e com qualidade de vida prejudicada (presença de prurido, doença óssea metabólica ou neuropatia xantomatosa) (BOTERO; LUCEY, 2003; FLYNN, 2003).

Uma vez que o candidato é ativado em lista de espera, outra classificação é delimitada, a qual é denominada MELD ou Model for End-stage Liver Disease, modelo que indica a gravidade da doença do fígado. O MELD é um valor numérico, variando de 6 (menor gravidade) a 40 (maior gravidade), usado para quantificar a urgência de transplante de fígado em adultos e crianças maiores de 12 anos. É uma estimativa do risco de óbito se não fizer o transplante nos próximos três meses, priorizando os candidatos em fila de espera (BOTERO; LUCEY, 2003; FLYNN, 2003). Para crianças menores do que 12 anos utiliza-se o PELD - Pediatric End-stage Liver Disease.

O valor MELD é calculado por uma fórmula a partir do resultado de três exames laboratoriais de rotina, ou seja: 
- bilirrubina, que mede a eficiência do fígado excretar bile;

- creatinina, uma medida da função renal;

- INR - Relação Normalizada Internacional, uma medida da atividade da protombina, que mede a função do fígado com respeito à produção de fatores de coagulação (BOTERO; LUCEY, 2003).

Esse modelo foi planejado para identificar de forma melhor os pacientes, baseado na urgência médica, na necessidade do transplante e assim diminuir o número de mortes de pacientes à espera por um transplante de fígado (BOTERO; LUCEY, 2003; FLYNN, 2003).

Dentre as principais complicações da doença hepática, destacamos a ascite, a encefalopatia, a peritonite bacteriana espontânea e a síndrome hepatorrenal. A ascite é definida como um acúmulo de líquidos na cavidade abdominal que ocorre quando fluidos extravasam do plasma sanguíneo para o interior da cavidade abdominal, principalmente através do peritônio, como resultado da hipertensão portal (ou seja, aumento de pressão no sistema porta, $>8 \mathrm{mmHg}$ ), da diminuição da capacidade dos vasos sangüíneos em reter fluidos, da retenção de fluidos pelos rins e de alterações na capacidade do fígado em regular os fluidos corporais. É um quadro comum principalmente em pacientes com doença crônica do fígado, tal como a cirrose. Os pacientes podem acumular até 25 litros de líquido na cavidade peritoneal (FLYNN, 2003).

A encefalopatia é um termo utilizado para descrever o que acontece com o paciente com doença hepática, quando sofre uma mudança em seu estado mental devido ao aumento de substâncias tóxicas no sangue. É causada quando a função hepática está prejudicada e o fígado não consegue mais remover tais substâncias durante a filtração do sangue; ou como resultado da doença hepática, tais toxinas podem passar completamente pelo fígado. O aumento secundário de substâncias tóxicas no sangue, tal como a amônia, ou condições que aumentam os níveis de produtos de quebra protéica no sangue, como a presença de sangramento gastrointestinal, infecção ou uma dieta hiperproteica, pode levar a ocorrência de encefalopatia. As mudanças no estado mental variam de leve alteração no pensamento lógico, alterações de humor e sonolência incontrolável, à confusão, desorientação, letargia e coma. O grau de encefalopatia é uma indicação da 
severidade da doença hepática e geralmente é classificado em leve, moderado ou grave (FLYNN, 2003; BUFTON; EMMETT; BYERLY, 2008).

O tratamento da encefalopatia consiste em cuidar de qualquer fator precipitante, tais como a infecção ou a interação de drogas, ou realizar modificações na dieta com restrição de proteína. A eliminação das substâncias tóxicas pode ser conseguida com o uso oral ou por sonda nasoenteral de um açúcar sintético (lactulose). A lactulose altera a acidez intestinal, mudando o tipo de bactéria presente, o que diminui a absorção de amônia, além disso, atua como um laxativo removendo do corpo as toxinas que causam a mudança no estado mental. A neomicina pode ser utilizada em substituição a lactulose. O tratamento pode também incluir a realização de um enema. No caso da encefalopatia severa, pode ser necessária a inserção de sonda nasogástrica, bem como a intubação endotraqueal, a fim de se prevenir a aspiração (FLYNN, 2003; BUFTON; EMMETT; BYERLY, 2008).

A peritonite bacteriana espontânea (PBE) ocorre em pacientes com doença avançada de fígado e que apresentam ascite. Clinicamente o paciente pode apresentar febre, dor abdominal, encefalopatia hepática, deterioração abrupta da função renal e hepática. A PBE é tratada com a administração de antibióticos na fase aguda e após a ocorrência do problema de forma a prevenir novos episódios. Também é necessária a realização de paracenteses diagnósticas posteriores ao tratamento com antibiótico, uma vez que a PBE contra-indica a realização do transplante de fígado (FLYNN, 2003).

Finalmente, a síndrome hepatorrenal, uma disfunção renal resultado de uma persistente vasoconstrição renal, na qual é freqüentemente presente em pacientes com falência hepática avançada. É caracterizada por uma grave hiponatremia não responsiva a reposição de fluidos. É evidenciada com um aumento da creatinina sérica de 1,5 ou mais, sem outras causas conhecidas de insuficiência renal. A síndrome hepatorrenal é geralmente uma condição reversível após a realização do transplante (FLYNN, 2003; BUFTON; EMMETT; BYERLY, 2008).

Frente às complicações graves da doença crônica do fígado, o candidato apresenta um alto risco de morte enquanto aguarda a realização do transplante de fígado, uma vez que existe uma grande diferença entre o número de pessoas que necessitam de um órgão, e o número de doadores disponíveis, sendo considerado um dos problemas graves de transplante de órgãos da atualidade. 
De um modo geral, todos os candidatos necessitam ser preparados para exames diagnósticos, devem entender o seu tratamento e aprender a manejar os cuidados necessários por um longo período, até a realização do transplante de fígado. A informação deve ser dada de modo verbal e escrita, dependendo do estado físico do paciente e do nível de educação. A informação poderá ser repetida algumas vezes e aos poucos ao longo do tratamento. Os membros da família ou os cuidadores devem ser incluídos, pois podem ajudar na apreensão e retenção das informações aos pacientes e participar do cuidado de uma maneira mais efetiva (OHLER, 2003).

A longo prazo, os cuidados requerem mudanças maiores no estilo de vida. As principais informações que o enfermeiro pode incluir no seu plano de ensino e aprendizagem, no sentido de auxiliar nas mudanças de estilo de vida, e que requerem um suporte contínuo a candidatos e familiares durante o período de espera para o transplante são: evitar progressão dos danos no fígado (absenteísmo alcoólico, evitar qualquer medicamento que não seja prescrito pelo médico), regime dietético (restrições de cloreto de sódio e proteínas), restrição de fluidos, discernimento dos sinais e sintomas que requerem avaliação imediata (ganho de peso repentino, aumento da circunferência abdominal, recorrência de edema, febre, sangramentos, mudanças no estado mental e comportamento), medidas para evitar hemorragias, terapêutica medicamentosa, plano de atividades que promovam repouso adequado e medidas de controle do prurido (THOMAS, 1999b). Desse modo, o uso de estratégias de ensino e aprendizagem, é uma condição sine qua non no cuidado a candidatos que aguardam a realização da cirurgia.

Frente ao exposto e com base em uma revisão integrativa da literatura publicada por Mendes e Galvão (2008) constatamos que o processo ensinoaprendizagem do paciente é uma temática pouco explorada pelos enfermeiros envolvidos em programas de transplantes de órgãos, no que se refere à produção do conhecimento, sendo esta uma motivação para a realização do presente estudo. 
2. \ieferencial Teárica-Atletodolóquico 


\section{REFERENCIAL TEÓRICO-METODOLÓGICO}

\subsection{Ensino-aprendizagem do paciente cirúrgico}

A educação de pacientes pode ser definida como um processo pelo qual o paciente atinge a compreensão de sua própria condição física e realiza o autocuidado pelo uso de diversos recursos e experiências (FOX, 2007). Geralmente a meta da educação é possibilitar que o paciente não só apresente um entendimento do seu atual estado de saúde, mas também esteja disponível para tomar decisões relacionadas ao cuidado em saúde; além de fazer as mudanças necessárias a fim de atingir um melhor estado de saúde (DOAK; DOAK; ROOT, 1996; FALVO, 2004; REDMAN, 2007).

Dentre os benefícios apontados para os pacientes submetidos ao processo de educação em saúde, incluem o aumento da satisfação do paciente, o aumento da qualidade de vida, a melhoria da continuidade dos cuidados no domicílio, a diminuição da ansiedade, a diminuição das possíveis complicações, a promoção de adesão ao plano de tratamento proposto, a maximização da independência e o empoderamento (FALVO, 2004; BASTABLE, 2006; REDMAN, 2007). Alguns estudos apontam que a satisfação do paciente com o tratamento aumenta de acordo com a provisão de informações (PARKES; SHEPPERD, 2000; JOHANSSON et al., 2003; FELDMAN-STEWART; BRENNENSTUHL; BRUNDAGE, 2007).

A educação de pacientes não se trata simplesmente do enfermeiro dizer ao paciente o que fazer enquanto estiver em casa. Ela tem um significado maior que direciona o enfermeiro para assistir o paciente com vistas ao aumento de habilidades em promover um autocuidado efetivo. Esse profissional está em uma posição chave, capaz de afetar positivamente a vida do paciente por meio da educação, produzindo desse modo, potencialidades de mudanças de longa duração (COATES, 1999; SYX, 2008).

O processo de educação consiste em elementos básicos de avaliação, planejamento, implementação e avaliação, semelhantes ao processo de enfermagem, e cujo foco está na avaliação das necessidades de aprendizagem dos clientes, na motivação para a aprendizagem e nos estilos de aprendizagem (REGA, 1993; BASTABLE, 2006; REDMAN, 2007). Os resultados do processo educacional são atingidos quando mudanças no conhecimento, habilidades e atitudes ocorrem (FALVO, 2004). 
Com efeito, o processo de educação é sistemático, seqüencial, lógico e planejado dentro de um curso de ação, consistindo em duas operações interdependentes, ensino e aprendizagem. Esse processo forma um ciclo contínuo que também envolve dois diferentes atores, o professor (enfermeiro) e o aprendiz (paciente). As atividades de ensino e aprendizagem juntas conduzem a resultados que mutuamente levam as mudanças de comportamento. Desse modo, o processo de educação é um cenário para uma aproximação participativa e compartilhada entre o ensino e a aprendizagem (REGA, 1993; REDMAN, 2003; 2007).

O ensino é um dos principais papéis do enfermeiro e como profissional de saúde está ética e legalmente comprometido com sua efetividade (FOX, 2007). As tendências atuais no cuidado em saúde têm apontado a importância dos pacientes e familiares estarem preparados para assumir a responsabilidade no manejo do autocuidado em saúde (REGA, 1993; COATES, 1999).

No contexto da literatura internacional destaca-se dentre as principais barreiras do ensino do paciente para o enfermeiro: a falta de tempo para ensinar, falta de competência ou confiança com habilidades de ensino, baixa priorização das atividades de ensino pelos administradores e equipe médica, problemas ambientais (falta de espaço, privacidade, barulho e freqüentes interrupções), ausência de incentivos financeiros para a educação de pacientes, questionamentos de médicos e enfermeiros sobre a eficácia da educação na promoção de melhoria da saúde, sistema de documentação e registro de atividades educativas, influenciando a qualidade e a quantidade de ensino ministrado aos pacientes (BASTABLE, 2006; REDMAN, 2007).

O ensino é definido como os recursos necessários para ajudar outro indivíduo a aprender. $O$ aprendizado pode ser definido com a aquisição de conhecimentos, atitudes ou competências. Essas definições indicam que o processo de ensinoaprendizagem é do tipo ativo, exigindo o envolvimento do professor e do aprendiz no esforço de alcançar o resultado desejado, uma alteração de comportamento. 0 professor não apenas fornece uma informação ao aprendiz, mas atua como facilitador do aprendizado (RANKIN; STALLINGS, 1996; SMELTZER; BARE, 2005).

O sucesso do esforço do enfermeiro no ensino depende não somente da quantidade de informações que são divulgadas, mas no quanto o indivíduo apreende, retém e aplica em situações diversas. A aprendizagem é definida como uma mudança no comportamento (conhecimento, habilidades e atitudes), que pode ser 
observada ou mensurada e ocorrer em qualquer espaço ou tempo (REGA, 1993; COATES, 1999).

Dessa forma, a aprendizagem também é definida como uma mudança relativa e permanente no pensamento, funcionamento emocional, e/ou comportamento como resultado de uma experiência. É o processo pelo qual indivíduos adquirem novos conhecimentos e habilidades, ou mudam suas atitudes e comportamentos (COATES, 1999). Apesar das pessoas em toda cultura apresentarem crenças sobre como deve ocorrer o ensino e a aprendizagem, estudiosos da área da psicologia desenvolveram teorias de aprendizagem que têm sido testadas por pesquisas. Cada teoria descreve ou explica como ocorre a aprendizagem, apresentando um vocabulário, uma perspectiva e generalizações próprias sobre os processos (BASTABLE, 2006; REDMAN, 2007).

O aprendizado do paciente é observado com a mudança de comportamento. 0 enfermeiro pode avaliar as necessidades de aprendizagem, transmitir informação, instrução e recursos, e comunicar-se com a família e os colegas de profissão para que o aprendizado ocorra, tudo isso como parte da assistência ao paciente. Entretanto, o enfermeiro não pode forçar o paciente a aprender. Em última instância, o paciente é o único responsável pela mudança de seu próprio comportamento (FOX, 2007).

O processo de aprendizagem do paciente e o método de aprendizagem empregado dependem em grande parte das atitudes e motivações do próprio paciente. A consciência do aprendiz do seu papel na aprendizagem é baseada em uma teoria construtiva, na qual um novo conhecimento não pode ser recebido passivamente, sendo desse modo fundamentado em informações e experiências prévias. A aprendizagem também depende da saúde e das condições de doença do paciente (PARKES; SHEPPERD, 2000; JOHANSSON et al., 2003).

O papel do enfermeiro como professor não é o de ser apenas um transmissor de informações, mas de promover a aprendizagem, preparando um ambiente compatível, criando desse modo o melhor momento para o ensino (WAGNER; ASH, 1998). O aprendiz não pode estar disponível apenas para aprender, mas sim buscar uma efetiva aproximação para o ensino, é envolver-se ativamente no processo de aprendizagem. O enfermeiro deve agir como um facilitador, criando situações que motivem o indivíduo a querer aprender e fazer o possível para isso. A avaliação das necessidades de aprendizagem, o planejamento e implementação do plano de 
ensino, a aplicação dos métodos de ensino e materiais instrucionais, e a avaliação do ensino e aprendizagem devem incluir a participação do enfermeiro e do paciente/familiar (BASTABLE, 2006).

Dentre os obstáculos da aprendizagem que interferem com a habilidade do paciente em receber e processar a informação salientamos: falta de tempo para aprender devido ao rápido atendimento nos serviços de saúde; o estresse de apresentar doenças agudas e/ou crônicas, ansiedade, déficits sensoriais, nível de escolaridade; a negativa influência do ambiente hospitalar, resultando em perda de controle, perda de privacidade e isolamento social; características pessoais do aprendiz; a necessidade de mudanças de comportamento (tanto em número quanto em complexidade); falta de suporte e reforço positivo do enfermeiro e de pessoas significativas; recusa da necessidade de aprender, sentimento de autoridade; não estar pronto para ter responsabilidades na mudança de comportamento; a inconveniência, complexidade, inacessibilidade e fragmentação do sistema de saúde, resultando em frustração e abandono na participação de metas e objetivos de aprendizagem (BASTABLE, 2006; REDMAN, 2007).

As teorias de aprendizagem utilizadas individualmente ou em combinação têm muito a oferecer para a prática do cuidado em saúde. Tais teorias contribuem para o ensino de informações aos pacientes sobre sua saúde e autocuidado, tentando melhorar a comunicação, as relações interpessoais, na busca de tornar o indivíduo um auto-aprendiz efetivo e esforçando-se para mudar comportamentos e quebrar maus hábitos (BASTABLE, 2006; REDMAN, 2007).

Outro fator relevante no processo de aprendizagem são as preferências do sujeito no modo como a informação é recebida. Em 2006, foi proposto um modelo visual, auditivo e tátil, chamado de VAK model (visual-auditory-knesthetic/tactile) (FLEMING, 2009). Esse modelo determina como a pessoa aprende, organiza, memoriza e acessa uma nova informação, de acordo com o Quadro 2. 
Tipo de Aprendiz

\begin{tabular}{cll}
\hline Visual & $\begin{array}{l}\text { Prefere figuras, diagramas e } \\
\text { outras imagens }\end{array}$ & $\begin{array}{l}\text { Álbuns seriados, algoritmos, } \\
\text { folhetos educativos } \\
\text { ilustrados }\end{array}$ \\
Auditivo & $\begin{array}{l}\text { Prefere aprender via } \\
\text { instrução verbal; imagens } \\
\text { podem gerar distração }\end{array}$ & Palestras, gravações \\
\hline Tátil & $\begin{array}{l}\text { Prefere aprender via } \\
\text { movimento e atividades } \\
\text { manuais }\end{array}$ & $\begin{array}{l}\text { Demonstrações, } \\
\text { simulações, apresentações } \\
\text { teatrais, discussões grupais }\end{array}$ \\
\hline
\end{tabular}

Quadro 2 - Aprendizagem baseada nas preferências do aprendiz segundo Fleming, 2009

O aprendiz visual prefere imagens, diagramas e outras imagens. Ele necessita ver para entender e pode interpretar de uma maneira incorreta direções ou ensino dado apenas de forma oral. Em contraste, o aprendiz auditivo pode necessitar ouvir a informação para entender e assimilar o seu conteúdo. As atividades físicas podem distrair tal aprendiz, ele entende melhor quando o instrutor fornece informação verbal. Esse aprendiz pode também se beneficiar de tecnologias disponíveis online, tais como arquivos de áudio (som). Já o aprendiz tátil tem a necessidade de aprender por meio de atividade física. Ele aprende de uma maneira mais ativa quando pode movimentar o que está sendo ensinado, tornando-se fisicamente ativo. A aprendizagem ativa pode incluir grupos de discussão, simulações, apresentações teatrais, demonstrações, questionamentos do grupo e tempestade de idéias (FLEMING, 2009).

A maioria dos aprendizes apresenta uma combinação de cada uma dessas características, mas em grau diverso, sendo que alguns tendem em favor de um determinado estilo de aprendizagem. Desse modo, os profissionais da saúde devem fornecer sessões de aprendizagem classificadas como multisensoriais, a fim de promover uma aprendizagem efetiva, e de acordo com as preferências dos aprendizes (pacientes) (FLEMING, 2009).

Os estudos mostram que os aprendizes retêm $10 \%$ do que lêem, $20 \%$ do que ouvem, $30 \%$ do que vêem, $50 \%$ do que vêem e ouvem, $70 \%$ do que discutem e $90 \%$ do que discutem e fazem. Desse modo, quanto mais órgãos dos sentidos são incluídos nos programas de ensino, maior a probabilidade de obter sucesso com a experiência de ensino. A instrução multisensorial demanda alguns requisitos. A 
utilização de slides durante uma apresentação didática, o encorajamento de uma discussão participativa, a exemplificação dos conceitos e o encorajamento dos pacientes para anotar são alguns exemplos de estimulação dos múltiplos sentidos durante o processo de ensino e aprendizagem pelo educador. O fato de ouvir a apresentação evoca o senso da audição; a visualização dos slides evoca o senso da visão; e a realização de anotações pelo paciente, acarreta em uma estimulação tátil. A demonstração de uma técnica na qual o paciente ou o familiar realiza uma injeção ou uma troca de curativo é mais efetiva, do que apenas a demonstração em si, pelo educador (OHLER, 2003).

O ensino do paciente cirúrgico deve ter início no período pré-operatório, durante a fase de avaliação e preparo para a cirurgia. Dentro do possível, os familiares ou as pessoas responsáveis pelo cuidado do paciente devem ser incluídos neste processo. O ensino deve ser apropriado à habilidade do paciente e familiar e na motivação para entender e aprender de ambos, bem como na idade do paciente (TSE; SO, 2008).

O ensino no período pré-operatório deve ser mais extensivo do que na fase imediatamente anterior a cirurgia. Ele deve ser direcionado para o preparo para a cirurgia e para a participação do paciente no processo de reabilitação pós-operatória. As informações por escrito, panfletos e vídeos sobre o procedimento são úteis no processo educativo (SMELTZER; BARE, 2005; SPRY, 2005; FOX, 2007).

As informações do período pré-operatório dividem-se em quatro categorias: procedimental, sensorial e temporal, enfrentamento e tranqüilização. A informação procedimental é uma descrição concreta de quais serão os procedimentos executados e suas razões. As informações sensoriais e temporais incluem a percepção dos procedimentos e qual a duração destes. As informações de enfrentamento indicam para o paciente os modos de controlar as respostas emocionais (FOX, 2007).

O enfermeiro perioperatório freqüentemente fornece informações de tranqüilização, ao invés de informações específicas, quando acredita que o paciente as considerará alarmantes. Uma combinação de pontos importantes de todas as categorias de informações é o conteúdo apropriado. Os pacientes gostam de receber livretos que proporcionam informações simples sobre procedimentos, experiências sensoriais e temporais, sugestões de enfrentamento e informações práticas sobre o procedimento de internação hospitalar (FOX, 2007). 
$\mathrm{Na}$ literatura há poucos estudos relacionados às necessidades de informação do paciente cirúrgico adulto, as informações que recebem e o conteúdo da informação. É importante que a informação vá de encontro com as necessidades do paciente cirúrgico, e seja dada de acordo com o estilo de cada indivíduo para a aprendizagem. Em adição, existem diferenças entre a visão da equipe de enfermagem e a percepção dos pacientes em relação à importância das necessidades de informação (DEMARCO; NYSTROM, 2009).

Sem dúvida, o ensino pré-operatório é essencial para o paciente que aguarda o transplante de fígado, para aumentar a sua consciência em relação ao procedimento em si e o seu preparo na recuperação pós-operatória. Contudo, a maneira de se realizar o ensino desses pacientes que aguardam um transplante é um grande desafio para os enfermeiros envolvidos em procedimentos terapêuticos tão complexos como os transplantes de órgãos, em especial o transplante de fígado (BUFTON; EMMETT; BYERLY, 2008; MENDES; GALVÃO, 2008).

Como enfermeiro, assumimos o papel de educador do paciente. Os pacientes que necessitam de um transplante de órgão sólido apresentam uma doença crônica, a qual por natureza lhe traz riscos e agravos à saúde. Alguns estudiosos mostram que o paciente que é capaz de entender o transplante, é capaz também de alterar sua experiência de vida. Ele precisa aprender a lidar com os novos medicamentos e tomá-los pelo resto de sua vida. Existem também muitas mudanças no estilo de vida, incluindo práticas de higiene, prevenção de infecção, monitoramento da função do novo órgão, mudanças na imagem corporal, adaptação a flutuações no humor e no nível de energia, questões do status profissional, e mesmo maiores mudanças em sua vida em geral (BASS et al., 1999).

Embora muitos destes temas sejam consistentes, as histórias dos pacientes diferem no tempo de doença, nos efeitos desta nos pacientes e familiares, nas crenças sobre saúde e doença e na ativa ou passiva participação no cuidado. As experiências prévias com doenças e com o sistema de saúde influenciam a reabilitação do paciente e a sua adaptação após o transplante (BASS et al., 1999).

Desse modo, observamos que o ensino do paciente é uma tarefa árdua do enfermeiro, uma vez que propõe intervenções na forma de vida dos pacientes, interferindo até em seus valores e crenças pessoais. A busca por estratégias para motivar a aceitação das mudanças de hábitos e sua prática, é um desafio constante para esse profissional responsável pela assistência aos pacientes submetidos ao 
transplante de fígado (SASSO et al., 2005; MENDES; GALVÃO, 2008). Nesse sentido, o ensino de pacientes é uma estratégia que promove o desenvolvimento de habilidades cognitivas, psicomotoras e atitudinais, com as quais os pacientes e seus cuidadores podem assegurar a continuidade do cuidado e manterem uma participação ativa no tratamento.

O impacto positivo das ações de ensino e aprendizagem pode ser atingido se esta for fundamentada nas necessidades do paciente (FELDMAN-STEWART; BRENNENSTUHL; BRUNDAGE, 2007).

\subsection{Necessidades de informação do paciente}

O processo de ensino e aprendizagem freqüentemente se inicia quando um indivíduo identifica a necessidade de obter um conhecimento ou de uma habilidade para se fazer algo (REDMAN, 1988). É esperado que a necessidade de informação seja maior na fase de descoberta e diagnóstico de uma doença, durante e após um tratamento proposto (FALVO, 2004). A provisão de informações é considerada uma intervenção terapêutica e faz parte do plano de cuidados de enfermagem (REDMAN, 2007).

O suprimento de informações de qualidade é uma responsabilidade legal dos profissionais da saúde em diversos países (CHARVET-BERARD; CHOPARD; PERNEGER, 2008). A informação adequada é essencial para o paciente se tornar parceiro ativo no processo de tomada de decisão do tratamento em saúde, reduzindo a sua ansiedade e permitindo que este planeje e se prepare para o futuro (FELDMAN-STEWART; BRENNENSTUHL; BRUNDAGE, 2007). Infelizmente é reconhecido que a provisão de informação relacionada ao processo saúde-doença aos pacientes e familiares ainda é incompleta tanto na prática clínica quanto nos materiais educativos fornecidos aos pacientes (ROACH; TREMBLAY; BOWERS, 1995; WILLS; HOLMES-ROVNER, 2003).

Um programa de ensino e aprendizagem de pacientes deve ser construído cuidadosamente com base na avaliação das necessidades de informação (LORIG, 2001a). As necessidades de informação (cognitiva, afetiva e psicomotora) devem ser conhecidas durante o processo de ensino e aprendizagem, a fim de que pacientes e familiares sejam capazes de atingirem metas para melhorar a saúde e a independência para o autocuidado (REGA, 1993; BASTABLE, 2006; REDMAN, 2007). 
A avaliação das necessidades de informação do paciente determina a sua natureza e a motivação para a aprendizagem, de modo que as metas e objetivos sejam mutuamente construídos com o auxílio dos próprios pacientes (LORIG, 2001a). As estratégias de ensino e aprendizagem são construídas a fim de promover uma estimulação para a instrução, exatamente de acordo com as necessidades de informação dos aprendizes. A avaliação ocorre durante o percurso da instrução e deve ser reavaliada em intervalos periódicos para determinar se as metas traçadas estão sendo atingidas. A repetição do ensino é freqüentemente necessária uma vez que não é possível prever qual é a intervenção de aprendizagem que está sendo seguida por determinado paciente. Na maioria dos casos, o seguimento com reforço das informações e a repetição do ensino são necessários periodicamente, principalmente em pacientes com problemas crônicos de saúde. O processo de ensino e aprendizagem pode ser resumido de acordo com o Quadro 3 (REDMAN, 2007).

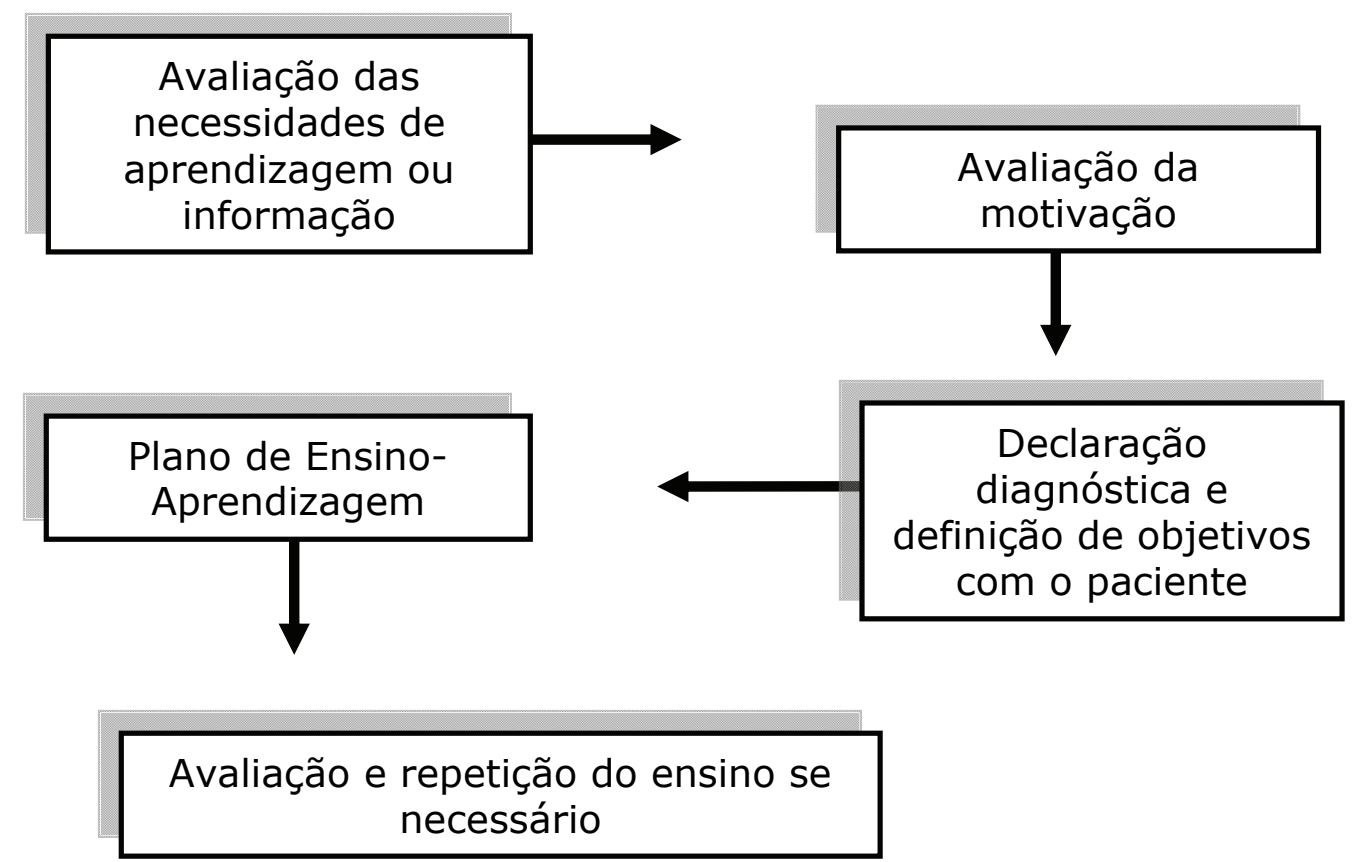

Quadro 3 - O processo de ensino e aprendizagem segundo Redman, 2007

O enfermeiro como educador é colocado à prova, não somente para fornecer a educação específica ao paciente e à família, como também para focalizar as necessidades educacionais da comunidade (FOX, 2007). O ensino é importante para o cuidado de enfermagem, pois pode determinar de que forma os indivíduos e as famílias são capazes de realizar comportamentos direcionados para o autocuidado (BRAZEN, 1995). O enfermeiro tem a responsabilidade de apresentar a informação 
que motivará a pessoa a reconhecer a necessidade de aprender. Desse modo, as pessoas com doenças crônicas precisam de informações de cuidados de saúde para criarem recursos que levem a participar ativamente e a assumir a responsabilidade pela maior parte de seus cuidados (SMELTZER; BARE, 2005).

A necessidade de informação é definida como uma deficiência de uma informação ou habilidade relacionada a um domínio de vida relevante para o paciente (MESTERS et al., 2001). Geralmente os pacientes necessitam de informações sobre sua doença e os cuidados necessários, além dos efeitos colaterais, complicações e os problemas relacionados com a saúde. Também é importante conhecer os cuidados adicionais necessários, bem como informações necessárias para atividades diárias, soluções práticas e questões financeiras (PARKES; SHEPPERD, 2000; JOHANSSON et al., 2003).

A primeira etapa do processo de ensino e aprendizagem é a avaliação das necessidades de informação do paciente, sendo esta a base de todo o processo educativo. A coleta de dados precisos e a avaliação sobre o que o paciente precisa saber, bem como o nível de preparo para o aprendizado, ajudam o enfermeiro perioperatório a determinar as prioridades de modo realista. As necessidades não são iguais para todos os pacientes, e nem todos os pacientes precisam ou desejam saber tudo relacionado ao processo saúde-doença. A maioria dos pacientes precisa saber o suficiente para autorizar a realização do procedimento invasivo, facilitar a cooperação intra-operatória, realizar o autocuidado no domicílio e sobreviver até que mais sessões de ensino possam ser proporcionadas (FOX, 2007).

Dentre os objetivos de fornecer informações ao paciente ressaltamos: auxiliar o paciente a manter ou adquirir controle de sua doença, reduzir a ansiedade, melhorar a adesão ao tratamento, criar expectativas realistas, implementar o autocuidado e a participação, além de gerar sentimentos de segurança e proteção ao paciente. Para a informação servir a um propósito, deve-se inicialmente ser recebida e interpretada pelo ouvinte, de modo que tenha um significado, um discernimento. A interpretação é um processo cognitivo. Desse modo, os objetivos que requerem apenas um processamento cognitivo são considerados os mais simples e de maior aplicação direta da informação (FELDMAN-STEWART; BRENNENSTUHL; BRUNDAGE, 2007).

Em contraste aos objetivos cognitivos, outras aplicações requerem mais do que o processamento cognitivo, chamadas de objetivos meta-cognitivos. Um 
exemplo disso é o desejo do paciente em "ganhar controle", o qual deve primeiramente requerer entendimento da informação, mas também um processamento adicional, como conectar a informação com sentimentos emocionais de controle, para que a informação auxilie-o a realmente ganhar o controle. Alternativamente, existem outros objetivos meta-congnitivos, como criar um bom relacionamento interpessoal, o que provavelmente ocorre devido ao processo de compartilhamento de informações entre pessoas, e não apenas a informação isoladamente (FELDMAN-STEWART; BRENNENSTUHL; BRUNDAGE, 2007).

Em relação à provisão de informações escritas relacionadas ao tratamento, deve se referir aos possíveis efeitos adversos do tratamento, o qual normalmente deve incluir informação sobre os seus riscos e a sua natureza. Na ausência de uma boa comunicação sobre os potenciais efeitos colaterais, os pacientes podem manifestar arrependimento, queixas e até processar legalmente a instituição de saúde em que realizou o tratamento (GARRUD; WOOD; STAINSBY, 2001).

Entretanto, ainda os profissionais de saúde apresentam limites e barreiras em fornecer informações detalhadas sobre possíveis efeitos adversos, sendo estas caracterizadas em dois tipos: o paciente que não está preocupado em relação a qualquer implicação possível e aquele em que quanto maior o número de informações sobre riscos pode levar a apresentar episódios de excessiva ansiedade, com conseqüente decisão de recusa ao tratamento proposto (GARRUD; WOOD; STAINSBY, 2001).

Muitos pacientes que aguardam a realização de um transplante de fígado têm perguntas a serem respondidas. Os estudos revelam que os pacientes desejam saber todo o tipo de informação disponível sobre sua condição de saúde, seja ela boa ou ruim. A literatura sobre as necessidades de informação dos pacientes que aguardam um transplante de fígado é escassa, indicando a existência de lacunas do conhecimento entre os profissionais de saúde. A falta de informação do paciente pode gerar alterações emocionais (tais como ansiedade e depressão) e subseqüentemente prejudicar sua recuperação quando submetido ao transplante de fígado (WEICHLER, 1990; MESTERS et al., 2001). 


\subsection{Referencial Teórico: o desenvolvimento de aprendizagens de Robert Gagné}

Para o planejamento e implementação do processo de ensino-aprendizagem do presente estudo, optou-se por utilizar os pressupostos teóricos trazidos pelo neocomportamentalista Robert Mills Gagné (1980 a, b). A teoria proposta por este estudioso tem como base um modelo de processamento da informação, considerado importante para o desenvolvimento da aprendizagem relacionada à saúde.

Embora essa teoria tenha sido desenvolvida na década de 1980, do século passado, ela ainda se mantém atual, pois delimita os tipos de aprendizagem possíveis de serem desenvolvidas pelo aprendiz-paciente, orientando as atividades pedagógicas do educador-enfermeiro. Assim, ela pode ser empregada com qualquer modelo pedagógico e método de pesquisa.

Gagné define a aprendizagem como um processo que permite aos indivíduos modificar seu comportamento de uma maneira permanente. A aprendizagem ocorre quando o indivíduo responde e recebe um estímulo do seu ambiente externo. Sabese que a aprendizagem ocorreu quando se observa que houve uma modificação no desempenho do aprendiz (GAGNÉ, 1980a, b).

Os eventos da aprendizagem dizem respeito a fatores internos e externos do aprendiz e são considerados um ato único de aprendizagem, como um todo. Na teoria de Gagné são descritos oito eventos essenciais que produzem um incidente de aprendizagem, de acordo com o Quadro 4. 
Fase de Motivação

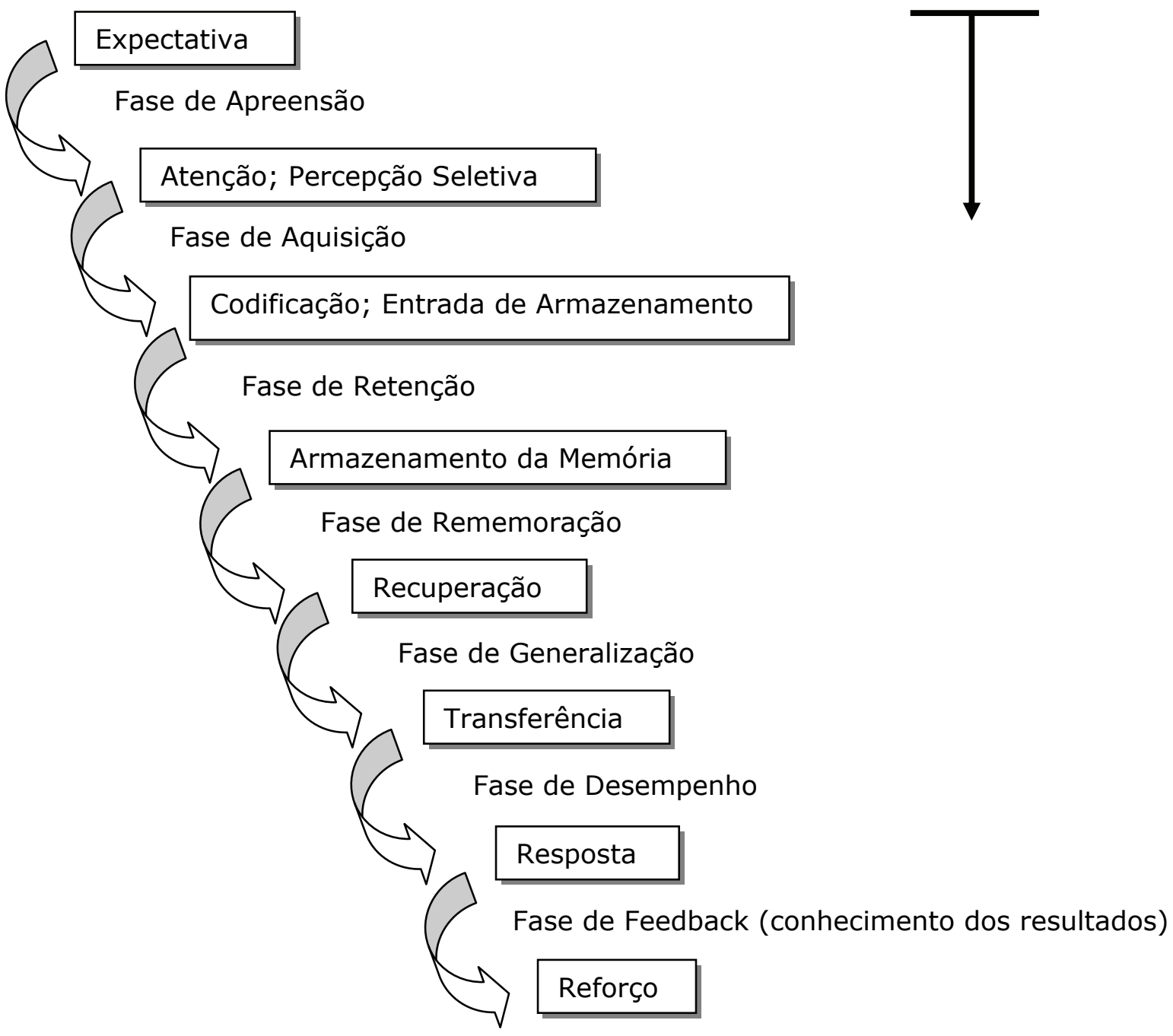

Quadro 4 - Fases de um ato de aprendizagem e os processos associados segundo Gagné, 1980b

Cada fase recebe um nome e identifica o processo principal considerado como operativo durante aquela fase. Nesta teoria são desdobrados os processos internos de aprendizagem, numa cadeia única (retângulos). Cada processo é considerado uma fase de um ato de aprendizagem, os quais são úteis para relacionar os processos internos aos eventos externos que constituem a ação pedagógica (GAGNÉ, 1980b).

A fase de motivação é inerente para a ocorrência da aprendizagem. Existe a motivação por incentivo, um tipo de motivação na qual o indivíduo se esforça para alcançar alguma meta, sendo posteriormente recompensado ao alcançá-la. Sua ação é direcionada para um ato exeqüível. Entretanto, quando o indivíduo não é 
inicialmente motivado pelo incentivo, há necessidade de se estabelecer a motivação. A motivação pode ser estabelecida através do desenvolvimento da expectativa, ou seja, uma antecipação do resultado que ele obterá quando atingir alguma meta (GAGNÉ, 1980b).

$\mathrm{Na}$ fase de apreensão, o aprendiz motivado, recebe a estimulação que entrará em sua memória, de alguma forma transformada, no incidente essencial da aprendizagem e aí será armazenada. O aprendiz desenvolve a atenção, ou seja, o estado interno temporário de conjuntos mentais, capaz de alertar o indivíduo para receber certos tipos de estimulação; e a percepção seletiva, ou seja, um conjunto de atenção adotado pelo aprendiz, os quais determinam quais são os aspectos da estimulação externa percebidos pelo indivíduo (GAGNÉ, 1980a, b).

A fase de aquisição inclui o incidente essencial da aprendizagem, ou seja, o momento no tempo em que alguma entidade recém-formada entra na memória de breve-duração, para ser mais tarde adicionalmente transformada em um estado persistente, na memória de longa-duração. Inclui a codificação, uma transformação da entidade percebida em uma forma facilmente armazenada; e a entrada de armazenamento de longa duração, momento em que a informação entra na memória de longa duração, tornando o que foi aprendido memorável (GAGNÉ, 1980a, b).

A fase de retenção é caracterizada pelo processo de codificação e depósito na memória de longa duração; entretanto, ainda trata-se de uma fase pouco conhecida, por suas dificuldades de acesso e investigação. $\mathrm{Na}$ fase de rememoração a modificação aprendida é relembrada de forma que possa ser exibida como um desempenho. O processo que funciona durante esta fase é denominado recuperação e este pode ser afetado por estimulação externa (GAGNÉ, $1980 a, b)$.

A recuperação do que é aprendido nem sempre ocorre na mesma situação ou dentro do mesmo contexto que cercou a aprendizagem original, sendo necessário haver a generalização da aprendizagem que ocorreu. $O$ processo que caracteriza a generalização é chamado de transferência da aprendizagem e envolve a lembrança do que foi aprendido e sua aplicação a novos e diferentes contextos. Na fase de desempenho da aprendizagem, o gerador de resposta organiza as respostas do aprendiz, permitindo-Ihe exibir um desempenho que reflita o que ele aprendeu. Uma vez que o desempenho se torna possível pelo ato da aprendizagem, ocorre o preparo 
do aprendiz para a retroalimentação ou feedback, ou seja, o conhecimento dos resultados (GAGNÉ, 1980a, b).

Uma vez que o aprendiz foi capaz de exibir um novo desempenho, tornado possível pela aprendizagem, ele percebe que atingiu a meta antecipada. Este feedback é considerado a essência de um processo denominado reforço. A importância da fase de motivação para o ato de aprendizagem é re-enfatizada pelo processo de reforço, desse modo, o "ciclo da aprendizagem" é fechado pelo reforço (GAGNÉ, 1980a, b).

A aprendizagem é ativada por uma variedade de tipos de estimulação provenientes do ambiente do aprendiz. Além disso, a aprendizagem estabelece estados permanentes no aprendiz, que tornam possíveis os desempenhos que são observados e caracterizados por capacidades. Os resultados da aprendizagem, então, são capacidades humanas que tornam possível uma variedade de desempenhos (GAGNÉ, 1980a, b).

Existem cinco categorias principais de resultados de aprendizagem, ou seja, capacidades humanas aprendidas, a saber: informação verbal, habilidades intelectuais, estratégias cognitivas, atitudes e habilidades motoras (GAGNÉ, 1980a, b). No presente estudo, apenas a informação verbal será enfocada como resultado de aprendizagem, em virtude da complexidade de mensurar os outros resultados mencionados, e porque ela é a aprendizagem essencial para os pacientes que aguardam o transplante de fígado, e que forma um corpo de conhecimento com o qual ele poderá participar ativamente no processo de recuperação da sua saúde.

Uma grande quantidade de informação verbal é adquirida pelas pessoas ao longo de suas vidas. As unidades de informação adquiridas podem ser classificadas como "fatos", "nomes", "princípios" e "generalizações". A informação verbal é o método humano fundamental de transmissão do conhecimento acumulado a gerações vindouras, e é freqüentemente aprendida por meio de comunicações verbais apresentadas ao aprendiz nas formas oral e escrita. Independente da forma como é aprendida, a aprendizagem da informação envolve sua codificação, ou seja, a informação é incorporada em algum conjunto significativo mais compreensivo que já se encontra na memória do aprendiz (GAGNÉ, 1980a, b).

A aprendizagem da informação verbal como uma capacidade indica que o indivíduo é capaz de enunciar, em forma proposicional, o que ele aprendeu. Ele pode 
dizer ou escrever ou, por outro lado, representar a informação aprendida na forma de sentença (proposição). A recuperação da informação pode ser também orientada por outras pistas que não as verbais, por meio de imagens ou diagramas (GAGNÉ, 1980a, b).

A informação verbal pode ser apresentada de diversas formas que despertam a atenção e guiam a percepção seletiva. Quando apresentada oralmente, variações no volume e entonação da fala são freqüentemente empregados. Quando a informação é apresentada na forma impressa, a atenção pode ser dirigida a características importantes da comunicação, mediante o uso de variações no tipo, na cor, nas aberturas de parágrafo, nas sublinhas e em outros elementos da montagem. Algumas vezes, empregam-se ilustrações ou diagramas com o intuito de despertar a atenção (GAGNÉ, 1980a, b).

O conhecimento é denominado como o conjunto organizado de informação, cujas palavras têm significado para o aprendiz. Se para o aprendiz a aquisição de conhecimento de várias espécies é uma meta educacional geralmente aceita, condições de aprendizagem devem ser planejadas para manter a aprendizagem da informação (GAGNÉ, 1980a, b).

A informação, especialmente quando ocorre como conhecimento organizado, tem muitas funções úteis para o aprendiz. Ela freqüentemente serve como um prérequisito necessário para ulterior aprendizagem. Além disso, alguns tipos de informação são de importância prática para o indivíduo durante toda a sua existência. Essas informações, por exemplo, incluem os nomes de objetos comuns, os dias da semana, os meses do ano e muitas outras necessárias para a comunicação diária (GAGNÉ, 1980a, b).

Outra função do conhecimento se refere aos conjuntos de conhecimentos organizados e relacionados, capazes de proporcionar um veículo para o pensamento. Quando o indivíduo tenta resolver um novo problema, ele pensa em muitas coisas na busca de uma solução. Neste estágio de seu pensamento, o indivíduo conduz uma investigação entre vários itens de informação disponíveis em sua memória. O imenso estoque de informação que possuímos oferece possibilidades ilimitadas para a flexibilidade de pensamento (GAGNÉ, 1980a, b).

Dessa forma, a aprendizagem é um processo capaz de levar o ser humano a modificar seu comportamento de modo relativamente rápido, de uma forma mais ou 
menos permanente, de tal modo que não tenha que ocorrer freqüentemente, a cada nova situação. Vale ressaltar a diferença existente caracterizada como maturação, inerente do processo de crescimento e desenvolvimento humano, ou seja, mudanças resultantes do desenvolvimento de estruturas internas. Enquanto que a aprendizagem tipicamente ocorre quando o indivíduo responde e recebe estimulação de seu ambiente externo, a maturação requer somente crescimento interno (GAGNÉ, 1980b).

A aprendizagem é um processo do qual são capazes o homem e outros animais. De forma típica, envolve interação com o ambiente externo, implicando em uma mudança ou modificação no comportamento, a qual permanece por períodos relativamente longos durante a vida do indivíduo. O princípio fundamental da aprendizagem é que ela ocorre dentro do indivíduo (GAGNÉ, 1980b).

O conhecimento sobre a aprendizagem precisa ser tanto fidedigno quanto válido. Os fatos sobre a aprendizagem são fidedignos quando o mesmo fato pode ser observado em repetidas vezes, sob as mesmas condições, ou seja, quando é digno de confiança. Para ser válido, o conhecimento precisa ser aplicável a uma série de situações. O conhecimento com estas características é obtido por meio de métodos científicos, é adquirido pela observação, a qual deve ser repetida, conduzida sob condições que controlem os limites de sua generalidade (GAGNÉ, 1980b).

Não é possível realizar uma observação direta sobre o processo de aprendizagem, é necessário realizar inferências sobre esse processo. Essas inferências são abstrações das observações, constituindo-se em um conhecimento generalizado. Para verificar se o princípio de aprendizagem está sendo efetivo, é necessário deduzir um ou mais resultados adicionais de aprendizagem. Quando os resultados preditos correspondem aos resultados observados, diz-se que o princípio de aprendizagem foi verificado e que tais conclusões suportam a validade do princípio (GAGNÉ, 1980b). Assim, nesta pesquisa, obteremos a inferência sobre a aquisição das aprendizagens por meio de instrumentos construídos especificamente.

A teoria do processamento de informação diz respeito aos processos necessários de serem compreendidos para explicar o fenômeno da aprendizagem. Tais processos são capazes de explicar o fenômeno da aprendizagem, uma vez que se observam determinados tipos de transformações de "insumos" para "exsumos". Quando um indivíduo está em uma situação de aprendizagem, a estimulação física dos seus olhos, ouvidos e outros sentidos é transformada em mensagens neurais. 
Essas mensagens sofrem outras transformações no sistema nervoso, de tal forma que possam ser armazenadas e, mais tarde, lembradas. A informação lembrada é novamente transformada em ainda outros tipos de mensagens, as quais controlam a ação dos músculos. O resultado é um discurso ou outros tipos de movimentos que indicam que o desempenho foi aprendido. Estas formas de transformação são chamadas processos de aprendizagem e se constituem naquilo que ocorre dentro da cabeça do individuo. A seguir, o Quadro 5 demonstra um modelo básico de aprendizagem e memória, representando as características essenciais da teoria de aprendizagem (GAGNÉ, 1980b).

A direita dos "executores" e "receptores", o modelo apresenta as estruturas que se pressupõe existirem no sistema nervoso central do indivíduo. Esse modelo é a base do processo de aprendizagem e suas implicações para a ação pedagógica. 0 estímulo proveniente do ambiente do aprendiz afeta seus receptores e entra no sistema nervoso, através de um registrador sensorial. Essa estrutura responsável pela recepção inicial de objetos e eventos que o aprendiz vê, ouve ou sente. A informação é codificada no registrador sensorial e adquire a forma de uma representação padronizada da estimulação original. Ao entrar na memória de breve duração a informação é novamente codificada, mas de uma forma conceptual (GAGNÉ, 1980b).

Quando a nova aprendizagem depende em parte da lembrança de algo que foi previamente aprendido, deve ser recuperado da memória de longa duração e precisa entrar novamente na memória de breve duração. Quando a informação é recuperada, proveniente da memória de breve ou longa duração, passa para um gerador de resposta que tem a função de transformar a informação em ação. A mensagem neural ativa os executores (músculos), produzindo um desempenho que afeta o ambiente do aprendiz. Esta ação é a prova concreta de que a informação foi processada e que o indivíduo aprendeu, de fato. Os sinais advindos do "controle executivo" e "expectativas" ativam e modificam o fluxo de informação. Sinais vindos destas duas estruturas supostamente ativam e modificam o fluxo de informação. Os processos de controle originados na estrutura de controle executivo podem determinar como a informação é codificada, quando entra na memória de longa duração e como a procura e recuperação são conduzidas, tendo-se em vista a rememoração. As formas que a aprendizagem ocorre, são influenciadas por processos iniciados nas estruturas de controle executivo e de expectativas (GAGNÉ, 1980b). 


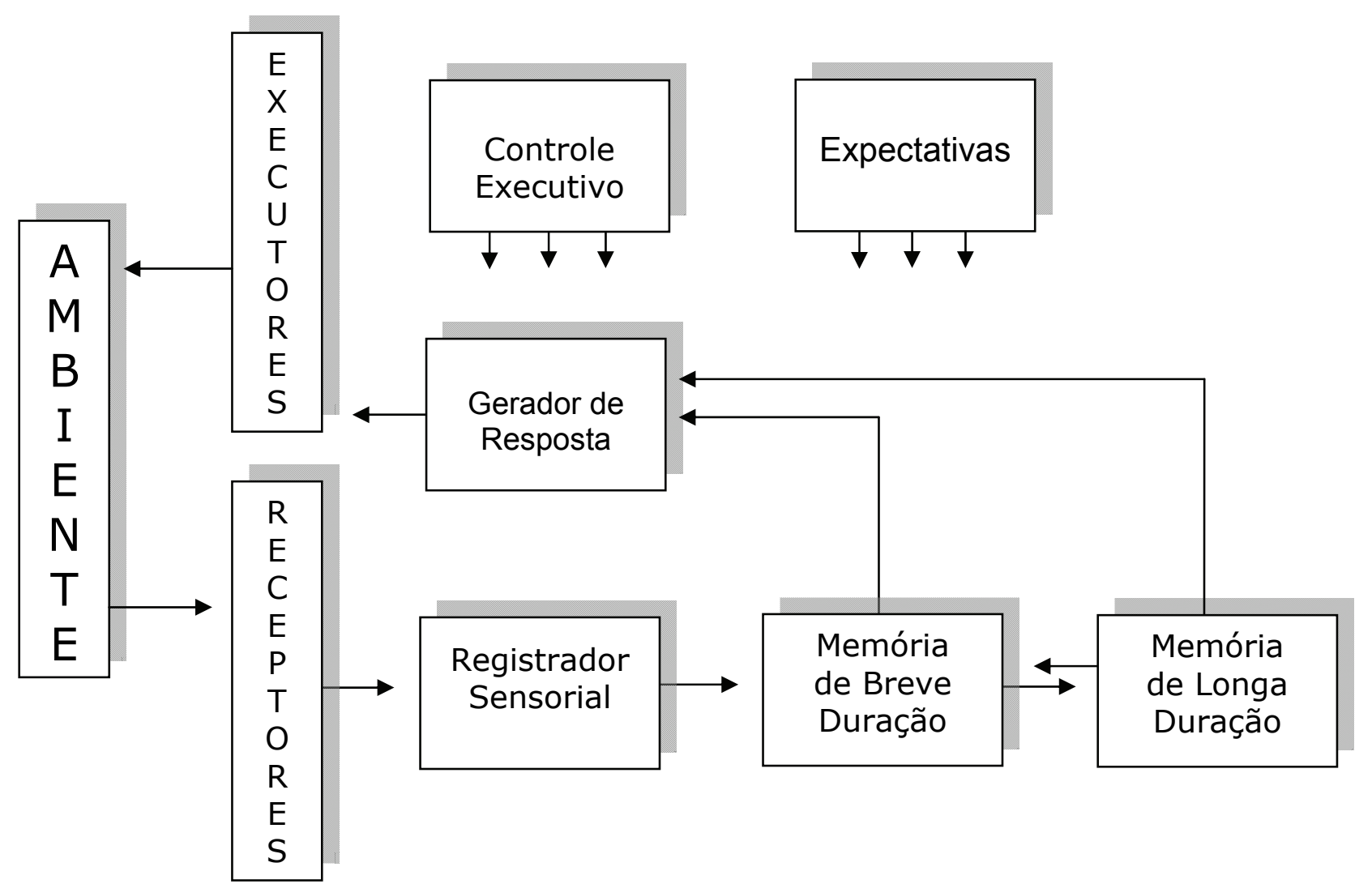

Quadro 5 - Modelo básico de aprendizagem e memória da teoria moderna de processamento da informação segundo Gagné, 1980b

Dessa forma, o conhecimento de uma teoria de aprendizagem é útil para o planejamento, implementação e avaliação da atividade de ensino. O conhecimento de uma teoria e dos princípios da aprendizagem norteia as várias atividades do professor/instrutor, oferecendo orientação, opções e prioridades para suas ações, mantendo como foco primário a aprendizagem do aprendiz (GAGNÉ, 1980b).

\subsection{Referencial Metodológico: Modelo de ensino-aprendizagem para transplantes de órgãos proposto por Ohler}

Os programas de ensino-aprendizagem podem ser individualizados para pacientes e familiares, ou podem ser realizados em sessões grupais sobre assuntos específicos (OHLER, 2003).

O ensino para pacientes críticos, do ponto de vista da evolução de sua doença de base em relação a sua necessidade de transplante, pode ocorrer em meio a grandes dificuldades, uma vez que alguns pacientes se apresentam muito debilitados para participarem de algum programa. Nesses casos, os familiares se beneficiam com a participação nas ações educativas. O entendimento do propósito do 
transplante e da complexidade de todo o processo para atingir as metas do tratamento, é freqüentemente benéfico para os familiares. Os pacientes em fase aguda e criticamente doentes podem não perceber a necessidade de indicação de um transplante. Tal grupo de pacientes requer maior tempo para se recuperar emocional e fisicamente, antes de estar apto para a aprendizagem (OHLER, 2003).

Alguns fatores fundamentais devem ser considerados no planejamento de intervenções de ensino para os pacientes, tais como o estado emocional, a saúde física, a motivação para a aprendizagem e o estilo de aprendizagem. Os indivíduos processam a informação de diferentes maneiras, sendo recomendadas abordagens que utilizem vários órgãos do sentido para o ensino. A informação segue um caminho diferente para o cérebro quando utilizamos a visão, e outros caminhos quando utilizamos as mãos ou a audição (OHLER, 2003).

O conteúdo apresentado para o paciente que está sendo avaliado para o transplante, pode variar consideravelmente de centro para centro, e é proporcional ao tipo de órgão envolvido, bem como a necessidade de aprendizagem do paciente. Assuntos que promovam uma visão geral do transplante são normalmente discutidos durante a fase de avaliação. A promoção de informações e o esclarecimento de percepções errôneas auxiliam os pacientes a formularem questionamentos para a equipe de transplante. No Quadro 6 apresentamos os tópicos que podem ser discutidos com os pacientes que estão sendo avaliados para um transplante (OHLER, 2003).

I. Visão geral do órgão a ser transplantado

II. Processo de avaliação para o transplante (exames, consultas, transfusão de sangue)

III. Esperando por um novo órgão (ficando saudável enquanto aguarda; dieta e exercício, quando ligar para o centro de transplantes)

IV. O sistema de alocação de órgãos
V. A cirurgia

VI. Período de internação no hospital

VII. Medicamentos para prevenir rejeição

VIII. Complicações após o transplante (infecções, rejeição, tumores)

IX. Qualidade de vida após o transplante

$X$. Seguimento no centro de transplantes após a cirurgia

Quadro 6 - Tópicos para discussão com os pacientes em período de avaliação para o transplante segundo Ohler, 2003 
O conteúdo do ensino para o paciente durante o período de espera depende do órgão a ser transplantado, das habilidades do paciente e das políticas específicas do programa de transplante da instituição. Os pacientes que aguardam o transplante de fígado são requisitados regularmente para monitoramento da evolução de sua doença pelo centro transplantador, antes da realização da cirurgia. Em adição à rotina de cuidados pré-operatórios, muitos programas promovem programas contínuos de ensino do paciente. Os pacientes incluídos na lista de espera para o transplante de fígado que não estejam hospitalizados podem também ser requisitados a participarem de grupos de apoio que incorporam atividades educacionais. No Quadro 7 apontamos os tópicos relevantes para os pacientes em período de espera (OHLER, 2003).

1. O sistema de alocação de órgãos

2. Medicamentos utilizados após o transplante

3. Questões financeiras

4. Complicações após o transplante

5. Debate entre candidatos e receptores sobre a vida após o transplante

6. Debate entre os cônjuges dos candidatos e receptores para falar sobre a vida com alguém em uso de esteróides

7. Debate entre crianças de candidatos e receptores

8. Prevenção de infecções após o transplante

9. Viagens após o transplante
10. Ficando saudável enquanto aguarda o transplante (dieta e exercício)

11. A cirurgia

12. Quando entrar em contato com a equipe após o transplante

13. Qualidade de vida após o transplante

14. A volta ao trabalho após o transplante

15. Cuidados odontológicos após o transplante

16. Vida sexual após o transplante

17. Casamento e família: aspectos emocionais

18. Comunicação com as famílias dos doadores

Quadro 7 - Tópicos para discussão com os pacientes em programas educativos durante o período de espera para o transplante segundo Ohler, 2003

Antes da alta hospitalar após a cirurgia do transplante, o paciente deve demonstrar certo nível de independência no seu cuidado. Ele deve ser capaz de identificar as metas da terapia medicamentosa, respondendo questões importantes sobre os medicamentos (o que é, como, quando e os efeitos colaterais) e ser capaz também de descrever os sinais e sintomas da rejeição e infecção (OHLER, 2003).

O uso de recursos audiovisuais com slides direcionados para a revisão dos medicamentos, dieta prescrita, sinais e sintomas de rejeição e infecção, quando entrar em contato com o centro transplantador é utilizado para resumir as 
informações que o paciente recebeu. Promover informações por escrito dessas recomendações serve como uma referência para o paciente após a alta hospitalar. Encorajar o autocuidado e o auto-monitoramento enquanto o paciente está hospitalizado transmite uma expectativa de independência. No Quadro 8 indicamos tópicos para serem trabalhados com o paciente antes da alta hospitalar (OHLER, 2003).

\begin{tabular}{ll}
\hline 1. Cuidados com a ferida cirúrgica & $\begin{array}{l}\text { 8. Autocuidado e auto-monitoramento } \\
\text { no domicílio }\end{array}$ \\
2. Medicamentos & $\begin{array}{l}\text { 9. Viagens } \\
\text { 3. Sinais e sintomas de rejeição }\end{array}$ \\
$\begin{array}{ll}\text { 10. Atividades fora de casa } \\
\text { 4. Sinais e sintomas de infecção }\end{array}$ & $\begin{array}{l}\text { 11. Exercícios } \\
\text { 5. Seguimento de exames clínicos e }\end{array}$ \\
laboratoriais & 12. Relações sexuais \\
6. Seguimento de visitas ambulatoriais & 13. Atividades laborais \\
7. Visitas ao dentista & 14. Contato com a família do doador
\end{tabular}

Quadro 8 - Tópicos para discussão com os pacientes submetidos ao transplante na alta hospitalar segundo Ohler, 2003

A capacidade de entendimento do processo de transplante é avaliada por uma série de características dos pacientes e familiares, as quais podem afetar sua habilidade para o aprendizado, e devem ser avaliadas antes do início das atividades educativas. Tais características são: nível cognitivo, estilo de aprendizagem, motivação para a aprendizagem, saúde física, saúde emocional, metas dos pacientes, ambiente de aprendizagem, conhecimento anterior sobre o transplante, crenças e práticas culturais, espirituais e religiosas (OHLER, 2003).

Os pacientes com falência hepática apresentam também problemas de concentração e podem desenvolver o coma hepático. A doença em fase terminal do fígado leva o paciente apresentar fadiga e impossibilidade de concentração. A promoção de pequenos períodos de ensino-aprendizagem pode ser benéfica, contudo, a maioria dos pacientes com problemas cognitivos relacionados à doença terminal do órgão pode não ser capaz de compreender as informações. O ensino pode ser postergado, mesmo para após o transplante (OHLER, 2003).

Os pacientes incapazes de ler ou escrever requerem estratégias de ensino especiais a fim de garantir a adesão com o complexo regime médico necessário após o transplante. Alguns pacientes analfabetos apresentam mecanismos compensatórios bem desenvolvidos, sendo que às vezes o analfabetismo acaba sendo descoberto 
apenas após o transplante. O uso de slides e figuras é excelente recurso para o ensino de pacientes analfabetos. Algumas companhias farmacêuticas disponibilizam adesivos com imagens dos medicamentos utilizados rotineiramente nos transplantes. Tais imagens podem ser anexadas nos frascos dos medicamentos e a partir de uma lista de medicamentos auxiliarem o paciente na ingestão de doses corretas dos medicamentos e nos horários corretos. A manutenção de uma cópia atualizada dos medicamentos utilizados pelos pacientes pode ajudar o enfermeiro na resposta rápida aos questionamentos dos pacientes e familiares a respeito destes medicamentos (OHLER, 2003).

A motivação para o aprendizado do paciente de transplante depende de alguns fatores. Para a maioria dos pacientes que recentemente recebeu o diagnóstico de uma doença terminal de um órgão, a aceitação do diagnóstico deve vir em primeiro lugar. Talvez não seja possível ensinar sobre transplante se o paciente acredita que a sua saúde irá melhorar sem a cirurgia. Os enfermeiros devem promover ensino adicional sobre o processo de doença, além de mostrar dados reais sobre o resultado da cirurgia. O estado geral de saúde e o bem-estar também devem ser considerados na determinação da motivação para o aprendizado. Sintomas tais como a dor, fadiga e náusea, não são condizentes com a aprendizagem. O alívio dos sintomas antes do ensino promove ao paciente uma maior capacidade para a aprendizagem. Ansiedade, depressão e raiva também interferem com o processamento das informações e devem ser levados em consideração antes da realização de estratégias efetivas de ensino e aprendizagem (OHLER, 2003).

O local da aprendizagem pode ser quase tão importante quanto a maneira que se aprende. Algumas pessoas aprendem melhor em um ambiente de sala de aula, enquanto outras não apresentam bom desempenho em um cenário tradicional. Também é improvável que alguém recebendo medicamentos endovenosos, com eletrodos ou sondas conectados no corpo, pessoas constantemente entrando e saindo do ambiente, e contínuas interrupções de pessoas e alarmes sonoros, possa efetivamente ajudar no processamento de qualquer informação (OHLER, 2003).

Os pacientes e familiares sempre trazem idéias pré-concebidas de suas experiências ou informações que receberam dos meios de comunicação ou amigos. Dessa forma, é importante avaliar o seu conhecimento prévio e explorar suas percepções (verdadeiras e falsas) sobre o transplante. As expectativas das famílias são baseadas nas crenças em que a vida irá retornar ao normal após o transplante. Assim que a presença de eventos inesperados no pós-operatório se torna mais 
evidente, os familiares passam por uma fase de adaptação, resultando inclusive em modificação de papéis e de expectativas. Os pacientes podem acreditar que o transplante irá retornar ao estado anterior ao da doença. Ainda há outras crenças de que o paciente irá assumir as características do seu doador. O ensino baseado na realidade é importante para ajudar os pacientes no entendimento dos riscos e benefícios do transplante e na desconstrução de mitos e percepções errôneas (OHLER, 2003).

Os familiares podem tentar direcionar o ensino para eles mesmos ao invés dos pacientes, baseados na crença de que o paciente deve ser preservado de informações estressantes ou mesmo más notícias. Uma família super protetora pode solicitar que o ensino seja postergado até o paciente estar em melhores condições de saúde, sem um completo entendimento que isso provavelmente não irá ocorrer até a realização do transplante. Nestas situações pode ser útil promover ensinoaprendizagem a pacientes e familiares de forma separada. Deve ser esclarecido às famílias que o paciente deve assinar o consentimento informado sobre o transplante, e que o entendimento de riscos e benefícios é essencial para isso, além de contribuir com o comprometimento de responsabilidade dos cuidados no pós-transplante (OHLER, 2003).

Muitas pessoas necessitam mais do que um folheto informativo ou um pequeno livro de bolso para o suprimento de informações necessárias para o transplante. Não existem modelos ou critérios reconhecidos para o ensinoaprendizagem de pacientes para transplante. Programas educacionais podem variar de órgão para órgão e são específicos para cada centro transplantador. Alguns centros promovem programas de ensino formal, nos quais os pacientes participam de atividades grupais de forma regular, enquanto outros promovem programas individualizados específicos para os pacientes nas várias fases do transplante, desde a fase de avaliação até a alta hospitalar após a cirurgia. Contudo, o período de avaliação para o transplante em si, pode se estender de meses para anos de lista de espera. Conseqüentemente, os pacientes podem ser requisitados a participar de programas educativos durante o período de espera (OHLER, 2003).

O ensino deve continuar durante o seguimento ambulatorial após a realização do transplante, principalmente nos primeiros meses após a cirurgia, sendo uma excelente oportunidade de reforço para os pacientes e familiares. Durante este período, os pacientes ainda necessitam de avaliações a fim de se observar o funcionamento adequado do órgão. Além disso, promover feedback para dar suporte 
aos pacientes sobre seus novos conhecimentos e habilidades, além de esclarecer erros de entendimentos são aspectos importantes e necessários durante esta fase. No Quadro 9 apontamos as habilidades de autocuidado que o paciente deve ser capaz de demonstrar no sentido de atingir o domínio (OHLER, 2003).

1. Quando entrar em contato com o enfermeiro

2. Manutenção do contato com o centro transplantador

3. Seguimento ambulatorial
4. Solicitação de reposição de medicamentos nos momentos apropriados

5. Manutenção do exercício e dieta

6. Viagens após um transplante

7. Equilíbrio na vida profissional e familiar

Quadro 9 - Reforçando o ensino no pós-transplante segundo Ohler, 2003

O ensino do paciente é considerado uma das atividades mais relevantes dos enfermeiros envolvidos com o transplante de órgãos. Estratégias de ensino necessitam ser adaptadas às necessidades de aprendizagem individuais de cada paciente. A utilização de uma teoria de aprendizagem e a sua aplicação no contexto de transplante de órgãos pode demonstrar a efetividade do ensino realizado pela enfermagem, produzindo conhecimento científico e a transferência deste para a prática clínica contribuindo para o sucesso do transplante por longos períodos (OHLER, 2003). 
2. 自ípótese 


\section{HIPÓTESE}

H0: O conhecimento dos candidatos que aguardam em fila de espera a realização de um transplante de fígado é igual, antes e depois da implementação de uma intervenção educativa.

H1: O conhecimento dos candidatos que aguardam em fila de espera a realização de um transplante de fígado é maior, após a implementação de uma intervenção educativa. 


\section{OBJETIVOS}

\subsection{Objetivo Geral}

O presente estudo tem como objetivo analisar o conhecimento dos candidatos que aguardam em fila de espera a realização de um transplante de fígado com doador falecido, antes e depois da implementação de uma intervenção educativa.

\subsection{Objetivos Específicos}

- Caracterizar os sujeitos do estudo segundo as variáveis sóciodemográficas e clínicas;

- Identificar as necessidades de informação dos candidatos em fila de espera sobre o transplante de fígado;

- Identificar o conhecimento dos candidatos sobre o processo de transplante de fígado, antes da implementação da intervenção educativa;

- Implementar uma intervenção educativa sobre o processo de transplante de fígado, para os candidatos que aguardam em fila de espera;

- Avaliar o resultado da intervenção educativa por meio da aplicação de um questionário de conhecimento dos candidatos sobre o processo de transplante de fígado, após a sua implementação;

- Avaliar a satisfação dos candidatos após a implementação da intervenção educativa. 


\section{PROCEDIMENTO METODOLÓGICO}

A pesquisa pode ser classificada em duas categorias metodológicas: qualitativa e quantitativa. O pesquisador opta por uma dessas categorias baseado primeiramente na sua questão ou pergunta de pesquisa. Isso significa que o pesquisador pode desejar testar uma situação de causa e efeito ou avaliar as variáveis relacionadas ou ainda, descobrir ou entender o significado de uma experiência ou de um processo (LOBIONDO-WOOD; HARBER, 2006; JOHNSON; CHRISTENSEN, 2008).

Enquanto a pesquisa qualitativa busca compreender significados, a pesquisa quantitativa investiga questões de pesquisa e/ou hipóteses que descrevem fenômenos, testam relacionamentos de variáveis, avaliam diferenças e procuram explicar interações de causa e efeito entre variáveis e testes de eficácia de intervenções. Os dados numéricos nos estudos quantitativos são analisados e resumidos pelo uso de métodos estatísticos. Desse modo, as técnicas empregadas na pesquisa quantitativa são sistemáticas e a metodologia é rigorosamente controlada, a fim de testar uma hipótese ou responder uma questão de pesquisa baseada em um cenário (LOBIONDO-WOOD; HARBER, 2006; JOHNSON; CHRISTENSEN, 2008).

Uma intervenção pode ser testada pelo uso de delineamento de pesquisa experimental ou quase-experimental, uma vez que o pesquisador procura ativamente trazer à tona o efeito desejado e está interessado em fazer algo acontecer (JOHNSON; CHRISTENSEN, 2008). No sistema de classificação de evidências proposto no movimento da Prática Baseada em Evidências, tais estudos promovem níveis II e III de evidência, ou seja, indica que os resultados destes estudos promovem a validação de uma intervenção para a prática clínica e a mudança de aspectos específicos desta prática. No entanto, vale ressaltar que, a maioria das pesquisas produzidas pela enfermagem é não-experimental, devido às dificuldades na manipulação das variáveis estudadas (LOBIONDO-WOOD; HARBER, 2006).

O delineamento de pesquisa quase-experimental é utilizado para testar relações de causa e efeito, contudo um controle completo do experimento não é possível. O pesquisador inicia um tratamento experimental, mas algumas características de um experimento verdadeiro, tais como o uso de grupo controle e/ou a randomização, não são possíveis de serem seguidos, devido à natureza da variável independente ou dos sujeitos disponíveis (JOHNSON; CHRISTENSEN, 2008). 
Desse modo, a validade interna do experimento pode ficar comprometida, e a habilidade de determinar se a intervenção causou as mudanças observadas nos resultados é enfraquecida. Como resultado, tais estudos produzem nível III de evidência científica, uma vez que a confiança é enfraquecida, pois os resultados gerados poderiam ser fruto tanto da intervenção realizada quanto de outras variáveis externas (POLIT; HUNGLER, 1999; LOBIONDO-WOOD; HARBER, 2006; JOHNSON; CHRISTENSEN, 2008).

O presente estudo foi realizado em duas fases. $\mathrm{Na}$ primeira fase, foi desenvolvido um estudo com delineamento de pesquisa não-experimental, tipo descritivo. O delineamento não-experimental é utilizado nos casos em que o pesquisador deseja construir um retrato de um fenômeno, explorar eventos, pessoas ou situações de uma maneira natural, sem intervenção experimental. O pesquisador explora relações ou diferenças entre as variáveis, as quais não podem ser controladas. Os estudos descritivos coletam descrições detalhadas de variáveis existentes, e utilizam os dados para justificar e avaliar condições e práticas atuais, ou ainda auxiliam no planejamento para incrementar práticas de cuidado a saúde. É utilizado quando se deseja buscar uma informação acurada relacionada a característica de um grupo particular de sujeitos, grupos, instituições, ou situações, ou ainda sobre a freqüência de ocorrência de um fenômeno, particularmente quando pouco se sabe a respeito dele (POLIT; HUNGLER, 1999; LOBIONDO-WOOD; HARBER, 2006; JOHNSON; CHRISTENSEN, 2008).

$\mathrm{Na}$ segunda fase, foi conduzido um estudo com delineamento de pesquisa quase-experimental, tipo grupo único pré e pós-teste. Esse tipo é utilizado quando apenas um grupo é disponível para o estudo. Neste delineamento, os dados são coletados antes e depois de um tratamento experimental em um único grupo de sujeitos. Desse modo, não há grupo controle e não há randomização (POLIT; HUNGLER, 1999; LOBIONDO-WOOD; HARBER, 2006). 


\subsection{Delineamento de pesquisa não experimental: estudo descritivo}

Conforme já mencionado, na primeira fase da presente investigação foi realizado um estudo descritivo, a fim de realizar uma avaliação diagnóstica das necessidades de informação dos candidatos que aguardam em fila de espera a realização de um transplante de fígado.

\subsubsection{Local do estudo}

O estudo foi desenvolvido em um hospital geral, público, do interior do Estado de São Paulo, cadastrado no Sistema Nacional de Transplantes do Ministério da Saúde, de acordo com a Lei no 9.434, de 4 de fevereiro de 1997. Foi utilizado o espaço físico do ambulatório ( $2^{\circ}$ andar), o qual ocorre as terças e sextas-feiras, no período da tarde, momento em que os candidatos ao transplante de fígado aguardavam avaliação médica e multiprofissional.

\subsubsection{População}

Este estudo teve como população-alvo os sujeitos que estão em cadastro técnico de fígado, com doador falecido, aguardando a realização do transplante.

No ambulatório, os pacientes realizam consultas periódicas que podem ocorrer uma vez no trimestre ou mensais ou semanais, de acordo com a classificação do Model for End-stage Liver Disease (MELD) e com a ocorrência de complicações da doença. Durante a primeira fase da coleta de dados do presente estudo, os pacientes com MELD de 11 a 18 precisavam renovar os exames laboratoriais a cada três meses; os pacientes com MELD de 19 a 24 precisavam renová-los a cada mês; e os pacientes com MELD maior que 25 precisavam renová-los a cada semana, uma vez que apresentavam maior chance de realizarem o transplante, devido à gravidade de sua doença. Vale ressaltar que após a coleta de dados da presente investigação, uma nota técnica do Sistema Nacional de Transplantes, publicada em primeiro de fevereiro de 2010, modifica os critérios de MELD mínimo para inclusão em lista de espera, de modo que pacientes com MELD $\leq 14$ pontos não apresentam indicação para o transplante de fígado, exceto sob condições especiais.

\subsubsection{Critérios de inclusão}

Os sujeitos incluídos no estudo foram: 
(1). aqueles na faixa etária igual ou superior a 16 anos, candidatos ao transplante de fígado com doador falecido;

(2). apresentaram classificação de MELD de seis (menor gravidade) a 25 (maior gravidade).

\subsubsection{Critérios de exclusão}

Foram excluídos os sujeitos que:

(1). verbalizaram ou apresentaram evolução da doença hepática que desfavoreceu o preenchimento do instrumento de coleta de dados;

(2). apresentaram encefalopatia hepática crônica e MELD maior que 25 ou ainda em algum momento da pesquisa recusaram a participar do estudo.

\subsubsection{Amostra}

A amostra foi constituída pelos pacientes que obedeceram aos critérios de seleção propostos, no período em que foi realizada a coleta de dados, a qual teve duração de quatro meses. Desse modo, haviam 77 pacientes registrados na Central de Transplantes de Ribeirão Preto, distribuídos de acordo com o tipo sanguíneo, ou seja, 34 candidatos do tipo A, 34 candidatos do tipo O, 8 candidatos do tipo B e 1 candidato do tipo $A B$, com valores de MELD que variaram de 6 a 29 pontos. Dos 77 candidatos cadastrados no programa de transplante de fígado, obteve-se uma amostra de 55 pacientes para a presente investigação.

\subsubsection{Elaboração e validação do instrumento de coleta de dados}

Para a coleta de dados foi elaborado um instrumento com três partes, sendo que na primeira os dados eram direcionados para a identificação sócio-demográfica do paciente. Os seguintes dados foram registrados: idade, data de nascimento, gênero, local de nascimento (urbana ou rural), estado civil, religião, grupo sangüíneo, endereço completo, telefones para contato, profissão, ocupação, número de filhos, tempo de afastamento do trabalho, escolaridade (anos de estudo), renda familiar com base no salário mínimo vigente na época ( $R \$ 465,00)$, classificação de CHILD e MELD, e se estava em situação especial para transplante.

$\mathrm{Na}$ segunda parte do instrumento, os dados estavam relacionados com a doença crônica do fígado. Os seguintes dados foram levantados: sinais e sintomas da 
doença crônica do fígado, dados antropométricos, tempo de doença crônica, diagnóstico médico, tempo de inscrição no cadastro técnico, conhecimento sobre o funcionamento da lista de espera, problemas de saúde nos sistemas orgânicos, medicamentos utilizados, hábitos de vida (exercícios físicos, refeições, restrição de alimentos, tabagismo, alcoolismo, horas de sono noturno e diurno, ingestão hídrica).

Além dos dados mencionados buscaram-se informações sobre o estado de humor do paciente, e para facilitar a coleta de dados, lançou-se mão do uso de uma escala de bem-estar subjetivo (ALBUQUERQUE; TRÓCCOLI, 2004). O paciente era estimulado a fazer a leitura da escala e a verbalizar até três afetos (positivos ou negativos) que estava sentido com mais freqüência nos últimos meses. Vale ressaltar que também se utilizou o prontuário do paciente e o cadastro técnico para transplante como fonte para a coleta de dados.

$\mathrm{Na}$ terceira parte do instrumento, os dados estavam relacionados às necessidades de aprendizagem ou informação dos pacientes. Assim, foram coletados dados sobre como foi o recebimento de informações relacionadas ao transplante de fígado e fonte dessas informações, realização de leitura do folheto informativo entregue no momento de entrada na fila de espera, bem como a justificativa do paciente caso não tinha realizado a leitura ainda, finalizando com os métodos de ensino que mais agradavam os pacientes na busca de novos conhecimentos e a aplicação da escala de necessidades de informação dos candidatos, sendo respondidas pelo próprio paciente, com auxílio do pesquisador apenas para o registro da informação.

A elaboração da escala de avaliação das necessidades de informação foi adaptada dos conceitos teóricos trazidos por Lorig (2001). A estudiosa aborda como avaliar as necessidades de informação baseadas nas crenças dos pacientes em relação ao problema de saúde vivenciado naquele momento. É importante que os pacientes que participam desta primeira etapa da atividade de ensino-aprendizagem, apresentem condições de saúde similares. Os pacientes devem ser motivados a verbalizar o que gostariam de aprender e então, estas respostas são ranqueadas em ordem decrescente de surgimento, de dez a um. Para as respostas similares entre os pacientes, é realizada uma média aritmética, a qual indica por prioridade, os tópicos mais importantes para aquele grupo.

No presente estudo, para auxiliar no levantamento das necessidades de informação foi formulado um cartão contendo 17 sugestões de assuntos relacionados 
ao processo de transplante de fígado, o qual poderia ou não ser utilizado pelos pacientes. Tais sugestões foram formuladas com base no modelo de ensinoaprendizagem proposto por Ohler (2003) para candidatos a um transplante de órgãos e no folheto informativo entregue aos candidatos ao transplante de fígado, no momento de entrada na fila de espera. Os candidatos foram orientados a realizar uma leitura prévia dos 17 itens, e motivados a esclarecer qualquer dúvida em relação ao conteúdo sugerido. Vale ressaltar que todos os candidatos fizeram uso do cartão para auxiliar na identificação das principais necessidades de informação para o transplante de fígado, facilitando desse modo, a análise dos dados obtidos.

Durante a aplicação da escala de avaliação das necessidades de informação, foi solicitado ao paciente ordenar por importância, dez assuntos que gostaria de aprender antes da realização do transplante de fígado. As respostas foram classificadas de um a dez pontos, sendo que a primeira resposta obteve uma pontuação igual a dez, a segunda resposta obteve uma pontuação igual a nove e assim por diante, até a décima resposta com uma pontuação igual a um, para cada paciente. Desse modo foi calculada uma pontuação final para cada resposta, obtida por meio da soma de cada pontuação de uma mesma resposta e calculada a média aritmética. As respostas com maior pontuação foram consideradas as mais importantes e os respectivos assuntos foram inseridos na elaboração da intervenção educativa.

O instrumento foi submetido à validação aparente e de conteúdo por três juízes, dois enfermeiros e um médico, sendo um dos enfermeiros e o médico, envolvidos na prática assistencial da Unidade de Transplante de Fígado (HC-FMRPUSP) e outro enfermeiro, docente de curso de graduação que ensina enfermagem perioperatória (APÊNDICE A).

Os juízes analisaram o instrumento quanto à forma de apresentação e ao conteúdo elaborado, relacionando estes elementos a sua capacidade de atingir o objetivo proposto na pesquisa, sendo dessa forma, acatadas todas as sugestões dos juízes.

Após a validação do instrumento foi realizado um teste piloto com cinco pacientes que aguardavam o transplante de fígado e atendidos no ambulatório do hospital selecionado para o desenvolvimento do estudo. Após o teste piloto realizamos alguns ajustes para facilitar o entendimento do paciente frente ao item questionado. 


\subsubsection{Coleta de dados}

O estudo foi realizado nos meses de março a junho de 2009. Para tanto, os enfermeiros responsáveis pelo ambulatório de transplante de fígado auxiliaram na identificação dos candidatos em fila de espera, uma vez que os pacientes que já tinham realizado o transplante de fígado (receptores), também eram atendidos no mesmo local e horário. A coleta de dados foi realizada pelo pesquisador em ambiente privativo, com a presença do paciente e quando presente, do familiar ou cuidador responsável, a partir da lista de espera.

\subsubsection{Análise de dados}

A análise dos dados foi realizada na forma descritiva. Os dados obtidos correspondem a variáveis quantitativas (discretas e contínuas) e qualitativas (nominais e ordinais). Os dados relativos a variáveis qualitativas ordinais foram convertidos em variáveis quantitativas discretas, atribuindo-se pontuações inversamente proporcionais às posições ocupadas (isto é, a primeira posição corresponde a uma maior pontuação, enquanto que a última posição corresponde a uma menor pontuação).

Os dados relativos a variáveis quantitativas foram sumarizados na forma de média aritmética e respectivo desvio padrão. Para se comparar os dados de uma determinada variável entre dois ou mais grupos estabelecidos foi inicialmente verificado se os dados apresentam distribuição normal por meio do teste de normalidade de Kolmogorov-Smirnov. Caso os grupos amostrais apresentassem distribuição normal $(p>0,05)$, métodos estatísticos paramétricos foram empregados: (1) teste $t$ de Student, para comparações entre as médias de duas amostras independentes; (2) coeficiente de correlação de Pearson ( $r$ ), para correlação linear simples entre duas variáveis. Caso ao menos um dos grupos amostrais apresentasse desvios significativos em relação à distribuição normal ( $p<$ $0,05)$, o teste $U$ de Wilcoxon-Mann-Whitney, método estatístico não-paramétrico para comparações entre as médias de duas amostras independentes, foi empregado.

Os dados relativos a variáveis qualitativas foram sumarizados na forma de porcentagens. Para se comparar os dados de uma determinada variável dicotômica entre dois grupos estabelecidos (tabelas de contingência $2 \times 2$ ) foi empregado o teste exato de Fisher. 
Em todas as análises realizadas, versões bicaudais dos testes foram empregadas e nível de significância de $5 \%(\alpha=0,05)$ foi adotado. O programa GraphPad InStat 3.05 (GraphPad Software, Inc) foi empregado para a realização de tais testes. 


\subsection{Delineamento de pesquisa quase-experimental: estudo piloto grupo único, antes e depois}

Um estudo piloto com delineamento de pesquisa quase-experimental, do tipo grupo único, antes e depois, prospectivo, comparativo, monocêntrico foi conduzido na segunda fase da presente investigação. É quase-experimental porque se constitui de uma intervenção sobre um grupo populacional, cuja amostra foi dada por conveniência. Nesse estudo, o paciente foi o próprio controle, antes e depois da intervenção. Assim, foi comparado o conhecimento acerca do processo de transplante de fígado, antes e depois da implementação da intervenção educativa.

A denominação da segunda fase da presente investigação como um estudo piloto foi devido ao tamanho amostral obtido para a implementação da intervenção proposta. Estudos do tipo piloto são úteis para estimar as variáveis de interesse, avaliar a exeqüibilidade do estudo, analisar a adequacidade dos instrumentos para a coleta de dados e realizar estimativas de cálculos estatísticos para o planejamento de um estudo maior. O objetivo principal de um estudo piloto é demonstrar a exeqüibilidade de uma intervenção (BECKER, 2008; HERTZOG, 2008).

A satisfação dos sujeitos participantes do estudo, depois da implementação da intervenção educativa também foi avaliada.

\subsubsection{Local do Estudo}

O estudo foi realizado em um hospital geral, público, do interior do Estado de São Paulo, que possui um programa de transplante de fígado cadastrado no Sistema Nacional de Transplantes. O programa de transplante de fígado, denominado Grupo Integrado de Transplante de Fígado, possui uma Unidade Especial de Transplante de Fígado na Clínica Cirúrgica, no $10^{\circ}$ andar. A enfermaria conta com dez leitos, sendo dois leitos de isolamento, para os pacientes recém-transplantados, uma enfermaria feminina e uma enfermaria masculina, com quatro leitos cada, para candidatos e receptores que necessitam de internação. Semanalmente, as terças e sextas-feiras, candidatos e receptores são atendidos no ambulatório, no período da tarde, sendo atendidos em média 20 pacientes por dia. A intervenção do estudo foi realizada no anfiteatro do Departamento de Cirurgia e Anatomia ( $10^{\circ}$ andar), próximo da Unidade de Transplante de Fígado, o qual conta com aparelho de multimídia, telão, 76 lugares e ar condicionado para promoção do conforto e bem-estar dos pacientes. 


\subsubsection{Casuística}

\subsubsection{Amostra}

Esta fase do estudo teve como amostra os sujeitos que estavam em cadastro técnico de fígado do Sistema Nacional de Transplantes de Ribeirão Preto, com doador falecido, aguardando a realização da cirurgia e que já haviam participado da primeira fase da pesquisa. No momento da coleta de dados, na segunda fase da presente investigação, havia 70 candidatos para o transplante de fígado, no hospital selecionado para o desenvolvimento da presente pesquisa. Frente aos 55 pacientes que foram sujeitos da primeira fase do estudo, 19 pacientes foram excluídos da segunda fase pelos seguintes motivos: nove foram submetidos ao transplante de fígado, sete tiveram a recuperação da função hepática e três faleceram no período de transição entre a primeira e a segunda fase desta pesquisa. Desse modo, a amostra final foi de 36 pacientes que ainda aguardavam a realização do transplante de fígado.

\subsubsection{Critérios de inclusão}

Foram incluídos os sujeitos que:

(1). estavam na faixa etária igual ou superior a 16 anos;

(2). eram candidatos ao transplante de fígado com doador falecido;

(3). apresentaram condições clínicas para receberem a intervenção educativa (ou seja, não apresentaram complicações sistêmicas agravantes que impediam a sua participação no plano, como encefalopatia);

(4). apresentaram classificação de MELD de 6 (menor gravidade) a 25 (maior gravidade);

(5). apresentaram habilidades para realizar tarefas de alfabetização (leitura e escrita) para viabilizar o preenchimento dos instrumentos de coleta de dados.

\subsubsection{Critérios de exclusão}

Foram excluídos os sujeitos que:

(1). verbalizaram ou apresentaram evolução da doença hepática que desfavorecia sua participação na intervenção educativa; 
(2). realizaram transplante de fígado, tiveram a função hepática recuperada ou evoluíram para falecimento durante o período de coleta de dados.

\subsubsection{Planejamento}

\subsubsection{Constituição da Amostra}

No período da coleta de dados, cuja duração foi de três meses consecutivos (janeiro, fevereiro e março de 2010), todos os pacientes que estiveram aptos a participarem da pesquisa, ou seja, aqueles que obedeceram aos critérios de seleção propostos (critérios de inclusão e exclusão) foram convidados para participarem da intervenção educativa, pelo pesquisador. O convite foi realizado no mês de dezembro de 2009, sendo, portanto, utilizada uma amostra de conveniência final de 36 pacientes. Dos 36 pacientes, 15 compareceram ao primeiro encontro. Frente às dificuldades verbalizadas pelos pacientes para a participação no estudo, foi planejado um segundo grupo, no qual os pacientes foram convidados por telefone. Desta vez compareceram mais quatro pacientes, totalizando 19 pacientes. No entanto, durante o período de intervalo entre uma intervenção e outra, um paciente foi submetido ao transplante de fígado, um paciente faleceu, um paciente estava em fase aguda de encefalopatia hepática, e outro não compareceu sem justificativa, totalizando para a segunda fase da presente pesquisa, 15 pacientes $(41,67 \%$ dos pacientes que ainda permaneciam na lista de espera para o transplante de fígado).

\subsubsection{Definição das variáveis}

- Variável independente: intervenção educativa

- Variáveis dependentes: conhecimento do paciente sobre o processo de transplante de fígado e a satisfação do paciente em relação a intervenção educativa.

\subsubsection{Implementação da intervenção}

O planejamento da intervenção se iniciou no final do mês de dezembro de 2009, quando foi levantado o número de pacientes que ainda permaneciam em cadastro técnico para o transplante de fígado e haviam participado da primeira fase deste estudo. Uma carta convite foi enviada para todos os pacientes, no dia 21 de dezembro (APÊNDICE G). No período próximo da aplicação da intervenção educativa (três dias antes) foi realizado contato telefônico prévio, confirmando ou justificando a 
importância da participação dos pacientes no dia do encontro, programado para 12 de janeiro (primeiro encontro) e 9 de fevereiro (segundo encontro) de 2010. Para o segundo grupo, a intervenção ocorreu no dia 2 de fevereiro (primeiro encontro) e 2 de março (segundo encontro) de 2010.

A implementação da intervenção, ou seja, do plano educativo foi planejada e executada pelo pesquisador fundamentada na teoria do desenvolvimento de aprendizagens proposta por Gagné (1980a, b), no modelo de ensino-aprendizagem ao paciente de transplante proposto por Ohler (2003) e na avaliação diagnóstica das necessidades de informação dos pacientes realizada na primeira fase desta pesquisa. O plano de ensino construído para nortear a intervenção educativa está descrito no apêndice $F$.

$\mathrm{Na}$ intervenção educativa foram utilizadas estratégias de ensino-aprendizagem ativas, com fomento de discussões dos pacientes (aprendizes) com o enfermeiro (professor) conforme os conteúdos eram desenvolvidos. Para cada conteúdo discutido, previamente eram feitos questionamentos aos pacientes, a fim de se identificar as informações prévias que cada um tinha sobre aquele assunto. Em cada encontro foram ministradas duas horas de aula dialogada, constituída de exposição visual, fazendo-se uso de slides construídos no Microsoft ${ }^{\circledR}$ PowerPoint $\& 2007$ e apresentados por meio de Data Show, bem como um período de uma hora para o esclarecimento de dúvidas ou discussão de assuntos abordados. As aulas dialogadas foram enviadas previamente para a enfermeira coordenadora do transplante de fígado e para a enfermeira chefe da unidade de transplante de fígado para avaliação e pertinência das informações contidas, bem como não fornecer informações que fugissem da realidade do serviço.

No final do segundo encontro foi promovida uma discussão entre os candidatos ao transplante com pacientes que já tinham sidos submetidos à cirurgia com duração de aproximadamente uma hora. A intervenção educativa teve a duração de seis horas, sendo quatro horas de aula dialogada e duas horas de discussão (primeiro e segundo encontros).

Os seguintes assuntos foram abordados no primeiro encontro:

1. Visão geral do órgão a ser transplantado e aspectos históricos do transplante de fígado; 
2. Processo de avaliação para o transplante (exames, consultas, transfusão de sangue) e atuação da equipe de transplante;

3. Complicações da doença do fígado antes do transplante, indicações e contra-indicações para o transplante;

4. Esperando por um novo órgão (ficando saudável enquanto aguarda; dieta e exercício, quando ligar para o centro de transplantes);

5. O sistema de alocação de órgãos e o doador de fígado;

6. O dia do transplante, a cirurgia e a anestesia;

No segundo encontro os seguintes assuntos foram abordados:

7. Período de internação no hospital: unidade de terapia intensiva e unidade de internação;

8. Medicamentos utilizados após o transplante;

9. Complicações após o transplante (infecções, rejeição, tumores);

10. Qualidade de vida após o transplante;

11. Cuidados necessários por toda a vida após o transplante;

12. Debate entre candidatos que aguardam a cirurgia e receptores já transplantados sobre a vida após o transplante.

A intervenção educativa foi realizada sempre às terças-feiras, das 8 às 11 horas. A escolha deste dia ocorreu uma vez que é um dos dias em que o Ambulatório de Transplante de Fígado realiza atendimento aos pacientes e a maioria necessita comparecer no início da manhã, para realizar a coleta de exames laboratoriais, com o intuito de atualização da classificação de MELD. Ao final de cada encontro foi servido um lanche de acordo com as recomendações da nutricionista da equipe de transplante (hipossódico, hipogorduroso, e sem adição de açúcar devido à presença de pacientes com diabetes mellitus).

O uso do espaço físico apropriado para receber os pacientes e familiares (anfiteatro) foi solicitado para o chefe do departamento de cirurgia e anatomia do 90 e $10^{\circ}$ andares que atendeu prontamente a solicitação feita. 
5.2.3.4 Avaliação do conhecimento sobre o processo de transplante de fígado e a satisfação do paciente em relação à intervenção educativa

Para a avaliação do conhecimento do paciente foi construído um instrumento com questões do tipo falso e verdadeiro e do tipo múltipla escolha, com o intuito de abranger as principais fases do processo de transplante de fígado (Questionário de Conhecimento sobre o Transplante de Fígado) (APÊNDICE B).

A confecção do instrumento foi baseada nos estudos de Ohler (2003), Gordon (2007) e nos materiais educativos da Sociedade Internacional de Enfermeiros de Transplante (INTERNATIONAL TRANSPLANT NURSES SOCIETY, 2008), bem como no folheto informativo destinados aos pacientes inscritos no programa de transplante de fígado do HC-FMRP-USP (GRUPO INTEGRADO DE TRANSPLANTE DE FÍGADO, 2008).

Os seguintes itens foram considerados para a elaboração do instrumento:

(1). identificação das necessidades de informação realizada na primeira fase do presente estudo;

(2). presença das informações de maior relevância para o candidato ao transplante de fígado;

(3). utilização de linguagem acessível para o público leigo.

O instrumento foi submetido à validação aparente e de conteúdo por sete juízes. Os juízes selecionados foram: três enfermeiros que prestam atendimento a candidatos ao transplante de fígado antes, durante e depois da cirurgia; um docente com conhecimento na temática pesquisada e validação de instrumentos; dois médicos que prestam atendimento a pacientes que aguardam o transplante de fígado, sendo um clínico e outro cirurgião; um paciente submetido ao transplante de fígado previamente.

Os juízes analisaram a forma de apresentação e o conteúdo do instrumento com a capacidade deste atingir o objetivo da segunda fase da pesquisa. A maioria das sugestões apresentadas pelos juízes foi acatada pelo pesquisador.

Ao final do segundo encontro foi avaliada a satisfação dos pacientes na participação da intervenção educativa. Para tal foi elaborado um questionário pelo pesquisador que também foi submetido à validação aparente e de conteúdo pelos mesmos juízes que realizaram a validação do instrumento descrito anteriormente. 
Um instrumento com sete questões do tipo Likert foi elaborado, no qual o paciente classificaria de zero a 10 pontos a sua satisfação, e uma questão aberta direcionada para a recomendação ou não da intervenção educativa pelo paciente, com espaço para tecer justificativa da sua resposta (APÊNDICE C).

\subsubsection{Procedimento de coleta de dados}

A coleta de dados da segunda fase da investigação ocorreu em três etapas distintas, a saber:

- $1^{\text {a }}$ etapa: pré-teste (aplicação do instrumento para avaliar o conhecimento dos pacientes e preenchimento do termo de consentimento livre e esclarecido);

- $\quad 2^{a}$ etapa: intervenção (desenvolvimento do plano educativo);

- $\quad 3^{a}$ etapa: pós-teste (aplicação do instrumento para avaliar o conhecimento dos pacientes e preenchimento do questionário de satisfação com as informações recebidas).

\subsubsection{Análise Estatística}

Para avaliar o conhecimento dos pacientes em relação ao transplante de fígado, antes e depois da implementação de uma intervenção educativa, foram obtidos diferentes tipos de dados. Tais dados correspondem a variáveis quantitativas (discretas e contínuas) e qualitativas (nominais e ordinais).

Os dados relativos a variáveis quantitativas foram sumarizados na forma de média aritmética e respectivo desvio padrão. Para se comparar os dados de uma determinada variável entre dois ou mais grupos estabelecidos foi inicialmente verificado se os dados apresentam distribuição normal por meio do teste de normalidade de Kolmogorov-Smirnov.

Caso todos os grupos amostrais apresentassem distribuição normal ( $p$ > $0,05)$, métodos estatísticos paramétricos foram empregados: (1) teste $t$ de Student, para comparações entre as médias de duas amostras independentes; 2 ) teste $t$ de Student para amostras pareadas, para comparações entre as médias de duas amostras pareadas; (3) coeficiente de correlação de Pearson ( $r$ ), para correlação linear simples entre duas variáveis. 
Caso ao menos um dos grupos amostrais apresentasse desvios significativos em relação à distribuição normal $(p<0,05)$, métodos estatísticos não-paramétricos foram empregados: (1) teste de Kruskal-Wallis, para comparações entre as médias de três ou mais amostras independentes; e (2) coeficiente de correlação para postos de Spearman $\left(r_{s}\right)$, para correlação linear simples entre duas variáveis.

Os dados relativos a variáveis qualitativas foram sumarizados na forma de porcentagens. Para se comparar os dados de uma determinada variável dicotômica entre dois grupos estabelecidos (tabelas de contingência $2 \times 2$ ) foi empregado o teste exato de Fisher.

O programa GraphPad InStat 3.05 (GraphPad Software, Inc) foi empregado para a realização de todas as análises descritas. Em todas elas, nível de significância de $5 \%(\alpha=0.05)$ foi adotado. Além disso, versões bicaudais dos testes foram empregadas, salvo em situações excepcionais claramente identificadas, nas quais o teste monocaudal se mostra mais apropriado.

\subsubsection{Aspectos Éticos}

O presente estudo foi submetido à aprovação do Comitê de Ética em Pesquisa do Hospital das Clínicas da Faculdade de Medicina de Ribeirão Preto da Universidade de São Paulo, sendo aprovado de acordo com o Processo HCRP n ${ }^{\circ}$ 12953/2008 (ANEXO 1).

Na primeira fase da pesquisa, os pacientes participantes do estudo assinaram o Termo de Consentimento Livre e Esclarecido, após o pesquisador fornecer informações quanto ao objetivo da pesquisa, ressaltando que eles poderiam, a qualquer momento, desistir do estudo, sem que houvesse nenhum tipo de risco ou prejuízo (APÊNDICE D).

Na segunda fase do estudo, após o pesquisador fornecer informações quanto ao objetivo da pesquisa, os sujeitos que concordaram com sua participação na intervenção educativa, assinaram o Termo de Consentimento Livre e Esclarecido (APÊNDICE E). 


\section{Resultados}

\subsection{Resultados do delineamento de pesquisa não experimental: estudo descritivo}

\subsubsection{Caracterização da amostra do estudo}

No estudo descritivo participaram 55 candidatos ao transplante de fígado, ou seja, $71,43 \%$ dos 77 pacientes que se encontravam em cadastro técnico para transplante no período da coleta de dados.

Dentre as características da amostra, observou-se que em relação ao gênero, houve predomínio do sexo masculino, sendo que 40 (72,73\%) eram homens e 15 $(27,27 \%)$ eram mulheres. A idade média foi de $50,25 \pm 10,26$ anos, sendo os extremos de idade de 19 e 68 anos; $34(61,82 \%)$ pacientes apresentaram 50 anos ou mais, destes, apenas $8(14,55 \%)$ pacientes têm mais do que 60 anos de idade.

No que se refere ao grau de instrução, avaliou-se os anos de estudos dos pacientes e verificou-se que a maioria dos pacientes (54,55\%) tinha o ensino fundamental (completo ou incompleto). Os pacientes apresentaram uma média de $8,49 \pm 4,32$ anos de estudo. Apenas um (1,82\%) paciente informou não ter freqüentado a escola, mas que mesmo assim, apresentava habilidade de leitura e escrita básicas. Dos pacientes que freqüentaram a escola, os extremos de anos de estudo foram de 3 a 17 anos.

Quanto ao estado civil, $41(74,55 \%)$ pacientes eram casados ou amasiados, seis $(10,91 \%)$ solteiros, cinco $(9,09 \%)$ separados ou divorciados e três $(5,45 \%)$ eram viúvos. A média de número de filhos foi de $2,55 \pm 1,68$ filhos, sendo que apenas sete $(12,73 \%)$ pacientes não possuíam filhos, $23(41,82 \%)$ tinham de um a dois filhos, $18(32,73 \%)$ tinham de três a quatro filhos e sete $(12,73 \%)$ tinham mais do que quatro filhos (destes, um paciente possuía nove filhos).

Em relação ao local de nascimento, $37(67,27 \%)$ pacientes nasceram na área urbana e $18(32,73 \%)$ pacientes na área rural. No que tange às atividades laborais, 39 pacientes $(70,91 \%)$ estavam afastados do trabalho. Os afastamentos variaram de um a 204 meses, sendo em média 50,92 $\pm 45,41$ meses. Esses afastamentos eram decorrentes das incapacidades que a doença crônica do fígado ocasionou na vida dos pacientes. Ainda em relação à ocupação dos pacientes, sete $(12,73 \%)$ trabalhavam 
ativamente, quatro $(7,27 \%)$ eram aposentados e cinco $(9,09 \%)$ não apresentavam remuneração formal, sendo estes mulheres que trabalham em casa ou estudantes.

Os pacientes também responderam sobre a renda familiar, no que diz respeito ao número de salários mínimos que recebiam. Na época da coleta de dados do estudo, o salário mínimo correspondia a $R \$ 465,00$. Desse modo, 28 (50,91\%) pacientes ganhavam de dois a seis salários mínimos, seguidos de 18 (32,73\%) pacientes que ganhavam apenas um salário e cinco $(9,09 \%)$ pacientes que não apresentavam renda alguma. Ainda assim, quatro $(7,27 \%)$ pacientes ganhavam mais do que seis salários mínimos.

A religião pode exercer influência e prejudicar a realização do transplante em decorrência da necessidade de transfusões sangüíneas, as quais são proibidas, por exemplo, pelas testemunhas de Jeová. Quanto à religião 40 (72,73\%) pacientes verbalizaram serem católicos, oito (14,55\%) eram evangélicos, cinco $(9,09 \%)$ espíritas, um $(1,82 \%)$ protestante e um $(1,82 \%)$ mórmon. Vale ressaltar que não havia nenhum paciente cuja religião proibia a transfusão sangüínea (testemunha de Jeová). A Tabela 1 ilustra o perfil sócio-demográfico dos candidatos que participaram deste estudo. 
Tabela 1. Descrição das variáveis sócio-demográficas dos candidatos ao transplante de fígado, Ribeirão Preto, Brasil.

\begin{tabular}{|c|c|c|}
\hline Variáveis & $\begin{array}{c}\text { Candidatos } \\
(n=55)\end{array}$ & Porcentagem \\
\hline $\begin{array}{r}\text { Sexo: Masculino } \\
\text { Feminino }\end{array}$ & $\begin{array}{l}40 \\
15\end{array}$ & $\begin{array}{l}72,73 \% \\
27,27 \%\end{array}$ \\
\hline Idade em Anos (Média \pm DP) & $50,25 \pm 10,26$ & - \\
\hline $\begin{array}{l}\text { Escolaridade (anos de estudo) } \\
\text { Média } \pm \text { DP } \\
\text { Analfabeto } \\
\text { Até ensino fundamental } \\
\text { Até ensino médio } \\
\text { Até ensino superior } \\
\text { Pós-graduação }\end{array}$ & $\begin{array}{c}8,49 \pm 4,32 \text { anos } \\
1 \\
30 \\
11 \\
11 \\
2\end{array}$ & $\begin{array}{c}- \\
1,82 \% \\
54,55 \% \\
20,00 \% \\
20,00 \% \\
3,64 \%\end{array}$ \\
\hline $\begin{array}{l}\text { Estado Civil } \\
\text { Solteiro } \\
\text { Casado ou Amasiado } \\
\text { Separado ou Divorciado } \\
\text { Viúvo }\end{array}$ & $\begin{array}{c}6 \\
41 \\
5 \\
3\end{array}$ & $\begin{array}{l}10,91 \% \\
74,55 \% \\
9,09 \% \\
5,45 \%\end{array}$ \\
\hline $\begin{array}{l}\text { Número de Filhos } \\
\text { Média } \pm \text { DP } \\
\text { Sem filhos } \\
1 \text { a } 2 \text { filhos } \\
3 \text { a } 4 \text { filhos } \\
\text { Mais do que } 4 \text { filhos }\end{array}$ & $\begin{array}{c}2,55 \pm 1,68 \\
7 \\
23 \\
18 \\
7\end{array}$ & $\begin{array}{c}- \\
12,73 \% \\
41,82 \% \\
32,73 \% \\
12,73 \%\end{array}$ \\
\hline $\begin{array}{l}\text { Local de Nascimento } \\
\text { Zona Urbana } \\
\text { Zona Rural }\end{array}$ & $\begin{array}{l}37 \\
18\end{array}$ & $\begin{array}{l}67,27 \% \\
32,73 \%\end{array}$ \\
\hline $\begin{array}{l}\text { Ocupação } \\
\text { Trabalha } \\
\text { Aposentado } \\
\text { Afastado do Trabalho } \\
\text { Não trabalha }\end{array}$ & $\begin{array}{c}7 \\
4 \\
39 \\
5\end{array}$ & $\begin{array}{c}12,73 \% \\
7,27 \% \\
70,91 \% \\
9,09 \%\end{array}$ \\
\hline $\begin{array}{l}\text { Renda (salário mínimo) } \\
\text { Sem renda } \\
\text { Até } 1 \text { salário } \\
\text { De } 2 \text { a } 6 \text { salários } \\
\text { Maior do que } 6 \text { salários }\end{array}$ & $\begin{array}{c}5 \\
18 \\
28 \\
4\end{array}$ & $\begin{array}{c}9,09 \% \\
32,73 \% \\
50,91 \% \\
7,27 \%\end{array}$ \\
\hline $\begin{array}{l}\text { Religião } \\
\text { Católica } \\
\text { Evangélica } \\
\text { Espírita } \\
\text { Outras }\end{array}$ & $\begin{array}{l}40 \\
8 \\
5 \\
2\end{array}$ & $\begin{array}{c}72,73 \% \\
14,55 \% \\
9,09 \% \\
3,64 \%\end{array}$ \\
\hline
\end{tabular}


Em relação ao grupo sangüíneo dos candidatos ao transplante de fígado, 27 $(49,09 \%)$ pacientes eram do grupo 0,23 (41,82\%) eram do grupo $A$, quatro $(7,27 \%)$ do grupo $B$ e um $(1,82 \%)$ do grupo AB. Assim, os tipos sanguíneos A e $O$ ( $90,91 \%$ dos pacientes) foram os que obtiveram maior freqüência.

Dentre as classificações utilizadas para avaliar a severidade da doença do fígado, 37 (67,27\%) pacientes eram classificados como CHILD B, 14 (25,45\%) como CHILD A e quatro $(7,27 \%)$ como CHILD C. Vale ressaltar que a maioria dos pacientes estava no estágio intermediário (CHILD B) da doença. Em relação ao MELD, a média de pontuação para o MELD corrigido foi de 14,91 $\pm 3,37$ pontos. Observou-se que 42 (76,36\%) pacientes apresentavam MELD entre 11 e 18 pontos, oito $(14,55 \%)$ apresentavam MELD de 19 a 22 pontos e cinco (9,09\%) apresentavam MELD até 10 pontos. Essa classificação é útil para avaliar o risco de complicações da doença crônica do fígado nos próximos três meses, sendo que pacientes com MELD entre 22 e 24 pontos apresentam de 10 a 15\% de risco de mortalidade em decorrência das complicações da doença. Apenas um dos pacientes apresentou MELD de 22 pontos.

Em algumas situações, os pacientes cujas classificações de CHILD e MELD não indiquem gravidade da doença hepática do fígado, podem apresentar um quadro clínico que aponte a necessidade do transplante em um menor prazo de tempo. Esses pacientes são considerados em situação especial para transplante de fígado, e incluem casos de tumores hepáticos, polineuropatia amiloidótica familiar, síndrome hepatopulmonar, hemangioma gigante e doenças metabólicas com indicação de transplante. Na amostra do presente estudo havia quatro $(7,27 \%)$ indivíduos nesta situação, destes, três tinham tumores no fígado.

A avaliação do Índice de Massa Corporal foi realizada com o intuito de observar se os pacientes estavam dentro dos padrões considerados saudáveis pela Organização Mundial de Saúde (WORLD HEALTH ORGANIZATION, 2010). No presente estudo, apenas $13(23,64 \%)$ pacientes estavam dentro dos padrões de peso normal, ou seja, com IMC entre 18,50 e 24,99. Com relação à desnutrição, apenas dois $(3,64 \%)$ pacientes se encontravam abaixo do peso normal, ou seja, com IMC menor do que 18,50. A maioria dos pacientes, ou seja, $40(72,72 \%)$ indivíduos se encontravam acima do peso, com IMC maior ou igual a 25. Desses 40, $22(40 \%)$ pacientes foram classificados em algum grau de obesidade, sendo que $13(23,64 \%)$ estavam com IMC de 30 a 34,99, seis (10,91\%) com IMC entre 35 e 39,99 e 3 $(5,45 \%)$ com IMC maior ou igual a 40 , sendo respectivamente considerados obesidade graus I, II e III. O IMC médio foi estimado em $28,77 \pm 6,50 \mathrm{~kg} / \mathrm{m}^{2}$. 
As pessoas com indicação para o transplante de fígado apresentam um prolongado tempo de evolução da doença crônica. No presente estudo, apenas nove $(16,36 \%)$ pacientes estavam vivenciando a doença crônica do fígado por até dois anos. A maior parte dos pacientes, ou seja, 17 (30,91\%) indivíduos apresentavam uma evolução da doença entre dois e cinco anos, 13 (23,64\%) pacientes vivenciavam a doença do fígado entre cinco e 10 anos e outros $13(23,64 \%)$ pacientes com mais de 10 anos, sendo que destes houve relatos de evolução da doença por até 35 anos. O tempo médio de evolução da doença foi estimado em $101,21 \pm 93,53$ meses. Na amostra, três (5,45\%) pacientes não souberam informar o tempo de doença.

Em relação ao diagnóstico médico, a doença crônica do fígado causada pelo alcoolismo ocorreu em $25,45 \%$ casos ( 14 pacientes), a causa viral foi de $27,27 \%$ (15 pacientes), a viral associada com a alcoólica chegou a $20 \%$ dos casos ( 11 pacientes) e outras causas com $27,27 \%$ dos casos (15 pacientes). Dentre os tipos de vírus, 0 vírus da hepatite $\mathrm{B}(\mathrm{VHB})$ acometeu apenas seis $(10,91 \%)$ pacientes, enquanto que o vírus da hepatite $\mathrm{C}(\mathrm{VHC})$ acometeu $20(36,36 \%)$ pacientes. No que se refere a outras causas, cinco $(9,09 \%)$ pacientes tinha cirrose hepática criptogenética, quatro $(7,27 \%)$ com cirrose hepática auto-imune, três $(5,45 \%)$ com esteatose não-alcoólica (NASH), um $(1,82 \%)$ com síndrome de Budd-Chiari, um $(1,82 \%)$ com cirrose biliar primária (CBP) e um $(1,82 \%)$ com síndrome colestática.

Devido à falta de órgãos para transplantes, o número de pacientes que necessita de um órgão supera a demanda de órgãos ofertados para as equipes de transplante. Um reflexo importante do baixo número de doadores de órgãos é o prolongamento do tempo de fila de espera, desse modo, a média e o desvio padrão de dias de fila de espera chegou a 1199,58 $\pm 742,31$ dias, sendo o mínimo e o máximo de dias em fila de espera respectivamente de 58 a 2626 dias (ou seja, mais de sete anos de tempo de espera). A maior parte dos pacientes $(41,82 \%)$ estava, na fila de espera em um período de dois a cinco anos, outra parcela $(32,73 \%)$ há menos de dois anos e outra ainda estava na fila por mais de cinco anos $(25,45 \%)$. A Tabela 2 ilustra o perfil clínico dos candidatos ao transplante de fígado. 
Tabela 2. Descrição do perfil clínico dos candidatos ao transplante de fígado, Ribeirão Preto, Brasil.

\begin{tabular}{|c|c|c|}
\hline Variáveis & $\begin{array}{c}\text { Candidatos } \\
(n=55)\end{array}$ & Porcentagem \\
\hline \multicolumn{3}{|l|}{ Tipo ABO } \\
\hline$A$ & 23 & $41,82 \%$ \\
\hline $\mathrm{B}$ & 4 & $7,27 \%$ \\
\hline $\mathrm{O}$ & 27 & $49,09 \%$ \\
\hline$A B$ & 1 & $1,82 \%$ \\
\hline \multicolumn{3}{|l|}{ Classificação de CHILD } \\
\hline CHILD A & 14 & $25,45 \%$ \\
\hline CHILD B & 37 & $67,27 \%$ \\
\hline CHILD C & 4 & $7,27 \%$ \\
\hline \multicolumn{3}{|l|}{ Classificação de MELD corrigido } \\
\hline MELD até 10 & 5 & $9,09 \%$ \\
\hline MELD de 11 a 18 & 42 & $76,36 \%$ \\
\hline MELD de 19 a 22 & 8 & $14,55 \%$ \\
\hline \multicolumn{3}{|l|}{ Situação Especial para Transplante } \\
\hline Não & 51 & $92,73 \%$ \\
\hline Sim & 4 & $7,27 \%$ \\
\hline \multicolumn{3}{|l|}{ Índice de Massa Corporal $\left(\mathrm{Kg} / \mathrm{m}^{2}\right)^{*}$} \\
\hline Abaixo do peso $(<18,50)$ & 2 & $3,64 \%$ \\
\hline Peso normal $(18,50$ a 24,99$)$ & 13 & $23,64 \%$ \\
\hline Sobrepeso $(\geq 25)$ & 18 & $32,73 \%$ \\
\hline Obesidade Grau I (30 a 34,99) & 13 & $23,64 \%$ \\
\hline Obesidade Grau II (35 a 39,99) & 6 & $10,91 \%$ \\
\hline Obesidade Grau III $(\geq 40)$ & 3 & $5,45 \%$ \\
\hline \multicolumn{3}{|l|}{ Tempo de Doença do Fígado (meses) } \\
\hline Não soube informar & 3 & $5,45 \%$ \\
\hline 12 a 24 meses (até 2 anos) & 9 & $16,36 \%$ \\
\hline 25 a 60 meses (até 5 anos) & 17 & $30,91 \%$ \\
\hline 61 a 120 meses (até 10 anos) & 13 & $23,64 \%$ \\
\hline Mais do que 120 meses & 13 & $23,64 \%$ \\
\hline \multicolumn{3}{|l|}{ Doença Crônica do Fígado } \\
\hline Causa Alcoólica & 14 & $25,45 \%$ \\
\hline Causa Viral & 15 & $27,27 \%$ \\
\hline Causa Viral + Alcoólica & 11 & $20,00 \%$ \\
\hline Outras causas & 15 & $27,27 \%$ \\
\hline \multicolumn{3}{|l|}{ Tempo de lista de espera (dias) } \\
\hline Média \pm DP (dias) & $1159,58 \pm 742,31$ & - \\
\hline Até 6 meses (até 180 dias) & 4 & $7,27 \%$ \\
\hline 7 a 24 meses (até 720 dias) & 14 & $25,45 \%$ \\
\hline 25 a 60 meses (até 1800 dias) & 23 & $41,82 \%$ \\
\hline Mais do que 60 meses & 14 & $25,45 \%$ \\
\hline
\end{tabular}

* Categorias definidas de acordo com a Organização Mundial da Saúde, 2010 
No que se refere à evolução da doença crônica do fígado existem diversas características que o paciente pode apresentar durante o curso da doença (Tabela 3). Essas manifestações clínicas são reflexos do mau funcionamento do fígado e podem inclusive resultar em morte do paciente. No presente estudo, $72,73 \%$ dos pacientes apresentavam icterícia da esclera ocular em decorrência da hiperbilirrubinemia e 30,91\% distúrbios de coagulação, uma vez que os fatores de coagulação são produzidos pelo fígado. O hiperestrogenismo é o responsável pelas alterações vasculares e cutâneas causadas pela cirrose e representadas pelo eritema palmar $(90,91 \%)$ e pelas telangiectasias, ou seja, aranhas vasculares (40\%); além disso, $72,50 \%$ dos homens apresentavam ginecomastia e $72,73 \%$ dos homens e mulheres tiveram perda da libido, também decorrentes dessa alteração hormonal causada pela doença hepática.

Em relação aos distúrbios alimentares, 34,55\% dos pacientes informaram inapetência. A alteração do ritmo do sono e da vigília foi verbalizada por $65,45 \%$ dos pacientes. Em relação a outros resultados do estudo ressalta-se a presença de ascite $(58,18 \%)$; varizes esofágicas $(81,82 \%)$; episódios de hemorragia digestiva alta $(47,27 \%)$; infecções freqüentes $(40 \%)$ e insuficiência renal aguda $(27,27 \%)$. Esses dados complementam a evolução do quadro clínico dos pacientes com doença hepática crônica.

Os pacientes também podem vivenciar alterações do hábito intestinal, tais como diarréia e constipação. Essas alterações estiveram presentes em 47,27\% dos pacientes. Além disso, os pacientes também apresentaram edema de membros inferiores $(65,45 \%)$; presença de hérnia umbilical, escrotal, inguinal ou abdominal $(41,82 \%)$; encefalopatia hepática $(50,91 \%)$; queixas de dor, principalmente na região do hipocôndrio direito $(52,73 \%)$; queixas de fadiga $(74,55 \%)$ e náuseas em $40 \%$ dos casos.

Apesar do resultado não estar relacionado com a doença hepática, os pacientes foram inquiridos em relação à realização de cirurgia abdominal prévia. Essa condição esteve presente em $43,64 \%$ dos casos, a qual pode ser um fator dificultador do procedimento cirúrgico devido à presença de aderências. Outras doenças crônicas que os pacientes apresentaram foram a hipertensão arterial sistêmica $(21,82 \%)$, diabetes mellitus $(23,64 \%)$ e obesidade $(72,73 \%)$. 
Tabela 3. Descrição dos sinais e sintomas da doença crônica do fígado presentes nos candidatos ao transplante de fígado, Ribeirão Preto, Brasil.

\begin{tabular}{|c|c|c|}
\hline Variáveis & $\begin{array}{c}\text { Candidatos } \\
(n=55)\end{array}$ & Porcentagem \\
\hline \multicolumn{3}{|c|}{ Icterícia da esclera ocular } \\
\hline Sim & 40 & $72,73 \%$ \\
\hline Não & 15 & $27,27 \%$ \\
\hline \multicolumn{3}{|c|}{ Distúrbios de coagulação } \\
\hline Sim & 17 & $30,91 \%$ \\
\hline Não & 38 & $69,09 \%$ \\
\hline \multicolumn{3}{|c|}{ Aranhas vasculares } \\
\hline Sim & 22 & $40,00 \%$ \\
\hline Não & 33 & $60,00 \%$ \\
\hline \multicolumn{3}{|c|}{ Eritema palmar } \\
\hline Sim & 50 & $90,91 \%$ \\
\hline Não & 5 & $9,09 \%$ \\
\hline \multicolumn{3}{|c|}{ Ginecomastia (40 homens) } \\
\hline Sim & 29 & $72,50 \%$ \\
\hline Não & 11 & $27,50 \%$ \\
\hline \multicolumn{3}{|c|}{ Diminuição libido } \\
\hline Sim & 40 & $72,73 \%$ \\
\hline Não & 15 & $27,27 \%$ \\
\hline \multicolumn{3}{|l|}{ Inapetência } \\
\hline Sim & 19 & $34,55 \%$ \\
\hline Não & 36 & $65,45 \%$ \\
\hline \multicolumn{3}{|c|}{ Alteração do sono e vigília } \\
\hline Sim & 36 & $65,45 \%$ \\
\hline Não & 19 & $34,55 \%$ \\
\hline \multicolumn{3}{|l|}{ Ascite } \\
\hline Sim & 32 & $58,18 \%$ \\
\hline Não & 23 & $41,82 \%$ \\
\hline \multicolumn{3}{|c|}{ Varizes esofágicas } \\
\hline Sim & 45 & $81,82 \%$ \\
\hline Não & 10 & $18,18 \%$ \\
\hline \multicolumn{3}{|c|}{ Hemorragia digestiva alta prévia } \\
\hline Sim & 26 & $47,27 \%$ \\
\hline Não & 29 & $52,73 \%$ \\
\hline \multicolumn{3}{|c|}{ Infecções freqüentes } \\
\hline Sim & 22 & $40,00 \%$ \\
\hline Não & 33 & $60,00 \%$ \\
\hline \multicolumn{3}{|c|}{ Insuficiência renal aguda } \\
\hline Sim & 15 & $27,27 \%$ \\
\hline Não & 40 & $72,73 \%$ \\
\hline
\end{tabular}


... Continuação da Tabela 3

\begin{tabular}{|c|c|c|}
\hline Variáveis & $\begin{array}{c}\text { Candidatos } \\
(n=55)\end{array}$ & Porcentagem \\
\hline \multicolumn{3}{|l|}{ Presença de constipação ou diarréia } \\
\hline Sim & 26 & $47,27 \%$ \\
\hline Não & 29 & $52,73 \%$ \\
\hline \multicolumn{3}{|l|}{ Edema de membros inferiores } \\
\hline Sim & 36 & $65,45 \%$ \\
\hline Não & 19 & $34,55 \%$ \\
\hline \multicolumn{3}{|l|}{ Presença de Hérnia } \\
\hline Sim & 23 & $41,82 \%$ \\
\hline Não & 32 & $58,18 \%$ \\
\hline \multicolumn{3}{|l|}{ Encefalopatia hepática } \\
\hline $\operatorname{Sim}$ & 28 & $50,91 \%$ \\
\hline Não & 27 & $49,09 \%$ \\
\hline \multicolumn{3}{|l|}{ Queixas de dor } \\
\hline Sim & 29 & $52,73 \%$ \\
\hline Não & 26 & $47,27 \%$ \\
\hline \multicolumn{3}{|l|}{ Queixas de fadiga } \\
\hline Sim & 41 & $74,55 \%$ \\
\hline Não & 14 & $25,45 \%$ \\
\hline \multicolumn{3}{|l|}{ Queixas de náuseas } \\
\hline Sim & 22 & $40,00 \%$ \\
\hline Não & 33 & $60,00 \%$ \\
\hline \multicolumn{3}{|l|}{ Cirurgia abdominal prévia } \\
\hline Sim & 24 & $43,64 \%$ \\
\hline Não & 31 & $56,36 \%$ \\
\hline \multicolumn{3}{|l|}{ Escala de bem estar subjetivo $*$} \\
\hline 3 afetos positivos & 8 & $14,55 \%$ \\
\hline 2 afetos positivos & 5 & $9,09 \%$ \\
\hline 1 afeto positivo & 19 & $34,55 \%$ \\
\hline Nenhum afeto positivo & 23 & $41,82 \%$ \\
\hline \multicolumn{3}{|l|}{ Outras doenças crônicas } \\
\hline Hipertensão arterial sistêmica & 12 & $21,82 \%$ \\
\hline Diabetes mellitus & 13 & $23,64 \%$ \\
\hline Obesidade & 40 & $72,73 \%$ \\
\hline \multicolumn{3}{|l|}{ Medicamentos mais utilizados } \\
\hline Bloqueador $\beta$ adrenérgico & 45 & $81,82 \%$ \\
\hline Diuréticos & 46 & $83,64 \%$ \\
\hline Antibióticos & 15 & $27,27 \%$ \\
\hline Regulador intestinal & 22 & $40,00 \%$ \\
\hline Vitaminas & 26 & $47,27 \%$ \\
\hline Protetor gástrico & 25 & $45,45 \%$ \\
\hline Insulina & 9 & $16,36 \%$ \\
\hline
\end{tabular}

* Segundo Albuquerque e Tróccoli, 2004 
Dentre os medicamentos de uso contínuo dos pacientes destacam-se os bloqueadores beta-adrenérgicos (como o propranolol) em 81,82\% dos casos; diuréticos em $83,64 \%$ dos casos; uso de complexos vitamínicos e minerais em $47,27 \%$ dos casos; protetor gástrico em 45,45\%; regulador intestinal em $40 \%$ dos casos; antibióticos em $27,27 \%$ dos casos e finalmente, insulina em 16,36\% dos casos.

A labilidade emocional ou instabilidade afetiva é um sintoma muito comum nos candidatos ao transplante de fígado, pois eles convivem com a expectativa da morte (em decorrência das complicações da doença do fígado) e da vida (em decorrência da chance de cura pelo transplante). Por meio da aplicação de uma escala de bem-estar subjetivo foi possível identificar três afetos positivos ou negativos sentidos pelos pacientes nos últimos meses durante a coleta de dados. Não foi surpresa o relato de afetos apenas negativos ( $41,82 \%$ dos casos), frente aos afetos positivos. Os afetos negativos mais verbalizados foram preocupação (14 relatos - 25,45\%), irritabilidade (14 relatos - 25,45\%), impaciência (13 relatos $23,64 \%$ ), angústia (12 relatos - 21,82\%), nervosismo (10 relatos - $18,18 \%$ ) e ansiedade ( 9 relatos $-16,36 \%$ ).

Em relação aos hábitos de vida diária (Tabela 4), 69,09\% dos pacientes não praticavam qualquer tipo de exercício físico. Dentre os 30,91\% que realizavam exercício físico, a caminhada era o exercício desenvolvido com maior freqüência, sendo realizada por 16 (29,09\%) pacientes. Apenas um (1,82\%) paciente era adepto do ciclismo como prática de exercício físico. 
Tabela 4. Descrição dos hábitos de vida presentes nos candidatos ao transplante de fígado, Ribeirão Preto, Brasil.

\begin{tabular}{|c|c|c|}
\hline Variáveis & $\begin{array}{c}\text { Candidatos } \\
(n=55)\end{array}$ & Porcentagem \\
\hline \multicolumn{3}{|l|}{ Prática de exercício Físico } \\
\hline Sim & 17 & $30,91 \%$ \\
\hline Não & 38 & $69,09 \%$ \\
\hline Refeições / dia (Média \pm DP) & $4,98 \pm 1,03$ & - \\
\hline \multicolumn{3}{|l|}{ Café da manhã } \\
\hline Sim & 49 & $89,09 \%$ \\
\hline Não & 6 & $10,91 \%$ \\
\hline \multicolumn{3}{|l|}{ Lanche da manhã } \\
\hline Sim & 37 & $67,27 \%$ \\
\hline Não & 18 & $32,73 \%$ \\
\hline \multicolumn{3}{|l|}{ Almoço } \\
\hline Sim & 54 & $98,18 \%$ \\
\hline Não & 1 & $1,82 \%$ \\
\hline \multicolumn{3}{|l|}{ Lanche da tarde } \\
\hline Sim & 47 & $85,45 \%$ \\
\hline Não & 8 & $14,55 \%$ \\
\hline \multicolumn{3}{|l|}{ Jantar } \\
\hline Sim & 53 & $96,36 \%$ \\
\hline Não & 2 & $3,64 \%$ \\
\hline \multicolumn{3}{|l|}{ Ceia } \\
\hline Sim & 34 & $61,82 \%$ \\
\hline Não & 21 & $38,18 \%$ \\
\hline \multicolumn{3}{|l|}{ Restrições alimentares } \\
\hline \multicolumn{3}{|l|}{ Sódio } \\
\hline Sim & 52 & $94,55 \%$ \\
\hline Não & 3 & $5,45 \%$ \\
\hline \multicolumn{3}{|l|}{ Proteínas } \\
\hline Sim & 22 & $40,00 \%$ \\
\hline Não & 33 & $60,00 \%$ \\
\hline \multicolumn{3}{|l|}{ Carboidratos (açúcares) } \\
\hline Sim & 8 & $14,55 \%$ \\
\hline Não & 47 & $85,45 \%$ \\
\hline \multicolumn{3}{|l|}{ Lipídios } \\
\hline Sim & 29 & $52,73 \%$ \\
\hline Não & 26 & $47,27 \%$ \\
\hline
\end{tabular}




\begin{tabular}{lcc}
\hline Variáveis & $\begin{array}{c}\text { Candidatos } \\
(\mathbf{n}=\mathbf{5 5})\end{array}$ & Porcentagem \\
\hline Tabagismo & 4 & $7,27 \%$ \\
Uso ativo & 26 & $47,27 \%$ \\
Ex-tabagista & 25 & $45,45 \%$ \\
Nunca usou tabaco & 15 & $27,27 \%$ \\
Ex-etilismo & 40 & $72,73 \%$ \\
Nunca usou & $1709,09 \pm 724,51$ & - \\
Ex-etilista & 27 & $49,09 \%$ \\
Ingestão hídrica diária (Média \pm DP) & 19 & $34,55 \%$ \\
Menos de 2 litros & 9 & $16,36 \%$ \\
2 litros & 27 & $49,09 \%$ \\
Mais do que 2 litros & 28 & $50,91 \%$ \\
Ingestão de xícaras de café & $7,36 \pm 2,01$ & - \\
Sim & 23 & $41,82 \%$ \\
Não & 19 & $34,55 \%$ \\
Horas de sono noturno (Média \pm DP) & 13 & $23,64 \%$ \\
Menor do que 8 horas & $1,63 \pm 0.89$ & - \\
8 horas de sono & 21 & $38,18 \%$ \\
Mais do que 8 horas & 15 & $27,27 \%$ \\
Não dorme & 19 & $34,55 \%$ \\
Até 1 hora de cochilo & & \\
Mais do que 1 hora de cochilo & &
\end{tabular}

Com relação ao padrão alimentar, os pacientes faziam em média 4,98 $\pm 1,03$ refeições ao dia. A dieta do portador de doença hepática crônica deve ser fracionada (até 6 refeições ao dia) e restrita a alimentos que não contenham sódio em excesso, lipídios, proteínas e açúcares. Desse modo, 89,09\% dos pacientes tomavam café da manhã diariamente, $67,27 \%$ dos pacientes faziam um pequeno lanche no intervalo entre o café da manhã e o almoço, $98,18 \%$ dos pacientes almoçava, $85,45 \%$ realizavam um lanche no período da tarde, 96,36\% tinham o hábito de jantar e $61,82 \%$ faziam a ceia antes de dormir.

Quanto às restrições alimentares, 94,55\% informaram evitar sódio durante as refeições, 40\% procuravam evitar proteínas, 14,55\% informaram evitar açucares e $52,73 \%$ disseram que evitam alimentos gordurosos. Nenhum paciente verbalizou fazer restrições hídricas devido ao acúmulo de líquidos, principalmente no abdômen (ascite).

Quanto aos hábitos nocivos à saúde, 47,27\% dos pacientes informaram ter deixado o hábito de fumar, 45,45\% disseram nunca ter adquirido este vício e 7,27\% ainda tinham esse hábito, apesar de terem recebido as orientações e informações 
sobre os prejuízos do cigarro durante a recuperação pós-operatória. Dentre os fumantes e ex-fumantes, a média do consumo de cigarros foi de 13,79 $\pm 9,67$ cigarros/dia. No que se refere ao etilismo, todos os pacientes que ingressam na fila de espera para o transplante necessitam ficar pelo menos seis meses sem ingerir bebidas alcoólicas. Frente ao exposto, nenhum paciente informou ingerir bebida alcoólica, $72,73 \%$ disseram ser ex-etilista e $27,27 \%$ nunca consumiram bebida alcoólica.

Em relação à ingestão hídrica, os pacientes consumiam em média 1709,09 \pm 724,51 ml de líquidos diariamente; 49,09\% consumiam menos do que 2 litros (três pacientes informaram que consumiam $500 \mathrm{ml}$ ao dia e outros 16 informaram que consumiam até um litro ao dia); $34,55 \%$ consumiam dois litros; por outro lado, $16,36 \%$ disseram que consumiam mais do que dois litros ao dia (oito consumiam $3000 \mathrm{ml}$ ao dia e um consumia $2500 \mathrm{ml}$ ao dia). O consumo de café é um hábito comum entre os brasileiros, sendo que $49,09 \%$ dos pacientes tinham esse hábito. $\mathrm{A}$ média de consumo entre os que possuem tal hábito era de $2,19 \pm 1,75$, sendo 0 mínimo de uma xícara (13 pacientes) e o máximo de oito xícaras (um paciente).

Em relação a necessidades de sono e repouso, $41,82 \%$ dos pacientes informaram que dormiam menos do que oito horas por noite $(41,82 \%)$. A maioria dos entrevistados informou que tem prática de cochilar durante o período diurno $(61,82 \%)$, realizando tal atividade por um período aproximado de $1,63 \pm 0,89$ horas, sendo que $34,55 \%$ dormiam mais do que uma hora ao dia. 
6.1.2 Necessidades de informação dos candidatos em fila de espera

Frente a uma condição de desequilíbrio entre o processo de saúde-doença, as pessoas naturalmente necessitam de informações acerca dos fatores que envolvem aquela nova condição de desequilíbrio com a saúde.

No presente estudo, de acordo com a Tabela 5, observou-se que a maioria dos pacientes $(87,27 \%)$ informou que conhecem a definição de transplante de fígado, como sendo a retirada total do fígado doente e a inserção de um novo fígado, pertencente a outro indivíduo falecido. No entanto chama a atenção que, $12,73 \%$ dos pacientes que fazem parte de uma fila de espera para transplante, desconheciam o significado do procedimento que poderão realizar.

Outro dado relevante se refere ao conhecimento do paciente sobre a causa da doença hepática crônica. Todos os indivíduos foram argüidos sobre o seu diagnóstico médico. Após a entrevista, o pesquisador realizava uma busca no prontuário a fim de verificar se o diagnóstico do prontuário era condizente com a resposta do próprio paciente. Nesse sentido, $76,36 \%$ dos pacientes sabiam de fato o real diagnóstico médico. Dos $13(23,64 \%)$ pacientes restantes, oito $(14,55 \%)$ informaram um diagnóstico diferente daquele encontrado no prontuário e cinco $(9,09 \%)$ disseram que não sabiam a doença que apresentavam.

No que se refere à percepção temporal do paciente em relação ao período de cadastro técnico para transplante de fígado, 49,09\% (27 pacientes) informaram valores aproximadamente corretos. Dos pacientes que não sabiam ou informaram incorretamente o tempo de fila de espera, cinco (9,09\%) pacientes responderam que de fato não tinham idéia do tempo que estavam aguardando o transplante. Dos 28 $(50,91 \%)$ pacientes que informaram incorretamente o dado, houve uma margem de erro que variou de $20,82 \%$ a $200 \%$ em relação ao tempo real de cadastro técnico no momento da entrevista.

Em relação ao funcionamento da lista de espera para transplante de fígado, desde 2006, a fila deixou de obedecer ao critério cronológico e passou a funcionar pelo critério de gravidade por meio do Modelo para Doença Hepática em Estágio Final (MELD). No presente estudo, 67,27\% dos pacientes informaram conhecimento sobre o funcionamento da lista de espera para o transplante. Dos 32,73\% restantes, 17 $(30,91 \%)$ disseram que nunca foram informados e apenas um $(1,82 \%)$ informou que a lista funcionava por tempo de espera. 
Tabela 5. Descrição do conhecimento e fonte de informações relacionadas às necessidades de aprendizagem presentes nos candidatos ao transplante de fígado, Ribeirão Preto, Brasil.

\begin{tabular}{|c|c|c|}
\hline Variáveis & $\begin{array}{l}\text { Candidatos } \\
(n=55)\end{array}$ & Porcentagem \\
\hline \multicolumn{3}{|l|}{ Conhecimento sobre a definição de } \\
\hline Sim & 48 & $87,27 \%$ \\
\hline Não & 7 & $12,73 \%$ \\
\hline \multicolumn{3}{|c|}{$\begin{array}{l}\text { Conhecimento sobre a causa da doença } \\
\text { hepática crônica }\end{array}$} \\
\hline $\operatorname{Sim}$ & 42 & $76,36 \%$ \\
\hline Não & 13 & $23,64 \%$ \\
\hline \multicolumn{3}{|l|}{$\begin{array}{l}\text { Conhecimento sobre o tempo de } \\
\text { cadastro técnico para transplante }\end{array}$} \\
\hline Sim & 27 & $49,09 \%$ \\
\hline Não & 28 & $50,91 \%$ \\
\hline \multicolumn{3}{|c|}{$\begin{array}{l}\text { Conhecimento sobre o funcionamento } \\
\text { da lista de espera para transplante }\end{array}$} \\
\hline $\operatorname{Sim}$ & 37 & $67,27 \%$ \\
\hline Não & 18 & $32,73 \%$ \\
\hline \multicolumn{3}{|c|}{$\begin{array}{l}\text { Recebimento de informações sobre o } \\
\text { transplante de fígado }\end{array}$} \\
\hline Sim & 50 & $90,91 \%$ \\
\hline Não & 5 & $9,09 \%$ \\
\hline \multicolumn{3}{|l|}{$\begin{array}{l}\text { Sente-se preparado diante do } \\
\text { conhecimento que possui }\end{array}$} \\
\hline Sim & 40 & $72,73 \%$ \\
\hline Não & 15 & $27,27 \%$ \\
\hline \multicolumn{3}{|c|}{$\begin{array}{l}\text { Realizou a leitura do folheto informativo } \\
\text { entregue }\end{array}$} \\
\hline Sim & 36 & $65,45 \%$ \\
\hline Não & 19 & $34,55 \%$ \\
\hline \multicolumn{3}{|l|}{$\begin{array}{l}\text { Métodos de ensino preferidos na } \\
\text { aquisição de conhecimentos } *\end{array}$} \\
\hline Leitura & 22 & $40,00 \%$ \\
\hline Discussões grupais & 24 & $43,64 \%$ \\
\hline Aula expositiva & 18 & $32,73 \%$ \\
\hline Vídeos & 18 & $32,73 \%$ \\
\hline Pesquisa na Internet & 12 & $21,82 \%$ \\
\hline Demonstrações & 10 & $18,18 \%$ \\
\hline Manuseio de um material & 8 & $14,55 \%$ \\
\hline Escrever & 3 & $5,45 \%$ \\
\hline Ouvir explicações & 30 & $54,55 \%$ \\
\hline Orientação individual & 20 & $36,36 \%$ \\
\hline
\end{tabular}

* Os pacientes poderiam optar por até três métodos de ensino 
No que tange ao recebimento de informações sobre o transplante de fígado, $90,91 \%$ dos pacientes informaram ter recebido essas informações. Dentre as fontes de informação citadas pelos pacientes, destacou-se o fornecimento de informações pela equipe de transplante (39 casos - 70,91\%), pelo folheto informativo (17 casos - 30,91\%), por outros pacientes (10 casos - 18,18\%), pela internet (5 casos $9,09 \%$ ) e por fim pela televisão ( 4 casos $-7,27 \%$ ).

Quando os pacientes foram questionados se estavam preparados para realizar o procedimento cirúrgico frente ao conhecimento que possuíam até o momento, $72,73 \%$ dos pacientes informaram que se sentiam preparados para a cirurgia. Dos $15(27,27 \%)$ pacientes que não se sentiam preparados, apenas dois pacientes justificaram a falta de preparo, sendo que um verbalizou sentir medo e o outro a necessidade de receber um treinamento para poder realizar o transplante.

No que se refere à leitura do folheto informativo geralmente entregue ao paciente no momento de entrada no cadastro técnico para o transplante de fígado, $65,45 \%$ dos pacientes informaram ter realizado a leitura do folheto. Dos 34,55\% que não leram o folheto informativo, $15(27,27 \%)$ informaram que ainda não haviam recebido o folheto, três $(5,45 \%)$ justificaram falta de interesse ou estímulo para a leitura, e um (1,82\%) informou sentir angústia ou ansiedade com as informações do folheto. Vale ressaltar que no momento da entrevista, com a anuência do enfermeiro da equipe de transplante presente no ambulatório, o folheto informativo foi entregue a todos os pacientes que ainda não haviam recebido o folheto.

Finalmente, os pacientes foram questionados sobre os métodos de ensino de preferência na aquisição de determinados conhecimentos. Os pacientes foram estimulados a verbalizarem pelo menos três opções. Dentre os métodos preferidos destacam-se ouvir explicações $(54,55 \%)$, discussões grupais $(43,64 \%)$ e leitura $(40,00 \%)$. Outros métodos informados foram a orientação individual (36,36\%), aula expositiva $(32,73 \%)$, vídeos $(32,73 \%)$, pesquisa na internet $(21,82 \%)$, demonstrações $(18,18 \%)$, manuseio de um material $(14,55 \%)$ e escrever $(5,45 \%)$.

Ao final da entrevista, foi aplicada uma escala de avaliação das necessidades de informação dos pacientes (Tabela 6). Eles foram estimulados a ordenarem por importância, dez assuntos que consideravam relevantes para o seu aprendizado, antes de realizar a cirurgia. Para facilitar a compreensão do paciente, bem como a análise dos dados, antes do paciente preencher a escala, foi entregue um cartão contendo 17 sugestões de assuntos considerados importantes, de acordo com o 
modelo proposto por Ohler (2003). Na ocasião estimulou-se a leitura completa do cartão e o esclarecimento de qualquer dúvida, antes de preencher a escala. Destas 17 sugestões, as oito primeiras eram referentes ao período pré-operatório, da nona à décima primeira, eram referentes ao período intra-operatório, e da décima segunda à décima sétima, eram referentes ao período pós-operatório do transplante de fígado.

Tabela 6. Distribuição dos valores da escala de avaliação das necessidades de informação (N.I.) dos candidatos ao transplante de fígado, Ribeirão Preto, Brasil.

\begin{tabular}{|c|c|c|c|c|}
\hline & $\begin{array}{c}\text { Sugestões } \\
\text { (N.I) }\end{array}$ & $\begin{array}{l}\Sigma \text { Classificação } \\
\text { por importância }\end{array}$ & $\begin{array}{c}\text { No de Pacientes } \\
\text { responderam } \\
\text { (Votos) }\end{array}$ & $\begin{array}{l}\text { Média } \\
\text { Final }\end{array}$ \\
\hline \multirow{8}{*}{ Pré } & S.01 & 149 & 28 & 2,71 \\
\hline & S.02 & 118 & 20 & 2,15 \\
\hline & S.03 & 195 & 31 & 3,55 \\
\hline & S.04 & 255 & 34 & 4,64 \\
\hline & S.05 & 199 & 36 & 3,62 \\
\hline & S.06 & 172 & 32 & 3,13 \\
\hline & S.07 & 176 & 32 & 3,20 \\
\hline & S.08 & 185 & 30 & 3,36 \\
\hline \multirow{3}{*}{ Intra } & S.09 & 128 & 27 & 2,33 \\
\hline & S.10 & 193 & 35 & 3,51 \\
\hline & S.11 & 213 & 33 & 3,87 \\
\hline \multirow{6}{*}{ Pós } & S.12 & 151 & 32 & 2,75 \\
\hline & S.13 & 141 & 29 & 2,56 \\
\hline & S.14 & 239 & 43 & 4,35 \\
\hline & S.15 & 108 & 23 & 1,96 \\
\hline & S.16 & 224 & 45 & 4,07 \\
\hline & S.17 & 179 & 40 & 3,25 \\
\hline
\end{tabular}

Nos resultados evidenciados houve correlação positiva entre o número de votos e a média final (pontuação) das diferentes sugestões (coeficiente de correlação de Pearson: $r=0,7873 ; \boldsymbol{p}=\mathbf{0 , 0 0 0 2}$ ). Considerando-se a pontuação, observa-se que as questões referentes ao período de espera para o transplante foram as que obtiveram pontuação maior, e, portanto, foram de maior interesse para os pacientes. A sugestão $n^{\circ} 4$, referente aos cuidados necessários antes do transplante, foi a que 
ganhou a maior pontuação $(4,64)$, seguida da sugestão $n^{\circ} 14$, referente às complicações após o transplante $(4,35)$ e sugestão $n^{\circ} 16$, que diz respeito aos cuidados necessários após o transplante de fígado $(4,07)$. Entretanto, considerandose o número de votos, as sugestões referentes ao período pós-operatório foram as mais votadas, tendo as sugestões $n^{\circ} 16, n^{\circ} 14$ e $n^{\circ} 17$ (relacionada a qualidade de vida após o transplante) obtido, respectivamente, $45(81,8 \%), 43(78,18 \%)$ e 40 $(72,72 \%)$ dos 55 votos possíveis.

As sugestões de menor interesse, ou seja, aquelas que obtiveram a menor pontuação final foram a sugestão $n^{\circ} 15(1,96)$, referente aos medicamentos utilizados após o transplante, a sugestão $n^{\circ} 2(2,15)$ relativa ao funcionamento da lista de espera, a sugestão $n^{\circ} 9(2,33)$, a qual diz respeito às indicações e contra-indicações para o transplante, a sugestão $\mathrm{n}^{\circ} 13(2,56)$, relacionada ao período pós-operatório imediato e mediato do transplante de fígado e a sugestão $n^{\circ} 1(2,71)$, relacionada ao sistema de distribuição de órgãos e o MELD. É interessante enfatizar que estas foram também as sugestões que obtiveram menores números de votos, respectivamente, $23(41,82 \%), 20(36,36 \%), 27(49,09 \%), 29(52,73 \%)$ e $28(50,91 \%)$.

De um modo geral, fazendo a média aritmética das notas de cada sugestão, de acordo com os três períodos que compõem o período perioperatório, ou seja, pré, intra e pós-operatório, as informações relacionadas ao pré-operatório foram observadas como a de maior interesse para os pacientes (média de 3,30), seguidas das informações relacionadas ao período intra-operatório (média de 3,24) e finalizando com as informações do pós-operatório (média de 3,16).

A fim de relacionar os dados obtidos, realizou-se uma comparação entre os candidatos com nível de ensino fundamental completo ou incompleto, com os candidatos que apresentavam nível médio, superior e pós-graduação. Essa comparação visou investigar se o nível educacional poderia exercer alguma influência sobre a amostra estudada, formando-se desse modo dois grupos distintos (Tabela 7). O Grupo I foi composto por 31 indivíduos, enquanto que o Grupo II foi composto por 24 indivíduos.

Em relação à idade, observou-se que os pacientes do Grupo II eram significantemente mais jovens em relação ao Grupo I $(\boldsymbol{p}=\mathbf{0 , 0 4 1 3}$, teste $t$ de Student). Quanto à gravidade da doença, observou-se que os pacientes do Grupo I apresentaram MELD discretamente maior do que o Grupo II. Em relação ao tempo de espera, os resultados foram semelhantes nos dois grupos. Observaram-se 
resultados superiores no Grupo II em relação ao Grupo I, no que se refere ao conhecimento da definição de transplante de fígado ( $\boldsymbol{p}=\mathbf{0 , 0 1 4 7}$, teste exato de Fisher), conhecimento da causa da doença hepática crônica, conhecimento do tempo de cadastro técnico para transplante de fígado e conhecimento do funcionamento da lista de espera. Também foi maior no Grupo II o recebimento de informações sobre o transplante de fígado, o sentimento de preparo em relação ao conhecimento para a cirurgia ( $\boldsymbol{p}=\mathbf{0 , 0 3 7 1}$, teste exato de Fisher) e a leitura do folheto informativo com informações sobre o processo de transplante.

Em relação às necessidades de informação observou-se que os pacientes do Grupo I apresentaram maiores necessidades de informação do período préoperatório (pontuação média $=3,36 \pm 3,65$ ), enquanto que no Grupo II foi o período intra-operatório (pontuação média $=3,61 \pm 3,93$ ) que obteve maior destaque. Em relação aos três períodos, pré, intra e pós-operatório, as menores necessidades de informação no Grupo I foram em relação ao período intra-operatório (pontuação média $=2,95 \pm 3,19$ ), enquanto que no Grupo II foram as informações relativas ao período pós-operatório (pontuação média $=3,09 \pm 3,06$ ) do transplante de fígado.

Com o intuito de observar se o fato de as pessoas estarem há mais tempo expostas a situação de "estar na fila de espera" para transplante de fígado poderia refletir nos conhecimentos inerentes a esse processo e nas necessidades de informação, foi realizada uma comparação dos candidatos em dois grupos distintos. O Grupo I seriam os pacientes com tempo igual ou inferior a 3,5 anos de fila de espera e o Grupo II seriam os pacientes com tempo igual ou superior a 3,5 anos de espera para o transplante (Tabela 8). 


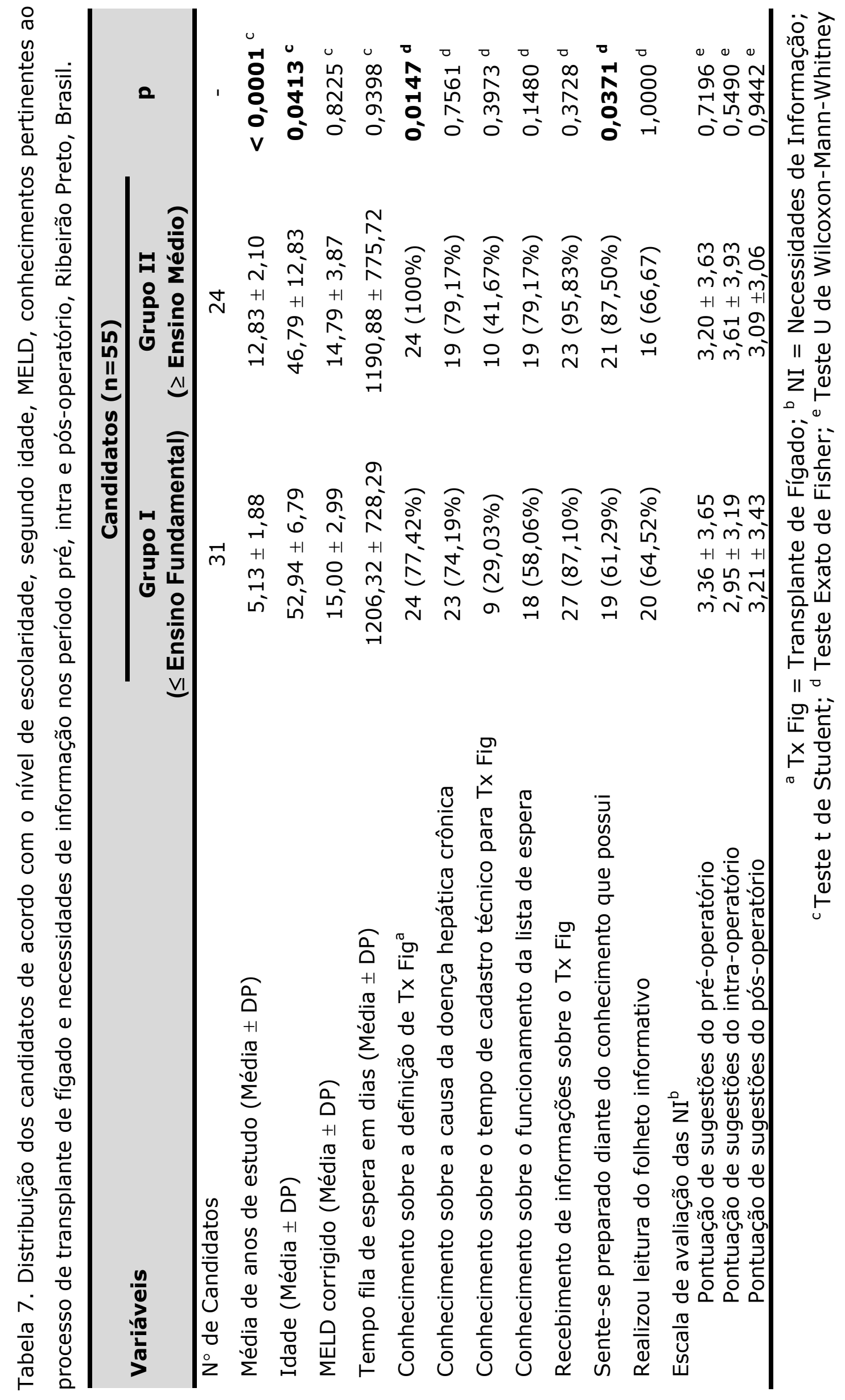




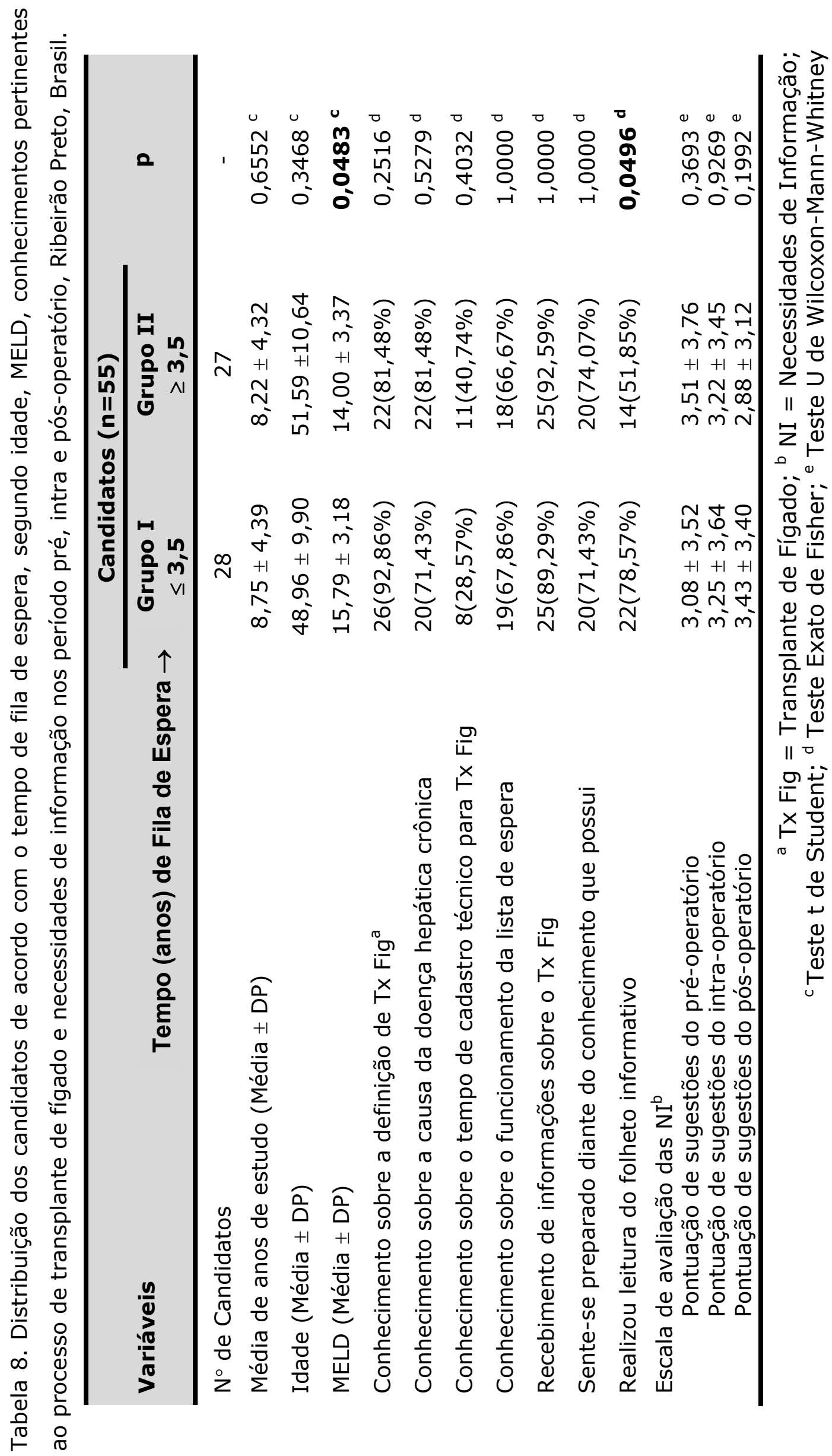


Observou-se diferença significativa em relação ao nível de gravidade dos dois grupos, sendo que os pacientes do Grupo I apresentaram valores de MELD médio maiores e os pacientes do Grupo II, valores de MELD menores ( $\boldsymbol{p}=\mathbf{0 , 0 4 8 3}$ ). Em relação aos conhecimentos sobre o processo de transplante avaliados, observou-se uma diferença não-significante principalmente no conhecimento sobre o tempo de cadastro técnico para transplante de fígado, sendo este conhecimento maior no Grupo II $(40,74 \%)$. Os pacientes do Grupo II $(92,59 \%)$ apresentaram valores maiores em relação ao recebimento de informações sobre o transplante de fígado, em relação ao Grupo I (89,29\%). Não houve diferenças no conhecimento sobre o funcionamento da lista de espera.

Os pacientes que estavam a mais tempo na fila de transplante, ou seja, os pacientes do Grupo II foram os que mais informaram sentimentos de preparo para a cirurgia diante do conhecimento que possuíam (74,07\%), em relação ao Grupo I (71,43\%). Entretanto, os pacientes do Grupo I (78,57\%), foram significantemente mais ativos em relação a leitura do folheto informativo entregue no momento de entrada na fila de espera ( $\boldsymbol{p}=\mathbf{0 , 0 4 9 6}$, teste exato de Fisher).

No que se refere às necessidades de informação do período pré, intra e pósoperatório, não houve diferença estatisticamente significante entre o Grupo I e II (Tabela 8). Apesar disso, pequenas diferenças foram encontradas: os pacientes do Grupo II $(3,51 \pm 3,76)$ sentiram necessidades de informação um pouco maior em relação ao período pré-operatório quando comparados ao Grupo I $(3,08 \pm 3,52)$; as necessidades de informação sobre o período pós-operatório mostraram-se mais necessárias para o Grupo I $(3,43 \pm 3,40)$ do que para o Grupo II $(2,88 \pm 3,12)$. Fazendo-se uma avaliação global dos resultados obtidos em relação às necessidades de informação nos três períodos, para os dois grupos, observou-se maior homogeneidade dos resultados para o Grupo I, quando comparado ao Grupo II. Os pacientes do Grupo II demonstraram necessidade maior de informação relacionada ao período pré-operatório, sendo as informações menos necessárias no período pósoperatório. 


\subsection{Resultados do delineamento de pesquisa quase-experimental: estudo piloto grupo único, antes e depois}

6.2.1 Conhecimento dos candidatos sobre o processo de transplante de fígado, antes e depois da implementação da intervenção educativa

Após o envio da carta convite em dezembro de 2009, planejou-se as datas para a implementação da intervenção educativa para os meses de janeiro e fevereiro de 2010. Inicialmente foram marcados dois encontros e encaminhado convite formal pelo correio para todos os pacientes que ainda permaneciam na lista de espera, desde a realização da primeira fase deste estudo.

Em um primeiro momento, os 55 pacientes que participaram da primeira fase do estudo, seriam convidados para participar da segunda fase. Entretanto, passados seis meses do término do estudo descritivo, uma parte dos pacientes foi excluída da segunda fase, por três razões distintas, a saber: a recuperação da função hepática, a realização do transplante de fígado e o falecimento. Desse modo, nove $(16,36 \%)$ pacientes realizaram o transplante de fígado, sete $(12,73 \%)$ apresentaram melhora da função hepática e foram excluídos da lista de espera e três $(5,45 \%)$ faleceram antes de realizar o transplante, somando-se 19 (34,55\%) exclusões para a segunda fase da pesquisa.

Foram então programados o local no qual seria realizada a intervenção e a organização de um lanche em virtude do tempo que seria necessário para a implementação da intervenção educativa. Por se localizar próximo à Unidade de Transplante de Fígado, optou-se por realizar os encontros no anfiteatro do Departamento de Cirurgia e Anatomia da FMRP-USP, com a anuência do Chefe do Departamento.

No terceiro dia anterior ao dia da intervenção realizou-se contato telefônico prévio, com todos os 36 pacientes aptos a compor a amostra da segunda fase deste trabalho. Dos 36 telefonemas realizados, foram obtidas 16 confirmações de participação. Destes, apenas um paciente não pode comparecer na intervenção, totalizando uma amostra inicial de 15 pacientes.

Frente ao exposto, tratando-se de um estudo quase-experimental cujo tamanho amostral é relevante, optou-se por planejar uma segunda intervenção (outros dois encontros) com os pacientes que não puderam participar da primeira convocação da segunda fase do estudo. Novamente foi realizado contato telefônico 
com todos os outros 21 pacientes aptos a compor a amostra. Destes, oito pacientes confirmaram participação nas reuniões propostas, no entanto, apenas quatro compareceram de fato no dia da intervenção. Diante das dificuldades apresentadas pelos pacientes para participarem da intervenção educativa, o estudo piloto foi composto por 19 pacientes. O Quadro 10 sumariza a trajetória da constituição da amostra da segunda fase do presente estudo.

Dos 19 pacientes, ou seja, 34,55\% em relação à amostra inicial, que participaram da segunda fase da pesquisa, $16(84,21 \%)$ eram homens e três $(15,79 \%)$ eram mulheres. A média de idade foi de $52,84 \pm 7,57$ anos; $14(73,68 \%)$ nasceram em área urbana e cinco (26,32\%) em área rural; 15 (78,95\%) eram casados ou amasiados, dois (10,53\%) divorciados e dois (10,53\%) viúvos; 16 $(84,21 \%)$ eram católicos, dois $(10,53 \%)$ evangélicos e um $(5,26 \%)$ espírita; 12 $(63,16 \%)$ eram aposentados e os outros sete $(36,84 \%)$ apresentavam diversas profissões. 

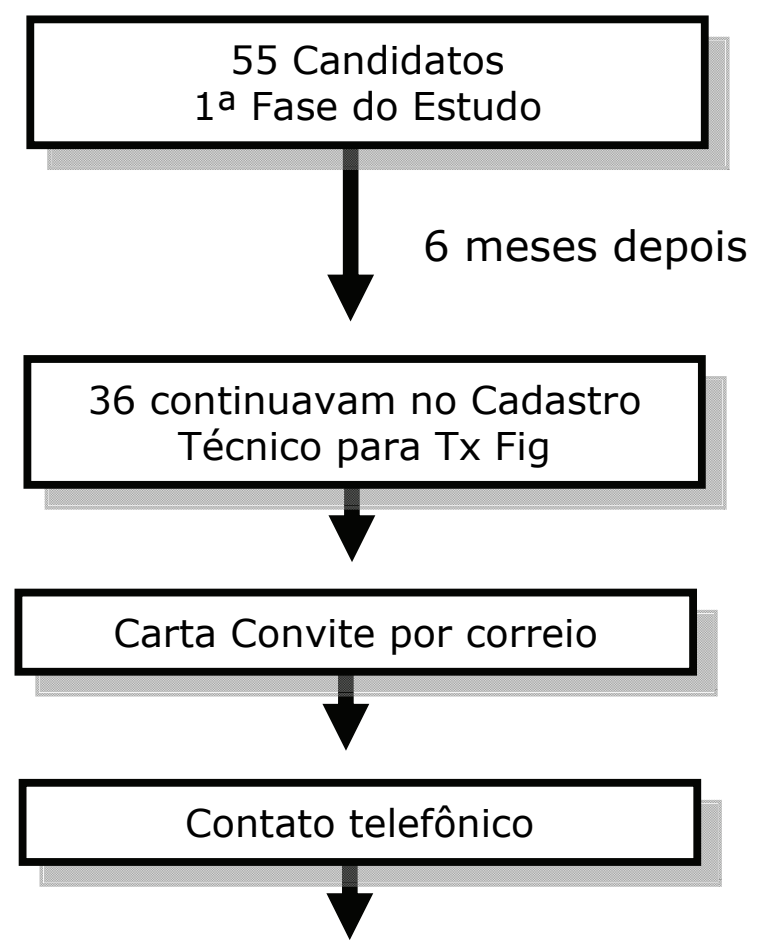

24 confirmações

15 Participaram (10 grupo)

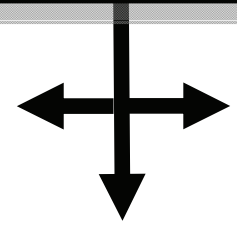

4 Participaram (20 grupo)

19 candidatos fizeram parte da $2^{a}$ Fase do Estudo

Quadro 10 - Trajetória da constituição da amostra do estudo piloto

O número de filhos variou de zero a nove, atingindo a média de 3,00 $\pm 1,94$ filhos por paciente. Dos 19 pacientes, apenas quatro $(21,05 \%)$ estavam trabalhando ativamente, sendo que os outros 15 (78,95\%) estavam afastados. Dentre os afastados, o tempo médio de afastamento do trabalho era de 53,47 $\pm 29,35$ meses, sendo o mínimo de 12 e o máximo de 120 meses longe de atividades laborais. A média de anos de estudo era de 7,53 $\pm 3,82$ anos, sendo o mínimo de três e o máximo de 15 anos de estudo. Em relação à renda familiar, apenas um paciente não recebia qualquer tipo de renda, sete $(36,84 \%)$ recebiam um salário mínimo, cinco $(26,32 \%)$ de dois a três salários mínimos, dois $(10,53 \%)$ recebiam de três a quatro salários, dois $(10,53 \%)$ de cinco a seis salários e dois $(10,53 \%)$ recebiam mais do que oito salários mínimos. 
Em relação às condições clínicas dos pacientes, três $(15,79 \%)$ eram CHILD A, 15 (78,95\%) eram CHILD B e um (5,26\%) era CHILD C. Quanto à gravidade apenas um $(5,26 \%)$ paciente tinha MELD maior do que 18 ; os outros $18(94,74 \%)$ apresentavam MELD entre 11 e 18, sendo a média de 15,16 $\pm 2,06$. Com relação ao diagnóstico médico, quatro $(21,05 \%)$ tinham cirrose hepática causada pelo álcool, 13 $(68,42 \%)$ tinham cirrose hepática causada pelo vírus da hepatite (cinco deles também associados ao etilismo), um $(5,26 \%)$ possuía cirrose hepática criptogenética e o outro $(5,26 \%)$ esteatohepatite não alcoólica (NASH).

A média de tempo na fila de espera para o transplante de fígado foi de $1247,53 \pm 661,78$ dias, sendo o mínimo de 58 dias e o máximo de 2497 dias. Dos 19 pacientes, $16(84,21 \%)$ receberam informações prévias sobre o transplante de fígado, sendo a equipe de transplante a maior fonte de informações $(57,89 \%$ dos pacientes); apenas seis $(31,58 \%)$ pacientes informaram ter o folheto informativo como fonte de informações, apesar de 14 (73,68\%) deles terem informado a leitura prévia do manual.

A Tabela 9 mostra uma visão geral da distribuição dos pacientes de acordo com as características demográficas, apresenta ainda os índices de acertos e erros do questionário aplicado antes da intervenção educativa.

Os pacientes obtiveram médias de 10,37 $\pm 3,06$ acertos e 6,63 $\pm 3,06$ erros, em relação às 17 questões que compunham o questionário de conhecimento sobre o transplante de fígado, sendo a porcentagem global de acertos de 60,99\%. O mínimo e máximo de acertos pelos pacientes foi de três a 15 questões respectivamente. 


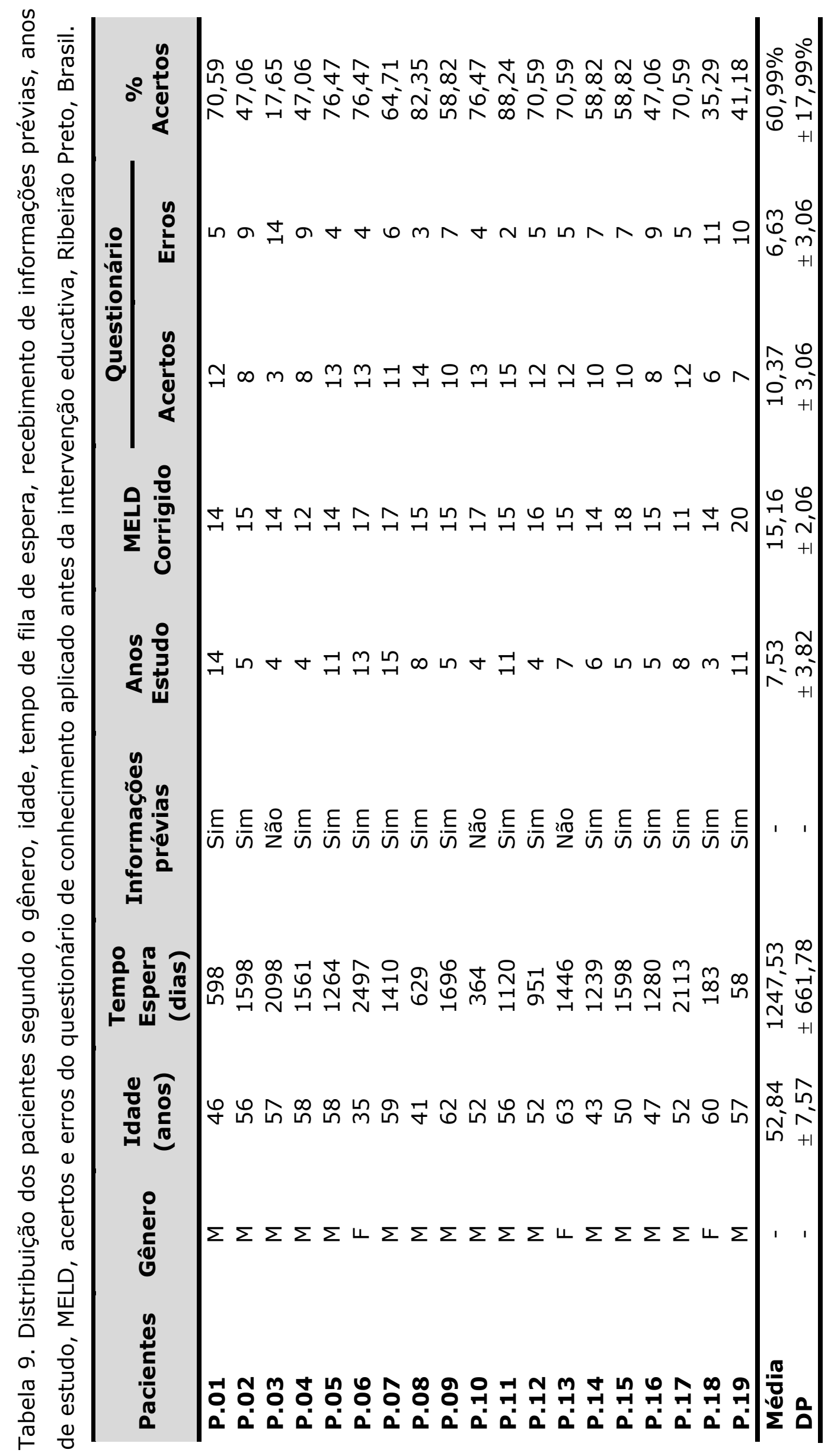


A análise de dados demonstrados na Tabela 9 permitiu observar que os pacientes com idade até 55 anos apresentaram maiores índices de acertos (67,97\%) quando relacionados com pacientes com mais de 55 anos de idade $(54,71 \%)$, embora tal diferença não tenha atingido significância estatística ( $p=0,1103$, teste $t$ de Student). A análise de correlação de Pearson revelou apenas uma tendência de correlação negativa entre porcentagem de acertos e idade (coeficiente de correlação de Pearson: $r=-0,3310 ; p=0,1663)$. Por outro lado, observou-se correlação positiva significativa entre a porcentagem de acertos e anos de estudo (correlação para postos de Spearman: $r_{S}=0,4899 ; \boldsymbol{p}=\mathbf{0 , 0 3 3 2}$ ). Entretanto, quando os candidatos são estratificados de acordo com o nível de ensino, observa-se que os candidatos que possuíam apenas o ensino fundamental, apresentaram índices de acertos menores $(57,01 \%)$, quando comparados com candidatos com nível médio, superior ou pós-graduação $(69,61 \%)$, embora tal diferença não seja significativa ( $p$ $=0,1619$, teste $t$ de Student).

O tempo de fila de espera não mostrou correlação com os índices de acertos dos pacientes (coeficiente de correlação de Pearson: $r=-0,0298 ; p=0,9036$ ), uma vez que os candidatos que estavam na fila até dois anos, apresentaram índice médio de acertos de $61,18 \%$, enquanto que os pacientes que estavam entre dois e cinco anos apresentaram índice de $62,57 \%$ e os pacientes com mais de cinco anos na fila, $54,90 \%$ de acertos ( $p=0,9900$, teste de Kruskal-Wallis). Na análise chamou a atenção que, quando se comparou os candidatos quanto a sua gravidade, ou seja, valores do MELD corrigido, os pacientes com MELD até 14 pontos, tiveram índices de $53,78 \%$ de acertos, enquanto que os pacientes com MELD maior do que 14 pontos tiveram $65,20 \%$ de acertos ( $p=0,1899$, teste $t$ de Student). Apesar de tal diferença visível, o MELD não mostrou correlação com os índices de acertos dos pacientes (coeficiente de correlação de Pearson: $r=0,0343 ; p=0,8891$ ).

Em relação aos índices de acertos e erros do questionário de conhecimento sobre o transplante de fígado, a Tabela 10 mostra a pontuação de cada uma das 17 questões. As questões de número um a oito estavam relacionadas com o período pré-operatório do transplante de fígado; as questões de número nove a onze estavam relacionadas com o período intra-operatório e as questões de número 12 a 17 com o período pós-operatório do transplante de fígado. As questões que obtiveram maiores índices de acertos foram as de $n^{\circ} 17(100 \%)$, seguida pela de $n^{\circ}$ $5(94,74 \%)$ e de $n^{\circ} 12(89,47 \%)$. A questão $n^{\circ} 17$ dizia respeito aos fatores que iriam contribuir para o sucesso do transplante de fígado. A questão $\mathrm{n}^{\circ} 5$ era 
relacionada com as responsabilidades do candidato durante o período de espera para o transplante. E a questão $\mathrm{n}^{\circ} 12 \mathrm{com}$ o período pós-operatório imediato e mediato.

Tabela 10. Distribuição dos acertos e erros do questionário de conhecimento aplicado antes da intervenção educativa nos candidatos ao transplante de fígado, Ribeirão, Preto, Brasil.

\begin{tabular}{|c|c|c|c|c|}
\hline & \multirow[t]{2}{*}{ Questões } & \multicolumn{2}{|c|}{$\begin{array}{c}\text { Candidatos } \\
(n=19)\end{array}$} & \multirow{2}{*}{$\begin{array}{c}\text { Porcentagem } \\
\text { de } \\
\text { Acertos }\end{array}$} \\
\hline & & Acertos & Erros & \\
\hline \multirow{8}{*}{$\begin{array}{l}\mathbf{r} \\
\text { é }\end{array}$} & Q.01 & 13 & 6 & $68,42 \%$ \\
\hline & Q.02 & 13 & 6 & $68,42 \%$ \\
\hline & Q.03 & 15 & 4 & $78,95 \%$ \\
\hline & Q.04 & 12 & 7 & $63,16 \%$ \\
\hline & Q.05 & 18 & 1 & $94,74 \%$ \\
\hline & Q.06 & 13 & 6 & $68,42 \%$ \\
\hline & Q.07 & 15 & 4 & $78,95 \%$ \\
\hline & Q.08 & 8 & 11 & $42,11 \%$ \\
\hline \multirow{3}{*}{ Intra } & Q.09 & 14 & 5 & $73,68 \%$ \\
\hline & Q.10 & 13 & 6 & $68,42 \%$ \\
\hline & Q.11 & 12 & 7 & $63,16 \%$ \\
\hline \multirow{7}{*}{$\begin{array}{l}\text { P } \\
\text { ó } \\
\text { S }\end{array}$} & Q.12 & 17 & 2 & $89,47 \%$ \\
\hline & Q.13 & 2 & 17 & $10,53 \%$ \\
\hline & Q.14 & 4 & 15 & $21,05 \%$ \\
\hline & Q.15 & 3 & 16 & $15,79 \%$ \\
\hline & Q.16 & 6 & 13 & $31,58 \%$ \\
\hline & Q.17 & 19 & 0 & $100 \%$ \\
\hline & $\begin{array}{c}\text { Média } \\
\text { Desvio Padrão }\end{array}$ & $\begin{array}{r}11,59 \\
\pm 5,18\end{array}$ & $\begin{array}{r}7,41 \\
\pm 5,18 \\
\end{array}$ & $\begin{array}{r}60,99 \% \\
\pm 27,29 \% \\
\end{array}$ \\
\hline
\end{tabular}

As questões que obtiveram os menores índices de acertos foram as de número $n^{\circ} 13(10,53 \%)$, seguidas pelas de $n^{\circ} 15(15,79 \%), n^{\circ} 14(21,05 \%)$ e a de $n^{\circ} 16$ $(31,58 \%)$. Todas as quatro questões estavam relacionadas com o período após o transplante de fígado. A questão $\mathrm{n}^{\circ} 13$ tratava sobre os medicamentos imunossupressores utilizados após o transplante de fígado, a questão 14 se referia às complicações após o transplante de fígado, a questão $\mathrm{n}^{\circ} 15$ era relativa aos cuidados necessários após o transplante de fígado e a questão $n^{\circ} 16$ voltada para 
aspectos da qualidade de vida após o transplante. A análise permitiu afirmar que todas as questões referentes ao pós-operatório estiveram entre aquelas que apresentaram maior índice de acertos (questões 17 e 12) e as com menor índice de acertos (questões 13, 15, 14, e 16).

Em relação ao conhecimento dos pacientes relacionado ao período anterior ao transplante de fígado (pré-operatório), as oito questões referentes a esse aspecto, abordavam: as funções do fígado (Q. 01 - 68,42\% de acertos), aspectos históricos do transplante de fígado (Q. 02 - 68,42\% de acertos), os cuidados necessários durante o período de espera (Q. 03 - 78,95\% de acertos), os sinais e sintomas da doença do fígado (Q. 04 - 63,16\% de acertos), a atuação da equipe de transplante (Q. 05 - 94,74\% de acertos), o funcionamento do cadastro técnico de fígado e o MELD (Q. 06 - 68,42\% de acertos), o sistema de distribuição de órgãos (Q. 07 $78,95 \%$ de acertos), e as indicações e contra-indicações para o transplante (Q. 08 $42,11 \%$ de acertos).

Quanto ao conhecimento do paciente relacionado ao dia do transplante de fígado foram formuladas três questões, que englobavam: aspectos do dia do transplante (Q. 09 - 73,68\% de acertos), aspectos do doador de fígado (Q.10 $68,42 \%$ de acertos) e aspectos da cirurgia e anestesia (Q. 11 - 63,16\% de acertos). É interessante dizer que, em relação a Q. 10 sobre o doador de fígado, dentre os erros de conceitos, três pacientes $(15,79 \%)$ acreditavam que o doador deveria ser do mesmo sexo que o receptor. Esse é um mito relativamente comum entre os pacientes que aguardam transplantes de órgãos.

Para avaliar o conhecimento dos pacientes no período pós-operatório imediato e tardio do transplante, seis questões foram formuladas. Essas questões eram sobre a internação em unidade de terapia intensiva e enfermaria: (Q. 12 - 89,47\% de acertos), medicamentos utilizados após o transplante de fígado (Q. 13 - 10,53\% de acertos), complicações após o transplante (Q. 14 - 21,05\% de acertos), cuidados necessários após o transplante (Q. 15 - 15,79\% de acertos e Q. 17 - 100\% de acertos) e qualidade de vida após o transplante (Q. 16 - 31,58\% de acertos).

De uma maneira geral, os pacientes tiveram maiores índices de acertos para as questões voltadas ao período pré-operatório do transplante $(70,40 \%$ de acertos), seguida do período intra-operatório $(68,42 \%)$ e pós-operatório (44,74\%). Entretanto, a taxa de acertos de questões não difere significantemente entre os três períodos ( $p=0,4560$, teste de Kruskal-Wallis). A Tabela 11 mostra a relação das 
necessidades de informação levantadas na primeira fase desta pesquisa, com os índices de acertos do questionário de conhecimento de transplante de fígado, de acordo com as fases do período perioperatório. De acordo com a pontuação média, observa-se que apesar dos pacientes expressarem necessidade maior de serem informados sobre questões relativas ao período pré-operatório, eles obtiveram índices maiores de acertos em questões sobre este período. Entretanto, se considerarmos o número médio de votos, observa-se uma maior necessidade de informações sobre o período pós-operatório, o que é consistente com os menores índices de acertos em questões sobre este período.

Tabela 11. Distribuição das médias de pontuação referentes às necessidades de informação (N.I.) e de acertos no questionário de conhecimento, segundo os períodos pré, intra e pós-operatório do transplante de fígado, Ribeirão Preto, Brasil.

\begin{tabular}{|c|c|c|c|c|c|c|}
\hline \multirow[b]{2}{*}{ N.I. } & \multirow{2}{*}{$\begin{array}{c}(n=19) \\
\text { Média } \\
\text { pontuação }\end{array}$} & \multirow[b]{2}{*}{$\begin{array}{l}\text { Média } \\
\text { votos }\end{array}$} & \multirow[b]{2}{*}{ Questões } & \multicolumn{2}{|c|}{$(n=19)$} & \multirow{2}{*}{$\begin{array}{c}\% \\
\text { Acertos }\end{array}$} \\
\hline & & & & Acertos & Erros & \\
\hline Pré & 3,69 & 11,00 & Pré & 13,38 & 5,62 & 70,40 \\
\hline Intra & 2,49 & 10,67 & Intra & 13,00 & 6 & 68,42 \\
\hline Pós & 3,00 & 11,67 & Pós & 8,50 & 10,50 & 44,74 \\
\hline
\end{tabular}

Diante da proposta de realizar dois encontros na segunda fase do presente estudo, apenas 15 pacientes puderam participar de todo o processo (primeiro e segundo encontros). Dos quatro pacientes excluídos (P.1; P.2, P.16 e P.19), um foi transplantado, um faleceu, um estava com encefalopatia hepática no momento do segundo encontro e um faltou sem justificativa. A partir de agora será mostrada a análise de acertos e erros dos questionários destes 15 pacientes remanescentes.

$\mathrm{Na}$ análise dos índices de acertos depois da intervenção educativa (Tabelas 12 e 13) foi possível observar um aumento global de acertos na margem de 2,13 questões $(12,55 \%)$ após a intervenção, o que leva a uma melhora média de desempenho equivalente a 19,75\% (valor obtido pela razão entre o aumento global $12,55 \%$ - e a porcentagem de acertos no questionário de conhecimento antes da intervenção - 63,53\%).

Antes da intervenção os pacientes tiveram 63,53\% de acertos e depois da intervenção esse índice subiu para 76,08\% de acertos (Tabela 12). Tal diferença se mostrou estatisticamente significante tanto em teste monocaudal $(\boldsymbol{p}=\mathbf{0 , 0 1 1 7}$, 
teste $t$ de Student monocaudal para amostras pareadas) quanto em teste bicaudal ( $\boldsymbol{p}$ $=\mathbf{0 , 0 2 3 4}$, teste $t$ de Student monocaudal para amostras pareadas). Vale ressaltar que o número de pacientes que obtiveram índices de acertos inferiores a $80 \%$ foi reduzido de $13(86,67 \%)$ antes da intervenção, para apenas seis (40\%) após a intervenção. Dois pacientes $(13,33 \%)$ apresentaram uma diminuição dos acertos após a intervenção, sendo que um dos pacientes estava preocupado com o auxílio que receberia para retornar ao seu município e o outro havia se esquecido dos óculos, sendo necessário auxiliá-lo durante o preenchimento do questionário. Outros dois pacientes apresentaram o mesmo desempenho antes e após a intervenção.

$\mathrm{Na}$ análise dos acertos e erros das 17 questões que compunham o questionário de conhecimento (Tabela 13), novamente observa-se diferença estatisticamente significante tanto em teste monocaudal ( $\boldsymbol{p}=\mathbf{0 , 0 0 4 3}$, teste $t$ de Student monocaudal para amostras pareadas) quanto em teste bicaudal ( $\boldsymbol{p}=$ 0,0086, teste $t$ de Student monocaudal para amostras pareadas). Apenas as questões $n^{\circ} 02, n^{\circ} 05, n^{\circ} 07, n^{\circ} 12$ e $n^{\circ} 17$, não tiveram aumento na porcentagem de acertos após a intervenção. De uma forma geral, apenas questões relacionadas ao período pós-operatório ( $\mathrm{n}^{\circ} 13, \mathrm{n}^{\circ} 14$ e $\mathrm{n}^{\circ}$ 16) experimentaram aumento significativo (teste exato de Fisher monocaudal). Verificou-se também que nenhuma questão obteve $100 \%$ de acertos após a intervenção educativa, como havia ocorrido com a Q.17 antes da intervenção. As questões que apresentaram índices maiores de acertos após a intervenção foram Q. 01, Q. 03, Q. 04 e Q. 09. A Q.15 foi a que obteve índice maior de erros após a intervenção, sendo que $66,67 \%$ dos pacientes erraram esta questão. 


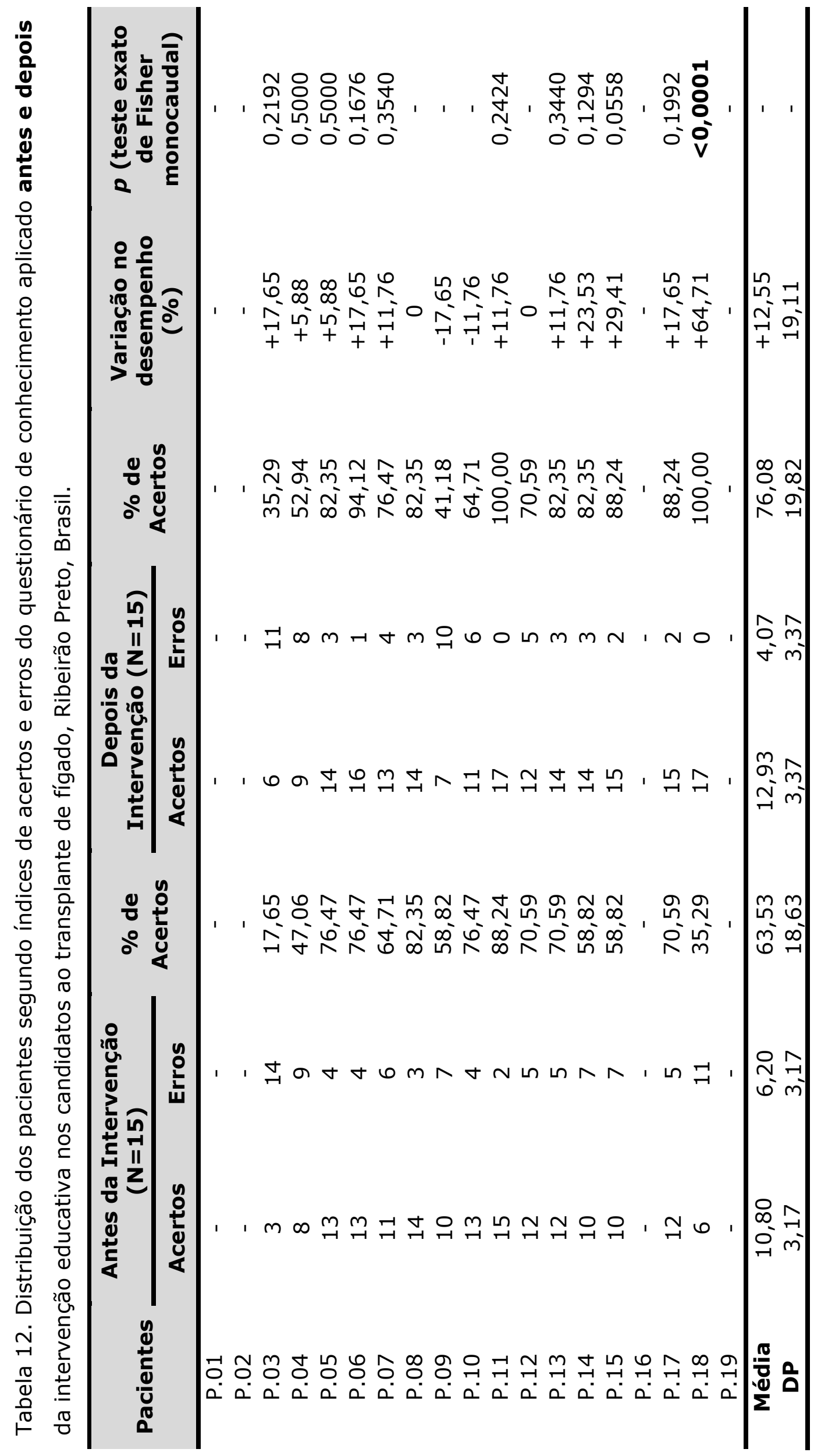




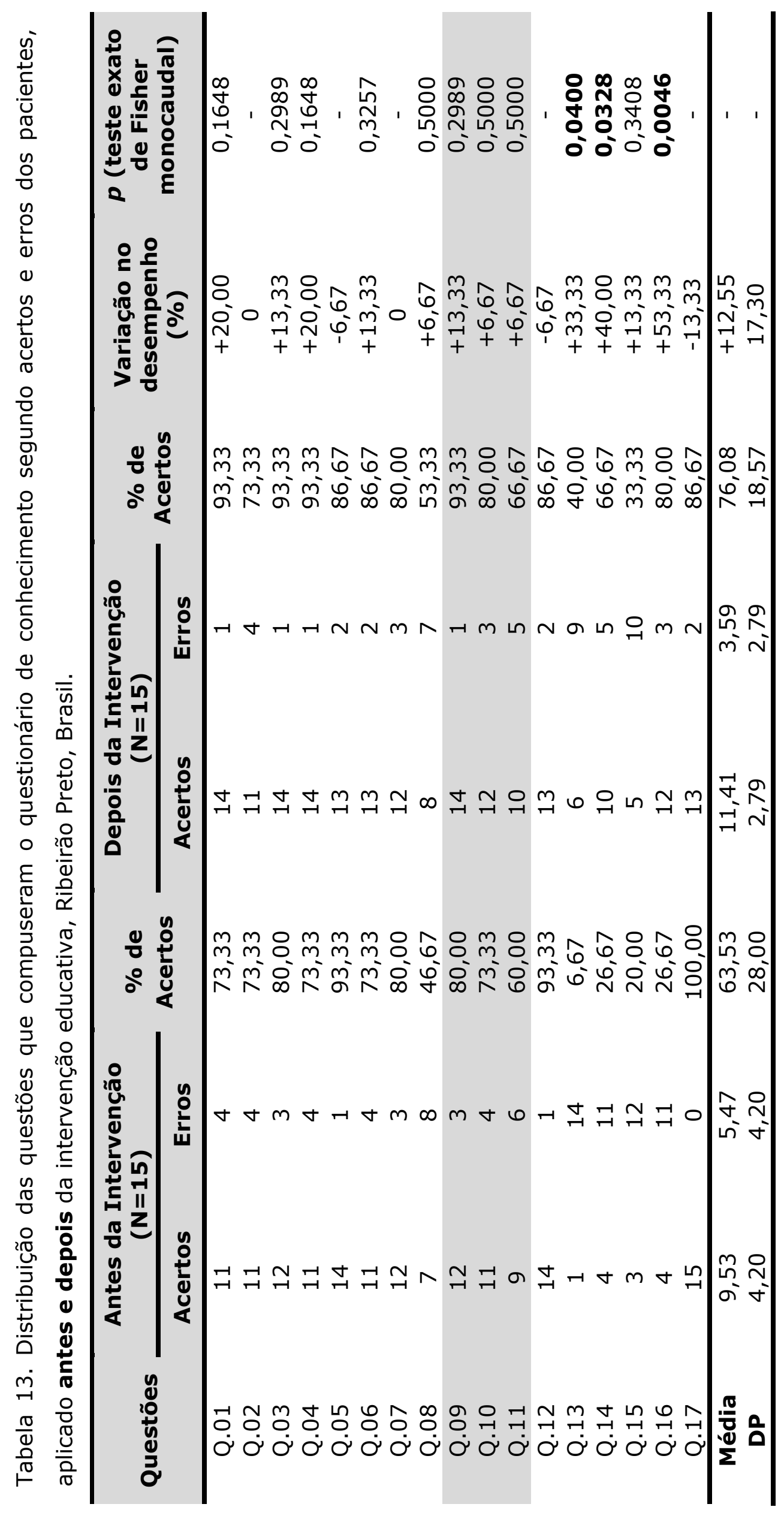


6.2.2 Satisfação dos candidatos após a implementação da intervenção educativa

A satisfação pode ser vista como uma reação que as pessoas apresentam diante de um contexto, processo ou resultado global de sua experiência relativa a um serviço (PASCOE, 1983). No presente estudo foi construído e validado um questionário para mensurar a satisfação com as informações recebidas após a implementação da intervenção educativa para os candidatos ao transplante de fígado.

Assim, utilizou-se uma escala do tipo Likert para classificar (de zero a 10) as informações recebidas sobre o período de espera, a cirurgia e anestesia, o período pós-operatório, os cuidados por toda a vida, a qualidade das informações recebidas, as aulas dialogadas e o aumento das informações com o programa educativo, com um escore total de 70 pontos. Apenas uma questão era do tipo aberta, na qual o paciente recomendaria ou não o programa educativo para outros pacientes, com espaço para tecer justificativas sobre sua resposta caso sentisse necessidade.

A avaliação global do instrumento de satisfação (Tabela 14) mostrou uma média de 64,93 \pm 4,83 pontos, sendo o mínimo e o máximo de 53 e 70 pontos. Todos os itens observados apresentaram uma avaliação positiva, com uma média de 9,28 pontos para todos os sete itens avaliados. Os itens que obtiveram o maior índice de satisfação dos pacientes foram as informações recebidas sobre o período pós-operatório (média de 9,60 pontos) e os cuidados por toda a vida (média de 9,60 pontos). $O$ item que obteve $o$ índice menor de satisfação foi relacionado com a percepção de aumento das informações pelos pacientes (média de 8,87 pontos). 


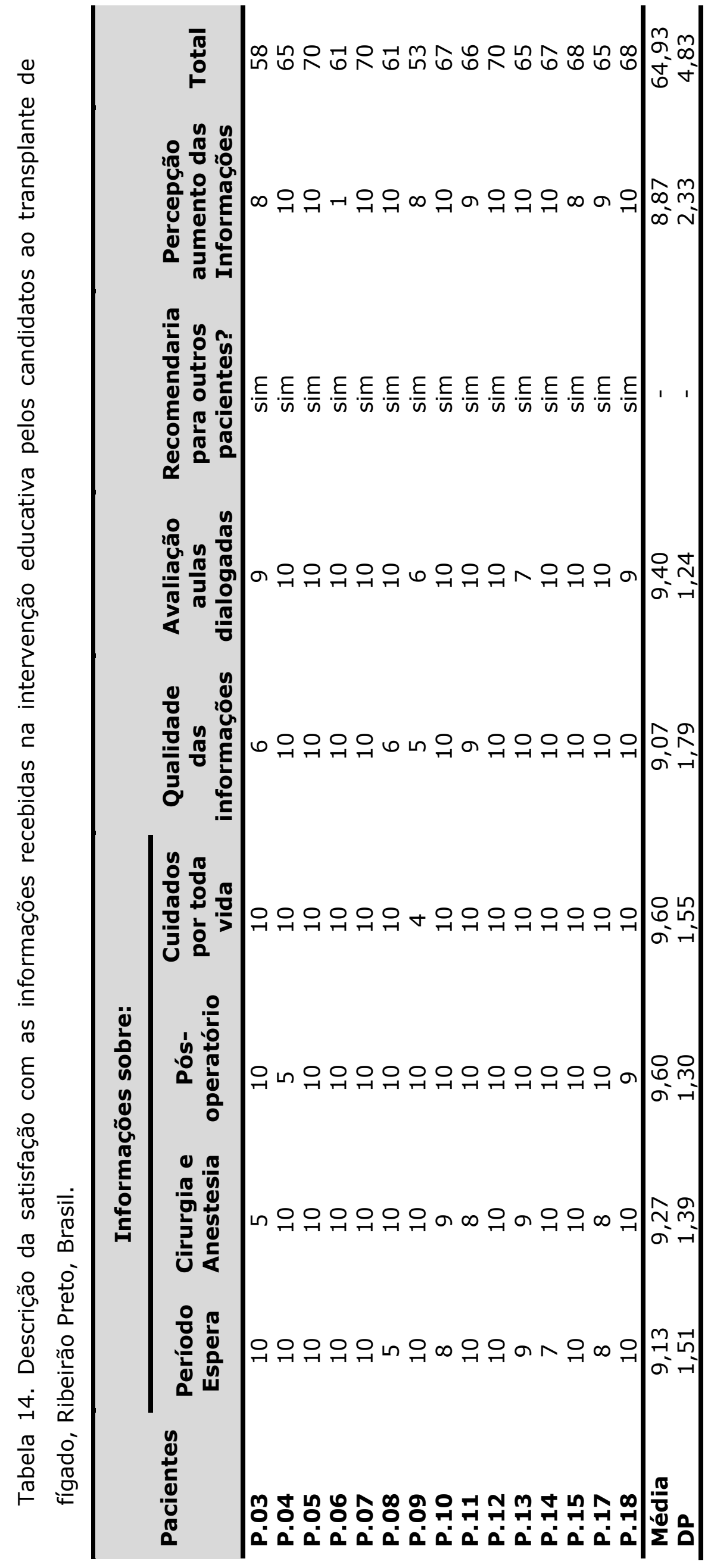


Quando os pacientes foram questionados se recomendariam ou não o programa educativo para outros candidatos ao transplante de fígado, foi unânime a avaliação positiva dentre os candidatos, sendo que $100 \%$ dos pacientes recomendariam a intervenção educativa para outros pacientes. Dentre as justificativas dos pacientes, destacamos os seguintes relatos:

"Ótimas aulas" (P.03)

"Sem as informações não seria possível fazer o transplante" (P.05)

"Pois ajuda-nos a compreender melhor a doença e como nós podemos evitar piora da saúde e ter uma vida mais saudável, e nos tranqüiliza muito" (P.06)

"Recomendo porque tira muitas dúvidas no transcorrer do início até a cirurgia" (P.07)

"Para que as pessoas saibam mais sobre o antes, durante e depois do transplante, e principalmente depois que é a parte mais difícil" ( $P .08)$

"Algumas pessoas que estão na fila e precisam de um transplante às vezes lêem muito pouco e não procuram se informar sobre o assunto. Estas aulas educativas feitas por alguém competente vão colocar as mesmas a par de tudo sobre o assunto" (P.11)

"Para tirar dúvidas que as pessoas têm e sempre aprender mais coisas" (P.13)

"Por esclarecer todos os pontos de dúvidas" (P.15)

"Para as pessoas terem a informação correta e adequada" (P.18) 


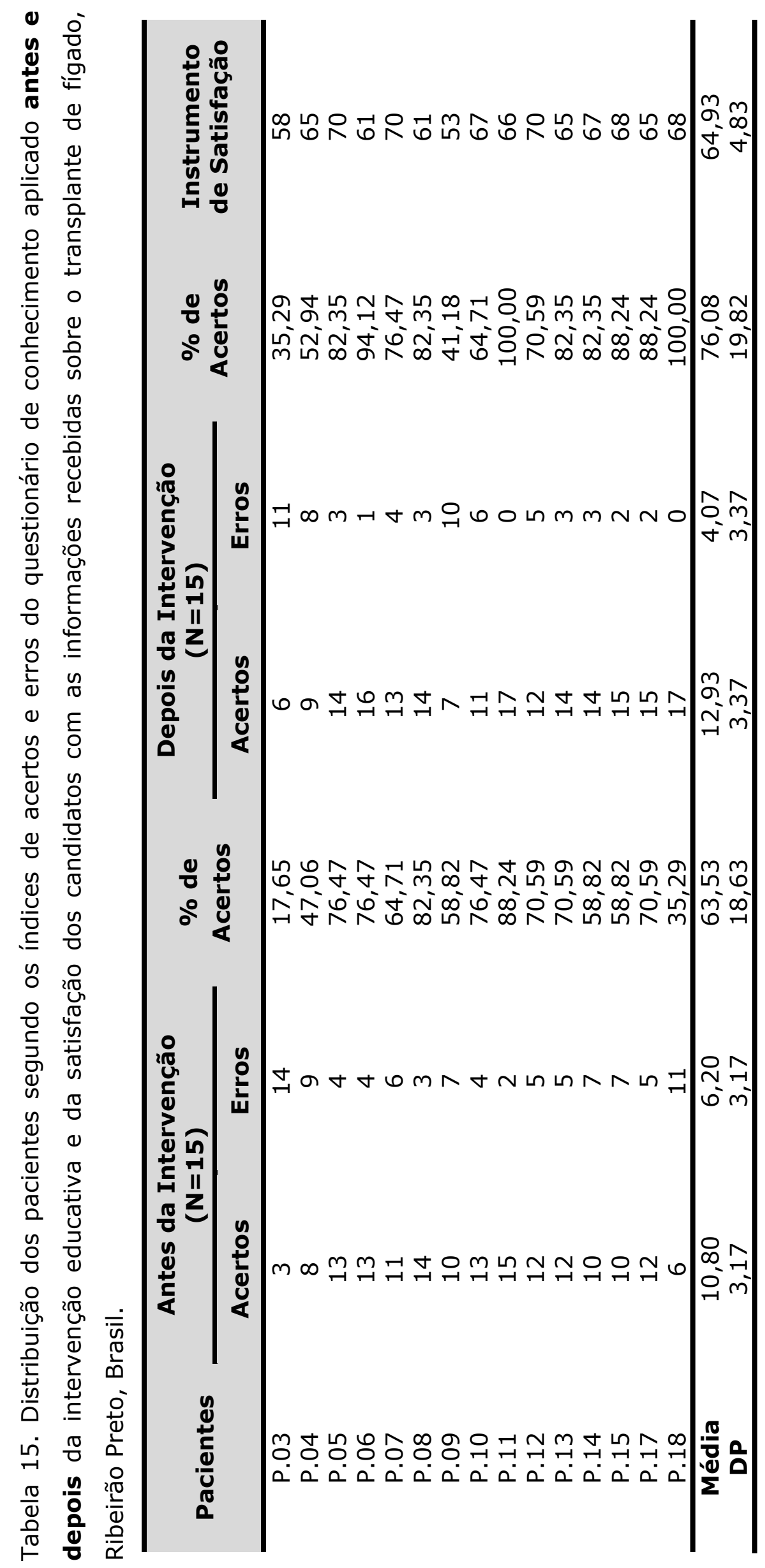


Para finalizar, mostramos na Tabela 15 uma comparação entre a satisfação e os índices de acertos e erros do questionário de conhecimento aplicado antes e depois da intervenção educativa. Observou-se que a pontuação do instrumento de satisfação apresentou correlação significativa com a porcentagem de acertos após a intervenção educativa (coeficiente de correlação de Pearson: $r=0,5481 ; \boldsymbol{p}=$ 0,0344), mas não com o desempenho inicial (coeficiente de correlação de Pearson: $r$ $=0,2371 ; p=0,3948)$ e tampouco com uma melhora no desempenho após a intervenção (coeficiente de correlação de Pearson: $r=0,3387 ; p=0,2169$ ).

De uma maneira geral, os resultados do presente estudo piloto mostraram que os candidatos tiveram um ganho de conhecimento no que se refere às informações do pré, intra e pós-operatório do transplante de fígado. Observou-se também uma satisfação positiva com a intervenção educativa, demonstrada com os altos índices obtidos pelo instrumento de satisfação aplicada após a intervenção. 


\section{Discussão}

\subsection{Discussão do delineamento de pesquisa não experimental: estudo descritivo}

\subsubsection{Caracterização da amostra do estudo}

O primeiro transplante de fígado foi realizado por Thomas Starzl em 1963; entretanto, o sucesso desta cirurgia ocorreu apenas em 1967. O regime imunossupressor era baseado no uso de corticosteróides e azatioprina e os resultados iniciais eram modestos. O refinamento das técnicas cirúrgicas, o melhor entendimento do cuidado clínico de doadores e receptores, e o descobrimento da ciclosporina proporcionaram uma melhora significante dos resultados dos transplantes para o tratamento de doença terminal do fígado. O desenvolvimento da solução de conservação em 1988 permitiu melhora e prolongamento da preservação do enxerto e adicionalmente o surgimento de outros imunossupressores contribuíram para resultados ainda melhores (MEHTA; MIRZA, 2008; VARO PEREZ; CASTROAGUDIN, 2010).

A meta do transplante de fígado é prolongar a vida e melhorar a qualidade de vida dos pacientes com doença do fígado avançada (aguda ou crônica) (VARO PEREZ; CASTROAGUDIN, 2010). A seleção e a avaliação adequadas do candidato para o transplante de fígado contribuem para melhores resultados. Os pacientes são incluídos em lista para transplante após uma completa avaliação realizada por uma equipe multidisciplinar. A incidência de complicações pós-operatórias é influenciada pela qualidade do fígado do doador, aspectos técnicos da cirurgia e fatores relacionados com os receptores (MEHTA; MIRZA, 2008).

Para serem incluídos em uma lista de espera, os candidatos evoluem com uma descompensação hepática irreversível (sangramento de varizes, ascite, peritonite bacteriana, encefalopatia, síndrome hepatorrenal, síndrome hepatopulmonar, câncer) ou com uma diminuição severa da qualidade de vida associada à doença hepática (MEHTA; MIRZA, 2008).

O número de transplantes de fígado realizado tem crescido mundialmente nos últimos 20 anos. Contudo, tem ocorrido um aumento do número de pacientes aguardando em fila de espera a realização da cirurgia, conseqüentemente, uma desproporção entre o número de órgãos disponíveis para o transplante e o número de potenciais receptores. A mortalidade durante o período de espera para o 
transplante de fígado ou exclusões devido à progressão irreversível da doença hepática são conseqüências obvias de tamanha desproporção (VARO PEREZ; CASTROAGUDIN, 2010).

Uma vez que o candidato é incluído em uma fila de espera, a maioria dos pacientes é removida por três razões principais, sendo elas a realização do transplante, morte ou mudança no quadro clínico. Uma análise descritiva de resultados de transplante de fígado, morte e causas de exclusão em lista de espera realizada na Espanha de 2002 a 2009 mostrou que de 254 pacientes incluídos em lista de espera, $87,4 \%$ foram transplantados, 2,8\% faleceram durante o período de espera e 9,8\% foram excluídos. Desses pacientes que foram excluídos, 52\% apresentaram recuperação da função hepática e $48 \%$ foram excluídos devido à progressão do carcinoma hepatocelular, septicemia, uso de álcool, condições clínicas e câncer colorretal (CADAHIA et al., 2010).

O MELD tem sido utilizado pelas Organizações de Procura de Órgãos (OPO) como uma base para a alocação de doadores falecidos de fígado para transplante entre adultos, no Brasil, desde julho de 2006. Esse modelo é baseado em um critério objetivo para classificar candidatos, priorizando pacientes de acordo com a urgência médica, não importando o tempo de lista de espera. O MELD foi rigorosamente validado para avaliar o risco de mortalidade entre os pacientes com doença crônica do fígado. $\mathrm{O}$ uso deste modelo tem reduzido a mortalidade em fila de espera com a realização do transplante de acordo com a gravidade do candidato (TENORIO et al., 2010). Após a coleta de dados da primeira fase do presente estudo, os critérios de inclusão relacionados aos valores de MELD sofreram nova modificação, de modo que apenas pacientes com MELD a partir de 15 são incluídos em lista, exceto no caso de situações especiais.

Nos transplantes de órgãos sólidos atuais, doadores em geral não podem ser alocados de acordo com o gênero dos candidatos, uma vez que não há suficiente número de doadores disponíveis (CSETE, 2008). Entretanto, diferenças relacionadas ao gênero nos resultados dos enxertos e receptores de fígado tem sido foco de alguns estudos (YAMAKAWA et al., 1996; BAKR et al., 2006). Em geral, os homens apresentam mais doenças do fígado do que mulheres (CSETE, 2008), o que corrobora com os resultados do presente estudo.

O transplante de fígado é uma modalidade terapêutica que tem oferecido um prolongamento da sobrevida para adultos com doença hepática em estágio final. 
Como um resultado da melhora de sobrevida, a demanda para o transplante de fígado em pessoas idosas tem aumentado. Contudo, apesar da melhora de sobrevida entre idosos submetidos ao transplante, a idade ainda é considerada uma barreira para os diversos centros transplantadores, possivelmente devido ao baixo número de doadores disponíveis para o transplante. Em uma análise multivariada realizada com 500 pacientes submetidos ao transplante de fígado na Itália observou-se que a idade dos candidatos não foi considerada um fator prognóstico negativo para a sobrevivência do enxerto e do paciente (ADANI et al., 2009). Na presente pesquisa, os resultados evidenciaram que mais de $75 \%$ dos pacientes tinham mais do que 50 anos de idade.

$\mathrm{Na}$ literatura alguns estudos sugerem a influência do grau de instrução com a evolução do período pré-transplante, bem como nos resultados do pós-transplante, sendo que os pacientes com maior grau de instrução apresentaram melhor evolução pré e pós-operatória (YOO et al., 2002; YOO; THULUVATH, 2004; GOETZMANN et al., 2006; DOBBELS et al., 2009). Nesses estudos a maioria dos pacientes tinha predominantemente ensino fundamental completo ou incompleto, o que vai de encontro com os resultados da presente pesquisa. Isso indica uma possível repercussão do nível de escolaridade com a adesão ao tratamento, frente às dificuldades de compreensão da terapêutica médica, podendo influenciar os resultados a curto e longo prazo.

No Brasil, mais de $80 \%$ da população vive na zona urbana. Nos Estados Unidos da América, aproximadamente $14 \%$ da população vive fora das grandes áreas urbanas. Os pacientes que vivem na zona rural e em pequenas cidades enfrentam múltiplas barreiras para o acesso à saúde, incluindo a necessidade de viajar longas distâncias, a falta de serviços especializados disponíveis na região, e dificuldades de seguimento médico. Os centros de transplantes são predominantemente alocados próximos a grandes centros urbanos. Para esses pacientes, a falta de acesso pode resultar em morte prematura e evitável. Um estudo recente demonstrou que os pacientes que viviam em regiões isoladas ou pequenos vilarejos apresentaram probabilidade menor de 10 a $20 \%$ na realização de transplantes de órgãos sólidos (AXELROD et al., 2008). Na amostra investigada $67,27 \%$ dos pacientes viviam em zona urbana.

Os candidatos que aguardam um transplante de fígado vivenciam significantes mudanças em suas vidas, tanto de ordem individual, quanto familiar e social. As mudanças de cunho social e emocional são diretamente afetadas pelas repercussões 
trazidas pela doença crônica do fígado (GUIMARO et al., 2008). Na literatura, estudos indicam que os aspectos psicossociais podem influenciar a adesão ao tratamento e os resultados do transplante (FLAMME; TERRY; HELFT, 2008; SANTOS JUNIOR et al., 2008; RODRIGUE et al., 2010). O afastamento das atividades laborais decorrente da incapacidade ocasionada pela doença crônica e a baixa renda familiar são fatores sociais importantes observados no presente estudo.

A história natural da doença dos pacientes deve ser cuidadosamente comparada com a antecipação de sobrevida após o transplante de fígado. As ferramentas clínicas utilizadas atualmente para avaliar o prognóstico de pacientes com doença crônica do fígado incluem a classificação de CHILD-Turcotte-Pugh e o MELD. A classificação de CHILD é útil para avaliar o risco relativo de mortalidade em pacientes com cirrose hepática; entretanto, essa classificação foi considerada um método subjetivo de avaliação do paciente para transplante (MOYLAN et al., 2008). A avaliação dos valores de MELD durante o tempo de espera para o transplante possibilita uma previsão de sobrevivência em curto prazo do paciente conforme as alterações das funções hepática e renal, baseadas em variáveis laboratoriais objetivas.

Esse modelo foi implantado nos Estados Unidos em 2002 a fim de priorizar a alocação de órgãos entre os candidatos com doença crônica de fígado (MURRAY; CARITHERS, 2005; BOURSIER et al., 2009; GALLEGOS-OROZCO; VARGAS, 2009). No Brasil, o MELD foi implantado apenas em 2006 pelo Sistema Nacional de Transplantes (MINISTÉRIO DA SAÚDE, 2006). Na presente investigação, 67,27\% dos pacientes eram CHILD B e 76,36\% tinham o MELD corrigido entre 11 e 18 pontos, o que indica um risco de mortalidade equivalente menor do que $10 \%$. Ressalta-se a importância de manter uma avaliação contínua dos pacientes que apresentam uma doença hepática crônica, com vistas à prevenção de complicações futuras. Mudanças do estilo de vida focadas na dieta, adesão da terapia medicamentosa, e privação de hábitos nocivos, tais como uso de bebida alcoólica, cigarro e drogas, são importantes para minimizar a progressão da doença, e deve ter atenção especial do enfermeiro coordenador de transplante em traçar estratégias que visem o cumprimento destas mudanças pelos candidatos.

Em contrapartida, os resultados do presente estudo mostraram um índice elevado de sobrepeso e obesidade entre os candidatos ao transplante. Na literatura, os resultados de uma pesquisa indicam que os pacientes obesos apresentam risco alto de morbidade e mortalidade após o transplante de fígado (PELLETIER et al., 
2007), sendo que alguns centros consideram a obesidade uma contra-indicação para a realização da cirurgia (THULUVATH, 2007; NAIR et al., 2009; THULUVATH, 2009; ZAYDFUDIM et al., 2009).

As indicações mais importantes para o transplante de fígado na Europa são a hepatite viral (24\%), doença alcoólica do fígado (20\%), doenças colestáticas do fígado (18\%) e carcinoma hepatocelular (10\%). Na doença alcoólica, um prérequisito para a realização do transplante na maioria dos centros é a abstinência alcoólica por pelo menos 6 meses. Em geral, pacientes com vírus da hepatite C, sofrem com recorrência da hepatite crônica e gradual progressão da cirrose nos 10 a 15 anos após o transplante (VERDONK et al., 2007). Na presente casuística, 27,27\% dos pacientes tiveram a causa viral, $25,45 \%$ o alcoolismo, e $20 \%$ dos casos tiveram uma associação do vírus da hepatite com o alcoolismo, como a principal etiologia da doença hepática crônica, o que corrobora com os resultados supracitados.

Devido à baixa demanda de órgãos ofertados para transplantes no Brasil, os candidatos ao transplante de fígado vivenciam prolongados períodos em fila de espera. Os resultados evidenciados nesta pesquisa corroboram essa afirmação uma vez que a amostra investigada apresentou a média e o desvio padrão de dias em fila de espera de 1199,58 \pm 742,31. Em contraste com outros países como, por exemplo, a Espanha onde o tempo de fila de espera é diminuído em virtude das inúmeras doações de órgãos para transplante. Uma das conseqüências do prolongado tempo de fila são os óbitos decorrentes das complicações da doença hepática crônica (JARRETT, 2009). Com o advento da Era MELD, os índices de óbitos entre candidatos têm diminuído gradativamente tanto no cenário nacional quanto no cenário internacional (ASRANI; KIM, 2010; CASTRO et al., 2010; TENORIO et al., 2010).

Indubitavelmente, a cirrose hepática e a hipertensão portal são os maiores responsáveis por muitas vidas perdidas em todo mundo, especialmente em áreas endêmicas de hepatite viral crônica. Apesar da patofisiologia da cirrose não ser completamente conhecida, as evidências acumuladas ao longo do tempo têm proporcionado um controle melhor de suas complicações, incluindo o sangramento de varizes esofágicas, encefalopatia hepática, ascite, síndrome hepatorrenal, síndrome hepatopulmonar e hipertensão portal. As terapias farmacológicas e intervencionistas são utilizadas para tratar estas complicações. No entanto, o transplante de fígado é o único tratamento capaz de curar estas complicações em pacientes com estágio final de doença hepática. Para garantir o sucesso no transplante de fígado, uma avaliação meticulosa do potencial receptor e doador são 
essenciais (HUANG; LEE; HUO, 2009). No presente estudo, 98,18\% dos pacientes apresentavam cirrose hepática de etiologias diversas. Dentre os sinais e sintomas de evolução da doença crônica do fígado, observou-se 58,18\% apresentavam ascite, $81,82 \%$ tinham varizes esofágicas, $47,27 \%$ já sofreram algum episódio de hemorragia digestiva prévia, 50,91\% apresentavam encefalopatia hepática e 74,55\% tinham queixas de fadiga.

A doença crônica do fígado está associada com sintomas físicos e mentais, que incluem depressão e fatiga, as quais afetam a qualidade de vida dos pacientes. As queixas de distúrbios do sono em geral ocorrem de 60 a $65 \%$ dos pacientes com doença crônica do fígado, sendo a fadiga e o cansaço físico os sintomas mais prevalentes. Tais sintomas acarretam um pobre funcionamento social, pobre funcionamento físico, aumento de depressão, afetando principalmente o gênero feminino (CARLSON et al., 2010). Para a prática clínica, esses dados indicam a necessidade de um rigoroso acompanhamento dos pacientes pela equipe multidisciplinar para a avaliação da presença de sintomas e a busca de alternativas de tratamento.

O bem-estar subjetivo tem sido definido como a soma total de reações cognitivas e emocionais que as pessoas vivenciam quando comparam o que tem e o que fazem na vida com suas aspirações, necessidades e outras expectativas. Tratase de um fenômeno de ampla categoria que inclui as respostas das pessoas em relação a suas emoções, ao domínio de satisfação e um julgamento global da sua satisfação com a vida (BARTELS; BOOMSMA, 2009). A doença crônica afeta a vida diária das pessoas e como elas têm se adaptado diante da doença, de modo a dar continuidade e significado à vida. Neste caso, é importante o desenvolvimento de estratégias adaptativas e a implementação de intervenções capazes de sustentar a independência dos indivíduos (SILVERMAN et al., 2009). Frente à condição crônica vivenciada pelos candidatos ao transplante de fígado, observou-se na amostra investigada uma freqüência importante de afetos negativos, isso pode indicar a necessidade de uma atuação mais próxima da equipe multidisciplinar em relação às necessidades afetivas e emocionais de cada paciente.

Os candidatos ao transplante de fígado vivenciam sinais e sintomas decorrentes da doença hepática crônica, dentre eles, destacam-se os distúrbios alimentares. As alterações metabólicas e nutricionais pelas quais os pacientes transplantados sofrem não se limitam na fase pós-operatória imediata (CAMPOS; MATIAS; COELHO, 2002). Pelo contrário, essas alterações se iniciam no momento 
em que a doença de base começa a afetar o estado nutricional e se desenvolvem posteriormente durante o processo de transplante como conseqüência de diversos mecanismos. Dentre as causas dos distúrbios alimentares destacam-se uma ingestão pobre de nutrientes (geralmente devido à ocorrência de náuseas e vômitos, restrições alimentares, hemorragia digestiva, alterações neurológicas, dispnéia e hipóxia), má-absorção dos nutrientes, tratamentos farmacológicos, alterações metabólicas relacionadas com a doença de base, diminuição do armazenamento de nutrientes pelo fígado, diminuição de atividade física e infecções de repetição (MONTEJO-GONZÁLEZ; CALVO-HERNÁNDEZ, 2008). Na literatura há estudos que mostram um estado de desnutrição em candidatos que aguardam o transplante, como conseqüência da hepatopatia crônica (MONTEJO-GONZÁLEZ; CALVOHERNÁNDEZ, 2008; FERREIRA et al., 2009). Os pacientes em fila de espera para o transplante apresentam uma freqüência de desnutrição de 20 a 50\% dos casos. Vale ressaltar que a desnutrição incide de maneira importante sobre a mortalidade tanto na fila de espera quanto no período pós-transplante (FERREIRA et al., 2009; THULUVATH, 2009).

Devido à ingestão nutricional alterada, alterações hidroeletrolíticas e aumento das necessidades metabólicas, pessoas com doença crônica do fígado relatam com freqüência uma indisposição as atividades regulares da vida diária ou simplesmente fatiga e fraqueza. É preciso dar atenção a essa problemática com o intuito de proporcionar segurança ao paciente. Os pacientes e familiares precisam entender que o nível de energia só voltará ao normal após a realização do transplante de fígado e a recuperação da função hepática. O candidato deve ser encorajado a limitar sua atividade física, a realização de exercícios deve ser até o limite de conforto, evitando exageros e exercícios vigorosos (THOMAS, 1999b). Em consonância com os dados apresentados, verificamos que quase $70 \%$ dos candidatos do presente estudo não realizavam qualquer tipo de exercício físico. O enfermeiro de transplante deve estimular os pacientes a realizarem algum tipo de exercício físico e manter um nível de atividade física cotidiana, desde que não acarrete em piora dos sintomas de fraqueza e fadiga comumente presentes entre os candidatos ao transplante de fígado.

O fígado desempenha um papel fundamental no metabolismo corporal, envolvendo múltiplos processos como a regulação do metabolismo de proteínas e energia. A doença hepática crônica implica em impacto nutricional concomitante ao grau de mau funcionamento do órgão. Atrelado a essa situação há a presença de 
anorexia secundária ao uso de drogas, assim como náuseas, vômitos e diminuição da saciedade precoce com a ingestão alimentar. Frente ao exposto, os candidatos apresentam risco elevado de carências nutricionais (FERREIRA et al., 2009). Com o auxílio de um profissional especializado em nutrição, os pacientes recebem atenção individualizada, com o planejamento de uma dieta com certas restrições alimentares. $\mathrm{Na}$ presente pesquisa, na amostra estudada mais de $90 \%$ dos candidatos informou restrição ao sódio e mais de 50\% restrição a alimentos gordurosos.

As implicações negativas para a saúde frente ao tabagismo fora do cenário dos transplantes são bem conhecidas. Os tabagistas apresentam risco aumentado de uma variedade de patologias, incluindo doenças cardiovasculares, derrame, câncer e úlcera péptica. Apesar de não ser completamente conhecido, tabagistas apresentam uma susceptibilidade aumentada a infecções e estão mais sujeitos ao risco de doença crônica de rins e a resistência insulínica (LEITHEAD; FERGUSON; HAYES, 2008). A prevalência de tabagismo entre a população geral é entre 20 e $30 \%$. Na literatura, estudos mostram que entre os receptores de transplante de fígado esses índices chegam a $40 \%$ dos pacientes, com conseqüências de aumento da mortalidade pós-transplante (EHLERS et al., 2004; DIMARTINI et al., 2005).Os resultados evidenciados neste estudo apontaram que menos de $10 \%$ dos candidatos tinham esse hábito nocivo para a saúde.

$\mathrm{Na}$ presente pesquisa, em relação ao consumo de bebida alcoólica, nenhum paciente alegou manter esse hábito. No entanto, mais de $70 \%$ alegaram serem exetilistas. A literatura aponta que muitos pacientes em fila de espera cuja indicação para o transplante foi devido ao uso do álcool, retornaram ao hábito mesmo antes da realização do transplante de fígado (WEINRIEB; LUCEY, 2007). Esse dado indica a necessidade de atenção e intervenções da equipe multidisciplinar com o objetivo de minimizar os hábitos que prejudicam o sucesso do transplante.

O conhecimento do perfil clínico, social e demográfico de uma população ou amostra é útil para que o enfermeiro possa planejar intervenções que venham de encontro com as necessidades de saúde/doença levantadas. Muitas vezes os pacientes com uma doença crônica hepática podem se comportar de modo a prejudicar ainda mais a sua condição de saúde. De posse das informações supracitadas, o enfermeiro terá condições de planejar e implementar estratégias de ensino e aprendizagem compatíveis com a situação clínica, social e demográfica dos pacientes, no presente caso, dos candidatos ao transplante de fígado. 
7.1.2 Necessidades de informação dos candidatos em fila de espera

A meta da educação ou ensino de pacientes é auxiliar na obtenção de conhecimentos, habilidades ou atitudes, os quais irão ajudar no desenvolvimento de comportamentos que poderão maximizar o potencial para resultados positivos de saúde. Para que a implementação de uma estratégia educativa possa ser efetiva em atingir metas pré-estabelecidas, contudo, os profissionais da saúde devem determinar que tipo de informação ou mudança seja apropriada para o paciente, e quais são os fatores que poderiam facilitar ou impedir a aprendizagem e mudanças de comportamento daquele indivíduo. Como um processo, o ensino do paciente envolve não apenas dar informações, mas também o recebimento de informações pelo paciente (FALVO, 2004).

Para tanto, antes do início da identificação das necessidades de informação dos candidatos, buscou-se conhecer informações importantes para o contexto do transplante de fígado, a saber: conhecimento prévio sobre a definição de transplante de fígado, a causa da doença hepática, tempo de cadastro técnico para o transplante, funcionamento da lista de espera, recebimento de informações previamente pela equipe de transplante, percepção sobre o preparo ou não para a cirurgia, leitura prévia de folheto informativo e métodos de ensino-aprendizagem preferidos durante a busca de um determinado conhecimento.

O conhecimento do que consiste um transplante de fígado é uma condição sine qua non para a tomada de decisão relativa à realização de um procedimento de tamanha complexidade e risco. Na amostra investigada, aproximadamente $13 \%$ dos pacientes entrevistados não conheciam o significado desta intervenção terapêutica, apesar de se encontrarem em cadastro técnico de fígado.

Vale ressaltar que como profissionais de saúde, o ensino durante o processo de avaliação é papel relevante, capaz de proporcionar o entendimento do paciente sobre o processo pelo qual ele irá vivenciar, bem como as mudanças necessárias após o transplante para minimizar as potenciais complicações do tratamento. Alguns centros de transplante promovem esse ensino por meio de materiais por escrito, vídeos educacionais, aulas grupais ou individuais. Sendo uma das importantes funções dos provedores de saúde, a meta deve ser direcionada para que os pacientes sejam ensinados e que eles possam entender o que irá acontecer, aprender o seu papel e responsabilidade como um potencial receptor de transplante. Espera-se com isso que os pacientes consigam aderir ao tratamento proposto, 
independente de sua complexidade, além das complicações que poderão surgir ao longo do tratamento (ROSENTHAL, 2008).

O termo de consentimento tem sido utilizado legalmente como base para permitir que os pacientes participem de um modo significativo do processo de tomada de decisão de sua experiência cirúrgica. Esse termo é um documento formal e legal, o qual reflete o desejo de médicos e cirurgiões em executar um procedimento com isenção de responsabilidades legais. No momento da assinatura deste termo, deve-se aproveitar o seu valor educacional, na obtenção da autorização pré-operatória para uma troca de informações, na qual o paciente pode tomar decisões importantes sobre suas opções de cuidados relacionados à sua saúde. O uso de estratégias de ensino e aprendizagem, incluindo o uso do consentimento informado para a realização do procedimento cirúrgico, é de grande valia para avaliar a efetividade do ensino, tornando maior a adesão dos pacientes frente à terapêutica proposta (BRENNER; BRENNER; HOROWITZ, 2009).

Para o candidato ao transplante é importante conhecer seu diagnóstico e indicação para a cirurgia. Muitas vezes os pacientes recebem informações sobre esses aspectos, as quais são transmitidas pelo médico, no entanto, parte destes não compreendem as informações dadas naquele momento. Esse fato indica a necessidade de encontrar um momento adequado para informar as pessoas sobre seu quadro clínico-patológico, bem como, na medida do possível, permitir a presença de um familiar neste momento tão delicado. Na amostra estudada, mais de $20 \%$ dos pacientes não compreendiam a indicação para o transplante, ou seja, o diagnóstico médico.

Outro resultado interessante da presente pesquisa está relacionado à percepção temporal dos candidatos sobre o cadastro técnico para o transplante de fígado. Mais de $50 \%$ dos pacientes informaram um período incorreto de inscrição em fila de espera, com uma margem de erro maior do que $20 \%$ da data correta. A análise dos dados não indicou nenhuma relação se o tempo de fila de espera influenciava no acerto das respostas dos candidatos sobre essa questão. No entanto, com o advento da Era MELD, a lista de espera tem se tornado muito dinâmica, em virtude dos pacientes mais graves ocuparem as primeiras posições da fila, requerendo uma maior atenção da equipe de transplante em informar para o paciente o seu posicionamento. Talvez esse seja um momento válido para relembrar a data de inclusão para os candidatos. 
Para ser incluído em fila de espera, o candidato passa por uma fase na qual um membro da equipe de transplante (por exemplo, o médico ou o enfermeiro) elucida para o paciente sobre o processo de transplante de fígado. Mais uma vez, se o candidato não está preparado para receber as informações e/ou não tem um acompanhante, as informações poderão não ser armazenadas de modo que o paciente tenha o entendimento da situação. No presente estudo, os pacientes receberam informações sobre o processo de transplante de fígado, sendo a equipe de transplante a principal fonte de informações. Apesar disso, quase $30 \%$ dos pacientes não se sentiam preparados para a realização do procedimento frente ao conhecimento que tinham, e quase $35 \%$ não haviam realizado a leitura do folheto informativo.

No cotidiano há diversas formas de buscar um conhecimento ou informações sobre um determinado tópico. A depender do estilo de aprendizagem de cada um, as pessoas identificam diferentes maneiras de aprender. $\mathrm{Na}$ presente pesquisa observou-se que os pacientes têm preferências por ouvir informações, participar de discussões em grupo e realizar leituras. O estilo de aprendizagem pode ser definido como as preferências inerentes dos indivíduos na maneira como eles se engajam no processo de aprendizagem. Sob a influência da genética, experiências educacionais anteriores, necessidades situacionais, idade e outros fatores, o aprendiz entende e processa a informação de uma forma diferente (CONTI, 2009).

Apesar de ser pouco abordada na literatura, a educação de candidatos e receptores é vital para garantir a segurança e o sucesso de um transplante. Os receptores de transplante devem de uma maneira geral ser um grupo altamente motivado e a adesão ao seguimento pós-transplante e regime medicamentoso deve ser também alta (ASHCROFT, 2009). Infelizmente essa situação não é uma realidade (BUNZEL; LAEDERACH-HOFMANN, 2000). Uma compreensiva educação de pacientes e familiares pode aumentar a adesão por meio do entendimento das condições vivenciadas, bem como aumentar a realização de técnicas de autocuidado que podem acarretar a melhoria dos resultados do tratamento e da sobrevida do enxerto (PARADIS, 2000).

A falta de adesão é reconhecida como uma causa determinante para o aumento da morbidade e mortalidade, redução da qualidade de vida, aumento dos custos médicos e utilização alta dos serviços de saúde para os pacientes transplantados (TELLES-CORREIA et al., 2008), podendo ser uma causa direta de $21 \%$ dos insucessos dos transplantes e $26 \%$ das mortes pós-transplantes (LISSON 
et al., 2005; TELLES-CORREIA et al., 2006). A adesão é definida como o seguimento às recomendações fornecidas pela equipe de transplante, uma vez que há necessidade de implementação do regime medicamentoso de imunossupressores complexo e um manejo próximo para garantir a adesão dos pacientes (REDMAN, 2009).

A importância da adesão nos transplantes de órgãos é um reflexo de vários fatores, dentre eles, as recomendações médicas após o transplante, as quais são designadas para prevenir ou atenuar a rejeição aguda ou crônica, o risco de infecções oportunistas, o surgimento de neoplasias, as complicações secundárias ao transplante e os efeitos colaterais associados ao uso dos medicamentos imunossupressores (REDMAN, 2009). O receptor de transplante deve ingerir os medicamentos diariamente, seguir um esquema de coleta de sangue agendado previamente, realizar biópsias, monitorar os sinais vitais no domicílio, seguir dieta nutricional e realizar exercícios físicos, evitar exposição solar, ser abstinente ao álcool, nicotina e outras substâncias ilícitas, comparecer as consultas agendadas e se comunicar regularmente com o coordenador de transplante (LISSON et al., 2005).

O paciente, antes de ser aceito para a inclusão em lista de espera, deve entender o que o transplante envolve, desde a aceitação para entrar na fila de espera, até a recuperação do transplante e a vida após o transplante. É vital que paciente, familiar ou cuidador tenham um completo entendimento desse processo, não apenas garantir que o cuidador ou familiar entendam as recomendações no sentido de dar um suporte melhor para o receptor, mas também para o próprio benefício destes (ASHCROFT, 2009). Essa necessidade está relacionada com o impacto que o processo de transplante pode causar na estrutura familiar, podendo acarretar diferentes tipos de conflitos (BUNZEL; LAEDERACH-HOFMANN; SCHUBERT, 1999).

A informação é reconhecida como sendo essencial para a tomada de decisão. Isso implica em fazer com que o paciente participe do processo de decisão (MOUMJID et al., 2007; WHITNEY et al., 2008), informe as expectativas (HAWKINS et al., 2008), reduza a ansiedade (JACOBS, 2000), aumente a adesão com o tratamento e promova o autocuidado (GALLOWAY et al., 1997; BROSTROM et al., 2009). Na literatura há evidências que sugerem que os pacientes apresentam uma variada necessidade de informações durante o processo de tomada de decisão e que este processo tem envolvido os familiares e amigos, os quais podem apresentar 
diferentes necessidades de informação em relação aos pacientes (NELSON et al., 2005; MOLONEY et al., 2007; HAWKINS et al., 2008).

Frente ao exposto e com base nos conceitos teóricos propostos por Lorig (2001) utilizou-se uma escala de avaliação das necessidades de informação para os candidatos ao transplante de fígado. Uma das dificuldades encontradas na aplicação deste instrumento foi fazer com que os pacientes compreendessem os objetivos e a importância de classificar os assuntos considerados relevantes para eles enquanto candidatos ao transplante de fígado, ou seja, de acordo com as suas reais necessidades. Para tal adotou-se a estratégia de permitir a leitura prévia dos tópicos construídos de acordo com a literatura e posteriormente houve o esclarecimento de dúvidas. Apesar de não ter sido significante para a análise estatística dos dados, alguns pacientes realizaram a classificação dos assuntos seguindo a leitura do cartão de sugestões, conforme a ordem numérica. Tal achado foi mais evidente entre os pacientes com menor nível educacional. Isso pode ser considerado um viés para este estudo e um ponto a ser observado nas futuras pesquisas a serem conduzidas nesta temática.

A literatura aponta diversas formas de identificar as necessidades de informação entre os pacientes. Os estudiosos da área de ensino (REDMAN, 1988; LORIG, 2001b; REDMAN, 2007) sugerem realizar estratégias de ensino e aprendizagem quando os pacientes verbalizam uma pergunta ou dúvida diretamente, ou executar uma avaliação das necessidades utilizando algumas ferramentas. No presente estudo foi construído um instrumento adaptado do método de avaliação de crença saliente, considerado pelo pesquisador a estratégia que mais se aproximou para o alcance do objetivo proposto, além da vantagem de ser uma técnica útil para a busca das necessidades de informação no contexto individual e grupal. Nesse método, pode-se lançar uma questão ao paciente, de modo a obter o maior número de respostas possíveis. As respostas são então classificadas por ordem de importância, sendo a primeira resposta considerada a mais importante e a última a menos importante. Realiza-se uma média aritmética para identificar as prioridades para o ensino a partir das pontuações médias maiores de cada tema apontado pelo paciente.

A literatura é escassa quando se trata de estudos que analisaram as necessidades de informação no transplante de fígado. Os únicos estudos encontrados foram realizados em 1989 e 1990, com o objetivo de buscar as necessidades de informação dos cuidadores primários de crianças submetidas ao transplante de 
fígado (WEICHLER; HAKOS, 1989; WEICHLER, 1990). Dentre as outras modalidades de transplantes, há dois estudos que abordaram as necessidades de informação no transplante de medula óssea (TARZIAN; IWATA; COHEN, 1999; KRASUSKA et al., 2002), uma pesquisa identificou as necessidades de informação no transplante de pulmão (MOLONEY et al., 2007) e um estudo que avaliou as necessidades de aprendizagem em receptores de transplantes de órgãos abdominais (MYERS; PELLINO, 2009).

O instrumento utilizado para o levantamento das necessidades de informação dos candidatos ao transplante de fígado permitiu uma análise entre o número de votos para cada sugestão apresentada e a média aritmética final. De acordo com a média aritmética, as informações do período pré-operatório foram as mais importantes para os pacientes. As maiores pontuações foram referentes aos cuidados necessários antes do transplante, as possíveis complicações após a cirurgia e os cuidados requeridos após o transplante. Em relação ao número de votos, no entanto, as sugestões relacionadas com o período pós-operatório foram as mais votadas. Dentre elas, os cuidados necessários após o transplante de fígado, as complicações inerentes do pós-operatório e a qualidade de vida após o transplante foram as que obtiveram o maior número de votos. Ao considerar que os candidatos classificaram cada sugestão de acordo com sua importância, fica claro que as necessidades de informação do período pré-operatório foram as mais relevantes; entretanto, não se pode deixar de lado o montante de votos recebidos por outros tópicos relacionados com a fase pós-transplante.

O ensino pré-operatório fornece ao paciente cirúrgico, informações relacionadas com o processo cirúrgico, procedimento operatório em si, além da antecipação de comportamentos do paciente (ansiedade, medo, depressão), sensações esperadas e possíveis resultados (BERNIER et al., 2003). É útil também como uma maneira de oferecer segurança para o paciente por meio de uma comunicação terapêutica, o que pode contribuir para a tranqüilização do paciente e a sua aquisição de estratégias para enfrentar a situação de uma maneira positiva (KRUZIK, 2009).

A literatura tem mostrado os benefícios do ensino no período perioperatório para os pacientes, tais como, diminuição da estadia hospitalar, redução de uso de analgésicos e aumento da satisfação para pacientes e familiares (KRUZIK, 2009). Em especial, quando se trata do transplante de fígado, fornecer informações para os potenciais receptores significa contribuir para os resultados do transplante, uma vez 
que o enfermeiro vai suprir as necessidades de autocuidado requeridas por toda vida após o transplante. As ações simples como a aplicação de um protetor solar diariamente, o uso de luvas para jardinagem e até mesmo a lavagem de mãos após manusear animais de estimação são exemplos que o enfermeiro pode informar e discutir com o paciente, os quais podem contribuir na prevenção de câncer de pele e de infecções oportunistas.

$\mathrm{Na}$ literatura, os resultados de pesquisa têm mostrado que o conhecimento do paciente em relação à cirurgia contribui para a redução de sintomas como a ansiedade (KIYOHARA et al., 2004), na melhoria da qualidade de vida (BARLESI et al., 2008) e na recuperação pós-operatória (CUPPLES, 1991). Um estudo recente avaliou o grau de ansiedade observado em candidatos ao transplante de fígado, e correlacionou essa variável com a etiologia diagnóstica. Dentre os resultados evidenciados observou-se que dos pacientes que apresentaram grau médio (27\%), moderado $(12 \%)$ e severo $(7 \%)$ de ansiedade, a correlação com o diagnóstico médico mostrou que $27 \%$ dos pacientes com cirrose auto-imune apresentaram níveis altos de ansiedade (SANTOS et al., 2010). Isso indica que os pacientes que apresentam sinais e sintomas da doença do fígado mais evidentes, podem necessitar de uma atenção maior da equipe multidisciplinar, uma vez que podem evoluir com níveis progressivos de ansiedade.

Devido à falta de doadores em relação ao grande número de candidatos aguardando em fila de espera a realização do transplante de fígado, é essencial considerar os fatores psicológicos e sociais que podem influenciar na evolução clínica e na qualidade de vida dos pacientes após a cirurgia. Uma pesquisa realizada em Portugal investigou as correlações psiquiátricas e psicossociais por meio da aplicação de um questionário multidimensional de adesão entre os candidatos a transplante de fígado. Os resultados mostraram que a adesão teve uma correlação positiva com os traços de personalidade (aceitação), suporte social adequado e estratégias de coping (planejamento) (TELLES-CORREIA et al., 2009).

Um ensaio clínico randomizado controlado realizado no Iran em 2005, avaliou os efeitos de uma intervenção educacional na qualidade de vida de pacientes em programa de transplante de fígado. A intervenção consistiu em prover informações sobre a doença crônica do fígado e seus efeitos na qualidade de vida, ajustamento a doença crônica (estratégias de coping), relaxamento, dieta e nutrição, medicamentos utilizados e possíveis efeitos colaterais para o grupo experimental. Além do uso de recursos audiovisual, foi entregue um folheto informativo relacionado aos temas 
abordados. Os pacientes do grupo experimental tiveram em quatro domínios de qualidade de vida avaliados - fadiga, suporte emocional, medos e sintomas sistêmicos - uma diferença significante $(p<0,001)$, quando comparados com o grupo controle.Tais resultados mostraram a importância da avaliação das necessidades dos pacientes com doença crônica do fígado, bem como a necessidade de intervenções que contribuam para a melhora da qualidade de vida destes pacientes. (SHARIF et al., 2005).

Um dos papéis essenciais dos profissionais de transplante, em especial do enfermeiro consiste no ensino dos candidatos durante o processo de avaliação a fim de auxiliá-los a compreender o transplante iminente e aprender novos hábitos de vida necessários após o transplante (ROSENTHAL, 2008).

Em relação aos cuidados necessários antes do transplante, os candidatos necessitam realizar uma dieta especial, com algumas restrições (proteínas, sódio, lipídios), seguir um regime medicamentoso para minimizar os sinais e sintomas da hipertensão portal (betabloqueadores, reguladores intestinais, antibióticos, complementos minerais e vitamínicos, entre outros), prática de exercícios físicos leves (não ultrapassando o limite do bem-estar), evitar situações estressantes e estabelecer um compromisso com a equipe por toda a vida (BUFTON; EMMETT; BYERLY, 2008). A depender da evolução da doença hepática crônica, os candidatos podem apresentar icterícia, ascite, varizes esofagianas, náusea, vômito, anorexia, retenção hídrica, desnutrição, fadiga e encefalopatia hepática. Frente a esses sinais e sintomas é imprescindível uma orientação especializada e focada na prevenção de complicações por parte da equipe multidisciplinar.

Um estudo canadense realizado com candidatos, receptores e familiares e/ou cuidadores em um programa de transplante de pulmão, buscou identificar as necessidades de informação frente ao processo de transplante. Os resultados evidenciados mostraram que a maioria dos pacientes tomou a decisão de realizar a cirurgia em colaboração com seus familiares ou cuidadores, sendo que informações sobre estatísticas de sobrevida, capacidade física após o transplante e efeitos colaterais dos medicamentos imunossupressores foram essenciais para a tomada de decisão. Além disso, os pacientes relataram o recebimento adequado de informações no momento de tomada de decisão para o transplante, as quais eram dadas de forma escrita e verbal(MOLONEY et al., 2007). 
Ainda em relação ao estudo, diversas necessidades de informação foram identificadas, dentre elas destacou-se as informações sobre questões práticas (tais como, estar próximo do centro de transplante e fontes de assistência financeira), vida após o transplante e as experiências de receptores de transplante. É interessante ressaltar que todos os pacientes que desenvolveram complicações após a cirurgia, relataram a importância de receber informações mais detalhadas sobre o período pós-transplante, a saber: diferenças no período de recuperação entre os pacientes, tipo de complicação desenvolvida e as mudanças relacionadas ao estilo de vida. Em relação aos cuidadores/familiares houve o relato das dificuldades com o volume de informações orais dadas no processo de avaliação para o transplante, sendo de extrema valia o oferecimento de informações escritas sobre esse processo (MOLONEY et al., 2007).

Um estudo realizado nos Estados Unidos buscou identificar a percepção de lacunas de conhecimento e as maneiras para melhorar o ensino de receptores de transplante de órgãos abdominais. Para tal foi utilizada uma escala de avaliação de necessidades de aprendizagem de pacientes modificada, para medir a percepção do paciente no manejo do cuidado em saúde no domicilio após a alta hospitalar. Os resultados mostraram que as questões relacionadas com a qualidade de vida, o uso de medicamentos e o seguimento após o transplante foram as que obtiveram as menores pontuações, sendo consideradas as lacunas maiores de conhecimento para os pacientes. O estudo mostrou também que os pacientes querem receber uma quantidade maior de informações antes da realização do transplante (MYERS; PELLINO, 2009).

Em contraposição aos resultados do estudo mencionado anteriormente, os resultados evidenciados na presente pesquisa mostraram um interesse menor dos candidatos em relação aos medicamentos utilizados após o transplante. Além disso, as informações sobre o funcionamento da lista de espera, indicações e contraindicações para o transplante, período pós-operatório imediato e mediato, sistema de distribuição de órgãos e o MELD também foram consideradas de importância menor para os candidatos.

Uma pesquisa européia avaliou as necessidades de informação dos períodos pré e pós-operatório da cirurgia de colecistectomia, utilizando um questionário de 48 itens, cujas respostas ocorreram por meio de uma escala de cinco pontos do tipo Likert. O estudo mostrou que os pacientes necessitam de muitas informações, especialmente durante a admissão e a alta. A necessidade maior de informação dos 
pacientes foi relacionada a dor e as complicações vivenciados no período pósoperatório ( $94 \%$ dos pacientes), além disso 30\% dos pacientes gostariam de receber informações escritas e verbais (LITHNER; ZILLING, 2000). Estes resultados mostram o quanto a informação é vital para o cuidado do paciente cirúrgico.

De acordo com estudos, os pacientes são incapazes de se tornarem parceiros ativos do cuidado pós-cirúrgico, caso não recebam as informações adequadas (CUPPLES, 1991; DEVINE, 1992). A falta de tempo da equipe de saúde para discutir assuntos de interesse de cada paciente reforça a relevância do conhecimento do tipo de informação que o paciente deseja, sendo de extrema valia o uso de estratégias para a identificação das necessidades de informação dos pacientes.

No Brasil, em 2004, foi publicado um estudo que avaliou os níveis de ansiedade no dia anterior ao procedimento cirúrgico, relacionando com as informações conhecidas pelos pacientes sobre o diagnóstico, procedimento cirúrgico e anestesia. Para tal foi utilizado um questionário com questões abertas para buscar o conhecimento adquirido pelo paciente e uma escala para mensurar os níveis de ansiedade. Os resultados mostraram que as mulheres apresentaram níveis maiores de ansiedade, e que a presença de um maior nível educacional entre os pacientes, estava relacionado com níveis menores de ansiedade. A não familiaridade com o procedimento cirúrgico também estava relacionada com níveis maiores de ansiedade. $O$ estudo concluiu que os pacientes com conhecimento maior sobre a cirurgia apresentaram níveis menores de ansiedade no período pré-operatório (KIYOHARA et al., 2004). No presente estudo, não foi objeto de investigação, avaliar os níveis de ansiedade de candidatos ao transplante de fígado; entretanto, fica claro a necessidade de oferecer para os pacientes conhecimentos específicos sobre 0 perioperatório de uma cirurgia de tamanha complexidade como o transplante de fígado.

$\mathrm{Na}$ presente investigação, as informações sobre o período pré-operatório se mostraram como as de maior necessidade para os candidatos ao transplante de fígado. Duas ressalvas precisam ser apontadas a fim de contribuir para o planejamento de estudos futuros. A primeira refere-se ao número de sugestões apresentadas aos pacientes (17 sugestões), ou seja, não houve uma proporção igualitária entre o número de sugestões relacionadas ao período pré (oito sugestões), intra (três sugestões) e pós-operatório (seis sugestões). Isso poderia estar relacionado com a quantidade de informações disponíveis na literatura sobre o processo de transplante de fígado, uma vez que os estudos abordam principalmente 
aspectos do pré e pós-operatório do transplante de fígado. Outro aspecto é o fato de não ter sido encontrado estudos que utilizaram a ferramenta ora apresentada para o levantamento das necessidades de informação.

A segunda ressalva consiste na ordem dos tópicos apresentados no cartão de sugestão para os pacientes. Apesar de não ter influenciado na análise estatística, alguns pacientes ao ordenarem por importância os tópicos apresentados, seguiram as sugestões apresentadas conforme a sua posição no cartão. Como sugestão para pesquisas futuras, caso o pesquisador deseje utilizar um cartão com sugestões, apresentar tais sugestões de forma não ordenada, de modo que os assuntos não sigam uma ordem lógica.

No presente estudo, o nível de escolaridade mensurado por meio de anos de estudo, mostrou uma diferença estatisticamente significante quando comparados os candidatos que estudaram até o ensino fundamental com os candidatos que tinham nível médio ou superior, em relação ao conhecimento sobre a definição de transplante e a percepção de preparo para o enfrentamento da cirurgia. Isso pode indicar que os pacientes com mais anos de estudo podem apresentar-se mais preparados para enfrentar o transplante, diante do conhecimento adquirido desde sua entrada na fila de espera. Os resultados evidenciados apontaram também que os pacientes com mais anos de estudo necessitam de mais informações sobre o período intra-operatório, enquanto que os pacientes com menos anos de estudo, necessitam de mais informações sobre o período pré-operatório. Tal resultado sugere que mesmo recebendo informações verbais e por escrito da equipe de transplante, os pacientes com menos anos de estudo, não conseguem processar tais informações adequadamente, sendo necessário o uso de outros recursos para suprir tal necessidade.

Além do nível de escolaridade nesta pesquisa, foi relacionado se o tempo de fila de espera poderia interferir com o ganho de conhecimentos e as necessidades de informação dos candidatos. A única variável que se mostrou estatisticamente significante foi a leitura do folheto informativo, de modo que os pacientes que estavam a mais tempo na fila de espera foram menos ativos na busca de informações contidas neste folheto. É interessante ressaltar que em relação às necessidades de informação houve discrepância (não-significativa) entre os pacientes com tempo de fila de espera maior e menor. Os pacientes com menor tempo de fila de espera tiveram maior necessidade de informações sobre o período pós-operatório, enquanto que os com maior tempo de fila de espera tiveram maior necessidade de 
informações sobre o período pré-operatório. Outras variáveis observadas foram a diferença de idade e gravidade da doença entre esses dois grupos, sendo que os pacientes com menor tempo de fila eram mais jovens e apresentaram valores de MELD mais elevados.

A literatura é rica em estudos que utilizam o levantamento de necessidades de informação em outras populações. Na oncologia, por exemplo, existem escalas validadas para avaliar as necessidades de informação dos pacientes (COX et al., 2006), mensuração de necessidades de informação entre pacientes com diversos tipos de cânceres (MESTERS et al., 2001; HALKETT et al., 2009), mensuração de necessidades de informação entre cuidadores (ADAMS; BOULTON; WATSON, 2009), entre outros. Em pacientes cirúrgicos, estudos sobre necessidades de informação no dia da cirurgia (ROSE, 1995), no dia da alta hospitalar (PIEPER et al., 2006), após a cirurgia (LITHNER; ZILLING, 2000). Em situações clínicas, estudos de necessidades de informação em pacientes cardiopatas (SCOTT; THOMPSON, 2003; TIMMINS; KALISZER, 2003), asmáticos (CARESS et al., 2002), com doenças pulmonares (RODGERS et al., 2007), e com doenças intestinais (REZAILASHKAJANI et al., 2006), entre outras.

Em relação aos transplantes de órgãos sólidos muito ainda precisa ser construído e validado na literatura. Conhecer como as necessidades de informação têm sido investigadas por diferentes estudos e traçar estratégias de ensinoaprendizagem que visem sanar lacunas do conhecimento entre pacientes, familiares e cuidadores é um dos papéis do enfermeiro e de toda a equipe de saúde. 


\subsection{Discussão do delineamento de pesquisa quase-experimental: estudo piloto grupo único, antes e depois}

7.2.1 Conhecimento dos candidatos sobre o processo de transplante de fígado, antes e depois da implementação da intervenção educativa

Planejar, executar e avaliar uma intervenção educativa é sem dúvida, uma atividade árdua para o enfermeiro. É necessário tempo para o seu planejamento e a utilização de recursos diferentes para viabilizar os encontros com os pacientes. Com certeza realizar sozinho esta atividade não seria possível.

$\mathrm{Na}$ condução do presente estudo houve a oportunidade de participar de um programa de transplante de fígado consolidado, assim as dificuldades foram abrandadas, pois foi possível contar com o apoio e auxílio profícuo, do coordenador médico e da coordenadora de enfermagem, além de membros da equipe, incluindo os enfermeiros da unidade de transplante. Uma parceria foi constituída, com a qual se almeja dar continuidade, frente à necessidade dos pacientes de obterem informações sobre o transplante de fígado.

Os resultados evidenciados apontaram as dificuldades de manejo de candidatos em fila de espera para um transplante, devido à dinâmica de mudança apresentada no cadastro técnico durante o período de coleta de dados. Outro aspecto se refere às dificuldades de recrutamento de pacientes para a implementação da intervenção educativa. Neste estudo, além do envio de correspondência formal para o domicílio, foram realizados contatos telefônicos previamente às datas dos encontros programados. Ressalta-se ainda que as condições clínicas de evolução da doença crônica do fígado são fatores intervenientes para um processo educativo efetivo. Apesar do uso dos recursos disponíveis para o recrutamento dos pacientes, não foi possível obter uma amostra representativa dos candidatos incluídos no cadastro técnico de fígado, tratando-se, portanto, de um estudo piloto.

A publicação de estudos pilotos têm sido de grande valia para garantir que os critérios metodológicos sejam os mais rigorosos possíveis. A translação de resultados de pesquisa para a prática clínica têm se apropriado do uso de estudos pilotos para avaliar em caráter preliminar, a eficácia de uma intervenção. Além disso, esse tipo de estudo possibilita que ajustes sejam realizados antes de se conduzir um estudo de maior magnitude. O objetivo inicial de um estudo piloto consiste na determinação 
da viabilidade de uma intervenção, frente aos possíveis eventos inesperados. Outro objetivo importante está relacionado ao poder da análise estatística para estimar o tamanho amostral, mostrando dessa forma, o poder das relações apresentadas nos resultados do estudo. A literatura é inconclusiva no quesito tamanho amostral para um estudo piloto, sendo que alguns autores recomendam $10 \%$ da amostra requerida no estudo completo, dependendo da natureza do estudo (BECKER, 2008; HERTZOG, 2008). No presente estudo buscou-se veementemente um tamanho amostral mais significativo em relação à amostra de conveniência disponível no serviço. As dificuldades de recrutamento dos pacientes encontradas, frente aos problemas sócioeconômicos e clínicos dos candidatos, acarretou na condução de um estudo piloto, com vistas a continuidade do estudo em um futuro próximo.

A análise sócio-demográfica da amostra do estudo piloto apontou a participação reduzida de mulheres $(n=3)$. Outro dado relevante é que apenas quatro dos candidatos ainda eram capazes de manter suas atividades laborais diante do quadro clínico que apresentavam. Quase 70\% dos pacientes tinham apenas até o ensino fundamental de formação e estavam a mais de dois anos na fila de espera. Quanto às condições clínicas, de forma geral, os pacientes não apresentavam sinais e sintomas da doença considerados incapacitantes, e gozavam de um estado de saúde de bom a regular, permitindo a participação destes na intervenção educativa.

A análise do questionário de conhecimento sobre o transplante de fígado antes da intervenção mostrou que os pacientes apresentavam um conhecimento prévio moderado (em torno de 60\%) em relação ao processo de transplante. Os resultados evidenciaram também que o nível de escolaridade do candidato foi estatisticamente significante $(\mathbf{p = 0 , 0 3 3 2})$, para o desempenho de acertos das questões, sendo que os pacientes que tinham apenas até o ensino fundamental obtiveram índices menores de acertos. Outro resultado interessante foi relacionado com a gravidade do paciente, ou seja, o valor de MELD e o desempenho dos candidatos, sendo que os pacientes mais graves tiveram os índices maiores de acertos.

Quanto ao desempenho dos candidatos frente às questões formuladas, chamou a atenção o conhecimento dos pacientes diante dos fatores que contribuem para o sucesso do transplante e suas responsabilidades enquanto candidatos em lista de espera, pois foram as questões que obtiveram os índices maiores de acertos. Isso indica que apesar das dificuldades de adesão ao tratamento proposto por parte dos pacientes em programas de transplante de órgãos, relatadas em estudos da literatura (REDMAN, 2009; TELLES-CORREIA et al., 2009; DE GEEST; DOBBELS, 
2010), os pacientes têm consciência do que deveria ser feito a fim de contribuir para o sucesso do seu tratamento. Para ilustrar a problemática da adesão, em 2007 foi publicado um estudo português, no qual se constatou que a não adesão de receptores de transplante de fígado é muito freqüente, sendo a sua prevalência média de 25,28\% (TELLES-CORREIA et al., 2007).

O conhecimento sobre o período pós-operatório imediato, quando o paciente é admitido na Unidade de Terapia Intensiva, e pós-operatório mediato, momento em que o paciente está na unidade de internação, também foi relevante, com índices de acertos perto de $90 \%$. É interessante relacionar esse resultado com as necessidades de informação obtidas na primeira fase deste estudo, uma vez que foram observadas como aquelas de menor interesse entre os candidatos de uma forma geral, devido à pontuação média obtida (2,56 pontos).

Um estudo descritivo realizado no pré-operatório para avaliar as necessidades de informação de pacientes e familiares admitidos em unidade de terapia intensiva, após o procedimento cirúrgico mostrou que, tanto os pacientes quanto os familiares expressaram preocupações relacionadas ao procedimento anestésico-cirúrgico e o período de cuidados intensivos no pós-operatório imediato, indicando níveis de ansiedade maiores entre os familiares. A necessidade de informação mais importante identificada foi relacionada à necessidade de entendimento do procedimento cirúrgico. O estudo concluiu que a natureza da informação apresentada por familiares e pacientes estava associada com a percepção de ameaças e injúrias relacionadas com a hospitalização, e que a provisão de informações estruturadas de acordo com necessidades individuais acarretaram na diminuição da ansiedade e aumento da satisfação (MCGAUGHEY; HARRISON, 1994).

$\mathrm{Na}$ presente pesquisa, os resultados evidenciaram também desempenhos insatisfatórios frente às questões que abordavam sobre os medicamentos imunossupressores utilizados após o transplante, as complicações mais freqüentes no pós-operatório, os cuidados necessários após a cirurgia e a qualidade de vida do receptor. Vários fatores podem ter contribuído para o desempenho negativo dos candidatos, dentre eles, ressaltam-se as dificuldades de entendimento do conteúdo das questões e das informações recebidas pelo paciente pela equipe de transplante (incluindo-se aqui as informações contidas no folheto informativo entregue aos candidatos), as quais poderiam ter influenciado os candidatos no momento da entrevista, no entanto, nenhum paciente verbalizou dificuldades de entendimento do questionário utilizado antes ou após a intervenção educativa. 
O conhecimento do paciente se faz necessário, principalmente para promover o desenvolvimento do autocuidado, quando este se defronta com uma situação nova relacionada à doença e arraigada a um futuro incerto. Uma casuística de 341 pacientes entrevistados em Israel foi utilizada para avaliar o conhecimento de pacientes sobre a terapia medicamentosa após a alta hospitalar. Os resultados mostraram que $73 \%$ dos pacientes tinham conhecimento sobre o propósito dos medicamentos prescritos; entretanto, esses demonstraram lacunas de conhecimento sobre os efeitos colaterais, mudanças de estilo de vida necessárias e posologia correta dos medicamentos (KERZMAN; BARON-EPEL; TOREN, 2005).

Um estudo realizado em 2003 avaliou o impacto do uso da terapia imunossupressora a longo prazo, no bem-estar físico e psicossocial de receptores de transplante de fígado. As complicações pós-transplante incluíram hipertensão arterial $(64 \%)$, diabetes mellitus pós-transplante (17\%), osteopenia $(40 \%)$, osteoporose $(26 \%)$ e doenças cardíacas (17\%). O estudo apontou ainda que a maioria dos receptores queixou sobre os efeitos dos agentes imunossupressores, apesar dos pacientes terem se mostrado satisfeitos com a vida pós-transplante e de apresentarem uma melhora da qualidade de vida (KIZILISIK et al., 2003).

Outro estudo mostrou que a não-adesão aos medicamentos imunossupressores entre os receptores de transplante é pouco freqüente, mas que quando ocorre apresenta sérias conseqüências, tais como: episódios de rejeição, perda do enxerto e aumento da mortalidade (DRENT et al., 2009). A literatura aponta que o uso de estratégias educacionais tem contribuído para a melhoria da adesão entre os receptores de órgãos sólidos (WAINWRIGHT; GOLD, 1997).

No momento em que os potenciais candidatos são indicados para entrar em um cadastro técnico para o transplante de fígado, eles necessitam receber informações pertinentes sobre o pré, intra e pós-operatório da cirurgia. A análise do questionário de conhecimento permitiu observar que o conhecimento sobre o préoperatório é maior em detrimento aos outros períodos. Talvez isso seja um reflexo da experiência que o candidato vivenciou até o momento. No entanto, conhecer o que se espera no futuro, diante de um procedimento complexo como o transplante de fígado, auxilia na conscientização e responsabilização do candidato e dos familiares para o autocuidado, especialmente na fase pós-operatória, na qual mudanças de estilo de vida são fundamentais para a manutenção e sucesso do tratamento. 
Um estudo fenomenológico, realizado na Suécia em 2000 propôs descrever as necessidades de informação e suporte de candidatos ao transplante de fígado durante o período de espera. Muitos candidatos consideraram as informações durante o período de espera como insuficientes, uma vez que importantes questionamentos dos pacientes não haviam sido respondidos satisfatoriamente. Isso trouxe sentimentos de insegurança e medo, especialmente com a preocupação de serem "esquecidos" na fila de espera. Tópicos sobre o período pré e pós-operatório foram apontados como importantes de serem informados aos pacientes. A maioria dos pacientes verbalizou satisfação com as informações médicas e técnicas relacionadas ao procedimento cirúrgico. Outros pacientes verbalizaram preocupação com as informações relacionadas ao risco do transplante, principalmente quando dadas imediatamente antes da cirurgia. Outros ainda solicitaram mais informações sobre o que poderia ocorrer após a cirurgia. Suporte emocional dos provedores de saúde durante o período de espera também foi considerado importante, sendo que em alguns casos os pacientes verbalizaram um insuficiente suporte da equipe (JONSÉN; ATHLIN; SUHR, 2000).

No presente estudo, quando comparamos as necessidades de informação identificadas com os índices de acertos do questionário de conhecimento sobre o transplante de fígado, ficou claro que há necessidade de enfocar com maior profundidade as questões inerentes ao período intra e pós-operatório, ainda durante o período de espera para o transplante. Apesar da provisão destas informações para os candidatos, seja de forma oral e/ou escrita, existem dificuldades no processamento das informações, concretizada pelo desempenho dos pacientes em relação às respostas dadas no questionário de conhecimento $(68,42 \%$ de acertos para as respostas relacionadas ao intra-operatório, e $44,74 \%$ de acertos para as respostas relacionadas ao pós-operatório do transplante de fígado).

Uma revisão conduzida em 1999 buscou evidências na literatura sobre o impacto do ensino pré-operatório na recuperação do paciente cirúrgico. Os resultados dos estudos analisados mostraram que informar o que se espera antes de se concretizar o procedimento cirúrgico tem sido benéfico para o paciente. Variáveis de estudos experimentais, tais como período de internação, complicações médicas, função respiratória, ansiedade, dor e satisfação, foram positivamente relacionadas com o ensino pré-operatório e contribuíram para a recuperação do paciente após a cirurgia (SHULDHAM, 1999). 
Depois de se obter o conhecimento prévio dos candidatos em relação ao período perioperatório do transplante de fígado, uma intervenção educativa foi implementada com o propósito de ampliar o conhecimento dos pacientes. 0 planejamento da intervenção foi pautado na literatura pertinente e a sua aplicação foi realizada em dois encontros distintos, obtendo uma boa aceitação dos candidatos, a qual será demonstrada posteriormente com base nos dados coletados sobre a satisfação dos candidatos com as informações recebidas.

É importante ressaltar que apenas quatro pacientes não puderam comparecer nos dois encontros, sendo que em um caso não houve justificativa. Dentre os três casos do não comparecimento dos pacientes na intervenção, um paciente estava com encefalopatia hepática, um fez transplante e um faleceu antes da realização do segundo encontro. Nesta pesquisa, a forma dialogada foi utilizada como estratégia de ensino-aprendizagem e permitiu que os pacientes se expressassem em um clima de descontração e interesse com as informações ministradas. Os encontros foram abertos aos familiares, que também interagiram de forma positiva, mediante o conteúdo proposto. Reunir o grupo de candidatos e familiares de uma forma planejada, em um ambiente tranqüilo, confortável e longe de ruídos e interrupções (muito comum no atendimento em ambulatoriais e enfermarias) foi essencial para garantir uma intervenção profícua para o ensino e a aprendizagem. Dos 15 pacientes que participaram dos dois encontros, apenas um não contava com a presença de um familiar.

O planejamento de dois encontros distintos, para a implementação de uma intervenção, consiste em um desafio para o enfermeiro. Para estudos futuros nesta área, talvez o planejamento de apenas um encontro pudesse facilitar a participação dos candidatos que apresentam maiores dificuldades de locomoção devido a problemas sociais. Uma outra alternativa seria o uso de recursos financeiros que cubram os custos de transporte e alimentação dos pacientes, os quais não eram disponíveis para a condução desta pesquisa.

Logo após o segundo encontro, no qual se finalizou a intervenção educativa, foi realizada nova mensuração do conhecimento por meio da aplicação do mesmo questionário aplicado antes da intervenção. A análise estatística do desempenho dos candidatos mostrou um aumento significante do conhecimento, quando comparado ao momento anterior à implementação da intervenção. A análise estatística dos índices de acertos e erros foi estatisticamente significante, corroborando desse modo, com a hipótese alternativa $(\mathrm{H} 1)$ do estudo, ou seja, houve aumento do 
conhecimento dos candidatos que aguardam em fila de espera a realização de um transplante de fígado após a implementação de uma intervenção educativa.

Apesar da intervenção ter se mostrado efetiva na aquisição de conhecimento, dois pacientes apresentaram um desempenho inferior à primeira mensuração do conhecimento antes da intervenção. Vale ressaltar que ambos sofreram interferência de fatores externos o que pode ter contribuído para tal desempenho. É interessante apontar também que dois pacientes mantiveram o mesmo desempenho antes e depois da intervenção.

Em relação às questões formuladas para mensurar o conhecimento apresentado pelos candidatos ao transplante de fígado, houve diferença estatisticamente significante entre os acertos das questões antes e após a intervenção educativa. As questões relacionadas com a experiência do pósoperatório apresentaram um aumento significativo nos acertos após a intervenção. Em contrapartida, a questão que obteve o índice menor de acertos foi relacionada aos cuidados necessários após o transplante. Ressalta-se que na intervenção educativa essa temática foi amplamente explorada, apesar de mais de $65 \%$ dos candidatos não terem compreendido a necessidade destes cuidados. A não compreensão da necessidade de mudança de estilo de vida após a cirurgia pode de alguma forma comprometer a evolução clínica pós-operatória. Isso sugere uma evidência de que o autocuidado e o automanejo da saúde/doença precisam ser fortalecidos ainda no período de espera para o transplante, para não comprometer o sucesso do tratamento, papel fundamental da equipe de transplante.

Em um centro de transplante de fígado do Reino Unido, antes do paciente ser aceito para inclusão em lista de espera, candidatos e familiares/cuidadores são requisitados a freqüentar uma sessão grupal educativa apresentada por uma equipe de enfermeiros coordenadores de transplante. É realizada uma sessão grupal de aproximadamente duas horas. Três meses após a sessão grupal é aplicado um questionário para avaliar a intervenção ministrada. Os autores concluíram que a introdução de sessões de ensino grupais têm ajudado a manejar o tempo dispedido pela equipe no ensino dos pacientes. Outro dado do estudo evidenciou um pobre entendimento sobre o processo de transplante tanto por pacientes quanto por familiares ou cuidadores (ASHCROFT, 2009).

Em outras populações, estudos conduzidos têm mostrado a eficácia de intervenções educativas na promoção de conhecimento para o autocuidado. Um 
estudo realizado na Itália objetivou investigar a eficácia de uma intervenção educativa para pacientes com psoríase, avaliando o ganho de conhecimento e atitudes relacionadas ao tratamento médico. Para tanto foi implementada uma intervenção educativa com a duração de duas horas, na qual informações sobre psoríase e seu tratamento foram dadas. Um questionário foi aplicado antes e depois da intervenção e após seis meses. Os resultados evidenciados mostraram um alto grau de satisfação com a intervenção, melhora do conhecimento sobre a doença e atitudes positivas com a terapia proposta (LORA et al., 2009).

Uma pesquisa européia, publicada em 2009, avaliou a validade de conteúdo e utilização de um sistema de informação sobre transplante de órgãos (OTIS ${ }^{\mathrm{TM}}$ ) na educação de receptores de transplante de rim. Esse sistema é computacional para o treinamento e avaliação de receptores de transplante idealizado por hospitais de transplante da Alemanha e Reino Unido em 2000, com o objetivo de aumentar o automanejo dos pacientes em relação ao transplante. O programa contém textos e componentes de multimídia tais como: gráficos, simulações e vídeos, divididos em seis módulos (pré-transplante, seu transplante, medicamentos no transplante, seus medicamentos no transplante, rejeição e infecção e alta hospitalar). Apesar dos problemas relacionados à linguagem e aspectos técnicos de navegação, o programa foi avaliado pelos pacientes como uma ferramenta útil na aquisição de conhecimento da doença, tratamento e necessidades de autocuidado para o desenvolvimento de automanejo a longo prazo do transplante de rim (SCHAFER-KELLER et al., 2009).

$\mathrm{Na}$ Espanha, estudo realizado com o objetivo de avaliar a eficácia de estratégias de ensino-aprendizagem para pacientes submetidos ao transplante de fígado, os autores compararam o cumprimento das recomendações dadas na alta hospitalar entre os pacientes que receberam somente informações verbais, com aqueles que receberam informações escrita e/ou audiovisual. Na pesquisa foi utilizado um questionário para mensurar o cumprimento da terapêutica proposta na alta hospitalar, o qual abordava hábitos de vida diária, hábitos nocivos, tratamento farmacológico, uso de medidas de prevenção (vacinas, protetor solar), exercício físico e situações de urgência. Os resultados mostraram que os pacientes que receberam apenas informações verbais tiveram um menor cumprimento das recomendações dadas na alta, quando relacionados aos pacientes que tiveram suporte escrito e/ou audiovisual no processo educativo (CEREZO et al., 2001). Tal estudo corrobora com os resultados do presente estudo uma vez que se utilizou 
recurso audiovisual para implementar a intervenção educativa, a qual à princípio, se mostrou eficaz para a amostra estudada.

No Brasil, existem poucos estudos que investigam o ensino e a aprendizagem de pacientes em programas de transplante de fígado. Em 2005 foi publicado um estudo, cujo objetivo foi descrever os resultados de aprendizagem da experiência de implementação de estratégias de ensino com candidatos em fila de espera para o transplante de fígado. Trata-se de um estudo descritivo, no qual foi aplicado um questionário de conhecimento, baseado nas informações escritas fornecidas ao candidato no momento de entrada no cadastro técnico (folheto informativo sobre o processo de transplante de fígado). O questionário foi aplicado antes da realização de uma discussão de caráter educativo, na qual os pacientes e os familiares verbalizavam suas dúvidas, e recebiam mais informações sobre o processo de transplante. Os resultados mostraram uma média de acertos global do questionário de conhecimento de aproximadamente $80 \%$, sendo que os pacientes obtiveram índices de acertos maiores nas questões relacionadas ao período pré-operatório (SASSO et al., 2005).

Em 2007, outro estudo brasileiro foi publicado e avaliou a eficácia de um grupo interdisciplinar de orientação para candidatos ao transplante de fígado. Utilizou-se um questionário com 17 itens para avaliar a opinião dos pacientes em relação ao processo de transplante. A eficácia do grupo foi avaliada de acordo com a porcentagem de respostas corretas, antes e após a participação no grupo. A intervenção se deu em uma sessão de aproximadamente duas horas. Os resultados mostraram que houve um incremento de 59\% nas respostas corretas após a intervenção (GUIMARO et al., 2007); entretanto, o estudo não apontou como o questionário foi construído e validado.

No presente estudo, observou-se um incremento próximo a $13 \%$ do desempenho dos candidatos, em relação ao conhecimento mensurado antes e depois da intervenção, o que corresponde a uma melhora média de desempenho equivalente a quase $20 \%$. Conforme já apontado, a elaboração do questionário foi baseada não somente no folheto informativo entregue ao candidato, mas, sobretudo, na literatura internacional, além deste aspecto, o instrumento foi submetido à validação aparente e de conteúdo para assegurar a confiabilidade dos resultados evidenciados. Assim, fica claro a necessidade de construção e validação de questionários de conhecimento voltados aos candidatos e receptores de transplante de fígado na realidade nacional, sendo esta uma sugestão para estudos futuros, o 
que possibilitaria a uniformização das variáveis mensuradas e viabilizaria a análise de conhecimento adquirido em diversos centros transplantadores.

Em Nebraska no ano de 1996 foi publicado um estudo que descreveu o desenvolvimento de um programa educativo de um centro de transplante para pacientes e familiares, o qual era fundamentado nos conceitos de cuidado cooperativo. Em relação ao transplante de fígado, no período pré-operatório, um pacote de informações é entregue ao paciente e a sua família. O enfermeiro coordenador de transplante discute com os pacientes e familiares o que se espera durante o processo de transplante, apontando os riscos e benefícios do procedimento. Adicionalmente, um folheto informativo por escrito é entregue para os candidatos e familiares. O contato telefônico gratuito é realizado para sanar dúvidas e questionamentos durante o processo de transplante. No período pós-operatório um novo material por escrito com informações inerentes a esse período, é novamente entregue aos pacientes. Ainda durante a internação, o enfermeiro coordenador de transplante diariamente revisa todas as informações com os pacientes, isso ocorre do quarto ao sétimo dia de pós-operatório e, 24 horas antes da alta hospitalar, toda terapêutica medicamentosa é revisada com instruções da alta e seguimento pósoperatório (FRANCO et al., 1996).

Um ensaio clínico randomizado realizado na Finlândia em 2008 comparou o ganho cognitivo de pacientes de um ambulatório de cirurgia ortopédica utilizando-se de estratégia educativa baseada na internet em contraste com a educação face a face conduzida por um enfermeiro. O conhecimento dos pacientes foi avaliado por meio de questionários específicos. Os resultados mostraram que os pacientes dos dois grupos apresentaram aumento do conhecimento; entretanto, os pacientes que foram submetidos à estratégia educativa computacional apresentaram ganho significativo em relação à estratégia face a face. Devido às dificuldades de manejo de tempo e recursos humanos para a condução de estratégias de ensino e aprendizagem para os pacientes, o uso do computador mostrou-se efetivo no estudo (HEIKKINEN et al., 2008). A área de transplantes de órgãos é carente em relação aos estudos de educação de pacientes, assim implementar uma estratégia com o uso do computador, seria de grande valia para aprimorar o conhecimento dos pacientes, em uma terapêutica tão complexa como o transplante de fígado.

Nesta mesma temática, em 2007 foi publicado um ensaio clínico randomizado na Holanda que comparou o nível de conhecimento e a satisfação após educação de paciente baseada no computador e educação face a face realizada pelo médico em 
uma clínica de cirurgia plástica. A análise dos resultados evidenciou que o uso do computador acarretou níveis maiores de conhecimento; entretanto, a satisfação foi semelhante nos dois grupos (KEULERS et al., 2007).

Os estudos mencionados anteriormente indicam uma nova era no que se refere ao ensino dos pacientes, uma vez que a tecnologia computacional tem se tornado mais acessível para as pessoas de uma forma geral.

Frente aos resultados obtidos na presente investigação, pode-se afirmar que houve aumento do conhecimento em relação ao processo de transplante de fígado pelos candidatos em fila de espera. Entretanto, não foi possível dizer se tal conhecimento levou ou não a mudanças de estilo de vida e de comportamento, uma vez que não foi objeto da presente pesquisa, sendo este um próximo passo para futuras investigações nesta temática.

Para o planejamento da intervenção educativa utilizou-se os conceitos teóricos propostos por Ohler (2003), os quais abordam aspectos a serem discutidos com os candidatos em processo de avaliação para um transplante, frente às características clínicas específicas a esta clientela. As recomendações feitas pelo autor foram de grande valia e se mostraram adequadas para o planejamento da intervenção educativa ora apresentada.

Os pressupostos teóricos de Gagné (1980a, b) mostram que a aprendizagem ocorreu quando se observa que houve uma modificação no desempenho do aprendiz. Segundo as fases de um ato de aprendizagem propostas por este autor - motivação, apreensão, aquisição, retenção, rememoração, generalização, desempenho e feedback - observou-se que por meio da informação verbal, utilizando-se as estratégias audiovisuais propostas, capazes de estimular os órgãos dos sentidos dos candidatos, a meta de aumento cognitivo a curto prazo foi atingida, por meio do desempenho dos pacientes no questionário de conhecimento sobre o processo de transplante de fígado, antes e após a intervenção educativa. A inferência sobre a aquisição de aprendizagem pelos candidatos foi realizada por meio do questionário de conhecimento e os resultados da aplicação deste permitiram observar que, de alguma forma, a aprendizagem foi efetiva, pelo menos a curto prazo.

Dentre as categorias principais de resultados de aprendizagem, a informação verbal, considerada essencial para os candidatos que aguardam o transplante de fígado, teve a potencialidade de gerar um corpo de conhecimento para os pacientes 
participantes desta pesquisa. Espera-se que tais informações tenham gerado uma codificação, ou seja, foram incorporadas em um conjunto significativo de outras informações presentes na memória do aprendiz, e dessa forma, gerar modificações necessárias para contribuir para o sucesso do transplante. Investigações futuras são imprescindíveis para avaliar os resultados de um processo de ensino-aprendizagem a longo-prazo, bem como a influência do ensino nas mudanças de comportamento e estilo de vida.

\subsubsection{Satisfação dos candidatos após a implementação da intervenção educativa}

A provisão de informações de qualidade para os pacientes têm sido reconhecida como essencial para promover um cuidado de saúde apropriado, capaz de desenvolver estratégias de autocuidado tão necessárias para a continuidade do tratamento fora do ambiente hospitalar. Igualmente, oferecer informações de qualidade para o paciente cirúrgico tem gerado aumento de conhecimento, satisfação e bem estar no período pós-operatório, além de uma diminuição da ansiedade com a experiência cirúrgica (WALKER, 2007; SENSOR, 2009).

Para promover o preparo de candidatos em fila de espera para o transplante, o presente estudo lançou mão de uma estratégia de ensino-aprendizagem para avaliar o ganho de conhecimento, o qual obteve resultados estatisticamente significantes de aumento cognitivo.

Um dos objetivos deste estudo foi avaliar a satisfação dos candidatos após a implementação da intervenção educativa. Para tanto foi construído e validado um instrumento auto-aplicável para a avaliação da satisfação com as informações recebidas na intervenção educativa. Neste estudo, a satisfação foi definida como uma avaliação positiva do indivíduo em relação às informações recebidas.

Vale ressaltar que a satisfação é considerada um importante indicador para a avaliação do cuidado nos serviços de saúde. Tem sido amplamente utilizada como tal pelas organizações de saúde em todo mundo. A satisfação do paciente é significante, pois prediz a continuidade do tratamento médico pelo paciente, o uso dos serviços de saúde, e até mesmo aspectos do relacionamento com provedores da saúde (WOODWARD et al., 2000; BOUDREAUX; MANDRY; WOOD, 2003).

Os resultados do instrumento de satisfação com as informações recebidas no programa educativo mostraram índices altos de satisfação entre os candidatos ao transplante de fígado. A pontuação máxima do instrumento era de 70 pontos e cada 
item recebeu uma classificação de um a 10 - sendo que um significava "insuficiente" e 10 "excelente". A análise estatística mostrou uma satisfação média de quase 65 pontos, sendo em termos de porcentagem equivalente a mais de $90 \%$ do total de pontos possíveis de serem obtidos em relação à satisfação. Sete itens foram avaliados, dentre eles as informações recebidas sobre o período de espera para o transplante, o procedimento cirúrgico e anestésico, o pós-operatório e os cuidados necessários por toda vida, além da qualidade das informações recebidas, avaliação das aulas educativas e percepção de aumento das informações pelo candidato.

Em relação aos itens que compuseram o instrumento, todos obtiveram uma avaliação positiva, com uma média superior a 9 pontos para cada um. As informações recebidas sobre o período pós-operatório e os cuidados necessários por toda a vida causaram índices maiores de satisfação entre os candidatos. $O$ item que obteve o menor índice de satisfação foi relacionado ao ganho cognitivo após a intervenção educativa, mesmo assim, obteve média de 8,87 pontos. Frente aos resultados anteriores obtidos no presente estudo - necessidades de informação e questionário de conhecimento sobre o transplante de fígado - fica claro a necessidade de prover mais informações sobre o que se espera em relação ao transplante de fígado, especialmente a experiência pós-cirúrgica e as necessidades de mudanças de estilo de vida, a fim de contribuir para o sucesso do tratamento.

Especula-se que a falta de tempo, a sobrecarga de atividades dos profissionais e mesmo as dificuldades dos pacientes em processar as informações providas pela equipe de transplante, têm a potencialidade de influenciar a provisão de informações sobre o processo de transplante aos candidatos, e repercutir na satisfação dos usuários. Entretanto, estudos futuros precisam ser desenvolvidos para avaliar a influência de tais fatores nos programas educativos existentes.

Todos os candidatos que compuseram a amostra do estudo piloto recomendaram o programa educativo para outros pacientes. Muitos pacientes julgaram importantes as aulas ministradas e valorizaram as informações fornecidas. De acordo com os relatos dos candidatos, as aulas permitiram obtenção de informações corretas e adequadas, com esclarecimento de dúvidas, além de ser uma oportunidade para o aprendizado. Apesar de compreenderem a importância de saberem informações específicas sobre o perioperatório, alguns pacientes relataram que a prevenção de complicações e a necessidade de mudanças de estilo de vida eram prioritárias, principalmente no período pós-operatório, considerado a fase de dificuldade maior por alguns candidatos. 
Um aspecto que pode ter contribuído para a satisfação com a intervenção educativa dos candidatos em fila de espera, foi promover um debate entre os candidatos e receptores de transplante. Ao final do segundo encontro com os candidatos, dois receptores foram convidados para trazer suas experiências de vida com o processo de transplante. Um com maior experiência (mais de três anos) e outro com menor experiência (menos de três anos) de transplante. Apesar de não ter sido mensurada, a estratégia de mostrar uma realidade que apresenta um potencial de sucesso - no caso a vida após o transplante - trouxe muita gratificação entre os candidatos. Recomenda-se estudos futuros que possam avaliar o impacto de permitir trocas de experiências entre candidatos e receptores de transplante, incluindo-se a presença de familiares como cônjuge e filhos, pois se trata das pessoas que irão vivenciar dificuldades no período de convalescença e reabilitação após o transplante.

A literatura é escassa de estudos que avaliaram a satisfação de candidatos e receptores de transplante de órgãos com informações fornecidas pela equipe de saúde. Os estudos encontrados na área dos transplantes enfocam principalmente a satisfação com o tratamento médico (HRICIK et al., 2001; MATAS et al., 2002), com a vida após o transplante (SIEGAL; HALBERT; MCGUIRE, 2002) e a qualidade de vida (FEURER; RUSSELL; PINSON, 2007).

O único estudo encontrado foi realizado no Canadá em 2003 com o objetivo de avaliar a satisfação de candidatos ao transplante de rim em relação a um programa educativo interativo desenvolvido para ensinar pacientes sobre o processo de transplante ("Transplant Friends"). A escala de satisfação avaliou o conteúdo fornecido, o facilitador e o perfil da programação proposta. Os pacientes avaliaram o programa como necessário para auxiliar no processo de tomada de decisão para o transplante e positivo para o ganho de experiências (SHARKEY; GOURISHANKAR, 2003). Esses resultados corroboram com os evidenciados na presente investigação, quando analisados os relatos obtidos em questão do tipo aberta e já mencionados anteriormente.

Em 2006, no Reino Unido foi publicado um ensaio clínico randomizado, com o objetivo de estabelecer o quanto à provisão de informações por escrito, em adição com a rotina de informação hospitalar, pode melhorar o conhecimento e a satisfação de pacientes submetidos a cirurgias eletivas. O grupo experimental foi composto pelos pacientes que receberam as informações por escrito e o grupo controle pelos pacientes que receberam informações padronizadas da rotina do hospital. O grupo 
experimental demonstrou conhecimento maior no período pré-operatório. Em relação à satisfação, os pacientes apresentaram altos escores, sendo os resultados similares nos dois grupos (SHEARD; GARRUD, 2006). Esses resultados também vão de encontro aos resultados obtidos na presente investigação, pois os candidatos apresentaram níveis maiores de conhecimento sobre o período pré-operatório e demonstraram altos índices de satisfação com as informações fornecidas.

Um estudo piloto publicado em 2007, teve como objetivo avaliar a relação do conhecimento com a satisfação de pacientes com osteoartite e artrite reumatóide. Foi avaliada a qualidade das informações fornecidas durante o processo de consentimento informado, a autopercepção de conhecimento, uma avaliação objetiva do conhecimento e a satisfação geral dos participantes. A qualidade das informações fornecidas durante o processo de consentimento informado foi considerada alta e $51 \%$ dos pacientes tinham percepção de ganho de conhecimento. A satisfação geral também foi alta (95\% dos pacientes). Entretanto, não foi encontrada correlação significante entre o conhecimento e a satisfação dos pacientes (BERTOLI et al., 2007). A presente investigação demonstrou relação significativa entre o conhecimento final com o grau de satisfação dos candidatos ao transplante de fígado, no entanto, a variação de desempenho no conhecimento antes e depois da intervenção não apresentou correlação significante com o nível de satisfação apresentado.

Nos EUA em 2000 foi realizada uma pesquisa para investigar a associação da obtenção de informações e seu impacto na satisfação de pacientes cirúrgicos. Os resultados obtidos mostraram uma forte correlação entre as informações recebidas e a satisfação dos pacientes (KRUPAT; FANCEY; CLEARY, 2000).

Frente ao exposto, as divergências de resultados de pesquisa podem ocorrer devido às diferentes metodologias adotadas nos estudos desta natureza, e a necessidade de análises rigorosas em casuísticas que possibilitem a generalização dos resultados de pesquisa.

Um estudo realizado no Reino Unido em 1995 avaliou a satisfação de pacientes atendidos em um ambulatório de doenças respiratórias com as informações recebidas. O estudo era um "survey" com 374 pacientes, os resultados indicaram que as informações sobre o tratamento da doença foram as mais relatadas pelos sujeitos participantes; entretanto, apenas um quarto dos pacientes recebeu informações sobre o prognóstico da doença. A média geral de satisfação com as 
informações recebidas foi de $88,3 \%$ e não há descrição de sessões formais de educação voltadas para os pacientes (PAPAGIANNIS; RICHARDS; SHALE, 1995).

Outra investigação realizada na Suécia em 2001 avaliou o suprimento de informações na satisfação de pacientes oncológicos com as informações recebidas durante o tratamento de radioterapia. Para avaliar a eficácia de vários meios de se obter a informação, 210 pacientes foram randomicamente divididos em três grupos, a saber: um com pacientes que receberam informações padronizadas associada a sessões educativas grupais e individuais por enfermeiros, outro de pacientes que receberam informações padronizadas associada com um folheto informativo por escrito, e o último grupo de pacientes que apenas receberam informações padronizadas sobre a rotina hospitalar. Os pacientes que participaram de sessões grupais e individuais de fornecimento de informações pelos enfermeiros tiveram índices de satisfação significativamente maior do que os outros grupos (HAGGMARK et al., 2001). Esses resultados corroboram com a presente investigação na qual utilizou de estratégia de ensino-aprendizagem grupal para fornecer informações aos candidatos ao transplante de fígado, os quais apresentaram níveis altos de satisfação com as informações recebidas.

Um estudo realizado na Austrália em 2004 investigou o entendimento do paciente e sua satisfação relacionada ao consentimento informado e a cirurgia no pré-operatório de artroscopia de joelho. Os resultados mostraram que apesar dos pacientes receberem muitas informações sobre a natureza da injúria e do procedimento cirúrgico, poucas informações eram dadas sobre as complicações e cuidados pós-operatórios. Poucos pacientes sentiram que receberam uma quantidade grande de informações em relação às variáveis questionadas. Em relação ao nível de satisfação foram constatados níveis altos de insatisfação com as informações dadas pela equipe de saúde (MCGAUGHEY, 2004). Tais resultados podem ter implicações médicas, éticas e legais que necessitam ser observadas. Isso indica a importância de implementar estratégias de ensino-aprendizagem no período pré-operatório. A tomada de decisão fundamentada nas informações recebidas sobre o procedimento cirúrgico é prioritária para promover a adesão ao tratamento proposto, além de permitir que 0 paciente se torne sujeito ativo para 0 autocuidado $e$, conseqüentemente, acarretar padrões de satisfação que indiquem qualidade das informações providas. 
Para concretizar o papel importante dos enfermeiros no quesito provisão de informações aos pacientes, em 2005 foi publicado um estudo francês, cujo objetivo foi avaliar as informações fornecidas e a satisfação dos pacientes em um ambulatório de cirurgia oncológica de mama. Os resultados apontaram níveis altos de satisfação entre os pacientes. Em relação à provisão de informações sobre o pós-operatório, foi observada na equipe médica uma média de 8,9 pontos (em uma escala de um a 10), enquanto que os enfermeiros receberam uma média de 9,33 pontos (MARCHAL et al., 2005). Esse estudo demonstra a importância do papel catalisador do enfermeiro no que se refere à educação dos pacientes.

Assim, o papel de educador do enfermeiro fica claro, bem como a sua relevância no preparo de pacientes, especialmente para os procedimentos cirúrgicos complexos como os transplantes de órgãos. É imperativo que esse profissional realize o planejamento e a implementação de estratégias educativas capazes de fortalecer os vínculos e os níveis de satisfação entre os pacientes.

Avaliar a satisfação dos candidatos ao transplante de fígado em relação às informações fornecidas na intervenção educativa foi útil na avaliação do planejamento e das ações propostas para aprimorar o ganho cognitivo dos pacientes. Os resultados forneceram dados que proporcionaram auxílio para a condução de estudos futuros nesta temática. Frente aos resultados obtidos, em análise conjunta com os dados da literatura, é visível a importância de estudos desta natureza. Os provedores da saúde, em especial os enfermeiros, devem estar abertos a mudanças e traçar intervenções educativas que vão de encontro com as necessidades dos pacientes. Os estudos de avaliação da satisfação com as informações recebidas é um caminho para considerar se as intervenções implementadas geraram sentimentos positivos em relação às expectativas dos pacientes, principal razão para o cuidado em enfermagem. 


\section{CONCLUSÕES}

$\mathrm{Na}$ conclusão da presente pesquisa e tendo como eixo norteador o objetivo geral que consistiu em analisar o conhecimento dos candidatos que aguardam em fila de espera a realização de um transplante de fígado com doador falecido, antes e depois da implementação da intervenção educativa, apresenta-se as conclusões desta investigação de acordo com a seqüência dos objetivos específicos propostos.

O primeiro objetivo proposto foi caracterizar a amostra do estudo segundo as variáveis sócio-demográficas e clínicas. Conhecer as características da amostra investigada foi importante para dar subsídios para o planejamento da estratégia de ensino-aprendizagem, bem como, estabelecer relações entre as variáveis. Neste estudo, frente a uma casuística de 55 candidatos, observou-se uma predominância do sexo masculino, com idade média de 50,25 anos, média de 8,49 anos de estudo, $70,91 \%$ estavam afastados de atividades laborais e a renda predominante foi de dois a seis salários mínimos.

A maioria era CHILD B, com MELD médio de 14,91 pontos, $72,72 \%$ se encontravam acima do peso de acordo com o IMC e apresentavam um curso de evolução da doença crônica do fígado médio de 101,21 meses. A maioria apresentava cirrose hepática causada principalmente por vírus e alcoolismo. O tempo médio de fila de espera foi de 1199,58 dias. Dentre as principais manifestações clínicas apresentadas, destaca-se a presença de ascite $(58,18 \%)$, varizes esofágicas $(81,82 \%)$, encefalopatia hepática $(50,91 \%)$ e hemorragia digestiva prévia $(47,27 \%)$.

O segundo objetivo proposto foi identificar as necessidades de informação dos candidatos em fila de espera sobre o transplante de fígado. Os resultados apontaram necessidades de informação maiores em relação ao período pré-operatório do transplante, evidenciadas pela pontuação média obtida quanto aos cuidados necessários antes do transplante. As necessidades de informação frente às complicações após o transplante e os cuidados necessários após o transplante também foram indicadas como relevantes. As sugestões que apontaram necessidades de informação menores foram relacionadas aos medicamentos utilizados após o transplante, o funcionamento da lista de espera e as indicações e contra-indicações para o transplante. 
Diante dos objetivos direcionados para o conhecimento dos candidatos sobre o processo de transplante de fígado, antes e depois da implementação da intervenção educativa, observou-se um ganho cognitivo significativo após a intervenção, com uma melhora média de quase $20 \%$ no desempenho. A análise estatística mostrou $\mathrm{p}<0,05$ em relação aos índices de acertos antes e depois da intervenção.

Finalmente, diante do objetivo de avaliar a satisfação dos candidatos após a implementação da intervenção educativa, observou-se uma avaliação positiva da satisfação com as informações recebidas. As informações que geraram índices maiores de satisfação foram relacionadas ao período pós-operatório e aos cuidados necessários por toda a vida. A relação entre o conhecimento dos pacientes após a intervenção e o grau de satisfação mostrou uma correlação significativa $(p<0,05)$.

Apesar de se tratar de um estudo piloto, cuja amostra foi reduzida, conclui-se que a implementação de uma intervenção educativa, utilizando os conceitos teóricometodológicos propostos por Ohler e Gagné, contribuiu para melhorar o conhecimento e a satisfação com as informações recebidas após a intervenção, de candidatos ao transplante de fígado de um centro transplantador do interior paulista. 
9. Consíderaçães JFinaís 


\section{CONSIDERAÇÕES FINAIS}

De acordo com os resultados evidenciados na presente investigação e com base na literatura consultada podemos inferir que a informação é vital para o cuidado de candidatos ao transplante de órgãos, em especial, o transplante de fígado. Na ausência de informações sobre o processo de transplante - antes, durante e após a cirurgia, os pacientes e familiares têm dificuldades de se tornarem sujeitos ativos para o autocuidado. Caso o paciente desconheça a importância de seguir as recomendações da equipe de transplante, tais como: mudanças de estilo de vida, ingestão dos medicamentos prescritos, prática cautelosa de exercícios físicos, restrições alimentares e dieta que auxilie no manejo dos sinais e sintomas da doença crônica do fígado, informações sobre a cirurgia e o curso pós-transplante, cuidados necessários por toda vida, entre outras, ele poderá se tornar um ser passivo, além de estar sujeito a complicações que poderiam ser prevenidas pela aquisição de uma determinada informação.

Outro aspecto importante são as atribuições das equipes de transplantes. Inúmeras tarefas voltadas para o cuidado de candidatos, somadas ao crescente número de pessoas em fila de espera, frente a pouca oferta de órgãos para transplante, faz com que o tempo disponível para informarem os pacientes seja cada vez mais escasso. Vale ressaltar que se trata de uma modalidade terapêutica de extrema complexidade, sem falar das dificuldades que muitos pacientes apresentam em processar, entender e colocar em prática as informações orais fornecidas, requerendo para tanto, outras estratégias de ensino-aprendizagem que venham de encontro com as necessidades dos pacientes.

Diante disso, as equipes de transplante de fígado, têm em sua composição o enfermeiro, geralmente responsável pela coordenação do transplante. Esse profissional, além de ter uma formação para a educação de pacientes, é o membro da equipe com vínculo mais próximo desta clientela. Muitas vezes o enfermeiro de transplante, que, sobretudo advoga pelos direitos e segurança dos candidatos ao transplante, é o membro da equipe mais apto a identificar as necessidades dos pacientes diante dos estreitos laços construídos na relação enfermeiro-paciente.

Saber que tipo de informações os candidatos desejam, juntamente com as características sociais, demográficas e clínicas desta população são de grande valia para o planejamento de estratégias de ensino-aprendizagem. Os dados da presente investigação mostraram que os candidatos são carentes de informações relacionadas 
especialmente à fase que estão vivenciando, ou seja, o período pré-operatório. Além desse aspecto, também houve a constatação de lacunas de informações sobre os cuidados necessários antes do transplante, as complicações após o transplante e os cuidados requeridos por toda a vida após a cirurgia.

Na literatura há estudos sobre as necessidades de informação de pacientes de uma forma geral. No entanto ainda é carente, as pesquisas dessa natureza que enfoquem os candidatos ao transplante de fígado. As formas para mensurar as necessidades de informação dos pacientes, também tem sido foco de alguns estudos, não havendo na literatura nacional nenhuma escala validada voltada para o processo de transplante.

A opção de utilizar um instrumento elaborado pelo pesquisador, o qual foi submetido à validação aparente e de conteúdo, bem como a realização de um teste piloto para a coleta de dados do presente estudo, mostrou ser adequado na obtenção das necessidades de informação de candidatos ao transplante de fígado. Entretanto, recomendam-se outros estudos que possibilitem a validação de instrumentos para mensurar as necessidades de informação de pacientes em programas de transplantes de órgãos. Também será de grande valia a produção de pesquisas que busquem as necessidades de informações de familiares e cuidadores, uma vez que no transplante de fígado, a família ou o cuidador exerce um papel fundamental principalmente na fase inicial de reabilitação da cirurgia.

Apenas fornecer informações por escrito para os pacientes não parece, a princípio, ser uma estratégia eficaz para propiciar conhecimento sobre o processo de saúde-doença, pois no presente estudo, observou-se que alguns pacientes não leram as informações contidas no folheto informativo. Além disso, a proposta de aplicar um questionário de conhecimento antes da condução de uma estratégia de ensinoaprendizagem apontou um conhecimento limitado dos pacientes sobre o processo de transplante. Este estudo demonstra a importância de se produzir estratégias educativas (aulas dialogadas, folhetos informativos, etc) em congruência com as necessidades de informação e os déficits de conhecimento identificados pelos pacientes. Além do aumento cognitivo conseguido, por meio da implementação da intervenção educativa, na presente investigação a satisfação mostrou ser um parâmetro indicativo da qualidade da intervenção proposta. 
O desenvolvimento de um programa educativo grupal na fase pré-transplante, capaz de melhorar o entendimento do paciente e promover mais informação sobre a experiência cirúrgica acarreta benefícios tanto para os candidatos quanto para os familiares ou cuidadores. As intervenções em grupos podem intensificar o entendimento, desenvolver habilidades e atitudes, além de promover uma responsabilização dos pacientes para o autocuidado. O planejamento de uma intervenção educativa, com uso de recursos audiovisual, pareceu ser efetivo em relação ao ganho de conhecimento antes e depois da intervenção, na proposta do estudo piloto conduzido. No entanto, pesquisas futuras que assegurem um tamanho amostral representativo da população devem ser elaboradas para reforçar as evidências da presente investigação.

O presente estudo foi o primeiro a oferecer uma base científica para atividades educativas voltadas aos candidatos ao transplante de fígado no contexto brasileiro. Trouxe também evidências que a provisão de informações de qualidade é capaz de aumentar o conhecimento e proporcionar a satisfação dos pacientes. Os resultados ora apresentados podem ser utilizados na prática clínica do enfermeiro nos diversos centros de transplantes nacionais. Espera-se também que tais evidências possam ser utilizadas no desenvolvimento de outras intervenções educativas durante o período pré-operatório, quiçá avaliando as modificações de comportamento e estilos de vida, advindas com as estratégias de ensinoaprendizagem incorporadas pelos pacientes. 


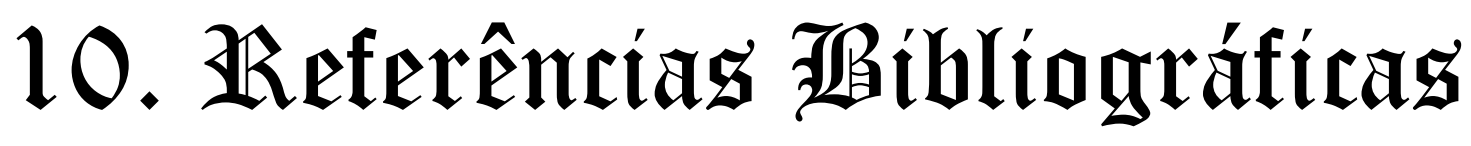




\section{REFERÊNCIAS BIBLIOGRÁFICAS ${ }^{1}$}

ABBASOGLU, O. Liver transplantation: yesterday, today and tomorrow. World Journal of Gastroenterology, v. 14, n. 20, p. 3117-3122, 2008.

ADAMS, E.; BOULTON, M.; WATSON, E. The information needs of partners and family members of cancer patients: a systematic literature review. Patient Education and Counseling, v. 77, n. 2, p. 179-186, 2009.

ADANI, G. L. et al. Elderly versus young liver transplant recipients: patient and graft survival. Transplantation Proceedings, v. 41, n. 4, p. 1293-1294, 2009.

ALBUQUERQUE, A. S.; TRÓCCOLI, B. T. Desenvolvimento de uma escala de bemestar subjetivo. Psicologia: Teoria e Pesquisa, v. 20, n. 2, p. 153-164, 2004.

ASHCROFT, P. Adapting patient education for potential liver transplant recipients in a climate of chronic donor organ shortfall. Progress in Transplantation, v. 19, n. 1, p. 59-63, 2009.

ASRANI, S. K.; KIM, W. R. Organ allocation for chronic liver disease: model for endstage liver disease and beyond. Current Opinion in Gastroenterology, v. 26, n. 3, p. 209-213, 2010.

ASSOCIAÇÃO BRASILEIRA DE TRANSPLANTE DE ÓRGÃOS. Dados gerais. Registro Brasileiro de Transplantes, v. Ano XV, n. 4, p. 1-21, 2009.

AXELROD, D. A. et al. Rates of solid-organ wait-listing, transplantation, and survival among residents of rural and urban areas. JAMA, v. 299, n. 2, p. 202-207, 2008.

$B A K R$, I. et al. Higher clearance of hepatitis $C$ virus infection in females compared with males. Gut, v. 55, n. 8, p. 1183-1187, 2006.

BARLESI, F. et al. Impact of information on quality of life and satisfaction of nonsmall cell lung cancer patients: a randomized study of standardized versus individualized information before thoracic surgery. Journal of Thoracic Oncology, v. 3, n. 10 , p. $1146-1152,2008$.

\footnotetext{
${ }^{1}$ Fonte: Universidade de São Paulo. Sistema Integrado de Bibliotecas da USP. Diretrizes para a apresentação de dissertações e teses da USP. $2^{a}$ Ed. São Paulo: SIBI USP, 2009. 102p.
} 
BARTELS, M.; BOOMSMA, D. I. Born to be Happy? The Etiology of Subjective WellBeing. Behavior Genetics, v. 39, n. 6, p. 605-615, 2009.

BASS, M. et al. A diversified patient education program for transplant recipients. ANNA Journal, v. 26, n. 3, p. 287-292, 343, 1999.

BASTABLE, S. B. Essentials of Patient Education. Sudbury, MA: Jones \& Bartlett Publishers, 2006. 502 p.

BECKER, P. T. Publishing pilot intervention studies. Research in Nursing and Health, v. 31, n. 1, p. 1-3, 2008.

BERNIER, M. J. et al. Preoperative teaching received and valued in a day surgery setting. AORN Journal, v. 77, n. 3, p. 563-572, 575-578, 581-582, 2003.

BERTOLI, A. M. et al. Lack of correlation between satisfaction and knowledge in clinical trials participants: a pilot study. Contemporary Clinical Trials, v. 28, n. 6, p. $730-736,2007$.

BOTERO, R. C.; LUCEY, M. R. Organ allocation: model for end-stage liver disease, Child-Turcotte-Pugh, Mayo risk score, or something else. Clinics in Liver Disease, v. 7, n. 3, p. 715-727, IX, 2003.

BOUDREAUX, E. D.; MANDRY, C. V.; WOOD, K. Patient satisfaction data as a quality indicator: a tale of two emergency departments. Academic Emergency Medicine, v. 10, n. 3, p. 261-268, 2003.

BOURSIER, J. et al. Comparison and improvement of MELD and Child-Pugh score accuracies for the prediction of 6-month mortality in cirrhotic patients. Journal of Clinical Gastroenterology, v. 43, n. 6, p. 580-585, 2009.

BRAZEN, L. Perioperative Clinical Education. In: ROTH, R. A. (Ed.). Perioperative Nursing Core Curriculum. Philadelphia: WB Saunders Company, 1995. p.349-363. 
BRENNER, L. H.; BRENNER, A. T.; HOROWITZ, D. Beyond informed consent: educating the patient. Clinical Orthopaedics and Related Research, v. 467, n. 2, p. 348-351, 2009.

BROSTROM, A. et al. Perceived informational needs, side-effects and their consequences on adherence - a comparison between CPAP treated patients with OSAS and healthcare personnel. Patient Education and Counseling, v. 74, n. 2, p. 228-235, 2009.

BUFTON, S.; EMMETT, K.; BYERLY, A. M. Liver transplantation. In: OHLER, L.; CUPPLES, S. (Ed.). Core Curriculum for Transplant Nurses. St. Louis: Mosby Elsevier, 2008. p.423-454.

BUNZEL, B.; LAEDERACH-HOFMANN, K. Solid organ transplantation: are there predictors for posttransplant noncompliance? A literature overview. Transplantation, v. 70, n. 5, p. 711-716, 2000.

BUNZEL, B.; LAEDERACH-HOFMANN, K.; SCHUBERT, M. T. Patients benefit--partners suffer? The impact of heart transplantation on the partner relationship. Transplant International, v. 12, n. 1, p. 33-41, 1999.

CADAHIA, V. et al. Exclusions and deaths on the liver transplant waiting list. Transplantation Proceedings, v. 42, n. 2, p. 622-624, 2010.

CAMPOS, A. C.; MATIAS, J. E.; COELHO, J. C. Nutritional aspects of liver transplantation. Current Opinion in Clinical Nutrition and Metabolic Care, v. 5, n. 3, p. 297-307, 2002.

CARESS, A. L. et al. An exploratory study of priority information needs in adult asthma patients. Patient Education and Counseling, v. 47, n. 4, p. 319-327, 2002.

CARLSON, M. D. et al. Role of Sleep Disturbance in Chronic Hepatitis C Infection. Current Hepatitis Reports, v. 9, n. 1, p. 25-29, 2010. 
CASTRO, R. S. et al. Survival before and after model for end-stage liver disease score introduction on the Brazilian liver transplant waiting list. Transplantation Proceedings, v. 42, n. 2, p. 412-416, 2010.

CEREZO, M. C. M. et al. Estudio del proceso educativo en el paciente con trasplante hepático. Enfermería Intensiva, v. 12, n. 2, p. 58-65, 2001.

CHARVET-BERARD, A. I.; CHOPARD, P.; PERNEGER, T. V. Measuring quality of patient information documents with an expanded EQIP scale. Patient Education and Counseling, v. 70, n. 3, p. 407-411, 2008.

COATES, V. E. Education for patients and clients. London: Routledge, 1999. 248 p.

CONTI, G. J. Development of a user-friendly instrument for identifying the learning strategy preferences of adults. Teaching and Teacher Education, v. 25, n. 6, p. 887-896, 2009.

COX, A. et al. Information needs and experiences: an audit of UK cancer patients. European Journal of Oncology Nursing, v. 10, n. 4, p. 263-272, 2006.

CSETE, M. Gender issues in transplantation. Anesthesia and Analgesia, v. 107, n. 1, p. $232-238,2008$.

CUPPLES, S. A. Effects of timing and reinforcement of preoperative education on knowledge and recovery of patients having coronary artery bypass graft surgery. Heart and Lung, v. 20, n. 6, p. 654-660, 1991.

D'ALBUQUeRQUE, L. A. C. et al. Transplante ortotópico do fígado: bases técnicas. In: SILVA, A. O.; D'Albuquerque, L. A. C. (Ed.). Doenças do Fígado. Rio de Janeiro: Revinter, v.2, 2001. p. 928-963.

DE GEEST, S.; DOBBELS, F. Transplantation: Increasing adherence to immunosuppression: a clinical priority. Nature Reviews Nephrology, v. 6, n. 3, p. 139-140, 2010. 
DEL PINO, M. et al. Mortality risk score in liver transplantation: changes over time in its predicting power. Pediatric Transplantation, v. 10, n. 4, p. 466-473, 2006.

DEMARCO, J.; NYSTROM, M. S. Expanding education technology to meet the needs of patients, families, and clinicians. Health Promotion Practice, v. 10, n. 1, p. 1523, 2009.

DEVINE, E. C. Effects of psychoeducational care for adult surgical patients: a metaanalysis of 191 studies. Patient Education and Counseling, v. 19, n. 2, p. 129$142,1992$.

DIMARTINI, A. et al. Tobacco use following liver transplantation for alcoholic liver disease: an underestimated problem. Liver Transplantation, v. 11, n. 6, p. 679683, 2005.

DOAK, C. C.; DOAK, L. G.; ROOT, J. H. Teaching patients with low literacy skills. $2^{a}$ ed. Philadelphia: J.B. Lippincott Company, 1996. 212 p.

DOBBELS, F. et al. Pretransplant predictors of posttransplant adherence and clinical outcome: an evidence base for pretransplant psychosocial screening. Transplantation, v. 87, n. 10, p. 1497-1504, 2009.

DRENT, G. et al. Symptom experience, nonadherence and quality of life in adult liver transplant recipients. The Netherlands Journal of Medicine, v. 67, n. 5, p. 161168, 2009.

EHLERS, S. L. et al. Tobacco use before and after liver transplantation: a single center survey and implications for clinical practice and research. Liver Transplantation, v. 10, n. 3, p. 412-417, 2004.

FALVO, D. R. Effective patient education: a guide to increased compliance. $3^{a}$. Sudbury: Jones and Bartlett Publishers, 2004. 388 p.

FELDMAN-STEWART, D.; BRENNENSTUHL, S.; BRUNDAGE, M. D. A purpose-based evaluation of information for patients: an approach to measuring effectiveness. Patient Education and Counseling, v. 65, n. 3, p. 311-319, 2007. 
FERREIRA, L. G. et al. Desnutrição e inadequação alimentar de pacientes aguardando transplante hepático. Revista da Associação Médica Brasileira, v. 55, n. 4, p. 389-393, 2009.

FERRER, L.; RAFFAN, F. Enfoque perioperatorio de pacientes sometidos a trasplante hepático previamente. Revista Colombiana de Gastroenterología, v. 18, n. 2, p. 88-99, 2003.

FEURER, I. D.; RUSSELL, R. T.; PINSON, C. W. Incorporating quality of life and patient satisfaction measures into a transplant outcomes assessment program: technical and practical considerations. Progress in Transplantation, v. 17, n. 2, p. 121-128, 2007.

FINK, M. A. et al. Risk factors for liver transplantation waiting list mortality. Journal of Gastroenterology and Hepatology, v. 22, n. 1, p. 119-124, 2007.

FLAMME, N. E.; TERRY, C. L.; HELFT, P. R. The influence of psychosocial evaluation on candidacy for liver transplantation. Progress in transplantation, v. 18, n. 2, p. 89-96, 2008.

FLEMING, N. D. VARK, A Guide to Learning Styles. New Zealand 2009. Disponível em: <http://www.vark-learn.com/english/index.asp.>. Acesso em: 04 Fev. 2009.

FLYNN, B. M. Liver Transplantation. In: CUPPLES, S. A.; OHLER, L. (Ed.). Transplantation Nursing Secrets. Philadelphia: Hanley and Belfus, INC., 2003. p. 151-171.

FOX, V. J. Educação do paciente e planejamento da alta. In: ROTHROCK, J. C. (Ed.). Alexander: cuidados de enfermagem ao paciente cirúrgico. $13^{\mathrm{a}} \mathrm{ed}$. Rio de Janeiro: Elsevier, 2007. p.271-296.

FRANCO, T. et al. Developing patient and family education programs for a transplant center. Patient Education and Counseling, v. 27, n. 1, p. 113-120, 1996.

GAGNÉ, R. M. Como se realiza a aprendizagem. Rio de Janeiro: Livros Técnicos e Científicos Editora, 1980a. 270 p. 
Princípios essenciais da aprendizagem para o ensino. Porto Alegre: Editora Globo, 1980b. 175 p.

GALLEGOS-OROZCO, J. F.; VARGAS, H. E. Liver transplantation: from Child to MELD. The Medical Clinics of North America, v. 93, n. 4, p. 931-950, IX, 2009.

GALLOWAY, S. et al. Discharge information needs and symptom distress after abdominal aortic surgery. Canadian Journal of Cardiovascular Nursing, v. 8 , n. 3, p. 9-15, 1997.

GARRUD, P.; WOOD, M.; STAINSBY, L. Impact of risk information in a patient education leaflet. Patient Education and Counseling, v. 43, n. 3, p. 301-304, 2001.

GOETZMANN, L. et al. Waiting for a liver transplant: psychosocial well-being, spirituality, and need for counselling. Transplantation Proceedings, v. 38, n. 9, p. 2931-2936, 2006.

GONZÁLEZ, E. M. et al. Causas de muerte y supervivencia en el trasplante hepático. In: LÓPEZ, E. V.; PEINADO, C. B.; PÉREZ, F. P. (Ed.). Curso de actualización en trasplante hepático. Madrid: Fujisawa, 1998. p.249-258.

GORDON, F. D. 100 Questions and answers about liver transplantation: a Lahey Clinic guide. Sudbury: Jones and Bartlett Publishers, 2007. 199 p.

GRUPO INTEGRADO DE TRANSPLANTE DE FÍGADO, G. Manual de orientações aos pacientes inscritos em lista de espera para transplante de fígado. Hospital das Clínicas da Faculdade de Medicina de Ribeirão Preto da Universidade de São Paulo. 20 p. 2008.

GUIMARO, M. S. et al. Evaluation of efficacy in a liver pretransplantation orientation group. Transplantation Proceedings, v. 39, n. 8, p. 2522-2524, 2007. Psychosocial profile of patients on the liver transplant list. Transplantation Proceedings, v. 40, n. 3, p. 782-784, 2008. 
HAGGMARK, C. et al. Effects of information supply on satisfaction with information and quality of life in cancer patients receiving curative radiation therapy. Patient Education and Counseling, v. 45, n. 3, p. 173-179, 2001.

HALKETT, G. K. et al. Meeting breast cancer patients' information needs during radiotherapy: what can we do to improve the information and support that is currently provided? European Journal of Cancer Care, D.O.I. 10.1111/j.13652354.2009.01090.x, 2009.

HAWKINS, N. A. et al. Informational needs of patients and perceived adequacy of information available before and after treatment of cancer. Journal of Psychosocial Oncology, v. 26, n. 2, p. 1-16, 2008.

HEIKKINEN, K. et al. A comparison of two educational interventions for the cognitive empowerment of ambulatory orthopaedic surgery patients. Patient Education and Counseling, v. 73, n. 2, p. 272-279, 2008.

HERTZOG, M. A. Considerations in determining sample size for pilot studies. Research in Nursing \& Health, v. 31, n. 2, p. 180-191, 2008.

HRICIK, D. E. et al. Life satisfaction in renal transplant recipients: preliminary results from the transplant learning center. American Journal of Kidney Diseases, v. 38, n. 3, p. 580-587, 2001.

HUANG, H. C.; LEE, F. Y.; HUO, T. I. Major adverse events, pretransplant assessment and outcome prediction. Journal of Gastroenterology and Hepatology, v. 24, n. 11, p. 1716-1724, 2009.

INTERNATIONAL TRANSPLANT NURSES SOCIETY. Transplant patient educational materials. Pittsburg, 2008. Disponível em: <http://itns.org/education/patientmaterials>. Acesso em: 05 nov. 2009.

JACOBS, V. Informational needs of surgical patients following discharge. Applied Nursing Research, v. 13, n. 1, p. 12-18, 2000. 
JARRETT, M. Use of clinical practice guidelines to promote best practice when managing clinical interventions for liver transplant candidates. Progress in Transplantation, v. 19, n. 2, p. 132-140, 2009.

JOHANSSON, K. et al. Need for change in patient education: a Finnish survey from the patient's perspective. Patient Education and Counseling, v. 51, n. 3, p. 239245, 2003.

JOHNSON, B.; CHRISTENSEN, L. Educational research: quantitative, qualitative and mixed approaches. $3^{\mathrm{a}}$ ed. Thousand Oaks: Sage Publications, 2008. 639 p.

JONSÉN, E.; ATHLIN, E.; SUHR, O. B. Waiting for a liver transplant: the experience of patients with familial amyloidotic polyneuropathy. Journal of Clinical Nursing, v. 9, n. 1, p. 63-70, 2000.

KERZMAN, H.; BARON-EPEL, O.; TOREN, O. What do discharged patients know about their medication? Patient Education and Counseling, v. 56, n. 3, p. 276-282, 2005.

KEULERS, B. J. et al. Can face-to-face patient education be replaced by computerbased patient education? A randomised trial. Patient Education and Counseling, v. 67, n. 1-2, p. 176-182, 2007.

KIYOHARA, L. Y. et al. Surgery information reduces anxiety in the pre-operative period. Revista do Hospital das Clínicas: Faculdade de Medicina, Universidade de São Paulo, v. 59, n. 2, p. 51-56, 2004.

KIZILISIK, A. T. et al. Impact of long-term immunosuppressive therapy on psychosocial and physical well being in liver transplant recipients. Progress in Transplantation, v. 13, n. 4, p. 278-283, 2003.

KRASUSKA, M. E. et al. Information needs of the patients undergoing bone marrow transplantation. Annales Universitatis Mariae Curie-Skłodowska. Sectio D: Medicina, v. 57, n. 2, p. 178-185, 2002. 
KRUPAT, E.; FANCEY, M.; CLEARY, P. D. Information and its impact on satisfaction among surgical patients. Social Science \& Medicine, v. 51, n. 12, p. 1817-1825, 2000.

KRUZIK, N. Benefits of preoperative education for adult elective surgery patients. AORN Journal, v. 90, n. 3, p. 381-387, 2009.

LEITHEAD, J. A.; FERGUSON, J. W.; HAYES, P. C. Smoking-related morbidity and mortality following liver transplantation. Liver Transplantation, v. 14, n. 8, p. 1159-1164, 2008.

LISSON, G. L. et al. A brief psychological intervention to improve adherence following transplantation. Annals of Transplantation, v. 10, n. 1, p. 52-57, 2005.

LITHNER, M.; ZILLING, T. Pre- and postoperative information needs. Patient Education and Counseling, v. 40, n. 1, p. 29-37, 2000.

LOBIONDO-WOOD, G.; HARBER, J. Nonexperimental designs. In: LOBIONDO-WOOD, G.; HARBER, J. (Ed.). Nursing research: methods and critical appraisal for evidence-based practice. $6^{a}$ ed. St. Louis: Mosby / Elsevier, 2006. p.238-259.

LORA, V. et al. Efficacy of a single educative intervention in patients with chronic plaque psoriasis. Dermatology, v. 219, n. 4, p. 316-321, 2009.

LORIG, K. How do I know what patients want and need? Needs Assessment. In: LORIG, K. (Ed.). Patient Education: a practical approach. $3^{\text {a }}$ ed. Thousand Oasks: Sage Publications, 2001a. p.1-20.

Patient education: a practical approach. $3^{\mathrm{a}}$ ed. Thousand Oaks: Sage Publications, Inc, 2001b. 246 p.

MARCHAL, F. et al. Post-operative care and patient satisfaction after ambulatory surgery for breast cancer patients. European Journal of Surgical Oncology, v. 31, n. 5, p. 495-499, 2005. 
MASSAROLLO, P. C. B. et al. Efeito da escala MELD na mortalidade após o transplante de fígado. Jornal Brasileiro de Transplantes, v. 6, n. 1, p. 14-20, 2003.

MATAS, A. J. et al. Life satisfaction and adverse effects in renal transplant recipients: a longitudinal analysis. Clinical Transplantation, v. 16, n. 2, p. 113-121, 2002.

MCGAUGHEY, I. Informed consent and knee arthroscopies: an evaluation of patient understanding and satisfaction. Knee, v. 11, n. 3, p. 237-242, 2004.

MCGAUGHEY, J.; HARRISON, S. Developing an information booklet to meet the needs of intensive care patients and relatives. Intensive \& Critical Care Nursing, v. 10, n. 4, p. 271-277, 1994.

MCGAUGHEY, J.; HARRISSON, S. Understanding the pre-operative information needs of patients and their relatives in intensive care units. Intensive \& Critical Care Nursing, v. 10, n. 3, p. 186-194, 1994.

MEHTA, N. N.; MIRZA, D. F. Liver transplantation. Surgery, v. 27, n. 1, p. 38-42, 2008.

MENDES, K. D.; GALVÃO, C. M. Liver transplantation: evidence for nursing care. Revista Latino-Americana de Enfermagem, v. 16, n. 5, p. 915-922, 2008.

MESTERS, I. et al. Measuring information needs among cancer patients. Patient Education and Counseling, v. 43, n. 3, p. 253-262, 2001.

MIES, S. Transplante de fígado. Revista da Associação Médica Brasileira, v. 44, n. 2, p. $127-134,1998$.

MINISTÉRIO DA SAÚDE. Regulamento técnico para distribuição de órgãos de doadores cadáveres para transplante. Portaria No 1.160, de 29 de Maio de 2006, Brasília, DF, 2006. 
MOLONEY, S. et al. Deciding about lung transplantation: informational needs of patients and support persons. Progress in Transplantation, v. 17, n. 3, p. 183192, 2007.

MONTEJO-GONZÁLEZ, J. C.; CALVO-HERNÁNDEZ, M. V. Trasplante hepático. Implicaciones nutricionales. Nutricion Hospitalaria. , v. 23, n. Supl. 2, p. 34-40, 2008.

MONTERO, J. L. et al. Manejo a largo plazo del enfermo trasplantado de hígado. In: LÓPEZ, E. V.; PERNADO, C. B.; PÉREZ, F. P. (Ed.). Curso de actualización en trasplante hepático. Madrid: Fujisawa, 1998. p.233-245.

MOUMJID, N. et al. Shared decision making in the medical encounter: are we all talking about the same thing? Medical Decision Making, v. 27, n. 5, p. 539-546, 2007.

MOYLAN, C. A. et al. Disparities in liver transplantation before and after introduction of the MELD score. JAMA, v. 300, n. 20, p. 2371-2378, 2008.

MURRAY, K. F.; CARITHERS, R. L., JR. AASLD practice guidelines: Evaluation of the patient for liver transplantation. Hepatology, v. 41, n. 6, p. 1407-1432, 2005.

MYERS, J.; PELLINO, T. A. Developing new ways to address learning needs of adult abdominal organ transplant recipients. Progress in Transplantation, v. 19, n. 2, p. 160-166, 2009.

NAIR, S. et al. Effects of obesity, diabetes, and prior abdominal surgery on resource utilization in liver transplantation: a single-center study. Liver Transplantation, v. 15, n. 11, p. 1519-1524, 2009.

NEIL, J. A. Cirurgia do fígado, trato biliar, pâncreas e baço. In: ROTHROCK, J. C. (Ed.). Alexander: cuidados de enfermagem ao paciente cirúrgico. $13^{\mathrm{a}}$ ed. Rio de Janeiro: Elsevier, 2007. p. 356-392.

NELSON, J. E. et al. When critical illness becomes chronic: informational needs of patients and families. Journal of Critical Care, v. 20, n. 1, p. 79-89, 2005. 
OHLER, L. Patient education. In: CUPPLES, S. A.; OHLER, L. (Ed.). Transplantation nursing secrets. Philadelphia: Hanley \& Belfus, INC, 2003. p.305-312.

PAPAGIANNIS, A.; RICHARDS, R.; SHALE, D. J. Patient satisfaction with information provided at an outpatient clinic for respiratory diseases. Respiratory Medicine, $v$. 89 , n. 10, p. 673-676, 1995.

PARADIS, I. Psychosocial issues in transplantation. Progress in Transplantation, v. 10, n. 4, p. 199-200, 2000.

PARKES, J.; SHEPPERD, S. Discharge planning from hospital to home. Cochrane Database of Systematic Reviews, n. 4, p. CD000313, 2000.

PASCOE, G. C. Patient satisfaction in primary health care: a literature review and analysis. Evaluation and Program Planning, v. 6, n. 3-4, p. 185-210, 1983.

PELLETIER, S. J. et al. Effect of body mass index on the survival benefit of liver transplantation. Liver Transplantation, v. 13, n. 12, p. 1678-1683, 2007.

PIEPER, B. et al. Discharge information needs of patients after surgery. Journal of Wound, Ostomy, and Continence Nursing, v. 33, n. 3, p. 281-289, 2006.

POLIT, D. F.; HUNGLER, B. P. Nursing research: principles and methods. $\sigma^{\text {a }}$ ed. Philadelphia: Lippincott, 1999. 757 p.

RANKIN, S. H.; STALLINGS, K. D. Patient education: issues, principles, practices. $3^{a}$ ed. Philadelphia: Lippincott, 1996. 373 p.

REDMAN, B. K. The process of patient education. $6^{\text {a }}$ ed. St. Louis: Mosby, 1988. $354 \mathrm{p}$.

A prática da educação para a saúde. 9a ed. Loures: Lusociência, 2003. $304 \mathrm{p}$.

The practice of patient education: a case study approach. $10^{\mathrm{a}}$ ed. St Louis: Mosby Elsevier, 2007. 157 p. 
Patient adherence or patient self-management in transplantation: an ethical analysis. Progress in Transplantation, v. 19, n. 1, p. 90-94, 2009.

REGA, M. D. A model approach for patient education. Medsurg Nursing, v. 2, n. 6, p. $477-479,495,1993$.

REZAILASHKAJANI, M. et al. Knowledge of disease and health information needs of the patients with inflammatory bowel disease in a developing country. International Journal of Colorectal Disease, v. 21, n. 5, p. 433-440, 2006.

ROACH, J. A.; TREMBLAY, L. M.; BOWERS, D. L. A preoperative assessment and education program: implementation and outcomes. Patient Education and Counseling, v. 25, n. 1, p. 83-88, 1995.

RODGERS, S. et al. Evaluation of the information needs of patients with chronic obstructive pulmonary disease following pulmonary rehabilitation: a focus group study. Chronic Respiratory Disease, v. 4, n. 4, p. 195-203, 2007.

RODRIGUE, J. R. et al. Quality of life and psychosocial functioning of spouse/partner caregivers before and after liver transplantation. Clinical Transplantation, D.O.I. 10.1111/j.1399-0012.2010.01224.x, 2010.

ROSE, G. Meeting information needs of day surgery patients. Nursing Times, v. 91, n. 35, p. 29, 1995.

ROSENTHAL, L. Design and implementation of an informed consent process before liver transplantation. Progress in Transplantation, v. 18, n. 4, p. 273-283, 2008.

SANCHEZ-PEREZ, B. et al. Preoperative factors and models predicting mortality in liver transplantation. Transplantation Proceedings, v. 37, n. 3, p. 1499-1501, 2005.

SANTOS, G. R. et al. Anxiety levels observed in candidates for liver transplantation. Transplantation Proceedings, v. 42, n. 2, p. 513-516, 2010. 
SANTOS JUNIOR, R. et al. Patients undergoing liver transplantation: psychosocial characteristics, depressive symptoms, and quality of life. Transplantation Proceedings, v. 40, n. 3, p. 802-804, 2008.

SASSO, K. D. et al. Transplante de fígado: resultados de aprendizagem de pacientes que aguardam a cirurgia. Revista Latino-Americana de Enfermagem, v. 13, n. 4, p. 481-488, 2005.

SCHAFER-KELLER, P. et al. Computerized patient education in kidney transplantation: testing the content validity and usability of the Organ Transplant Information System (OTIS). Patient Education and Counseling, v. 74, n. 1, p. 110-117, 2009.

SCOTT, J. T.; THOMPSON, D. R. Assessing the information needs of post-myocardial infarction patients: a systematic review. Patient Education and Counseling, v. 50, n. 2, p. $167-177,2003$.

SENSOR, W. A. Embracing transparency: providing more information--good and bad-can improve patient satisfaction and quality of care. Healthcare Executive, v. 24, n. 6 , p. 50, 52, 2009.

SHARIF, F. et al. Effects of psycho-educational intervention on health-related quality of life (QOL) of patients with chronic liver disease referring to Shiraz University of Medical Sciences. Health and Quality of Life Outcomes, v. 3, p. 81, 2005.

SHARKEY, C.; GOURISHANKAR, S. Transplant Friends: an interactive education program for patients awaiting kidney transplantation. Transplantation Proceedings, v. 35, n. 7, p. 2405-2406, 2003.

SHEARD, C.; GARRUD, P. Evaluation of generic patient information: effects on health outcomes, knowledge and satisfaction. Patient Education and Counseling, v. 61, n. 1, p. $43-47,2006$.

SHULDHAM, C. A review of the impact of pre-operative education on recovery from surgery. International Journal of Nursing Studies, v. 36, n. 2, p. 171-177, 1999. 
SIEGAL, B.; HALBERT, R. J.; MCGUIRE, M. J. Life satisfaction among kidney transplant recipients: demographic and biological factors. Progress in Transplantation, v. 12, n. 4, p. 293-298, 2002.

SILVERMAN, M. et al. "Is it half full or half empty?" Affective responses to chronic illness. Journal of Cross-Cultural Gerontology, v. 24, n. 3, p. 291-306, 2009.

SMELTZER, C. S.; BARE, B. G. Educação da saúde e promoção da saúde. In: SMELTZER, C. S.; BARE, B. G. (Ed.). Brunner \& Suddarth, tratado de enfermagem médico-cirúrgica. 10ª ed. Rio de Janeiro: Guanabara Koogan, 2005. p.48-61.

SPRY, C. Essentials of perioperative nursing. $3^{\mathrm{a}}$ ed. Sudbury, Massachusetts: Jones and Bartlett Publishers, 2005. 348 p.

SYX, R. L. The practice of patient education: the theoretical perspective. Orthopaedic Nursing, v. 27, n. 1, p. 50-54, 2008.

TARZIAN, A. J.; IWATA, P. A.; COHEN, M. Z. Autologous bone marrow transplantation: the patient's perspective of information needs. Cancer Nursing, $v$. 22, n. 2, p. 103-110, 1999.

TELLES-CORREIA, D. et al. Abordagem psiquiátrica do transplante hepático. Acta Medica Portuguesa, v. 19, n. 2, p. 165-179, 2006.

Adesão nos doentes transplantados. Acta Medica Portuguesa, v. 20, n. 1, p. $73-85,2007$.

.Validação do questionário multidimensional da adesão no doente com transplante hepático. Acta Medica Portuguesa, v. 21, n. 1, p. 31-36, 2008.

Adherence correlates in liver transplant candidates. Transplantation Proceedings, v. 41, n. 5, p. 1731-1734, 2009. 
TENORIO, A. L. et al. Survival on waiting list for liver transplantation before and after introduction of the model for end-stage liver disease score. Transplantation Proceedings, v. 42, n. 2, p. 407-411, 2010.

THE TRANSPLANTATION SOCIETY OF LATIN AMERICA AND THE CARIBBEAN. Latin America Transplantation Report. São Paulo, SP, Sociedad de Transplante de América Latina y El Caribe, p.85. 2009

THE TRANSPLANTATION SOCIETY OF LATIN AMERICA AND THE CARIBBEAN. Latin America Transplantation Report. São Paulo, SP, Sociedad de Transplante de América Latina y El Caribe, p.72. 2007

THOMAS, D. J. Assessment of the hepatic system. In: PHIPPS, W. J.; SANDS, J. K.; MAREK, J. F. (Ed.). Medical-surgical nursing: concepts and clinical practice. $6^{\text {a }}$ ed. St Louis: Mosby, 1999a. p.1183-1194.

. Management of persons with problems of the hepatic system. In: PHIPPS, W. J.; SANDS, J. K.; MAREK, J. F. (Ed.). Medical-surgical nursing: concepts and clinical practice. $6^{a}$ ed. St Louis: Mosby, 1999b, p.1195-1234.

THULUVATH, P. J. Morbid obesity with one or more other serious comorbidities should be a contraindication for liver transplantation. Liver Transplantation, v. 13, n. 12, p. 1627-1629, 2007.

. Morbid obesity and gross malnutrition are both poor predictors of outcomes after liver transplantation: what can we do about it? Liver Transplantation, v. 15, n. 8, p. 838-841, 2009.

TIMMINS, F.; KALISZER, M. Information needs of myocardial infarction patients. European Journal of Cardiovascular Nursing, v. 2, n. 1, p. 57-65, 2003.

TSE, K. Y.; SO, W. K. Nurses' perceptions of preoperative teaching for ambulatory surgical patients. Journal of Advanced Nursing, v. 63, n. 6, p. 619-625, 2008.

VARO PEREZ, E.; CASTROAGUdiN, J. F. The future of liver transplantation. Transplantation Proceedings, v. 42, n. 2, p. 613-616, 2010. 
VERDONK, R. C. et al. Liver transplantation: an update. The Netherlands Journal of Medicine, v. 65, n. 10, p. 372-380, 2007.

WAGNER, P. S.; ASH, K. L. Creating the teachable moment. The Journal of Nursing Education, v. 37, n. 6, p. 278-280, 1998.

WAINWRIGHT, S. P.; GOLD, D. Non-adherence with medications in organ transplant patients: a literature review. Journal of Advanced Nursing, v. 26, n. 5, p. 968977, 1997.

WALKER, J. A. What is the effect of preoperative information on patient satisfaction? The British Journal of Nursing, v. 16, n. 1, p. 27-32, 2007.

WEICHLER, N.; HAKOS, L. Information needs of primary caregivers in pediatric liver transplantation. Transplantation Proceedings, v. 21, n. 3, p. 3562, 1989.

WEICHLER, N. K. Information needs of mothers of children who have had liver transplants. Journal of Pediatric Nursing, v. 5, n. 2, p. 88-96, 1990.

WEINRIEB, R. M.; LUCEY, M. R. Treatment of addictive behaviors in liver transplant patients. Liver Transplantation, v. 13, n. 11 Suppl 2, p. S79-82, 2007.

WHITNEY, S. N. et al. Beyond shared decision making: an expanded typology of medical decisions. Medical Decision Making, v. 28, n. 5, p. 699-705, 2008.

WILLS, C. E.; HOLMES-ROVNER, M. Patient comprehension of information for shared treatment decision making: state of the art and future directions. Patient Education and Counseling, v. 50, n. 3, p. 285-90, 2003.

WOODWARD, C. A. et al. Patient satisfaction as an indicator of quality care in independent health facilities: developing and assessing a tool to enhance public accountability. American Journal of Medical Quality, v. 15, n. 3, p. 94-105, 2000. 
WORLD HEALTH ORGANIZATION. Global Database on Body Mass Index: BMI classification. $2010 . \quad$ Disponível em: <http://apps.who.int/bmi/index.jsp?introPage=intro_3.html>. Acesso em: 08 Mai. 2010.

YAMAKAWA, Y. et al. Higher elimination rate of hepatitis $C$ virus among women. Journal of Viral Hepatitis, v. 3, n. 6, p. 317-321, 1996.

YOO, H. Y. et al. Socioeconomic status does not affect the outcome of liver transplantation. Liver Transplantation, v. 8, n. 12, p. 1133-1137, 2002.

YOO, H. Y.; THULUVATH, P. J. Outcome of liver transplantation in adult recipients: influence of neighborhood income, education, and insurance. Liver Transplantation, v. 10, n. 2, p. 235-243, 2004.

ZAGO, M. M. F. Considerações sobre o ensino do paciente cirúrgico. Revista da Escola de Enfermagem da USP, v. 27, n. 1, p. 67-71, 1993.

ZAYDFUDIM, V. et al. The negative effect of pretransplant overweight and obesity on the rate of improvement in physical quality of life after liver transplantation. Surgery, v. 146, n. 2, p. 174-180, 2009. 


\section{APÊNDICES}

\section{APÊNDICE A}

Data: 1

Entrevistador:

INSTRUÇÕES: As perguntas a seguir são para identificarmos informações a seu respeito, sua doença e o que o $\mathrm{Sr}$ (a) gostaria de aprender sobre o processo de transplante de fígado. As informações serão anônimas e somente serão vistas pela pesquisadora responsável. Agradeço sua valiosa participação.

\section{DADOS DE IDENTIFICAÇÃO}

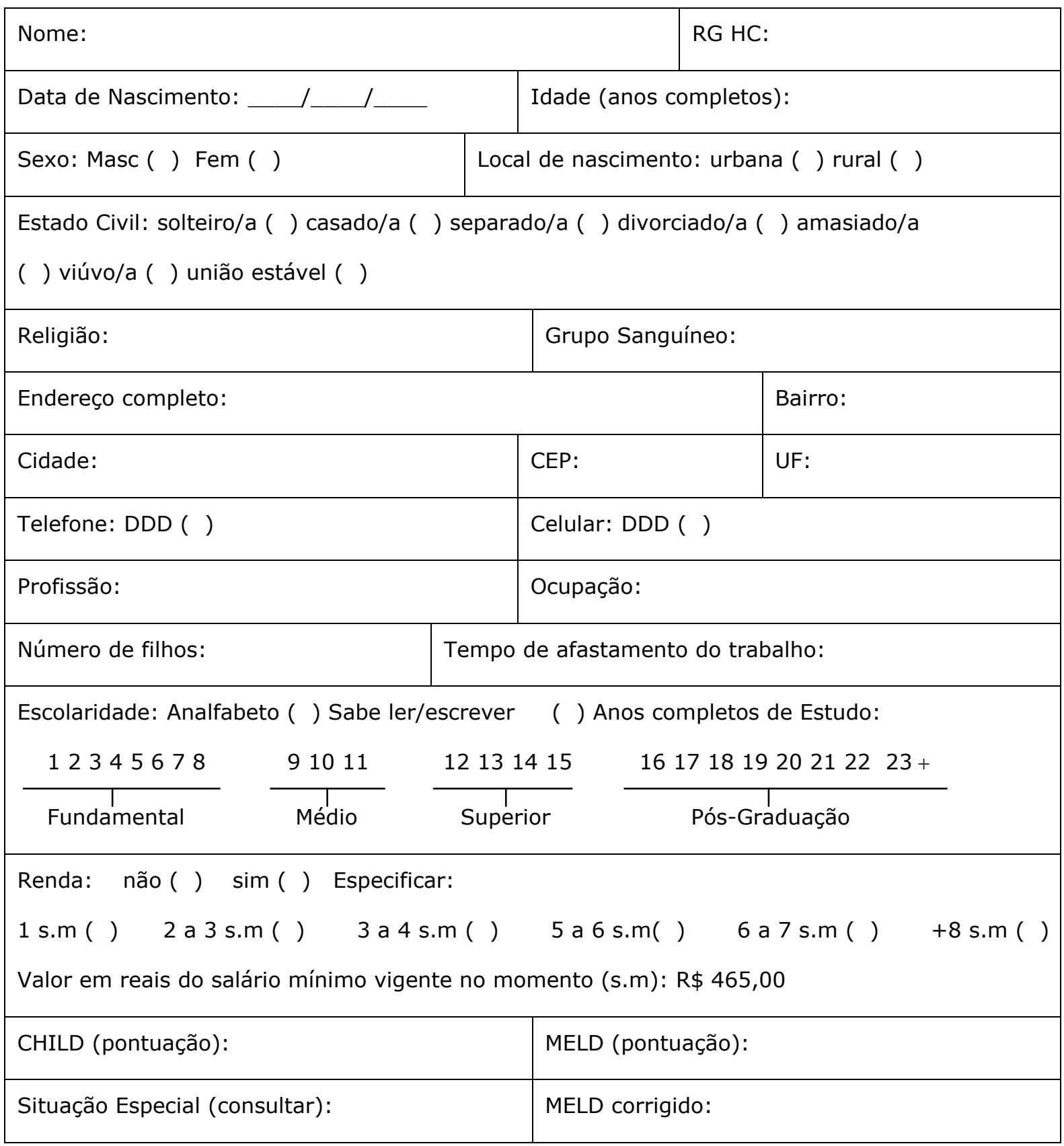




\section{DADOS RELACIONADOS À DOENÇA CRÔNICA DO FÍGADO}

1. O senhor sabe o que é o transplante de fígado?

Não: ( ) Sim ( ) Selecione uma das opções a seguir:

a) Retirada parcial do meu fígado e colocação do fígado de um doador

b) Não é retirado o meu fígado, apenas coloca-se outro junto

c) Retirada total do meu fígado e colocação de um fígado de um doador

2. Quais são os sinais e sintomas da doença crônica do fígado que o $\operatorname{Sr}(a)$ tem?

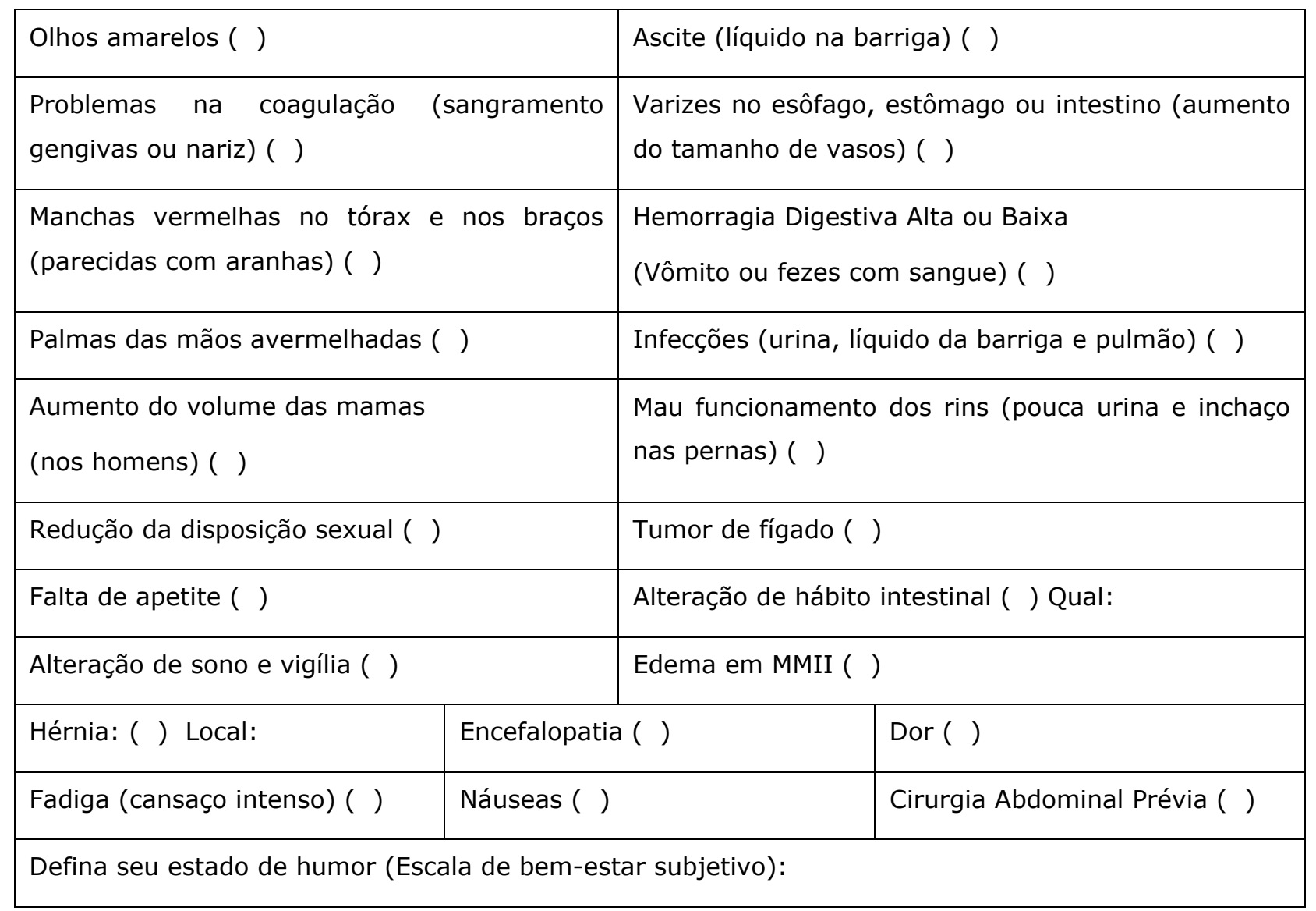

3. Dados Antropométricos

\begin{tabular}{|l|l|l|}
\hline Peso $(\mathrm{Kg}):$ & Altura $(\mathrm{m}):$ & $\mathrm{IMC}\left(\mathrm{Kg} / \mathrm{m}^{2}\right):$ \\
\hline
\end{tabular}

4. Desde quando o Senhor (a) sabe que apresenta doença crônica do fígado?

Tempo em meses completos: 
5. Sabe dizer o nome da doença crônica do fígado que apresenta?

Não: ( ) S Sim ( ) Se sim, por favor, selecione uma opção a seguir:

\begin{tabular}{|c|c|}
\hline ( ) Cirrose biliar primária & ( ) Cirrose hepática por vírus Hepatite \\
\hline ( ) Cirrose biliar secundária & ( ) Cirrose hepática auto-imune \\
\hline ( ) Colangite esclerosante primária & ( ) Cirrose hepática por tóxicos ou chagas \\
\hline \multirow{3}{*}{$\begin{array}{l}\text { ( ) Hemocromatose avançada } \\
\text { ( ) Doença de Wilson } \\
\text { ( ) Deficiência de alfa-1-antitripsina, em } \\
\text { fase cirrótica }\end{array}$} & ( ) Cirrose criptogenética ou criptogênica \\
\hline & ( ) NASH - Esteato-hepatite não-alcoólica \\
\hline & $\begin{array}{l}\text { ( ) Síndrome de Budd-Chiari } \\
\text { ( ) Doença hepática veno-oclusiva }\end{array}$ \\
\hline ( ) Tumor Primário do Fígado & ( ) Trauma \\
\hline
\end{tabular}

Diagnóstico Médico (consultar prontuário):

6. Há quanto tempo o Sr. (a) está inscrito no Cadastro Técnico para realizar o transplante de fígado?

Período Informado pelo paciente:

Não soube informar ( )

Data de Inscrição na lista de espera (consultar):

7. O Sr ou a Sra sabe informar como funciona a lista de espera para um transplante de fígado?

\begin{tabular}{|l|l|l|}
\hline ( ) Nunca fui informado & $\begin{array}{l}\text { ( ) Acredito que seja por } \\
\text { tempo de espera }\end{array}$ & $\begin{array}{l}\text { ( ) Acredito que seja por } \\
\text { gravidade da doença }\end{array}$ \\
\hline $\begin{array}{l}\text { ( ) Acredito que seja de acordo } \\
\text { com a cidade onde mora }\end{array}$ & $\begin{array}{l}\text { ( ) Depende do tipo de sangue } \\
\text { da pessoa }\end{array}$ & $\begin{array}{l}\text { ( ) Está relacionada com o } \\
\text { peso e a altura da pessoa }\end{array}$ \\
\hline
\end{tabular}

8. Apresenta algum dos problemas listados abaixo?

\begin{tabular}{|c|c|c|c|c|}
\hline Hipertensão Arterial ( ) & Desnutrição ( ) & \multicolumn{2}{|c|}{ Obesidade ( ) } & Diabetes Mellitus ( ) \\
\hline $\begin{array}{l}\text { Problemas na pele ( ) } \\
\text { Tipo: }\end{array}$ & \multicolumn{2}{|c|}{$\begin{array}{l}\text { Problemas no coração ( ) } \\
\text { Tipo: }\end{array}$} & \multicolumn{2}{|c|}{$\begin{array}{l}\text { Problemas nos rins ( ) } \\
\text { Tipo: }\end{array}$} \\
\hline $\begin{array}{l}\text { Problemas no cérebro ( ) } \\
\text { Tipo: }\end{array}$ & \multicolumn{2}{|c|}{$\begin{array}{l}\text { Problemas nos pulmões ( ) } \\
\text { Tipo: }\end{array}$} & \multicolumn{2}{|c|}{$\begin{array}{l}\text { Alergias ( ) } \\
\text { Tipo: }\end{array}$} \\
\hline $\begin{array}{l}\text { Problemas no sangue ( ) } \\
\text { Tipo: }\end{array}$ & \multicolumn{2}{|c|}{$\begin{array}{l}\text { Problemas no ossos ( ) } \\
\text { Tipo: }\end{array}$} & \multicolumn{2}{|c|}{ Outros: } \\
\hline
\end{tabular}


9. Medicamentos em uso:

\begin{tabular}{|l|l|l|}
\hline Medicamentos & Dose & Horário \\
\hline & & \\
\hline & & \\
\hline & & \\
\hline & & \\
\hline
\end{tabular}

10. O Sr. (a) realiza exercício físico?

Não: ( ) Sim ( ) Se sim, por favor, selecione uma opção a seguir:

\begin{tabular}{|l|l|l|l|}
\hline \multicolumn{2}{|l|}{ Quantas vezes por semana? } & \multicolumn{2}{l|}{ Qual exercício? } \\
\hline 1 a 2 vezes ( ) & 4 a 5 vezes( ) & Caminhada ( ) & Natação ( ) \\
2 a 3 vezes( ) & 5 a 6 vezes( ) & Bicicleta ( ) & Hidroginástica( ) \\
3 a 4 vezes( ) & Todos os dias( ) & Musculação ( ) & Outro ( ) \\
\hline
\end{tabular}

11. Quais são as refeições que o Sr. (a) realiza diariamente?

\begin{tabular}{|l|l|}
\hline Café da manhã ( ) & Lanche da tarde $($ ) \\
\hline Lanche da manhã ( ) & Jantar ( ) \\
\hline Almoço ( ) & Ceia ( ) \\
\hline
\end{tabular}

12. O Sr. (a) faz algum tipo de restrição em sua alimentação diária?

\begin{tabular}{l|l} 
Evita sal ( ) & Evita doces e carboidratos ( ) \\
Evita carne vermelha (proteínas) ( ) & Evita gorduras ( ) \\
Evita água ( ) & Outras:
\end{tabular}

13. Outros hábitos de vida

\begin{tabular}{|c|c|}
\hline $\begin{array}{l}\text { Fumante ( ) Ex-Fumante ( ) } \\
\mathrm{N}^{\circ} \text { de cigarros/dia: }\end{array}$ & $\begin{array}{l}\text { Uso de Álcool ( ) Ex-Alcoolismo ( ) } \\
\text { Tipo de bebida/quantidade: }\end{array}$ \\
\hline $\mathrm{N}^{\circ}$ de horas de sono noturno: & Ingestão de água: ___ copos / ml dia \\
\hline $\mathrm{N}^{\circ}$ de horas de sono diurno: & Café: ___ xícaras/dia \\
\hline Drogas ( ) & \\
\hline
\end{tabular}




\section{DADOS RELACIONADOS ÀS NECESSIDADES DE APRENDIZAGEM}

1. O Sr (a) já recebeu informações a respeito de sua doença e do processo de transplante de fígado?

Não: ( ) S Sim ( )Por favor, especifique qual a fonte de informações?

\begin{tabular}{|l|l|l|}
\hline Folheto informativo ( ) & Internet ( ) & Médicos / Enfermeiros ( ) \\
\hline Televisão ( ) & Amigos e Familiares ( ) & Outros pacientes ( ) \\
\hline Jornal ( ) Rádio ( ) & Folhetos explicativos ( ) & Outros ( ) \\
\hline
\end{tabular}

2. Considera-se preparado para a cirurgia, em relação ao seu conhecimento sobre todo o processo do transplante de fígado (antes, durante e depois da cirurgia)?

$\operatorname{Sim}($ ) Não: ( )

Comentários:

3. Já realizou a leitura do folheto informativo ("manual") que the foi entregue no momento de sua entrada na lista de espera?

Sim ( ) Não: ( ) Por favor, justifique a não leitura:

\begin{tabular}{|l|l|}
\hline Falta de tempo ( ) & Angústia ou ansiedade com as informações ( ) \\
\hline Falta de interesse ou estímulo ( ) & Perda do folheto informativo ou empréstimo para outros ( ) \\
\hline Medo ( ) & Não consegue ler ( ) \\
\hline Ainda não recebeu o manual ( ) & Outras: \\
\hline
\end{tabular}

4. Qual dos seguintes métodos de ensino mais te ajudam a adquirir um determinado conhecimento? Escolha no máximo três das opções a seguir:

\begin{tabular}{|l|l}
\hline Leituras (folhetos, manuais) ( ) & Demonstração de uma técnica ( ) \\
Discussões em grupos ( ) & Manuseio de um material ( ) \\
Aula expositiva com figuras e explicações ( ) & Tomar anotações ( ) \\
Vídeos ( ) & Ouvir explicações ( ) \\
Buscas ou Pesquisas na Internet ( ) & Orientação individual ( ) \\
Outros ( ) &
\end{tabular}




\section{AVALIAÇÃO DAS NECESSIDADES DE INFORMAÇÃO}

Prezado Sr ou Sra.

No ano de 2010 será proposto um programa educativo para as pessoas que aguardam o transplante de fígado, no Hospital das Clínicas da Faculdade de Medicina de Ribeirão Preto da Universidade de São Paulo, com o objetivo de oferecer conhecimento e esclarecimentos sobre este problema de saúde, e com isso, colaborar com o sucesso do tratamento. Para tanto, precisamos saber as suas reais necessidades de informação em relação ao transplante de fígado. A seguir, solicitamos que o senhor (a). coloque em ordem de importância, 10 assuntos que gostaria de aprender antes de realizar a cirurgia. Abaixo tem um quadro de sugestões de alguns tópicos, por favor, fique à vontade para sugerir outros.

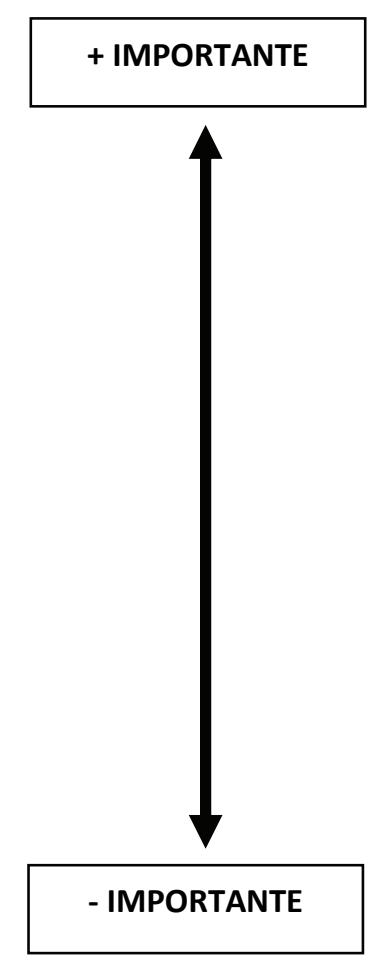

\begin{tabular}{|l|l|}
\hline 10 & \\
\hline 20 & \\
\hline $3^{\circ}$ & \\
\hline $4^{\circ}$ & \\
\hline $5^{\circ}$ & \\
\hline $6^{\circ}$ & \\
\hline 70 & \\
\hline $8^{\circ}$ & \\
\hline $9^{\circ}$ & \\
\hline $10^{\circ}$ & \\
\hline
\end{tabular}

\section{SUGESTÕES}

1.O Sistema de distribuição de Órgãos e o MELD; 2.Funcionamento da lista de espera; 3. História do Transplante de Fígado; 4.Esperando por um novo órgão (cuidados antes do transplante); 5.Atuação da Equipe de Transplante; 6.Anatomia e Fisiologia (funções) do Fígado; 7.Sinais, Sintomas e Complicações da doença do fígado; 8.Complicações antes do transplante; 9.Indicações e contra-indicações para o transplante; 10.0 doador de fígado; 11.O dia do transplante; 12.A cirurgia e a anestesia; 13.0 pós-operatório do transplante (Unidade de Terapia Intensiva e Internação); 14.Complicações após o transplante; 15. Medicamentos após o transplante; 16.Cuidados necessários após o transplante; 17.Qualidade de vida após o transplante. 


\section{APÊNDICE B}

QUESTIONÁRIO DE CONHECIMENTO SOBRE O TRANSPLANTE DE FÍGADO

Data: 1

INSTRUÇõES: As perguntas listadas a seguir são para avaliarmos o seu conhecimento sobre o transplante de fígado. Com os resultados deste estudo acreditamos que teremos informações importantes que possam nos ajudar no planejamento de futuras intervenções educativas, de tal forma que contribua para o sucesso tratamento das pessoas que serão submetidas ao transplante de fígado. 0 instrumento contém 17 perguntas, cada uma tem quatro alternativas de resposta. Assinale apenas uma alternativa que, em sua opinião, é a correta. As informações serão anônimas e somente serão vistas pela pesquisadora responsável.

Garantimos que será guardado segredo de sua identidade!

Não se preocupe em acertar ou errar as questões.

O importante é você responder de acordo com o que sabe!

Agradeço sua participação! 
1. Por que o fígado é considerado um órgão tão importante?
a. Devido ao seu tamanho
b. Por realizar funções relacionadas com a digestão dos alimentos
c. Além da digestão, é responsável pelo controle hormonal, limpeza de substâncias tóxicas do sangue e produção de proteínas
d. Não sei

2. O que fez o transplante de fígado se tornar um tratamento bom para as pessoas com doença do fígado avançada? Assinale a alternativa mais correta.

a. O melhoramento das técnicas de cirurgia

b. Os novos medicamentos contra a rejeição, o desenvolvimento de uma solução para a conservação do órgão, além do melhoramento das técnicas de cirurgia

c. 0 descobrimento dos medicamentos contra a rejeição d. Não sei

3. Enquanto estou na lista de espera aguardando a realização do transplante de fígado:

a. Devo estabelecer um compromisso com a equipe por toda a vida

b. Posso comer alimentos ricos em proteínas, gorduras e sal

c. Posso realizar exercícios físicos pesados

d. Não sei

\section{São sinais de piora da doença} do fígado:

a. Dores de cabeça

b. Mal estar nas juntas

c. Olhos amarelos e sangramento nas gengivas ou nariz

d. Não sei

5. Dentre suas responsabilidades enquanto candidato que aguarda o transplante de fígado:

a. Tenho que realizar exames de sangue sempre b. Posso tomar medicamentos sem ordem médica

c. Não preciso informar alterações sobre minha saúde à Equipe de Transplante

d. Não sei

\section{Quando entro na fila de espera} para o transplante:

a. Quem controla a distribuição dos órgãos para o transplante é a minha equipe médica

b. Recebo uma pontuação relacionada a piora ou melhora da doença do fígado (MELD)

c. As pessoas menos doentes fazem o transplante primeiro

d. Não sei

7. A lista de espera para transplante de fígado funciona da seguinte forma:

a. As pessoas que entram primeiro na fila, são as que fazem o transplante primeiro

b. Existe uma fila única independente do tipo de sangue

c. Tem prioridade a pessoa com a doença do fígado mais grave

d. Não sei

8. O transplante de fígado é indicado quando:

a. O fígado é atacado por qualquer tipo de problema

b. Não há qualquer outra forma de tratamento disponível

c. Sempre que o fígado é atacado por uma doença hepática aguda

d. Não sei

9. Em relação ao dia do transplante, a partir do momento que tem um doador disponível:

a. Preciso ser localizado o mais rápido possível

b. A minha cirurgia deverá ocorrer em até 24 horas

c. Não posso comer alimentos, mas posso ingerir líquidos

d. Não sei 
10. Sobre o doador de fígado:

a. Qualquer pessoa pode doar órgãos, mas somente a família pode autorizar a retirada dos órgãos

b. Pode ser qualquer pessoa que tenha sofrido uma parada cardíaca fatal

c. Deve ser do mesmo sexo da pessoa que irá receber o fígado

d. Não sei

11. Para a realização da cirurgia e da anestesia é necessário:

a. Administrar medicamentos apenas para dormir

b. Realizar uma pequena incisão em minha barriga para remover o fígado doente

c. A presença de pelo menos um familiar durante todo o procedimento d. Não sei

\section{Após o transplante de fígado:}

a. Quando acordar da cirurgia não estarei em uma unidade de cuidados intensivos (UTI)

b. O tempo de internação no hospital poderá variar de 10 a 15 dias após a cirurgia, mas poderei ficar mais tempo caso seja necessário

c. Minha família não poderá me visitar no hospital durante toda a internação

d. Não sei

\section{Em relação aos medicamentos \\ imunossupressores utilizados após o transplante de fígado:}

a. Tenho que tomá-los todos os dias, pois estes ajudarão no combate a infecções

b. Esses medicamentos não serão tomados pelo resto da vida

c. Esses medicamentos podem aumentar a pressão arterial e o açúcar do sangue

d. Não sei
14. Dentre as complicações após o transplante de fígado:

a. Todos os pacientes transplantados apresentam maior risco de desenvolver câncer de pele

b. Pacientes transplantados não desenvolvem diabetes devido aos medicamentos que tomam

c. A rejeição só poderá ocorrer nos primeiros meses após o transplante d. Não sei

15. Não faz parte dos cuidados necessários após o transplante de fígado:

a. Lavar bem as mãos antes das refeições e após ir ao banheiro

b. Evitar a exposição do fígado a toxinas, tais como álcool e cigarro

c. Comer e beber de tudo

d. Não sei

16. Dentre o que se espera após o transplante de fígado:

a. Não poderei retornar ao trabalho

b. Após o transplante, poderei sentir um aumento do desejo sexual (libido) e voltar a ter relações sexuais

c. Deverei tomar medicamentos para evitar a rejeição do fígado apenas por alguns meses

d. Não sei

17. O que irá contribuir para o sucesso do meu transplante de fígado?

a. Proteger meu fígado, evitando uso de bebidas alcoólicas e cigarro e adotar um estilo de vida saudável

b. Realizar uma higiene mediana dos meus dentes e gengivas

c. Tomar banho de sol diariamente, independente do horário

d. Não sei

Muito Obrigada! Sua colaboração foi muito importante! 


\section{APÊNDICE C}

\section{AVALIAÇÃO DA SATISFAÇÃO COM AS INFORMAÇÕES RECEBIDAS NA INTERVENÇÃO EDUCATIVA}

\section{Prezado Sr ou Sra.}

Sua opinião é muito importante. Gostaríamos de saber a sua satisfação em relação às informações recebidas na intervenção educativa Por favor, responda o questionário. Agradeço sua valiosa participação.

1. As informações que o $\operatorname{Sr}(a)$ recebeu em relação ao período de espera para o transplante de fígado foram suficientes?

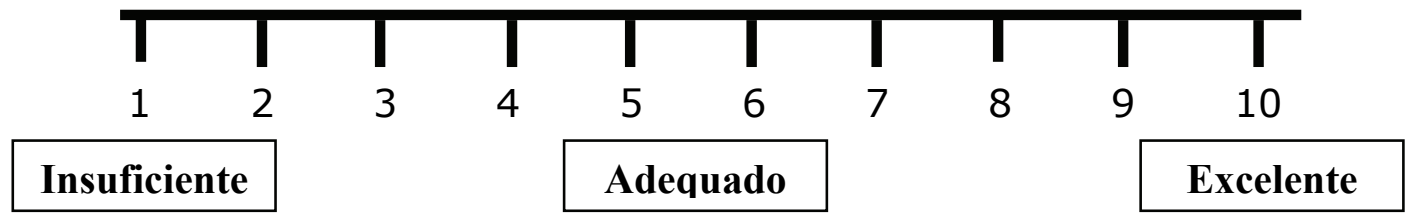

2. As informações que o $\operatorname{Sr}(a)$ recebeu em relação à cirurgia e anestesia do transplante de fígado foram suficientes?

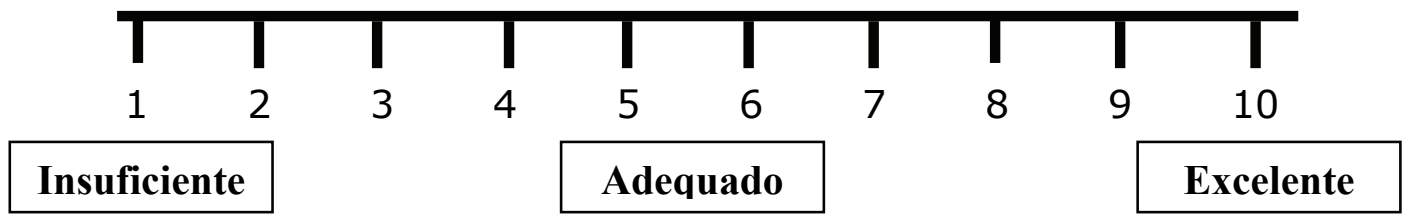

3. As informações que o $\operatorname{Sr}(a)$ recebeu em relação ao pós-operatório do transplante de fígado foram suficientes?

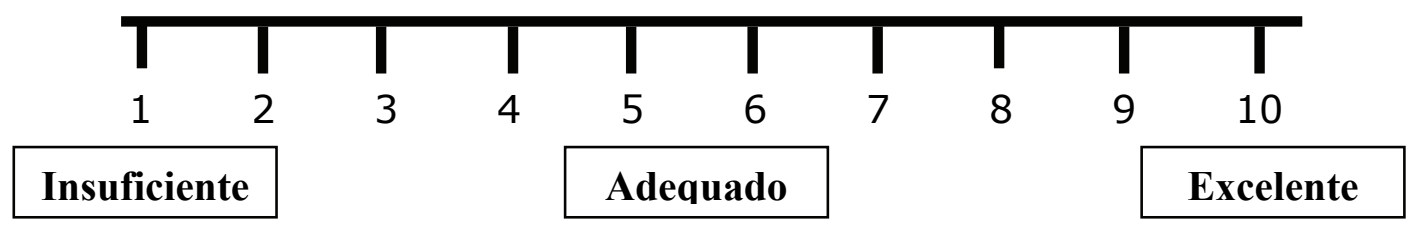

4. As informações que o $\operatorname{Sr}(a)$ recebeu em relação aos cuidados necessários para toda a sua vida após o transplante de fígado atenderam as suas necessidades?

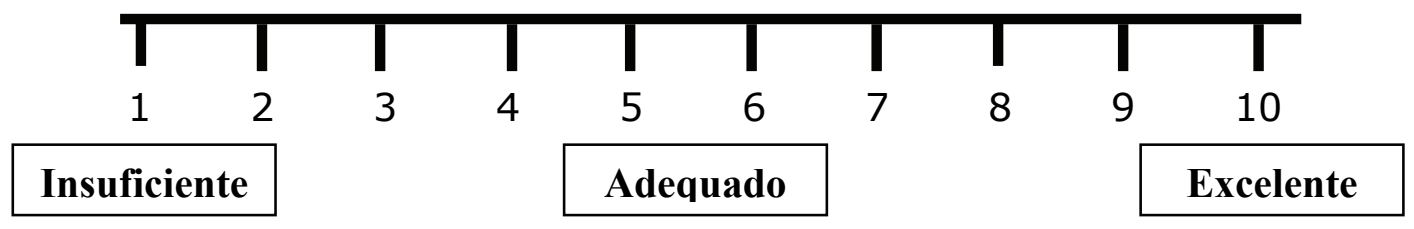


5. Como o $\operatorname{Sr}(a)$ avalia a qualidade das informações recebidas de uma forma geral?

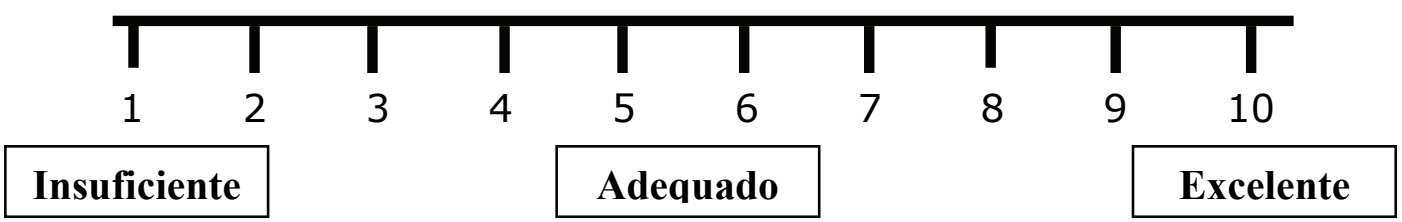

6. Como o $\mathrm{Sr}$ (a) avalia as aulas educativas realizadas para as pessoas que aguardam o transplante de fígado?

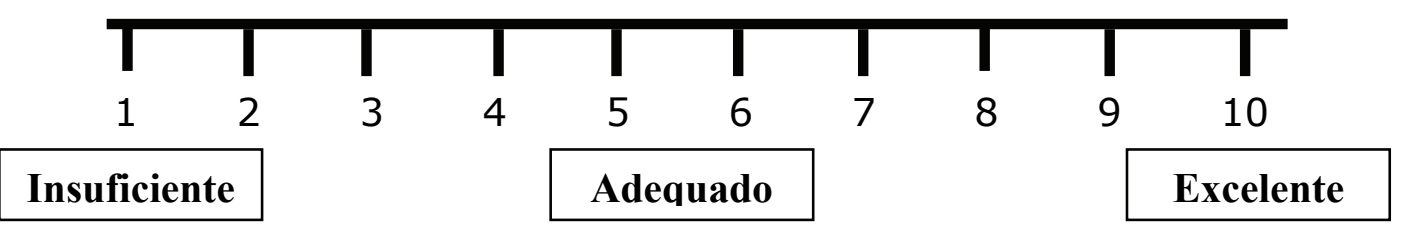

7. O Sr recomendaria as aulas educativas realizadas para outras pessoas que precisam fazer um transplante de fígado?

\begin{tabular}{|l|l|}
\hline $\operatorname{Sim}($ ) & Não ( ) \\
\hline Justifique: & \\
& \\
& \\
\hline
\end{tabular}

8. Por favor, em relação ao aumento de informações em relação ao transplante de fígado, como você classificaria esse aumento:

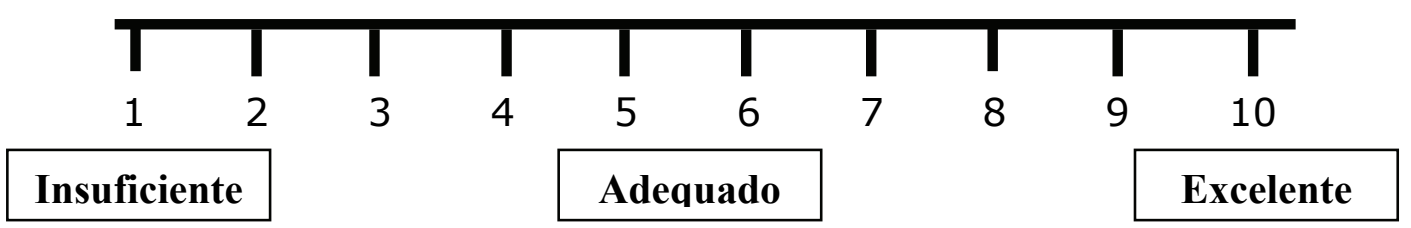

Muito Obrigada! Sua colaboração foi muito importante! 


\section{APÊNDICE D \\ Termo de Consentimento Livre e Esclarecido}

Nome da Pesquisa: O processo ensino-aprendizagem para o candidato ao transplante de fígado

Pesquisadores responsáveis: Karina Dal Sasso Mendes Cristina Maria Galvão

Endereço para contato: Escola de Enfermagem de Ribeirão Preto, Av. Bandeirantes, 3900, Monte Alegre, CEP 14040-902 - Ribeirão Preto - SP

Email: dalsasso@eerp.usp.br

Telefone: (16) 36023438; (16) 81131294

Prezado Sr ou Sra,

Estamos realizando o estudo intitulado "O processo ensino-aprendizagem para o candidato ao transplante de fígado", ligado à Escola de Enfermagem de Ribeirão Preto, da Universidade de São Paulo, o qual será dividido em duas etapas diferentes. $\mathrm{Na}$ primeira etapa gostaríamos de identificar as necessidades de aprendizagem dos pacientes, ou seja, o que as pessoas que aguardam a realização de um transplante de fígado gostariam de aprender antes de realizar a cirurgia, sendo esta a finalidade deste estudo. Sabe-se que a pessoa informada sobre o seu problema de saúde, é mais capaz de lidar com a sua doença e realizar os cuidados necessários para auxiliar o sucesso do tratamento. Este estudo irá ajudar na realização de um programa educativo para as pessoas que aguardam o transplante de fígado em um futuro próximo (segunda etapa do estudo).

As pessoas que participarão do estudo serão selecionadas a partir da listagem de atendimento do Ambulatório de Transplante de Fígado do Grupo Integrado de Transplante de Fígado do Hospital das Clínicas da Faculdade de Medicina de Ribeirão Preto, da Universidade de São Paulo, e serão atendidas conforme a rotina da unidade.

Sua participação consistirá em responder a dois questionários: um referente às características sociais, demográficas e dados relacionados à doença crônica do fígado; e outro referente aos dez principais assuntos que os pacientes gostariam de aprender antes da realização da cirurgia. A finalidade destes questionários é identificar as suas necessidades de aprendizagem. Estes questionários serão aplicados por mim em um único encontro com você em sala privativa, no mesmo dia de sua consulta com a equipe de saúde, durante o período em que você aguarda o atendimento ambulatorial, ou, se você preferir, em outra data a ser agendada em comum acordo, e deverá tomar por volta de 30 minutos do seu tempo.

Portanto estamos convidando o (a) senhor (a) para participar do presente estudo e esclarecemos que:

a) Sua participação é voluntária, ou seja, você pode se recusar a participar;

b) Sua participação não será remunerada e nem Ihe trará prejuízos financeiros;

c) Você terá assegurado o anonimato, ou seja, não será divulgado o seu nome em nenhum momento;

d) Você terá a liberdade de retirar o seu consentimento a qualquer momento sem que isso lhe traga prejuízo algum ou qualquer tipo de constrangimento 
e) Caso você não concorde em participar do presente estudo, não haverá prejuízos no seu atendimento neste Hospital;

f) Você terá o direito de receber toda e qualquer informação sobre o estudo, bem como sobre sua participação;

g) Os resultados da pesquisa poderão ser apresentados em reuniões científicas (simpósios e congressos) e poderão ser publicados em revistas científicas especializadas;

h) Você não está sujeito a qualquer tipo de risco em participar deste estudo.

\section{Karina Dal Sasso Mendes \\ Pesquisador Responsável \\ COREN /SP: 88846}

Por este instrumento particular declaro, para os efeitos éticos e legais, que eu (nome)

(nacionalidade)

domiciliado à Rua portador do RG_r residente $\mathrm{e}$ Estado de , tendo recebido as informações acima e ciente dos meus direitos, concordo em participar da pesquisa por livre e espontânea vontade.

Tendo ciência do exposto acima, assino abaixo.

Ribeirão Preto, de de 2009. 


\section{APÊNDICE E}

\section{Termo de Consentimento Livre e Esclarecido}

Nome da Pesquisa: $O$ processo ensino-aprendizagem para o candidato ao transplante de fígado

Pesquisadores responsáveis: Karina Dal Sasso Mendes Cristina Maria Galvão

Endereço para contato: Escola de Enfermagem de Ribeirão Preto, Av. Bandeirantes, 3900, Monte Alegre, CEP 14040-902 - Ribeirão Preto - SP

Email: dalsasso@eerp.usp.br

Telefone: (16) 36023438; (16) 81131294

Prezado Sr ou Sra,

Estamos realizando o estudo intitulado "O processo ensino-aprendizagem para o candidato ao transplante de fígado", ligado à Escola de Enfermagem de Ribeirão Preto, da Universidade de São Paulo. A finalidade deste estudo é realizar um programa educativo sobre o processo de transplante de fígado, para os pacientes que aguardam em fila de espera; identificar o conhecimento dos pacientes sobre o processo de transplante de fígado, antes e depois da participação no programa educativo; e identificar a satisfação dos pacientes após a participação no programa educativo. Entende-se por processo de transplante de fígado, o antes, durante e após a cirurgia do transplante. Sabe-se que as pessoas que são mais informadas, são capazes de lidar melhor com a sua doença e de realizar comportamentos que minimizem a ocorrência de novos problemas. Esses comportamentos podem influenciar o sucesso do seu tratamento.

As pessoas que participarão do estudo foram selecionadas a partir da listagem de atendimento do Ambulatório de Transplante de Fígado do Grupo Integrado de Transplante de Fígado do Hospital das Clínicas da Faculdade de Medicina de Ribeirão Preto, da Universidade de São Paulo, e serão atendidas conforme a rotina da unidade.

Sua participação envolverá responder a dois questionários: um referente às suas características sociais e demográficas e outro referente ao seu conhecimento sobre o processo do transplante de fígado. O questionário sobre o seu conhecimento será aplicado em dois momentos diferentes, ou seja, antes da sua participação no programa educativo (no primeiro encontro) e depois da sua participação no programa educativo (no último encontro). Os questionários serão aplicados por mim, durante o período de realização do programa educativo, e deverá tomar por volta de 40 minutos do seu tempo. O programa educativo, coordenado por mim, consistirá em duas reuniões em grupo, com 2 horas de duração, que acontecerá durante dois meses consecutivos (uma reunião por mês). Durante este período também estarei no ambulatório de transplante de fígado, semanalmente, para discutir e esclarecer eventuais dúvidas que possa ter.

Portanto estamos convidando o (a) senhor (a) para participar do presente estudo e esclarecemos que:

a) Sua participação é voluntária, ou seja, você pode se recusar a participar;

b) Sua participação não será remunerada e nem lhe trará prejuízos financeiros; 
c) Você terá assegurado o anonimato, ou seja, não será divulgado o seu nome em nenhum momento;

d) Você terá a liberdade de retirar o seu consentimento a qualquer momento sem que isso lhe traga prejuízo algum ou qualquer tipo de constrangimento

e) Caso você não concorde em participar do presente estudo, não haverá prejuízos no seu atendimento neste Hospital;

f) Você terá o direito de receber toda e qualquer informação sobre o estudo, bem como sobre sua participação;

g) Os resultados da pesquisa poderão ser apresentados em reuniões científicas (simpósios e congressos) e poderão ser publicados em revistas científicas especializadas;

h) Você não está sujeito a qualquer tipo de risco em participar deste estudo.

\section{Karina Dal Sasso Mendes \\ Pesquisador Responsável \\ COREN /SP: 88846}

Por este instrumento particular declaro, para os efeitos éticos e legais, que eu (nome)

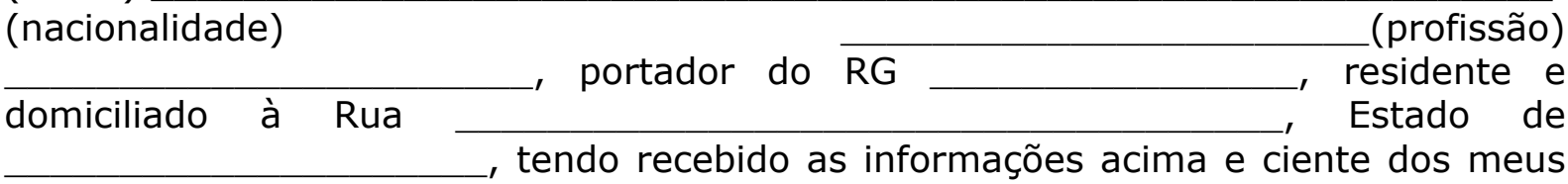

direitos, concordo em participar da pesquisa por livre e espontânea vontade.

Tendo ciência do exposto acima, assino abaixo.

Ribeirão Preto, de de 2010. 


\section{APÊNDICE F}

UNIVERSIDADE DE SÃO PAULO

ESCOLA DE ENFERMAGEM DE RIBEIRÃO PRETO

\section{PLANO EDUCATIVO}

O PROCESSO ENSINO-APRENDIZAGEM PARA O CANDIDATO AO

TRANSPLANTE DE FÍGADO

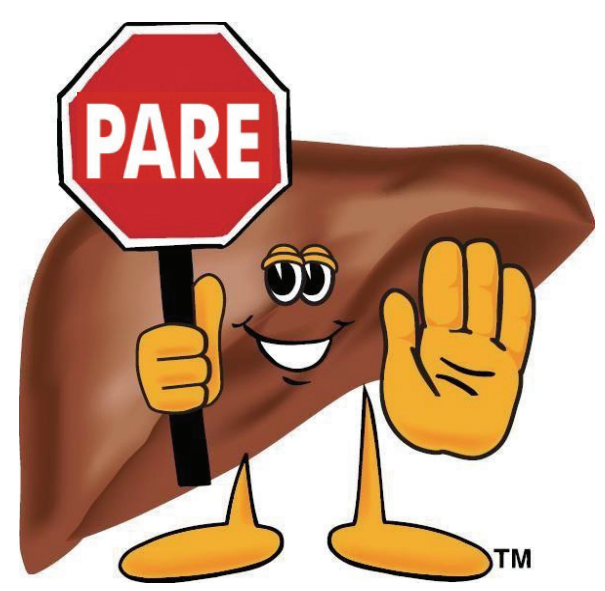

Enfa Karina Dal Sasso Mendes

Ribeirão Preto 


\section{Proposta}

Oferecer informações relevantes para os candidatos que aguardam um transplante de fígado, de modo a estimular a aquisição de conhecimento sobre o processo de transplante de fígado.

\section{* Características}

Curso voltado ao público leigo, nível fundamental e médio, cuja população alvo é os candidatos ao transplante de fígado do Hospital das Clínicas da Faculdade de Ribeirão Preto da Universidade de São Paulo (HCFMRP-USP).Carga horária total de 6 horas, divididas em período de dois dias não-consecutivos, número de alunos de até 36 pacientes acompanhados por pelo menos um familiar ou acompanhante.

\section{* Ementa}

O curso oferece informações sobre o processo de transplante de fígado, contemplando os períodos antes, durante e depois da cirurgia, auxiliando os candidatos na aquisição de conhecimento relevante para o sucesso do tratamento.

\section{Objetivos}

\section{Geral}

- Informar os candidatos que aguardam a cirurgia sobre o processo de transplante de fígado

\section{Específico}

- Identificar as principais informações sobre o processo de transplante de fígado

\section{Conteúdo Programático}

\section{Primeiro Encontro}

I. Visão geral do órgão a ser transplantado e aspectos históricos do transplante de fígado 
II. Processo de avaliação para o transplante (exames, consultas, transfusão de sangue) e atuação da equipe de transplante

III Complicações da doença do fígado antes do transplante, indicações e contraindicações para o transplante

IV. Esperando por um novo órgão (ficando saudável enquanto aguarda; dieta e exercício, quando ligar para o centro de transplantes)

V. O sistema de alocação de órgãos e o doador de fígado

VI. O dia do transplante, a cirurgia e a anestesia

\section{Segundo Encontro}

VII. Período de internação no hospital: unidade de terapia intensiva e unidade de internação

VIII. Medicamentos utilizados após o transplante

IX. Complicações após o transplante (infecções, rejeição, tumores)

X. Qualidade de vida após o transplante

XI. Cuidados necessários por toda a vida após o transplante

XII. Debate entre candidatos que aguardam a cirurgia e receptores já transplantados sobre a vida após o transplante

\section{+ Estratégias de Ensino}

$\mathrm{Na}$ intervenção educativa serão empregadas estratégias de ensino-aprendizagem ativas, com fomento de discussões. Em cada encontro serão ministradas 2 horas de aula dialogada, constituída de exposição visual, fazendo-se uso de slides construídos no Microsoft ${ }^{\circledR}$ PowerPoint $\AA 2007$ e apresentados por meio de Data Show, bem como um período de 1 hora para esclarecimentos de dúvidas.

No segundo encontro será promovido também um encontro dos candidatos ao transplante com pacientes que já foram submetidos à cirurgia com duração 
prevista de 1 hora. A intervenção educativa terá a duração de 6 horas, sendo 4 horas de aula dialogada e 2 horas de discussão e debate.

\section{Avaliação}

Antes e após a implementação da intervenção educativa, será aplicado um instrumento para mensurar o conhecimento dos pacientes sobre o processo de transplante de fígado. Os pacientes que participarem dos dois encontros receberão um certificado de participação. Ao final do segundo encontro será aplicado um instrumento para avaliar a satisfação dos candidatos com as informações recebidas na intervenção educativa implementada.

Ao final da intervenção educativa, espera-se que os pacientes sejam capazes de:

- Acertar $70 \%$ ou mais do instrumento de dados sobre o conhecimento do processo de transplante de fígado;

- Avaliar positivamente a intervenção educativa com uma média de $70 \%$ em relação a sua satisfação com as informações recebidas.

\section{Bibliografia Recomendada}

GRUPO INTEGRADO DE TRANSPLANTE DE FÍGADO. Manual de orientações aos pacientes inscritos em lista de espera para transplante de fígado. Hospital das Clínicas da Faculdade de Medicina de Ribeirão Preto da Universidade de São Paulo: 20 p. 2008.

MENDES, K. D.; GALVÃO, C. M. Liver transplantation: evidence for nursing care. Rev. Latino-Am. Enfermagem, v. 16, n. 5, p. 915-22, 2008.

SASSO, K. D. et al. Transplante de fígado: resultados de aprendizagem de pacientes que aguardam a cirurgia. Rev. Latino-Am. Enfermagem, v. 13, n. 4, p. 481-8, 2005. 


\section{APÊNDICE G \\ CONVITE}

Gostaríamos de convidar o Sr / a Sra para participar de um programa educativo para as pessoas que aguardam a realização do transplante de Fígado. Serão dois encontros, realizados nos dias $\mathbf{1 2}$ de janeiro (terça-feira) e $\mathbf{9}$ de fevereiro (terça-feira) de 2010 das 8:00 às 12:00 hs, no Anfiteatro do Departamento de Cirurgia do $\mathbf{1 0}^{\circ}$ andar (ala administrativa, próximo à Unidade de Fígado). Solicitamos a presença de um familiar para participar do programa juntamente com o Sr/a Sra.

Em cada encontro serão abordados temas diferentes e de extrema importância para seu conhecimento durante esse período de espera para a cirurgia, o que poderá contribuir para o sucesso do seu tratamento. Caso possa participar dos dois encontros será fornecido um certificado de participação. Ao término de cada encontro também será oferecido um lanche.

Informamos que o programa será realizado pela enfermeira Karina Dal Sasso Mendes, colaboradora deste grupo desde 2001, juntamente com as enfermeiras Luciana, Kátia e Fabiana.

Aguardamos ansiosamente a sua presença!

Atenciosamente

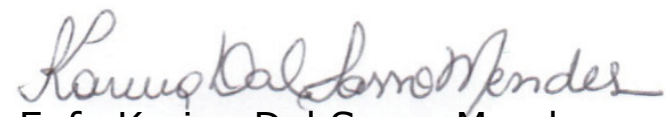

Enfa Karina Dal Sasso Mendes

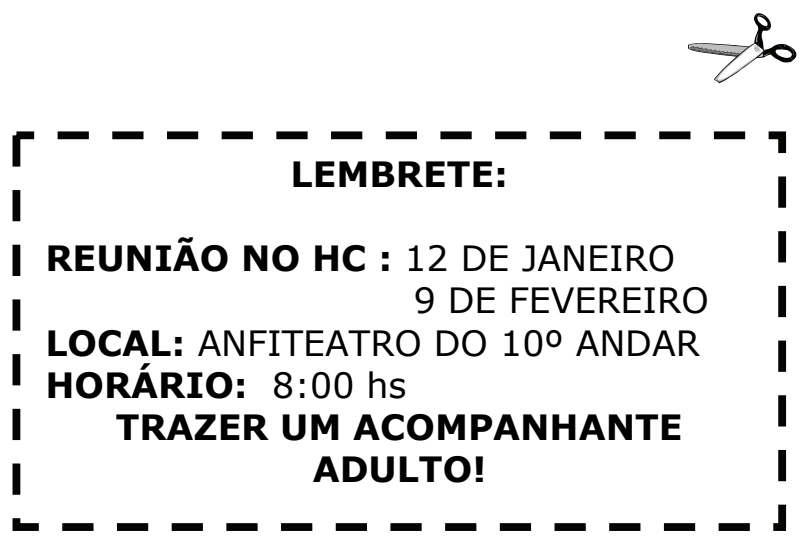




\section{ANEXOS}

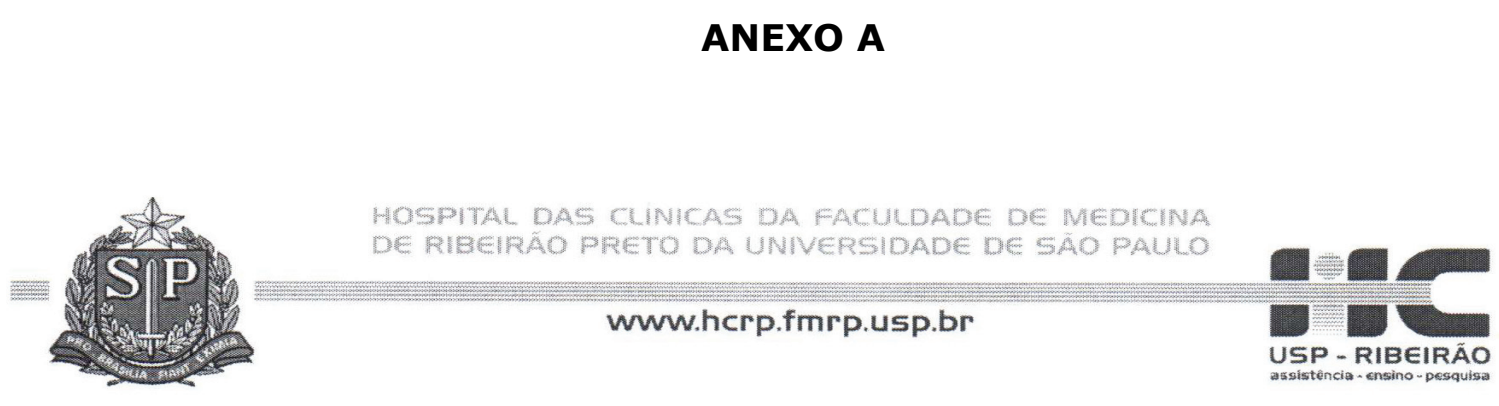

Ribeirão Preto, 03 de fevereiro de 2009

Ofício $n^{\circ} 278 / 2009$

CEP/SPC

Prezadas Senhoras,

O trabalho intitulado "O PROCEsSO ENSINOAPRENDIZAGEM PARA O PACIENTE QUE AGUARDA O TRANSPLANTE DE FÍGADO", foi analisado pelo Comitê de Ética em Pesquisa, em sua $279^{\circ}$ Reunião Ordinária realizada em 02/02/2009 e enquadrado na categoria: APROVADO, bem como o Termo de Consentimento Livre e Esclarecido, de acordo com o Processo HCRP n ${ }^{\circ} 12953 / 2008$.

Este Comitê segue integralmente a Conferência Internacional de Harmonização de Boas Práticas Clínicas (IGH-GCP), bem como a Resolução no 196/96 CNS/MS.

Lembramos que devem ser apresentados a este CEP, o Relatório Parcial e o Relatório Final da pesquisa. Atenciosamente.

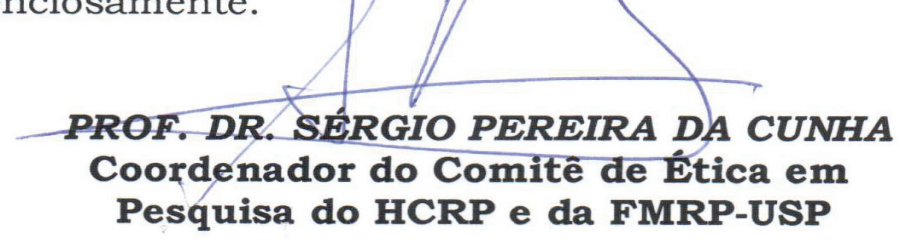

Ilustrissimas Senhoras

KARINA DAL SASSO MENDES

PROF $^{a}$ DR $^{a}$ CRISTINA MARIA GALVÃO (Orientadora)

Escola de Enfermagem de Ribeirão Preto-USP 